\title{
Significance of Soft Zone Sediments at the SRS
}

by

R. K. Aadland

Westinghouse Savannah River Company

Savannah River Site

Aiken, South Carolina 29808

R. J. Cumbest

R. L. Gelinas

W. Parker

F. H. Syms

C. Rothammer
K. Whaley 
This document was prepared in conjunction with work accomplished under Contract No.

DE-AC09-96SR18500 with the U.S. Department of Energy.

\section{DISCLAIMER}

This report was prepared as an account of work sponsored by an agency of the United States Government. Neither the United States Government nor any agency thereof, nor any of their employees, makes any warranty, express or implied, or assumes any legal liability or responsibility for the accuracy, completeness, or usefulness of any information, apparatus, product or process disclosed, or represents that its use would not infringe privately owned rights. Reference herein to any specific commercial product, process or service by trade name, trademark, manufacturer, or otherwise does not necessarily constitute or imply its endorsement, recommendation, or favoring by the United States Government or any agency

thereof. The views and opinions of authors expressed herein do not necessarily state or reflect those of the United States Government or any agency thereof.

This report has been reproduced directly from the best available copy.

Available for sale to the public, in paper, from: U.S. Department of Commerce, National Technical Information Service, 5285 Port Royal Road, Springfield, VA 22161, phone: (800)

553-6847, fax: (703) 605-6900, email: orders@ntis.fedworld.gov online ordering: http://www.ntis.gov/ordering.htm

Available electronically at http://www.doe.gov/bridge

Available for a processing fee to U.S. Department of Energy and its contractors, in paper, from: U.S. Department of Energy, Office of Scientific and Technical Information, P.O. Box 62, Oak Ridge, TN 37831-0062, phone: (865 ) 576-8401, fax: (865) 576-5728, email: reports@ adonis.osti.gov 
WSRC-TR-99-4083

Rev. 0

September, 1999

SIGNIFICANCE OF SOFT ZONE SEDIMENTS AT THE

SAVANNAH RIVER SITE (U)

\section{HISTORICAL REVIEW OF SIGNIFICANT INVESTIGATIONS AND CURRENT UNDERSTANDING OF SOFT ZONE ORIGIN, EXTENT AND STABILITY}

Site Geotechnical Services Department

Westinghouse Savannah River Company Savannah River Site

Aiken, SC 29808

Prepared for the U.S. Department of Energy Under Contract No. XX-XXXX-XXXXXXXX

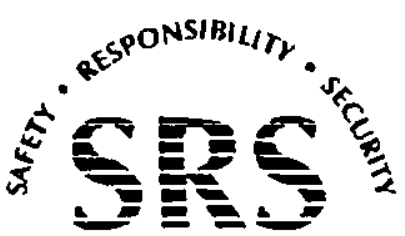

SAVANNAH RIVER SITE 


\section{EXECUTIVE SUMMARY}

\section{Introduction}

The purpose of this report is to provide information on the origin, extent and stability of "soft zones" in the carbonate bearing strata at the Savannah River Site (SRS). This report brings together the knowledge and experience of several SRS geologists, engineering geologists and geotechnical engineers that have been studying this issue. As part of this study, a comprehensive historical compendium of how soft zones have been addressed during the past 47 years at SRS is reviewed. The General Separations Area (GSA) is presented as a study area to address the origin and extent of soft zones. Finally, a review of the current state-of-practice regarding stability of the soft zones is presented, as well as recommended methods for subsurface investigations.

The SRS has been the subject of many detailed subsurface geologic and geotechnical investigations since the early 1950's. A time line showing when major investigations occurred, as well as the locations throughout the SRS, is presented on Figure E-1. Across SRS the soil zone between approximately 100 to 250 feet below the ground surface is a marine deposit laid down during the Middle Eocene epoch, which occurred approximately 35 to 50 million years ago. Past geologic studies have characterized the upper middle part of this interval as having locally high concentrations of calcium carbonate.

Often found within these sediments, particularly in the upper third of this section, were weak zones interspersed in stronger matrix materials. These weak zones, which vary in apparent thickness and lateral extent, have variously been termed as "soft zones", "the critical layer", "underconsolidated zones", "bad ground", and "void". For this report, the preferred term used to describe these zones will be "soft zones".

The initial Corps of Engineers (COE) characterization in 1952 identified soft zones as being the major concern for foundation design. This initial study made many important observations concerning the formation, geometry, distribution, and physical attributes of soft zones (and potential associated voids) within the Santee Formation. Some of the soft zone observations and hypotheses set forth by the COE report have remained unchanged to this day. However, several important aspects of early soft zone analyses run counter to current thinking on this subject.

Historically, the soft zones were grouted as an expedient way of resolving any potential foundation stability issues. This method continued through the restart of the K-reactor where the project chose to grout the Santee formation beneath the cooling water lines to resolve a potential foundation stability issue. The results of that effort were carefully studied and it was found that the grout was not having the desired effect on the subsurface soft zones as was previously thought. The results showed that the grout traveled in thin sheets along preferential pathways. Soft zones that existed prior to 
grouting still existed after grouting was completed. The grouting provided limited benefit in reducing the potential settlement from the soft zones.

More recently, technology improvements have allowed sampling and testing which have resulted in additional insight to the properties of the soft zone soils. With these properties, advanced analytical techniques have been used to resolve the foundation stability issues without requiring soil remediation. The information provided herein allows for a clearer understanding of the geologic underpinnings that established the carbonates and the attendant soft zones.

\section{Origin of Carbonates and Soft Zones}

The origin of the carbonates in the Santee Formation is fairly clear. The Santee formation carbonate content ranges from zero to approximately 90 percent. The presence of glauconite along with a normal marine fauna including foraminifers, molluscs, bryozoans, and echinoderms, indicates that the limestones and limy sandstones were deposited in clear, open-marine water of normal salinity on the inner to middle shelf. The abundance of carbonate mud (micrite) in the limestones suggests deposition in quiet water below normal marine wave base. The presence of abraded and well-worn skeletal grains indicates that bottom transport by currents or stormgenerated waves alternated with quiet-water conditions in which the sediments accumulated.

Viewing the Santee sedimentary package parallel to the shoreline, the carbonate-rich sediments would be concentrated in the areas furthest removed from the tidal inlets at the shoreface where clastic sediments supplied by riverine-input is concentrated. The clastic-rich sediments on the other hand would concentrate opposite the tidal inlet areas where clastic sediment is more readily available. The lateral facies transition of the sediments in the subtidal shelf environment from carbonate-rich to clastic-rich lithologies is therefore gradual and measures in the thousands of feet. Shifting locations of the tidal inlets at the shoreline has resulted in a complex sedimentary package where facies gradually transition from one lithology to another both laterally and vertically. Therefore both vertical and lateral lithologic variability in the Santee sequence is the rule rather than the exception. Locally the contact between carbonate sediments and laterally comparable clastic sediments is often sharply drawn, occurring over distances of only a few feet.

The original thoughts were that the soft zones were the result of bio-herm dissolution. This premise has since been proven to be false. Significant study of the deposition of the Santee formation precludes the formation of bioherms. Several hypotheses exist concerning the origin of the soft zones. One being that these zones consisted of varying amounts of carbonate material that has been altered (solutioned) over geologic time leaving sediments that are now subjected to low vertical effective stresses due to arching of more competent soils above the soft zone intervals. Carbonate material still 
exists in the subsurface, however solutioning is so slow (if it is occurring at all) that it is not expected to affect any facility, present or future, at the SRS.

A second hypothesis is based on recent studies that indicate the controls were available for silica replacement/cementation to occur. This results in the spatial geometry of the silicified "areas" being very irregular. The silicification of the enclosing sediment would follow and spread along bedding planes, along microfractures of varied orientations and along corridors of locally enhanced permeability. The resulting "soft zone" could be in the form of irregular isolated pods, extended thin ribbons or stacked thin ribbons separated by intervening unsilicified parent sediment. Soft zones encountered in one Cone Penetrometer Test (CPT) sounding could be absent in the neighboring CPT only a few feet away: Only where silicification has spread far enough away from the bedding planes and/or fractures along which the silica replacement has taken place, where all the intervening sediment is replaced, would the soft zones be large enough and coherent enough to pose a question for the siting of new facilities. In all likelihood this would be a most uncommon event.

Our present thinking is that the soft zones result from a complex open-marine water deposition of carbonates along with post placement dissolution and replacement in complex combinations. After deposition complex water movement of both fresh and saline conditions allowed both dissolution and replacement to occur in varying proportions along complex facies.

\section{Extent of Carbonate and Soft Zones}

In general, where carbonates are found soft zones are likely to be found as well. This conclusion is based on a significant study of soil samples from borings, boring logs, geophysical logs, and cone penetration test soundings throughout the GSA. This review was instrumental in delineating the extent of both carbonates and soft zones. The data was studied in many different ways but resulted in the simple conclusion that although carbonates and soft zones are not found in every drill hole or CPT, they are generally found in every area we have investigated in the GSA.

Isopach maps developed for this investigation reveal that carbonate thickness and concentration is directly related to the isopach thickness of the Santee interval. Where the Santee interval is thick, carbonate is more concentrated, where the interval is thin, carbonate thickness and concentration is reduced. It is further observed that where carbonate is concentrated in the Santee section the overlying "upland unit", Tobacco Road/Dry Branch section is generally structurally high, and where the carbonate content is reduced or absent the overlying "upland unit", Tobacco Road/Dry Branch section is generally structurally low. This indicates that the removal of carbonate and the thinning of the Santee interval occurred in post Tobacco Road time.

Since the thickness and distribution of soft zones is closely linked to the thickness and distribution of carbonate, those structurally low areas where a great deal of carbonate 
has been removed would be areas where soft zones may not be present. This however would not reduce the need to investigate these areas for potential siting of new facilities but would aide in siting and land use issues.

\section{Stability of Soft Zones}

The soft zones are stable under static conditions. The Santee section, in which the carbonate and soft zones are found, is generally in the saturated zone in the GSA (except near Upper Three Runs Creek) well below the water table. Here the sediments are in a stable chemical environment, and carbonate dissolution is minimal. The further dissolution and removable of the Santee carbonate (in the engineering sense i.e., the next 100 years) is a non-issue.

For the types of facilities constructed at the SRS, the increase in load on the soft zone soils is negligible. However, potential load increase due to a seismic event needs consideration even though the geologic record shows that soft zones encountered today have withstood the earthquakes that have occurred since their formation. Based on the knowledge gained by the many investigations performed and due diligence we recommend that site specific investigations be performed and analyses be done to assess the impact soft zones may have on any new facility.

\section{Subsurface Investigations and Analysis}

Geotechnical investigation programs are performed routinely for new facilities at SRS. Detection of soft zones will not prevent the siting of new facilities in these areas: Exploration to locate soft zones should include soil borings and cone penetration test (CPT) soundings. Our experience indicates the CPT is the best tool to determine the presence of soft zones. However, exploration programs for critical facilities include combinations of soil borings, CPT soundings, surface and down-hole geophysical measurements, compression and shear wave velocity determinations, and sampling for laboratory testing. It is recommended that initial soft zone identification be determined using the CPT tip resistance and the SPT N-value. For depths between 100 and 150 feet below the ground surface, the CPT criteria would be tip stress less than 15 tons per square foot (tsf) and the SPT criteria would be an $\mathrm{N}$-value less than 5 . The exploration program depth must be designed to penetrate through the layer where soft zones occur. In the GSA, that translates to depths of approximately 180 feet below ground surface.

For critical facilities it is recommended that a phased investigation program be performed. This could be done in combination with a site selection program, if warranted. The phased program allows for determination of stratigraphy (particularly soft zones) early in the program, then targeting those critical layers that require sampling and laboratory testing. Generally, the initial phase relies heavily on the CPT. and the second phase relies heavily on drilling, sampling and laboratory testing. Because of the depth of the soft zones (100 to 150 feet in the GSA) there is no static 
stability issue. Dynamic settlement, on the other hand, requires evaluation. Analyses include dynamic settlement determinations from partial liquefaction and consolidation from load transfer due to a seismic event. 


\section{TABLE OF CONTENTS}

TABLE OF CONTENTS $x$

LIST OF TABLES. XII

LIST OF FIGURES XIII

LIST OF PLATES XV

1.0 INTRODUCTION .1

1.1 Background 2

2.0 CHRONOLOGICAL SUMMARY OF SIGNIFICANT INVESTIGATION 6

2.0.1 COE Geologic Engineering Investigations at SRS (1952) .......................6

2.0.2 Foundation Investigations and Treatment at SRP (1963) .......................

2.0.3 Danger of Soil Liquefaction Caused by Earthquake at SRP (1976) ............10

2.0.4 Geotechnical Report DWPF 200-S Area (1984) ......................................11

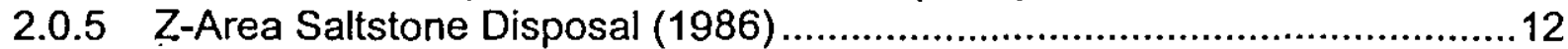

2.0.6 K-Area Cooling Tower Reports (1990).................................................13

2.0.7 HWRF Phase I Geotechnical Study (1991) .........................................14

2.0.8 K-Reactor Area Geotechnical Report For Seismic Issues (1991) ...............15

2.0.9 Integrated Geologic Analysis of the K-Reactor Area (1992) ...................... 19

2.0.10 K-Area Soil Stabilization Program (1992) ..............................................19

2.0.11 PAR Pond Dam Seismic Evaluation (1992) ..........................................21

2.0.12 Replacement Tritium Facility Geotechnical Investigation (1993) ...............22

2.0.13 ITP Facility Final Report - Phase I and II CPT Studies (1994) .................23

2.0.14 ITP and H Tank Farm Report (1995) ...............................................23

2.0.15 TEF Geotechnical Summary Report (1998) .........................................26

2.0.16 Actinide Packaging and Storage Facility Geotechnical Report (1998) .......27

2.0.17 Use of the Cone Penetrometer at the SRS-Whitepaper (1998) ................28

2.0.18 F-area Northeast Expansion Report (1999) ............................................28

2.1 Outside Reviewer Comments Relevant to Soft Zone Technical Issues.....................30

2.1.1 K-Reactor Area Geotechnical Report For Seismic Issues (1991) ..............30

2.1.2 Replacement Tritium Facility Geotechnical Investigation (1993) .................31

2.1.3 Senior Seismic Advisory Panel (1994) .................................................32

2.1.4 ITP and H Tank Farm Geotechnical Investigation Report (1995) ..............33

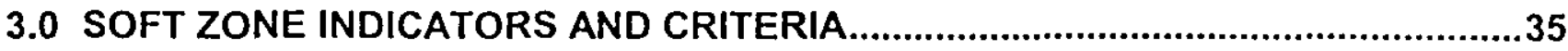




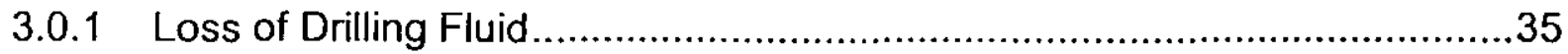

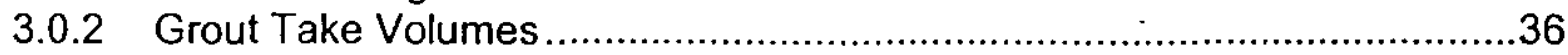

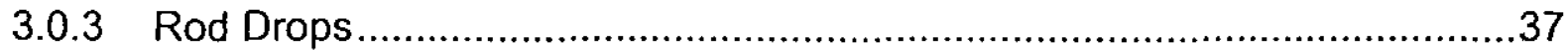

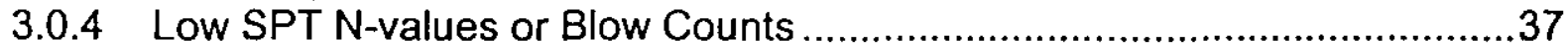

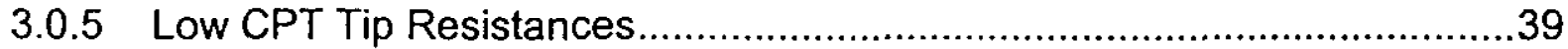

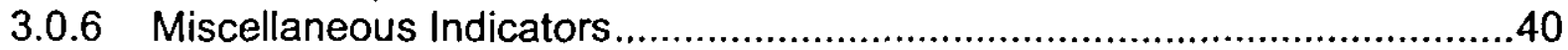

3.1 Current Soft Zone Identification Criteria .............................................................

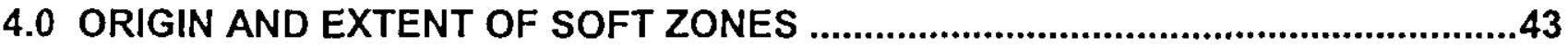

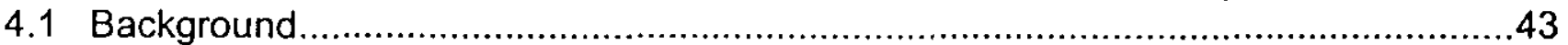

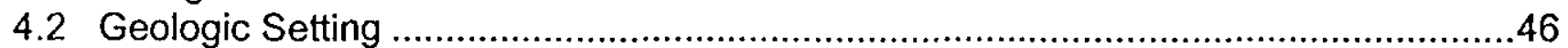

4.2.1 Chronology of Tertiary Geologic Events in the GSA ............................47

4.2.2 Distribution and Environments of Deposition of Carbonates at SRS .........49

4.2.3 Stratigraphy of the Carbonate Sediments in the GSA .............................49

4.3 Origin of Carbonate Sediments in the GSA ..................................................50

4.3.1 Diagenesis of the Carbonate Sediments and Formation of Soft Zones ......51

4.3.2 Timing of Diagenetic Events ..................................................................53

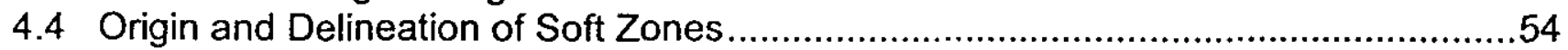

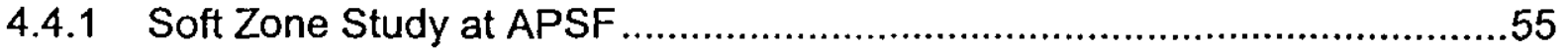

4.5 Extent of Carbonate Zones and Soft Zones ..................................................57

4.5.1 Stratigraphy of the Dry Branch-Tinker/Santee (Utley) Interval ....................57

4.5.2 Delineation of the Extent of Carbonate Zones ............................................5

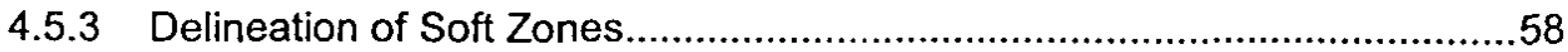

4.5.4 Delineation of the Extent of Carbonate Zones/Soft Zones...........................59

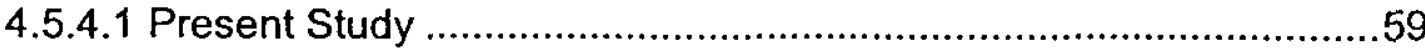

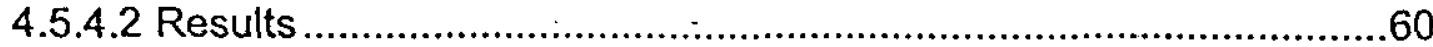

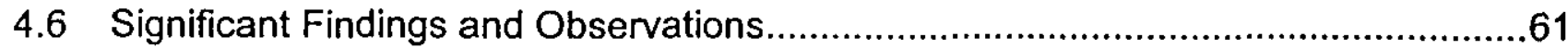

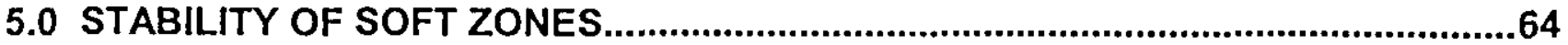

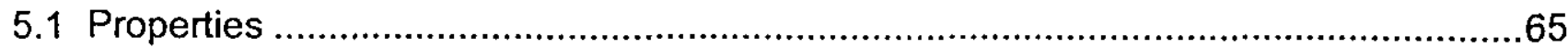

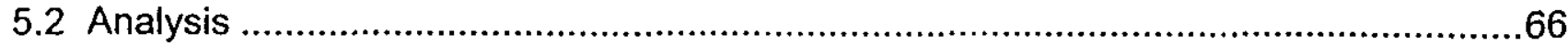

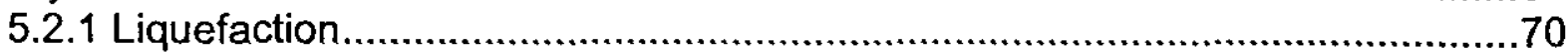

5.2.2 Consolidation Due to Full Overburden Pressure........................................71

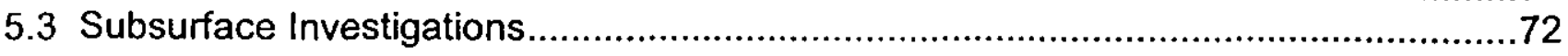

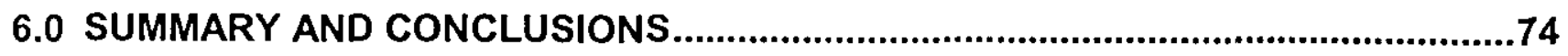

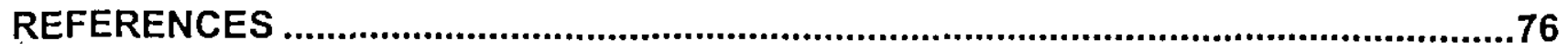




\section{LIST OF TABLES}

Table 1-1 Historical Soft Zone Criteria and Indicators Used at SRS

Table 3-1 SPT Criteria Used During Various SRS Geologicl Geotechnical Investigations

Table 3-2 CPT Criteria Used During Various SRS Geologicl Geotechnical Investigations

Table 4-1 Historical Observations of Soft Zone Geometry and Distribution.

Table 5-0 Comparison of Investigation Methods and Analysis of Soft Zone Sediments

Table 5-1 CPT Sample at APSF Laboratory Data Compared to Calculated Data

Table 5.2 Summary of Analytical Methods Used To Determine Soft Zone Stability During SRS Geologic/Geotechnical Investigations 


\section{LIST OF FIGURES}

E-1 SRS Soft Zone Engineering Investigation Timeline

1-1 SRS Soft Zone Engineering Investigation Timeline

4-1 Regional location of SRS with blowup of the Site

4-2 Lithostratigraphic and Sequence Stratigraphic units at SRS

4-3 Well HSB-TB with summary of insoluble residue data and carbonate WT.\%

4-4 Spatial relationships of depositional environments typical of the Tertiary sediments at SRS

4-5 Spatial relationships of depositional environments typical of the Tinker/Santee (Utley) sediments at SRS

4-6 Regional distribution of carbonate in the Tinker/Santee (Utley)-Dry Branch sequence

4-7 Schematic Cross section of the Tinker/Santee (Utley) sediments deposited parallel to the shoreline

4-8 Slump faulting at $\mathrm{H}$ Area Tank Farm (Parra and others, 1998)

4-9 Diagrammatic summary showing steps in solution and precipitation of calcium carbonate by fresh water

4.10 Diagrammatic representation of the interpreted diagenetic history of the sandy biomoldic chert facies at APSF

4-11 Porosity classification of Choquette and Pray (1970). A. Basic porosity types. B. Genetic, size and abundance modifiers.

4-12 Porosity classification of Choquette and Pray (1970). A. Format for construction of porosity name and code designations. B. Common stages in evolution of pore, a mold, showing application of genetic modifiers and classification code.

4-13 Photomicrograph of quartz-rich skeletal packstone, Skeletal Packstone Microfacies, Tinker/Santee (Utley) section, GSA, SRS. Sample diagenetically altered to sandy, molluscan-mold microsparite. Well .BGO-14A, $122 \mathrm{ft}$.

4-14 Photomicrograph of extensive dissolution of allochems in a skeletal grainstone (?) resulting in vugular porosity. Well HBOR-50, $165 \mathrm{ft}$.

4-15 Photomicrograph of collapsed and fractured shell fragments in a skeletal grainstone (?). Well HBOR-50, $179 \mathrm{ft}$.

4-16 Photomicrograph of quartz bearing, skeletal, pellet packstone, Skeletal Packstone Microfacies, Tinker/Santee (Utley) section, GSA, SRS.

4-17 Photomicrograph of sandy biomoldic chert microfacies, core CPT-157S3 at 109.86 feet below land surface. Top picture crossed-nicols, bottom picture plane polarized light

4-18 Photomicrograph of sandy siliceous mudstone, siliceous mudstone microfacies, Warley Hill Formation, GSA, SRS. Well BGX-2B, 151.2 feet depth. Crossed-nicols.

4-19 Photomicrograph of chalcedony-cemented quartz arenite, Terrigenous Sand and Sandstone Microfacies, Tinker/Santee (Utley) section, GSA, SRS. Well YSC-2A, $109 \mathrm{ft}$.

4-20 Schematic cross section showing contact relations between the meteoric phreatic zone and the marine phreatic zone between the Hope gate and Falmouth formations (after Land, 1973).

4-21 Schematic diagram illustrating the lateral and vertical distribution of soft zones due to silica replacement of carbonate in the GSA. 
4-22 Photomicrograph of quartz-rich, skeletal grainstone, with detritus present in vuggy pores, Skeletal Grainstone Microfacies, Tinker/Santee (Utley) section, GSA.SRS. Well HBOR-50, $166 \mathrm{ft}$.

4-23 - Drilling data for Well BGX-4A illustrating indurated layer underlain by a rod drop/no core recovery zone.

4-24 Diagrammatic representation of the interpreted diagenetic history of the siliceous sandy mudstone microfacies at APSF.

4-25 Photomicrograph of siliceous sandy mud microfacies from Core CPT-157S3 at APSF at 108.35 feet below land surface, plane polarized light.

4-26 Schematic block diagram illustrating the migration of the fresh water/marine water mixing zone through the Tinker/Santee (Utley) section in Dry Branch and Tobacco Road time.

4-27 Isopach map of the calcareous zone in the Tinker/Santee (Utley) section, GSA (Aadland and others, 1990)

4-28 Isopach map of the calcareous zone in the GSA (Richardson, 1995)

4-29 Isopach map of the calcareous zone in the "lower" aquifer zone in the GSA (Thayer and others, 1994)

4-30 Isopach map of the calcareous sediments in the GSA (Aadland and others, 1994)

5-1 Comparison of Compressibility Index $\mathrm{C}_{\mathrm{c}}$ vs. Moisture Content 


\section{LIST OF PLATES}

4-1 Regional Lithostratigraphic Cross-Section

4-2 Base map of the GSA with location of cored and geophysically logged wells and borings, CPT pushes and SPT borings queried for the study

4-3 Tinker/Santee (Utley) carbonate thickness map based on core data.

4-4 Average percent carbonate map from core in the Tinker/Santee (Utley) interval.

4-5 Total percent carbonate in the Tinker/Santee (Utley) interval based on core.

4-6 Extent of soft zones from CPT data in the Tinker/Santee (Utley) interval.

4-7 Tinker/Santee (Utley) carbonate thickness map based on core data, ITP Area

4-8 Soft zone map at ITP, map area \#1 in the Tinker/Santee (Utley) interval. 


\subsection{INTRODUCTION}

The Savannah River Site (SRS) has been the subject of many detailed subsurface geologic and geotechnical investigations since the early 1950's. The soil stratigraphy at SRS within 200 feet of the ground surface is complex. The soils consist of many interbedded layers of predominantly clayey sands, silty sands and clean sands varying in thickness and composition. Across SRS the soil zone between approximately 100 to 250 feet below the ground surface is a marine deposit laid down during the Middle Eocene epoch, which occurred approximately 35 to 50 million years ago. Past geologic studies have characterized the upper middle part of this interval as having locally high concentrations of calcium carbonate. In 1952, the United States Army Corps of Engineers (COE) focused much of the initial foundation investigation efforts on these marine deposits. At the time of the COE investigation, these sediments were assigned to the McBean formation. However, geologic strata in the SRS area have since been renamed due to additional geologic data obtained in the last 40 years. Based on current geologic designations, this marine deposit is included in portions of the Dry Branch and Santee Formations. To simplify this matter, "Santee" has been used as a common reference to the geologic interval where soft zones are discussed.

Often found within these sediments, particularly in the upper third of this section, are weak zones interspersed in stronger matrix materials. These weak zones, which vary in apparent thickness and lateral extent, have variously been termed as "soft zones", "the critical layer", "underconsolidated zones", "bad ground", or "void". For this report, the preferred term used to describe these zones will be "soft zones".

The first major characterization at SRS (conducted by the COE in 1952) identified soft zones as being the major concern for foundation design. This initial study made many important observations concerning the formation, geometry, distribution, and physical attributes of soft zones (and potential associated voids) within the Santee Formation. Some of the soft zone observations and hypotheses set forth by the COE report have remained unchanged to this day. However, several important aspects of early soft zone analyses run counter to current thinking on this subject.

The intent of this report is to provide a chronological summary of how soft zones have been addressed during the past 47 years, with particular focus on the origin, extent and stability of these soils. Section 2.0 summarizes the major findings of large foundation characterization and/or remediation programs that have been undertaken for important facilities at SRS. Section 3.0 provides a summary of soft zone criteria and indicators that have been used in previous SRS studies and what is considered technically reasonable based on current information. Section 4-0 presents the results of recent analysis and the current thinking on soft zones, including discussion of their origin and extent/geometry. Section 5.0 discusses soft zone stability and analysis. Section 6.0 summarizes the conclusions of this study. 


\section{$1.1 \quad$ Background}

Soft zones were initially recognized in the subsurface at SRS during the 1952 COE site characterization. Initial soft zone indicators the COE established were based upon:

- Low $N$-value (sum of blow counts from the $2^{\text {nd }}$ and $3^{\text {rd }} 6$ inch interval of a Standard Penetration Test)

- Weight of rod during Standard Penetration Test

- Weight of hammer during Standard Penetration Test

- Rod or tool drops (quick advance of the drill string with little or no resistance)

- Fluid loss (substantial or total drill fluid loss into the formation during drilling activities)

These indicators, or slight variations on them, remained largely unchanged for nearly 40 years. The single most important change in soft zone delineation has taken place during the past decade, with the introduction of the Cone Penetrometer Test (CPT). This rapid and relatively inexpensive investigation technique allowed for significant improvements in characterization and definition of both soft zones and potential voids. Key improvements the CPT has over conventional drilling methods include:

- Higher frequency of data collection (vertical measurements made every $2 \mathrm{~cm}$ ).

- CPT measures three independent parameters (tip resistance, sleeve resistance and pore pressure)

- CPT is 5 to 10 times faster in deep pushes than continuous SPT borings (for a $200 \mathrm{ft}$ deep hole a CPT takes 1 day, whereas a continuous SPT boring might take 4-10 days).

- The CPT has superior (automatic and continuous) depth control characteristics relative to conventional SPT borings.

- The CPT technique allows for direct and accurate testing of in situ soils (strength, shear wave, hydraulic, video, etc.).

- The speed and cost of CPTs often allows for more penetrations than SPT's, yielding greater definition of the lateral extent of soft zones.

- The CPT method has a high degree of reproducibility, with markedly less operator dependent variation (relative to the SPT technique).

- The CPT is a quasi-static technique accurately measuring resistance against the cone and not the total force applied against a drill string and hammer. The SPT technique complicates determination of soft zone characteristics due to the substantial weight of rods (particularly at the depths in which these zones commonly appear) and introduction of large hydraulic heads associated with the drilling fluids.

- The CPT has no large hydraulic heads associated with drilling fluids.

These CPT attributes listed above have substantially influenced how foundation investigations have been carried out at the SRS during the past 6-8 years. The CPT has become a primary tool for subsurface investigations, and has allowed for a reduction and more focused use of conventional drilling techniques (WSRC, 1998c). The most recent advance in CPT technology is the ability to sample soils with much success in soft zone intervals.

Eighteen geotechnical/geologic reports and studies have been identified in the historical record that address soft zones in a rigorous manner. These reports are summarized in Section 2.0 of this report. Numerous summary tables are also included. Note that the 
reference within these tables has been abbreviated to reduce the table size. The following list of the eighteen reports and the abbreviated reference is provided below.

COE Geologic Engineering Investigations at SRS (1952) Ref:COE (1952)

Foundation Investigations and Treatment at SRP (1963) Ref:MPMRCE (1963)

Danger of Soil Liquefaction Caused by Earthquake at SRP (1976) Ref:Rutledge (1976)

Geotechnical Report DWPF 200-S Area (1984) Ref:MRJD (1984)-DWPF

Z-Area Saltstone Disposal (1986) Ref: MRCD (1986)-Salt

K-Area Cooling Tower Reports (1990) Ref: MRCE (1986-1990)-Cool

HWRF Phase I Geotechnical Study (1991) Ref: Law (1991)-HWRF

K-Reactor Area Geotechnical Report For Seismic Issues (1991) Ref: GEI (1991)-K

Integrated Geologic Analysis of the K-Reactor Area (1992) Ref: WSRC (1992)-K

K-Area Soil Stabilization Program (1992) Ref: WSRC (1992)-KASS

PAR Pond Dam Seismic Evaluation (1992) Ref: Ebasco (1992)-Par Pond

Replacement Tritium Facility Geotechnical Investigation (1993) Ref: WSRC (1993)-RTF

ITP Facility Final Report - Phase I and II CPT Studies (1994) Ref: Ebasco (1994)-ITP

ITP and H Tank Farm Report (1995) Ref: WSRC (1995)-ITP

TEF Geotechnical Summary Report (1998) Ref: WSRC (1998)-TEF

Actinide Packaging and Storage Facility (1998) Ref: WSRC (1998)-APSF

Use of the Cone Penetrometer at the SRS.Whitepaper (1998) Ref: WSRC (1998)-White

F-area Northeast Expansion Report (1999) Ref: WSRC (1999)-NEC

The A timeline of these reports and significant activities, including a project location map, is presented on Figure 1-1. Criteria and indicators used to identify soft zones during these investigations are chronologically summarized on Table 1-1. The criteria used during each respective program was based both on the nature of the work being performed (i.e., purely investigative or remedial) and technology available at the time.

Table 1-1. Historical Soft Zone Criteria and Indicators Used at SRS

\begin{tabular}{|l|l|l|l|}
\hline Reference & $\begin{array}{l}\text { Conventional Drilling Criteria and } \\
\text { Indicators }\end{array}$ & CPT Criteria & $\begin{array}{l}\text { Grouting or Backfill } \\
\text { Criteria }\end{array}$ \\
\hline COE (1952) & $\begin{array}{l}\text { Soft zones defined as: } \\
\text { Low SPT blow count } \\
\text { Mud losses } \\
\text { Rod drops }\end{array}$ & $\begin{array}{l}\text { Pressure grouted only holes } \\
\text { with rod drops or remarkable } \\
\text { fluid losses. }\end{array}$ \\
\hline $\begin{array}{l}\text { MPMRCE } \\
\text { (1963) }\end{array}$ & $\begin{array}{l}\text { Soft zones defined as: } \\
\text { Low resistance to penetration of sampling } \\
\text { tools (primary) } \\
\text { Loss of drilting mud (less indicative) } \\
\text { Presence of calcareous material }\end{array}$ & $\begin{array}{l}\text { N/A } \\
\text { ofl borings at SRP, regardiess } \\
\text { of their purpose, should be } \\
\text { grouted (with a thick viscous } \\
\text { mix) to prevent free seepage } \\
\text { into the solution zone from } \\
\text { overlying soils. }\end{array}$ \\
\hline $\begin{array}{l}\text { Rutledge } \\
\text { (1976) }\end{array}$ & $\begin{array}{l}\text { No criteria. } \\
\text { MRJD (1984) }\end{array}$ & $\begin{array}{l}\text { Soft zones defined as: } \\
\text { Low resistance to penetration of sampling }\end{array}$ & $\begin{array}{l}\text { Necessity for foundation } \\
\text { grouting determined by risk- } \\
\text { based matrix that evaluated } \\
\text { structure category, stress } \\
\text { relationship to solution zone, } \\
\text { depth/severity/frequency of } \\
\text { subsoil defects, and } \\
\text { consequence of differential } \\
\text { settlements. }\end{array}$ \\
\hline
\end{tabular}




\begin{tabular}{|c|c|c|c|}
\hline Reference & $\begin{array}{l}\text { Conventional Drilling Criteria and } \\
\text { Indicators }\end{array}$ & CPT Criteria & $\begin{array}{l}\text { Grouting or Backfill } \\
\text { Criteria }\end{array}$ \\
\hline & $\begin{array}{ll}\text { tools } & \text { Loss of drilling mud } \\
\text { - } \quad \text { Positive HCL reaction }\end{array}$ & & $\begin{array}{l}\text { theoretical) as follows: } \\
>6 \text { voids or leached } \\
\text { zones } \\
3-6 \text { thin leached zones } \\
<3 \text { slightly enlarged } \\
\text { borehole and wastel } \\
\text { overflow }\end{array}$ \\
\hline $\begin{array}{l}\text { MRCE (1986) } \\
\text { - Salt }\end{array}$ & $\begin{array}{l}\text { No soft zone discussion; low blow count } \\
\text { zones and rod drops identified, but no criteria } \\
\text { given. }\end{array}$ & N/A & $\begin{array}{l}\text { Backfill grout take ratio as } \\
\text { follows: } \\
\text { - }>6 \text { voids or leached } \\
\text { zones } \\
\text { - } 3-6 \text { thin leached zones } \\
\text { - } 3 \text { slightly enlarged } \\
\text { borehole and wastel } \\
\text { overflow }\end{array}$ \\
\hline $\begin{array}{l}\text { MRCE (1986- } \\
\text { 1990)-Cool }\end{array}$ & $\begin{array}{l}\text { No exact criteria indicated. Extensive low blow } \\
\text { count and rod drop zones identified. }\end{array}$ & N/A & $\begin{array}{l}\text { Significant void defined as a } \\
\text { grout take of }>100 \mathrm{cu} / \mathrm{ft} \text { (grout } \\
\text { take ratio of } 10 \text { ). }\end{array}$ \\
\hline $\begin{array}{l}\text { Law (1991)- } \\
\text { HWRF }\end{array}$ & $\begin{array}{l}\text { Soft zone defined as SPT blow count }=0 \\
\text { (including rod drops and weight of hammer) } \\
\text { Circulation losses, rapid increases in drilling } \\
\text { rate, calcareous material, and staged backfill } \\
\text { grouting instances noted, but nol made part } \\
\text { of criteria. }\end{array}$ & $\begin{array}{l}\text { - Soft zone }=\text { tip resistance of } \\
<=15 \text { tsf for at least a } 1 \mathrm{ft} \\
\text { section. }\end{array}$ & N/A \\
\hline GEI $(1991)-K$ & $\begin{array}{l}\text { Soft zone designated as: } \\
\text { - } \quad \begin{array}{l}\text {-value }=0 \text { (including weight of rods or } \\
\text { weight of hammer) } \\
\text { Hydraulic pressure }<50 \text { psi to push a shelby } \\
\text { tube } \\
\text { Rod drops during drilling } \\
\text { - } \quad \text { Start of a drilling fluid loss episode } \\
\text { - Shear wave velocity of critical zone } \\
\text { determined to be between } 350-950 \mathrm{ft} / \mathrm{s}\end{array} \\
\end{array}$ & $\begin{array}{l}\text { - } \quad \text { oft zone }=\text { tip resistance } \\
<200 \text { psi }(14-4 \text { tsf }) \text { for a } \\
\text { distance }>1 \mathrm{ft}\end{array}$ & None \\
\hline $\begin{array}{l}\text { WSRC 1992) } \\
\text { K }\end{array}$ & $\begin{array}{l}\text { - Direct indication of soft zone = rod drop } \\
\text { Indirect indication of soft zone = drilling fluid } \\
\text { losses }\end{array}$ & $\begin{array}{l}\text { Direct indication of soft zone } \\
\text { = 7ow tip pressures and } \\
\text { sleeve resistance }\end{array}$ & $\begin{array}{l}\text { Indirect indication of soft } \\
\text { zone = grout take }\end{array}$ \\
\hline $\begin{array}{l}\text { WSRC (1992) } \\
\text { - KASS }\end{array}$ & $\begin{array}{l}\text { Soft zones designated as: } \\
\text { - Sedimentary sections w/ significant } \\
\text { percentage of cartonate-rich material at time } \\
\text { of deposition, which subsequent dissolution } \\
\text { has removed leaving a high porosity ( }>60 \% \\
\text { [from density log]) zone containing fine } \\
\text { grained material in an underconsolidated } \\
\text { state. } \\
\text { Borehole compensated density logs with } \\
\text { readings below } 108{\text { ib } / \mathrm{f}^{3}}^{3} \\
\text { Rod drops (evaluated but determined to be } \\
\text { poor soft zone indicator) }\end{array}$ & $\begin{array}{l}\text { Soft zone = tip resistance } \\
<200 \text { psi }\end{array}$ & $\begin{array}{l}\text { Areas with borings having } \\
\text { grout takes of } 300 \text { cf or more } \\
\text { interpreted to be associated } \\
\text { with well-developed soft zone } \\
\text { complexes in the subsurface. }\end{array}$ \\
\hline $\begin{array}{l}\text { Ebasco (1992) } \\
\text { - Par Pond }\end{array}$ & $\begin{array}{l}\text { Loose zones designated as: } \\
\text { - Corrected SPY } N \text {-values less than or equal } \\
\text { to } 10 \text { blows per foot }\end{array}$ & $\begin{array}{l}\text { No CPT soft zone criteria } \\
\text { indicated }\end{array}$ & \\
\hline $\begin{array}{l}\text { WSRC (1993) } \\
\text { - RTF }\end{array}$ & $\begin{array}{l}\text { Soft zones defined as: } \\
\text { SPT } N \text {-value }<=4 \\
\text { Sampler advance due to weight of } \\
\text { rods/hammer } \\
\text { - Loss of drilling fluid } \\
\end{array}$ & $\begin{array}{l}\text { Soft zone }=\text { tip resistance }<200 \\
\text { psi (13.6 tsf) }\end{array}$ & None \\
\hline $\begin{array}{l}\text { Ebasco }(1994) \\
\text { - ITP }\end{array}$ & N/A - CPT only investigation & $\begin{array}{l}\text { Soft zones defined as: } \\
\text { - Tip resistance }<15 \text { tsf, and } \\
\quad \text { Sleeve resistance }<1 \text { tsf, } \\
\text { and } \\
\text { - Zone thickness }>=6 \text { inches } \\
\text { Void identification logic tree } \\
\text { developed. Voids must meet all }\end{array}$ & N/A \\
\hline
\end{tabular}


WSRC-TR-99-4083

Significance of Soft Zone Sediments

Rev. 0 at the Savannah River Site

September, 1999

\begin{tabular}{|c|c|c|c|}
\hline Reference & $\begin{array}{l}\text { Conventional Drilling Criteria and } \\
\text { Indicators }\end{array}$ & CPT Criteria & $\begin{array}{l}\text { Grouting or Backfill } \\
\text { Criteria }\end{array}$ \\
\hline & & $\begin{array}{l}\text { of the following criteria: } \\
\text { - Tip resistance }<15 \mathrm{tsf} \text {, and } \\
\text { - Sleeve resistance }<1 \text { tsf, } \\
\text { and } \\
\text { - Pore pressure = hydrostatic }\end{array}$ & \\
\hline $\begin{array}{l}\text { WSRC (1995) } \\
\text { - ITP }\end{array}$ & $\begin{array}{l}\text { Soft zones defined as: } \\
\text { - SPT N-Value }<=5\end{array}$ & $\begin{array}{l}\text { Soft zones defined as: } \\
\text { Vip resistance }<15 \text { tsf } \\
\text { Void identification logic tree } \\
\text { modified. Voids must meet all of } \\
\text { the following criteria: } \\
\text { - Tip resistance }<=3 \text { tsf, and } \\
\text { - Sleeve resistance }<=1 \text { tsf, } \\
\text { and } \\
\text { Pore pressure approximates } \\
\text { hydrostatic }\end{array}$ & None \\
\hline $\begin{array}{l}\text { WSRC (1998) } \\
\text { - TEF }\end{array}$ & $\begin{array}{l}\text { Soft zones defined as: } \\
\text { - SPT N-Value }<5\end{array}$ & $\begin{array}{l}\text { Soft zones defined as: } \\
\text { - Tip resistance }<15 \mathrm{tsf} \text {, and } \\
\text { - Zone thickness }>=2 \mathrm{ft} \\
\text { (Some judgement used for layers } \\
\text { approaching } 2 \mathrm{ft} \text { in thickness). }\end{array}$ & None \\
\hline $\begin{array}{l}\text { WSRC (1998) } \\
\text { - APSF }\end{array}$ & $\begin{array}{l}\text { Soft zones defined as: } \\
\text { - SPT N-Value }<5\end{array}$ & $\begin{array}{l}\text { Soft zones defined as: } \\
\text { - Tip resistance }<15 \mathrm{tsf} \text {, and } \\
\text { - Zone thickness }>=2 \mathrm{ft} \\
\text { (Some judgement used for tayers } \\
\text { approaching } 2 \mathrm{ft} \text { in thickness). }\end{array}$ & None \\
\hline $\begin{array}{l}\text { WSRC (1998) } \\
\text { - White }\end{array}$ & $\begin{array}{l}\text { None. Use of SPT N-Value as soft zone criteria } \\
\text { considered to be misleading, but still } \\
\text { recommends SPT N-Value of }<5 \text { as indicator. }\end{array}$ & $\begin{array}{l}\text { Soft zones defined as: } \\
\text { - Tip resistance }<15 \text { tsf, and } \\
\text { - Zone thickness }>=2 \mathrm{ft}\end{array}$ & None \\
\hline $\begin{array}{l}\text { WSRC (1999) } \\
\text { - NEC }\end{array}$ & $\begin{array}{l}\text { Soft zones defined as: } \\
\text { - SPT N-Value }<5\end{array}$ & $\begin{array}{l}\text { Soft zones defined as: } \\
\text { - Tip resistance }<15 \mathrm{tsf} \text {, and } \\
\text { - Zone thickness }>=2 \mathrm{ft}\end{array}$ & None \\
\hline
\end{tabular}




\subsection{CHRONOLOGICAL SUMMARY OF SIGNIFICANT INVESTIGATIONS}

The following sections summarize 18 reports considered to be the most significant investigations performed at the SRS where soft zones were encountered and discussed in some detail. The reports are reviewed in chronological fashion (from oldest to most recent). Only the key findings pertinent to soft zone issues are presented here. These summaries are historical accounts extracted from the reports and do not necessarily represent the most current thinking about soft zones. It should be noted to the reader that names of geologic stratum as well as engineering layers have changed since some of these older reports were issued. To simplify this matter, "Santee" has been used as a common reference to the geologic interval where soft zones are discussed.

\subsubsection{COE Geologic Engineering Investigations at SRS (1952)}

Reference: US Army Corps of Engineers (COE), Charleston District. "Geologic Engineering Investigations, Savannah River Plant", Volumes 2, Waterways Experiment Station, Vicksburg, MS, 1952.

As a part of the initial construction phase at Savannah River Site (SRS), in 1951 and 1952, the U.S. Army Corps of Engineers (COE) performed: (1) the original site wide geologic characterization, and (2) an extensive exploration and grouting program of the soft soil zones beneath the foundation areas of critical structures at the 5 reactors and both canyon facilities. This report, the precursor to all following investigations at SRS, made numerous key findings. These include:

- At a depth of about 100 to $200 \mathrm{ft}$ below the surface [of the general SRS site], a zone of sandy marl and calcareous sand was found. This calcareous zone was identified as part of the McBean [Santee] Formation.

- Although the Santee sediments have been subjected to consolidation by 100 to $150 \mathrm{ft}$ of overburden. later solution of calcium carbonate destroyed some or all of the benefits of that compaction so that the soil may be more compressible than would normally be the case. Most of the major foundation problems were ascribed to be a result of solution in these calcareous soils, and a large scale grouting program in soft zones was recommended and undertaken.

- Cavernous underground conditions were found to be extensive and widespread in the upper-middle part of the McBean [Santee] Formation in or just above the calcareous strata. Water collected in such beds was found to be relatively high in carbonates, whereas water in sandy layers above and below was very soft; thus proving active solution of lime at the present time. The distribution of calcareous materials, zones of low penetration resistance, and mud losses (the first soft zone criteria) were largely within this 50 to $70 \mathrm{ft}$ thick zone. Zones of low penetration resistance were interpreted to reflect a skeletal structure resulting from leaching, while the mud losses reflected a more or less cavernous condition due to the same cause.

- Solution cavities/voids of many feet in diameter were judged to be unlikely. It was deemed probable that the materials reflected a honeycombed structure of numerous small "rat holes" rather than a single large void. These cavities were not necessarily open, but probably were partly filled, to varying degrees, with soft, semiliquid clays or loose sitts and sands. 
- The COE presented evidence showing that many of the numerous "sinks" or shallow depressions on the surface resulted from the collapse of cavities in this zone of calcareous material. Explorations found openings beneath areas where no surface sinks exist, suggesting that although the surface has not collapsed, it may be in a state of unstable equilibrium.

- Soft zone strata in a state of unstable equilibrium might experience cavity collapse brought on by a slight additional loading, vibration, or sudden shock. The removal of the hard surface crust by excavations, which may be as deep as $50 \mathrm{ft}$, will reduce the arching strength of the soils. In some cases the weight of structures might exceed the weight of the soil removed, which might result in overloading the underlying strata beyond their arching strength. Under such conditions, it was believed that collapse of underground openings would be quickly transmitted to the surface or to the superimposed building.

\subsubsection{Foundation Investigations and Treatment at SRP (1963)}

Reference: Moran, Proctor, Mueser \& Rutledge Consulting Engineers, (1963), "Foundation Investigations and Treatment at Savannah River Plant", April 19, 1963.

This study was conducted to evaluate foundation investigation and treatment techniques at the Savannah River Site. General recommendations regarding subsurface characterization programs, engineering design for fill supported structures, and utilization and limitations of existing subsurface data were developed and discussed. This study was not intended to provide facility specific recommendations for foundation investigation and design; rather it provided general guides and considerations and cautioned that these were to be considered subordinate to application of professional engineering judgment as complex operational requirements for structures at the SRS introduce numerous special requirements. Major observations, recommendations, and conclusions of this report are:

- Engineering and geologic studies performed for construction of the plant in 1951-52 established that the surface sinks present throughout the plant area result from subsurface solution of calcareous materials occurring in a relatively well-defined zone, 60 to 80 feet thick, in the McBean [Santee] Formation, which is generally found at depths of about 100 to 200 feet. The extent of solution is variable and is more pronounced towards the southern and eastern portions of the project area. As a result of these investigations, and because the behavior of large and heavily loaded foundations in the Southeastern Coastal Plain was unknown, grouting was performed in 1951-52 beneath selected critical structures to permit their safe and immediate construction. The engineering and geologic studies disclosed that the surface sinks undoubtedly developed very slowly, over geologic time, but there was no assurance that this would continue to be true and, therefore, a conservative approach was adopted.

- Adequate subsoil exploration and testing first must satisfy normal requirements for determining soil types, consolidation behavior, shear strength and other physical properties relevant to settiement, bearing capacity, slope stability and foundation design. For important structures, additional subsoil considerations are imposed by the solution zone underlying the project and it is frequently necessary to answer questions such as:

a) Is it necessary to explore, by borings, the condition of the solution zone beneath the proposed structures?

b) To what extent is exploration required of soils overlying the solution zone? 
c) When is grouting of the solution zone or of the overburden indicated?

- The principal factors involved in planning a subsoil exploration program for new facilities are: (1) type of structure, (2) thickness of soil between subgrade elevation and the top of the solution zone, and (3) the expected prevalence and severity of subsurface solution induced defects in the solution zone and overlying materials. The importance of the thickness of soil between subgrade and the top of the solution zone with reference to the building or fill size cannot be overemphasized. Because of the southeast dip of the solution zone and the large variations in plant topography, the overburden thickness in one area of the plant may be sufficient to preclude difficulties from subsurface solution defects whereas the converse may be true elsewhere. Special care should, therefore, be exercised when constructing structures where the ground surface elevation is unusually low. Low ground surface elevations decrease the thickness of soil above the solution zone and may have resulted in locally accelerated solution rates. An unusually thin zone of natural soil between subgrade elevation and the top of the solution zone may not provide sufficient protection even for relatively non-critical structures. While voids may be found in the overburden above the solution zone, current knowledge indicates that solution induced defects are restricted to the solution zone in the McBean formation or the material immediately overlying it.

- The equilibrium of soil overlying solution induced defects often decreases because of variations in surface or ground-water movement, whether resulting from pumping, natural causes, or construction of plant facilities. This was taken into account when the plant was constructed by locating water supply wells away from major structures. However, ground-water seepage from canals or storage ponds may eventually be responsible for some changes in the present equilibrium of soil over solution defects. Careful annual inspections of adjacent areas should provide adequate control, as major structures are not located adjacent to canals or storage ponds.

- Acceptable Degree of Risk: The cost and delay of a comprehensive foundation investigation and treatment program must be balanced against: (1) structural requirements, (2) consequences of possible differential settlements, and (3) other factors such as contingent operational problems. Structural, operational, and economic considerations may warrant assuming a calculated risk, at least under some circumstances, in lieu of adopting technically desirable and relatively safe foundation. exploration and treatment procedures. The successful behavior of structures constructed during the initial plant construction program over ten years ago is of special interest because the locations and types of structures constructed at that time are probably as critical as may apply for future work. Structures were constructed at some locations, for example, in D-Area, where subsurface solution defects are relatively critical. Yet in this area, and beneath some major structures in other areas, subsurface grouting was not attempted and a modified foundation design and calculated risk were accepted instead. The successful performance of these structures is, therefore, reassuring and significant in indicating that existing solution defects are not highly active and that calculated risks can be assumed under some circumstances.

- Subsurface solution apparently proceeds very slowly and limited voids or soft areas are expected to remain stable unless subjected to: (1) large stress increases resulting from construction activities, (2) major changes in surface drainage, (3) subsurface water movement resulting from pumping from wells, or (4) shocks such as earthquakes, blasting or explosions. The importance of these factors was recognized and taken into account when the plant was originally designed, except that parts of Item 4 are of more recent significance.

- Without attempting to formulate rigid design planning procedures, it appears desirable, as a means of promoting consistent design approaches, to classify structures as regards their sensitivity to possible results from subsoil solution defects. This can be done, of course, only by departments concerned with designing and using structures and involves operational and policy elements. Generai structure classification promotes a consistent basis for either omitting or undertaking foundation grouting at 
proposed structures, when used with other data available. The proposed structure categories, along with considerations for each, are given below.

Category 1 - Non-sensitive or Minor Structures. Structures in this category would ordinarily not increase the stress at the top of the solution zone and would, therefore, not require subsoil exploration in addition to that for normal foundation design requirements. However, should such structures be placed on deep fills, or be sufficiently heavy to increase significantly the stress at the top of the solution zone, deeper subsoil explorations would be warranted. Typical structures would include office buildings, minor process structures, and service structures.

Category II - Structures of Medium Sensitivity or Large Cost. A basic requirement for structures to be placed in this category is that serious problems would not arise if cracks developed. Thus, the feasibility of repairing the structure would be one requirement for a structure to be placed in this category. A second requirement might be that loss of the contents of the structure would not present major hazards. Structures in this category should receive adequate exploration for normal design purposes and, in addition, fishtail type borings in the overburden above the solution zone to assure that an intact band of soil of adequate thickness separates the foundations of the structure and the top of the solution zone. The thickness of this zone should be sufficient to permit arch action to develop; capable of spanning solution induced defects. In general, a zone at least 75 feet thick between the subgrade and the top of the solution zone should be explored for structures in this category. This suggested thickness is, of course, variable and may be modified according to the size of the structure. At least one such boring should be made for small buildings; additional borings should be spaced on a grid approximately 100 feet square for larger buildings. Special precautions should be taken to observe and record: (1) dropping or slow settling of the drill rods, (2) gradual or sudden losses of drilling water, and (3) presence of calcareous materials. Typical structures would include power houses, evaporator buildings, and $244-\mathrm{H}$.

Category III - Structures of Maximum Sensitivity. The subsoils beneath all structures placed in this category should be explored by fishtail borings to the bottom of the solution zone and all defects in the solution zone and in the overlying soils should be grouted unless they obviously are minor. The spacing of borings in the overburden and in the solution zone depends upon the size of the structure and the loads imposed by it on the subsoil. In general, boring spacing should not exceed the equivalent of a 100 -foot square grid with a boring in the center and comers of each square. In areas where significant subsurface defects are revealed, closer spacing and additional borings should be used. Typical structures would include waste storage tanks, 105 and 221 buildings, and major pump houses.

- The 1951-52 boring and grouting work indicated that sudden dropping of drill rods results primarily from displacement of soft material, rather than from the drill rods entering a relatively unfilled cavity. Borings made in grouted areas, where relatively large droppings of the drill rods had been observed, failed to reveal thick layers of grout and indicated that probably the most severe common subsoil condition existing throughout the solution zone is a porous, spongy, relatively open strata that has substantial structural competence. Consequently, it is concluded that the mere loss of drilling fluid when making a boring is not in itself indicative of major subsoil defects, automatically requiring remedial grouting. While this is believed to be generally true, there may be exceptional cases where solution has resuited in relatively large cavities, which pose more of a threat to overlying structures than has been revealed by borings to date. If these conditions exist on the project, they are considered most likely to be found where the ground surface is low and surface water has tended to concentrate, thereby accelerating the solution processes and tending to wash out previously formed, partially or completely filled cavities.

- Losses of drilling fluid and their frequency and severity are considered less significant than the behavior of the drill rods during drilling and the observed resistance when recovering samples. Where 
no rapid dropping or slow settling of the drill rods occurs, and where the sampling penetration in the solution zone is high, a serious open solution cavity condition is not considered probable even though some borings may lose drilling fluid. However, if a large percentage of the borings freely lose drilling fluids, it would be necessary to re-examine critically this conclusion.

- Borings made at the Savannah River Plant, regardless of their purpose, should be grouted to prevent free seepage into the solution zone from overlying soils as this might wash out existing cavities. The ground-water level is often at substantial depths below the ground surface (i.e. 50 feet), therefore; the grout will be under relatively high pressure. A thick viscous grout should be used to prevent excessive travel and careful records should be maintained of the quantity required to fill each boring. If drilling fluid was lost, some grout in addition to that required to fill the borehole may be anticipated. Where these quantities are small, a few cubic yards for example, a serious subsoil condition is not indicated especially if the loss of drilling fluid is the only abnormal event observed in the boring. Grouting the borings constitutes an important test of the solution zone and should be considered together with other data in evaluating the subsoil defects at the site.

- Evidence of abnormally soft material, in the overburden above the solution zone, should be given special attention as such behavior indicates an upward development of subsurface defects from the solution zone, the presence of which, between the bottom of proposed structures and the top of the solution zone, would generally require further exploration and probably a need for remedial grouting. The thickness of intact soil between subgrade elevation and the solution zone, with respect to the size of structures and net loading, is considered of major importance.

- Because surface sinks are believed to develop slowly over long periods of time, study of periodic settlement observations should enable appropriate corrective action to be taken, if required, before large settlements occurred. Settlement observations have value only if performed with unusual accuracy and should be referenced to at least two benchmarks; each located a minimum of 1,000 feet from the structure being observed.

\subsubsection{Danger of Soil Liquefaction Caused by Earthquake at SRP (1976)}

Reference: Rutledge, Philip C. of Meuser, Rutledge, Wentworth \& Johnson, (1976), "Danger of Soil Liquefaction Caused by Earthquake at the Savannah River Plant", October, 1976.

This study was undertaken to review previous liquefaction evaluations made for the Savannah River Plant (SRP). The review considered only the SRP installations on the higher ground of the Aiken Plateau (generally above Elev. 250). No review was made for any installation on recent sedimentary deposits along the Savannah River. For the areas reviewed the conclusion was that the danger of soil liquefaction caused by earthquakes is extremely remote for the following reasons:

- The soil deposits on which the SRP installations reviewed are constructed are geologically old deposits of the Tertiary period. In the more than five million years since their deposition they probably have been subjected too much more severe earthquakes than can now be visualized. There are no records of soil liquefaction in such geologically old deposits causing damage to structures.

- The soil deposits apparently have been subjected to both small and rather large scale distortions in their geologic history and continuity of lithologically similar soils over distances of one to two hundred feet in the upper eighty feet below ground surface is rare. 
- Soil liquefaction damage, from the records, is almost entirely confined to structures on sand fills or recent alluvium so located that there is a lower area toward which the temporarily liquefied soil can flow. This condition does not exist at or near SRP installations.

- The assumption of earthquake causing ground surface accelerations as great as $0.2 \mathrm{~g}$. in the area considered is highly conservative.

- The criteria for soil liquefaction stated herein and utilized in this review are conservative interpretations of the actual records of soil liquefaction in earthquakes.

- In the very large number of samples reviewed in the boring records for depths less than $60 \mathrm{ft}$ below ground surface less than four per cent could be considered cohesionless sands or silts and in most cases these had standard penetration resistances greater than 20 blows per foot.

- In the $\mathrm{H}$ area there are layers of cohesionless silty sand between depths of 7 feet to 12 feet. These sand layers are above the bearing level of the waste storage tanks. If these sand layers exist under the earth fill that has been placed around the tanks and if they could become saturated even though they are 10 feet or more above ground water level, the layers could lose shear strength under the effects of a major earthquake. The only consequence would be that the fill around the tanks, which extends above the existing ground surface, might tend to slump and move away from the tanks. This would have no effect on the tanks themselves.

\subsubsection{Geotechnical Report DWPF 200-S Area (1984)}

Reference: Mueser, Rutledge, Johnston, and DeSimone (1984), "Geotechnical Report, Design and Construction, Defense Waste Processing Facility, 200-S Area, Savannah River Plant," Aug. 7, 1984-

This investigation evaluated subsurface conditions at the Defense Waste Processing Facility (DWPF) in S-Area. The scope of work included review of previous studies, a large-scale subsurface investigation, geophysical surveys, a laboratory testing program, and extensive engineering analyses. Significant findings and conclusions include:

- The soil profile in S-Area is generally similar to adjacent H-Area and consists of complexly interbedded clayey sand, sand, and stiff silty clay.

- The strata of major concern in foundation design for the proposed structures were the sand and clay layers within the Barnwell and McBean [Santee] Formations. The stresses imposed by the proposed structures on the soil mass were relatively insignificant at depths greater than 150 feet (the approximate depth of the base of the McBean [Santee] Formation).

- Strata within the Barnwell Formation had occasional $\mathrm{N}$-values of less than 10 blows per foot (less than $<7 \%$ of the samples). The McBean [Santee] formation was found to consist primarily of alternating layers of sand with some clay, and sand with trace of clay or silt, ranging in thicknesses from 60 to 70 feet. The bottom of this formation ranges from elevation 125 to $135 \mathrm{ft}$, and includes isolated layers of calcareous sand. The calcareous sands are susceptible to solution resulting in soft skeletal soil structure or voids. Instances of low blow counts, low resistance during drilling, and loss of drilling fluid were noted at depths containing the calcareous sands, indicating voids or leached zones of limited extent are present beneath the DWPF.

- Clayey soils are generally heavily preconsolidated to stresses well above pressures induced by foundation loads from the proposed facility. The exception is a discontinuous clay layer up to 10 feet 
thick encountered 70 to 80 feet below ground surface. Some consolidation tests performed on samples from that layer indicate a preconsolidation pressure approximately equal to the existing overburden pressure.

- All of the samples exhibiting low preconsolidation pressures and shear strengths were recovered below the Barnwell Formation in Stratum C2 and the undertying McBean [Santee] clayey sands. Occasional sandy samples from the McBean formation react with a weak hydrochloric acid solution indicating the presence of calcareous materials that are subject to leaching. None of the clayey soils exhibiting low preconsolidation stresses reacted with the acid. Previous investigations concluded that calcareous material may have existed within these clayey soils, but they may have been leached out by the downward flow of ground water into the lower, porous soils. This loss of material would increase the void space within the soil and reduce its ability to support vertical load, thereby lowering the apparent preconsolidation stress. These weaker zones are generally characterized as pockets rather than as continuous layers.

- Because of the critical nature of the proposed structures, a grouting program (consisting of 39 grout holes) was performed to minimize the risk of irregular building settlements. Subsurface voids and leached zones were identified during the grouting program by examining grout take ratios (theoretical hole volume/volume of grout). Grout take ratios greater than six were interpreted as indicating the presence of voids or leached zones. Grout take ratios between three and six were interpreted as thin zones of leached materials. Grout take ratios up to three were attributed to boring diameters enlarged during the drilling process and wasted grout due to surface overflow. The grout take ratio in all the holes (with one exception) varied from 0.9 to 2.7 with most of the ratios close to 1.3 , indicating enlarged holes during the dritling process or wasted grout, not large subsurface voids present beneath the Category I structures.

- Total settlements, including soil heave plus settlements due to the net structural loads were estimated for all Category I structures. Ranges of settlement values calculated for various Category I structures are as follows:

Excavation heave:

Foundation settlement:

Maximum differential settlement:
0.4 in to 1.2 in

0.8 in to $4-3$ in

$0.1 \mathrm{in} / 100 \mathrm{ft}$ to $2.0 \mathrm{in} / 40 \mathrm{ft}$

\subsubsection{Z-Area Saltstone Disposal (1986)}

Reference: Mueser, Rutledge Consulting Engineers, (1986), Saltstone disposal, Z-Area SRP.

This investigation was conducted in support of construction of new vaults at the Saltstone Disposal Facility. The proposed 21 reinforced concrete vaults were designed to receive liquid saltstone waste, which similar to a concrete pour, would harden within about 30 days (resulting in massive concrete blocks). The dimension of each cell (vault) was $100 \mathrm{ft} \times 600 \mathrm{ft} \times 25 \mathrm{ft}$ deep.

A geotechnical program for the initial eight vaults was undertaken, which included 25 split spoon/shelby tube borings, 5 wellpoint piezometers, and laboratory testing. Significant findings and conclusions include:

- Of the 23 borings extended through the calcareous layer, one significant void was encountered in the Santee Formation at elevation $180 \mathrm{ft}$ (Boring Z-217, depth of $115.5 \mathrm{ft}$ ). The void was evidenced by an 
initial loss of drilling fluid followed by a drill rod drop of four feet. At completion, 1000 gallons of cement-bentonite grout were pumped into the borehole without grout return to ground surface. After allowing the grout to set for 8 days, the borehole was filled with grout. A six inch rod drop occurred in another boring at elevation $169 \mathrm{ft}$ (depth of $119.1 \mathrm{ft}$ ); however there was no significant loss of drilling fluid nor unusual grout take.

- The Santee Formation was broken into three substrata (from upper to lower, S3a, S3b, and S4). S3a, described as sand, some clay, had a few weight of rod/hammer soft zones. S3b, described as sand, trace clay and silt, had penetration resistances significantly higher than Stratum S3a (typically $\mathrm{N}$ of 40 to >100). S4 was described as calcareous sand, some clay or silt, trace shells and limestone fragments with some limestone and siltstone layers. The surface of Stratum S4 is between elevation 190 and $170 \mathrm{ft}$ (approximately 95-115 ft depth). Drilling through this stratum was characterized by alternating low and high resistances indicating presence of limestone and siltstone layers within the calcareous sands. Penetration resistances were generally greater than 30 blows per foot; about 50 percent of the $\mathrm{N}$-values were greater than 100 .

- One consolidation test was performed on a sample recovered from Stratum S3a immediately below a split-spoon sample recovered under the weight of rods. The preconsolidation stress of this sample is two tons per square foot (tsf) below existing overburden stress. MRCE interpreted this sample as representing an isolated weak zone, possibly the result of leaching of calcareous soils. The low preconsolidation stress may have reflected arching by stronger soils around the weak zone.

- There is no evidence of ground subsidence in the vicinity of the saltstone vaults, which are on top of a relatively flat plateau.

\subsubsection{K-Area Cooling Tower Reports (1990)}

Mueser Rutledge Consulting Engineers, (1990), "Foundation Investigation and Grouting Program K-Area Natural Draft Cooling Tower", February 5, 1990.

Mueser Rutledge Consulting Engineers, (1988), "K-Area Cooling Tower Eastern Site", December 5, 1988.

Mueser Rutledge Consulting Engineers, (1986), "K-Area Cooling Tower and Pump Pit", January 6, 1986.

The K-Area cooling tower is a large concrete structure 348 feet in diameter presenting an established load of 15,000 tons on ninety 24 inch diameter columns bearing on a ring beam foundation. The foundation subgrade lies at elevation $178.5 \mathrm{ft}$, with original grade across the site ranging from elevation 205 to $225 \mathrm{ft}$. A geotechnical program was undertaken to: (1) investigate foundation conditions, (2) fill with grout any significant "voids" or leached zones in the McBean [Santee] Formation beneath the tower site, and (3) to obtain information concerning the depth, thickness and lateral continuity of any underlying loose sands potentially susceptible to liquefaction under the design earthquake. It is important to note that several alternative facility footprints were investigated during the various phases of study, and foundation conditions were different at each location. Significant findings and conclusions include:

- The initial 1986 MRCE investigation found no calcareous soils, losses of drilling fluids, voids, rod drops or significant grout takes (only a few SPT tests encountered low blow counts). 
- During the $1987 / 1988$ MRCE program, calcareous materials were encountered in the deep borings at the revised tower site. One of the five borings revealed the presence of a significant void within the calcareous stratum. The COE has previously identified large sinks immediately adjacent to the tower site. Therefore, a low pressure grouting program at the tower site was recommended to identify and fill voids or leached zones and minimize the possibility of long term subsidence.

- In the 1988 MRCE report the McBean [Santee] Formation was subdivided into three substrata (from upper to lower, S3a, S3b, and S4). S3a, described as sand, some clay, had penetration resistances ranging from 6 to 92 blows per foot (averaging 31 blows per foot). Losses in drilling fluid circulation were noted within S3a at depths of 167 to 175 feet, 87.5 to 89 feet, and at 142 feet. S3b, described as a sand, trace silt or clay, had high $\mathrm{N}$-values of between 25 and 174 blows per foot, averaging 89 blows per foot. $\$ 4$ was described as calcareous sand, some silt or clay, cemented particles, shells with occasional layers of limestone and calcareous sandy gravel. Drilling through this stratum was met occasionally with alternating low and high resistances indicating the presence of limestone layers within the calcareous sands. Penetration resistances range from 29 blows per foot to in excess of 100 blows per six-inch increment. No significant voids evidenced by drill rod drops were noted in this stratum. However, there was a loss of drilling fluid circulation in one boring (K-501) in the calcareous zone from a depth of 147 to 153 feet (El 122 to El $116 \mathrm{ft}$ ).

- During 1990, the drilling and grouting program identified and filled significant voids in the calcareous stratum beneath the tower footprint. Voids were indicated by sampling spoon and drill rod drops up to 13 feet followed by loss of drilling fluid. Most of the significant voids were found beneath the southwest side of the tower. These observations indicated significant leaching of the calcareous material had occurred in the southwest portion of the site.

- As had been done before, the McBean [Santee] Formation was subdivided into three different strata. S3a (uppermost unit at approximately 45 to $125 \mathrm{ft}$ depth), was characterized as a sand, some clay, with penetration resistances in the upper portion of this stratum ranging from one to 22 blows per foot (averaging 10 blows per foot), and in the lower portion of S3a blow counts ranging from weight of rods for $18^{\prime \prime}$ to 89 blows per foot (averaging 21 blows per foot). The middle portion of the Santee (S3b) at approximately elevation 170 to $120 \mathrm{ft}$ (approximately 50 to $100 \mathrm{ft}$ depth) was described as a sand, trace clay or silt, with penetration resistances varying from weight of rods for $18^{\text {n }}$ to 94 blows for nine inches (averaging approximately 32 blows per foot). The lower portion of the Santee (S4) at elevation 140 to $100 \mathrm{ft}$ (approximately 80 to $120 \mathrm{ft}$ depths) was described as calcareous sand, some clay, with shells and some interbedded limestone layers. Drilling through this stratum was often characterized by alternating low and high resistances indicating the presence of limestone layers within the calcareous sands. Penetration resistances ranged from weight of hammer for $18^{n}$ to 100 blows for three inches (averaging approximately 57 blows per foot).

- During grouting the presence of a significant void was defined as a grout take of greater than 100 cubic feet. Seventeen of the 89 primary holes $(19 \%)$ had grout takes exceeding 100 cubic feet. The majority of primary holes experiencing rod drops, drilling fluid losses and grout takes exceeding 100 cubic feet were located in the southwest portion of the site. The average grout take for all primary holes was $\mathbf{8 9}$ cubic feet. The average grout take for primary holes in just the southwest portion was 170 cubic feet, while the average for the remainder of the primary holes was 52 cubic feet. Grout take ratios in all primary and secondary holes varied from 0.9 to 101.

\subsubsection{HWRF Phase I Geotechnical Study (1991)}

Reference: Law Environmental, Inc., and Law Engineering, Inc. (1991), "Savannah River Site Heavy Water Reactor Facility Phase I Geotechnical Study", Revision 1, SRS DCN PI-GE-210-I, June 10, 1991. 
The purpose of this geotechnical study was to provide information used to evaluate two locations within the "M12 Site" (located several miles south of $\mathrm{H}$-Area), for construction of a heavy water reactor. This facility was part of the New Production Reactor effort to construct new reactors for the production of nuclear materials. The scope of work for the geotechnical study included drilling and sampling within 21 soil test borings ( 7 on the Northwest site, 14 on the Southwest site), performing 14 electric piezocone penetration tests (CPT) at the Southwest site, seismic testing in 12 of the CPT's, installation of 10 piezometers (a single piezometer cluster at both the Northwest and Southwest sites, consisting of five piezometers each), and laboratory testing. A summary of significant findings is as follows:

- The subsurface soils at M12 Site were divided into three layers (upper, middle, and lower) based on differing geotechnical characteristics. The middle layer (the lithology of which correlates with that of the Dry Branch, Clinchfield, and Santee Formations) extends from an approximate elevation of $190 \mathrm{ft}$ to elevation $90 \mathrm{ft}$ (approximately 130 to $230 \mathrm{ft}$ depths). Calcareous materials occur intermittently within this layer. The upper 40 feet generally consists of dense sands. Underlying this is a mixture of materials including sands, clayey or silty sands and some clay. Occasionally, calcareous soils, shells, and fossiliferous limestone fragments and layers were encountered. SPT $N$-values were widely variable, ranging from 0 too greater than 100 .

- The middle [Dry Branch/Clinchfield/Santee] layer had the lowest average shear wave velocities that ranged from 740 to $1530 \mathrm{fps}$. The interval shear wave velocities exhibited the greatest variability in this layer.

- At the northwest of the two investigated sites, four of the seven borings encountered soft soils (SPT values of zero bpf), whereas six of the fourteen borings encountered soft soils at the southwest site. The borings on the northwest site encountered approximately 32 linear feet of soft soils within approximately 2040 linear feet of drilling (2 percent). Within the southwest site approximately 69 linear feet of soft soil was encountered within approximately 4010 feet of drilling (2 percent). Aggregate (total) linear feet of zero blow materials in a single boring ranged from 4 to 21 feet.

- Loss of drilling fluid circulation occurred in several soil test borings. Attempts were usually made to regain circulation by altering characteristics of the drilling fluid. On occasion a thicker bentonite slurry was used or materials such as mica flakes or cottonseed hulls were added. When these above methods were unsuccessful, or when a total circulation loss occurred, a temporary steel casing was set to reestablish drilling fluid circulation.

- For the CPTUs, soft or loose soils were defined as materials exhibiting tip resistances of 15 tsf or less over a minimum of one foot. Sections in three CPTUs (M12A-22, M12A-28, and M12A-30) were identified as meeting these criteria, with minimum tip resistances of approximately 4 tsf.

- One sample (out of seven consolidation tests) from a soil test boring M12-30 at elevation 98.5 to 96.5 $\mathrm{ft}(227.5$ to $229.5 \mathrm{ft}$ depths) was underconsolidated with an overconsolidation ratio of 0.1 .

\subsubsection{K-Reactor Area Geotechnical Report For Seismic Issues (1991)}

Reference: Geotechnical Engineers, Inc. (1991), “K-Reactor Area, Geotechnical Investigation for Seismic Issues, Savannah River Site (U), Volume 1: Seismic Structural Engineering," WSRC-TR-91-47, March 1991. 
This geotechnical investigation program characterized the soil properties and foundation conditions in the K-Reactor area, and was completed as part of the Reactor Seismic Qualification Program. The study included a large field effort (SPTs/CPTUs, down-hole shear wave and cross-hole tests, pore pressure dissipation tests), laboratory testing program (index and strength properties), and completion of a wide variety of engineering analyses. This was the first effort to attempt an engineering evaluation of the soft zones. Significant findings from this study include:

- Soil stratigraphy within 200 feet below the ground surface was found to be complex, consisting of many interbedded soil layers of predominantly clayey sands, silty sands and clean sands varying in thickness and composition. In the K Area, the soil zone between El 159 and $\mathrm{El}-1$ (approximately 110 to 270 feet below the ground surface) is a marine deposit, which based on current geologic designations, is included in portions of the Dry Branch and Santee Formations.

- Within these marine strata a layer at El 154 to El 124 (approximately depths of 115 to 145 feet below ground surface) was found to contain weak zones ("soft zones") of clayey sand, interspersed in stronger matrix materials. The soft zones varied in apparent thickness and lateral dimension and caused fluid loss and rod drops to occur during drilling.

- As with previous investigations at K-Area, subsurface strata in this report were broadly subdivided into different zones (upper, middle, and lower) on the basis of the exploration data. The middle zone at El 154 to El 99 (about 115 to 170 feet depth) consists primarily of clayey sands (SC), and sands with varying amounts of clay and silt (SP-SC/SP-SW). The middle zone was the only zone in which some samples reacted positively to hydrochloric acid, indicating the presence of calcareous materials. The upper 30 feet of the middle zone contained isolated "soft zones" and is termed the "critical layer". SPT $\mathrm{N}$-values in the middle zone ranged from weight of rods to $>100$ blows per foot. Shear wave velocity measurements were also erratic and ranged from about 350 to 2500 feet per second.

- A detailed soft zone criteria was developed:

- CPTU tip resistance less than 200 psi for a distance of at least one foot

- SPT $\mathrm{N}$-values equal to 0 , corresponding to weight of rods or weight of hammer

- Hydraulic pressure less than or equal to 50 psi to push a thin-walled sampling tube (3-inch diameter, 1/16-inch wall thickness).

- Rod drops during drilling.

- Start of a drilling fluid-loss episode. Drilling fluid losses occurred in areas other than soft zones, but were more common in the vicinity of known soft zones.

- Use of a series of widely spaced, as well as clustered, CPTUs combined with strategically located soil borings allowed for the determination that the soft zones in the critical layer at El 154 to El 124 (approximately 115 to $145 \mathrm{ft}$ below ground surface) were erratic in areal distribution and varied in thickness from 3 to $15 \mathrm{ft}$, with a least lateral dimension not exceeding about $15 \mathrm{ft}$.

- The soft zones consist of soil rather than open water-filled cavities and appear to be elongated "channel-like" features that occupy only about 10 to 15 percent of the critical layer volume. Extensive sampling and specialized laboratory tests were performed to determine consolidation properties of the soft zone and matrix materials. This sampling was made possible by utilizing the CPTUs to identify locations and elevations were the soft material appeared. The soft material appeared approximately $50 \%$ of the time (in 14 out of 32 CPTUs in the area surrounding the CWR and in 7 out of 15 CPTUs in a closely spaced pattern near the southwest corner of the CWR). 
- Soft zone CPTU resistances varied from 0 psi to 200 psi, and measured CPTU hydrostatic pressure ranged from about 25 to $40 \mathrm{psi}$. Some very low values of tip resistance may be too low because of locked-in tension created by the lodging of particles at the top of the cone tip. Soft zone sleeve friction measurements varied from 0 psi to greater than 3 psi.

- Pore pressure dissipation tests were performed in soft zones to accurately define pore pressure conditions in soft zones. These tests showed that excess pore pressures generated in soft zones during advancement of the piezocone dissipated to hydrostatic pressure.

- Down-hole shear wave velocity measurements performed in soft zones indicated velocities from about 350 to 950 feet per second. The average of the lowest three velocities measured in the soft zones was $385 \mathrm{ft} / \mathrm{s}$. Soft zone matrix materials have a best estimate shear wave velocity of $1,100 \mathrm{ft} / \mathrm{s}$.

- Detailed cone and boring logs in the soft zones indicate that soft zones consist of soil rather than open water-filled cavities. The soil in the soft zones was actually sampled in the borings, and the cone records indicate that one or more of the following indications of soil presence were obtained:

- Tip resistance in excess of hydrostatic

- Measurable sleeve friction

- Piezometer responses other than hydrostatic pore pressure

- Pore pressure dissipation tests that showed the expected gradual change towards hydrostatic, confirming the validity of the piezocone response, and

- Down-hole shear wave transmission through the soft zones.

- Samples of soft zone material were primarily clayey sand (SC), with some samples consisting of sand with clay (SP-SC). The sand fraction was primarily fine to medium grained. The amount of fines in soft zone samples varied erratically from about 6 to 50 percent. The fines content was typically highly plastic clay. Liquid limits of samples (after passing the sample through the No. 40 sieve) ranged from 51 to 104 and plasticity indices ranged from 23 to 86 . The liquid limit and plasticity index of the portion of one sample passing the No. 200 sieve was 234 and 165, respectively.

- In situ dry unit weights of soft zone samples ranged from about 48 to 76 pcf. These low unit weights are consistent with the softness or looseness of the material.

- Calcium carbonate cementation does not appear to be present in the soil immediately above soft zones. Calcium carbonate materials still exist in portions of the matrix material in the lower portion of the critical layer.

- Some soft zone samples contained shells and some contained relatively hard, apparently cemented nodules. The nodules appeared to be closely spaced in a matrix of softer material. Shell fragments up to $3 / 4$ inch and zones of cemented nodules 6 to 18 inches thick were observed. In general, the shells and nodules did not react positively with $\mathrm{HCl}$. This may have been due to silicification of calcium carbonate materials. Some samples did react positively with $\mathrm{HCl}$, and these were typically near the bottom of the soft zones.

- An undisturbed sample of soft zone material that contained small fossils or shells was observed under a microscope. The sample contained an openwork structure and appeared to contain minute channels with rust colored staining on the channel walls. These observations are consistent with the low dry unit weights of the samples and the possibility that calcium carbonate material had once existed in the sample and was removed by dissolution.

- An interpretation of the origin of the soft zone materials is that they were originally sedimentary deposits predominantly composed of quartz sand, silt, and sand-to-pebble-sized shell fragments (Price, 1991). With geologic time, percolating ground water removed much of the shelly material by 
dissolution, leaving highly porous but still self-supporting poorly compacted SC and SP-SC soils. Shell fragments were locally replaced by precipitated silica as they dissolved.

- These processes have led to overall compression of the critical layer. Because of concentrations of soluble shells in certain zones of the layer, these zones would tend to compress more than the surrounding ground, causing arching of the ground above and around these zones. The reduction in vertical stresses due to arching would result in the formation of localized soft zones, consistent with what was encountered in subsurface explorations.

- Compression ratios (CR) of consolidation test samples of soft zone material ranged from 16 to 47 percent strain per log cycle change in effective stress. The average value of CR for the five consolidation tests was 29 percent. In general, the samples had high compressibilities which is consistent with their low dry unit weights and high plasticity. Compression indices $(\mathrm{Cc})$ in terms of void ratio ranged from about 0.35 to 1.39 , and averaged about 0.81 . Results of the consolidation tests indicate that preconsolidation pressures on samples are in the range of about 12 to 43 percent of the average effective overburden stress at the depths of the samples. The average ratio for the five consolidation tests is 32 percent.

- Fluid losses during advancement of borings through soft zones likely resulted from net drill fluid pressure at the bottom of boreholes exceeding the vertical effective stress in the soft zones, thus causing consolidation of the soft zone material.

- Grout pumped into the ground during original construction of K Reactor compressed some, but not all, of the soft zones. A total of four borings in this investigation were performed at locations in the reactor area where grouting was performed by the COE. Grout was encountered in all of these borings below a depth of 90 feet.

- Estimates of differential ground surface settiements resulting from deep volume changes were determined by using a model for estimating soil movement induced by soft ground tunneling (Attewell et al., 1986). Two soft zone cases were developed, including:

1. a single 15 foot diameter soft zone of infinite length at a top depth of $115 \mathrm{ft}$ (top of critical layer) with a volumetric compression of 0.22 percent, and

2. ten 15 foot diameter soft zories spaced 20 feet center-to-center, also at a depth of $115 \mathrm{ft}$ and experiencing a volumetric compression of 0.22 percent.

- The maximum differential settlement estimated to occur was $1 / 2000$ or about 0.06 inches per 10 feet. To further study the potential for damaging settlements to the site structures several conditions were assumed to occur simultaneously:

- Soft zones were assumed adjacent to material that exhibits no settlements

- Lower bound shear wave velocity was taken as $750 \mathrm{fps}$

- Multiple 15 foot diameter soft zones were spaced 20' on center

- Strains were based on $25 \%$ distribution of soft material in the critical layer

These more conservative (worst case) assumptions resulted in a maximum differential settlement of about $1 / 1200$ or about 0.1 inch per 10 feet.

- Liquefaction was assessed utilizing two separate approaches the cyclic strain approach (Dobry) and the empirical blow count assessment (Seed). The primary method used was the cyclic strain approach. Best estimate and lower bound analyses were conducted for this assessment. The results indicated no potential for liquefaction at resulting levels of strain and pore pressures. As a supplement to this analysis the empirical approach by Seed was employed and likewise resulted in no potential for liquefaction.

- Total ground surface settlements from design earthquake loading were estimated to be between 1.4 to 1.75 inches, with most ( $85 \%$ ) soil compression was computed to occur at depths greater than $90 \mathrm{ft}$. 
Analyses indicate that arching will be maintained by the matrix material, because cyclic strains and pore pressure increases in the matrix material will be small. Cyclic strains and pore pressure increases in other material layers in the soil profile will be very small.

\subsubsection{Integrated Geologic Analysis of the K-Reactor Area (1992)}

Reference: Westinghouse Savannah River Company, (1992), "Integrated Geologic Analysis of the K-Reactor Area (U)," Reactor Engineering Department, Document No. WSRC-TR-92-42-004, January, 1992.

This investigation was conducted to define the occurrence, distribution, and areal extent of soft zones underlying the K-Reactor. Major findings include:

- Soft zones underlying the K-Reactor area primarily occur in three intervals of the Santee Formation, at El 149 to El 139 (approximately 120-130 ft below land surface), El 134 to El 119 (approximately 135$150 \mathrm{ft}$ below land surface), and El 114 to El 99 (approximately 155-170 feet below land surface). The El 134 to El 119 range (135-150 foot depth) is the primary interval in which soft zones were encountered.

- Direct indications of soft zones (SPT rod drops, low CPT tip pressure/sleeve friction) were encountered in approximately $10 \%$ of the deep penetrations in the study area.

- The most developed soft zone complexes are approximately 15 feet thick. The upper portion of these complexes is composed of a soft zone, approximately three to five feet thick, with porosities ranging from 65 to $75 \%$ (void ratios of 1.85-3.0). The lower zone is composed of underconsolidated silty sands and varies from eight to 10 feet thick, with porosities in the range of $50-65 \%$ (void ratios of 1.0 1.85).

- Soft zones are distributed sporadically along three southwest trends. The areal extent of the most well developed soft zone encountered at K-Area measures approximately 200 feet long by 50 feet wide and exhibits a strong northeast to southwest orientation.

- Soft zones at the K-Reactor are poorly developed, limited in size and areal extent, and poorly interconnected. Data obtained from the WSRC/GEl investigation shows that rapid lateral changes in the Santee can occur within five feet from closely spaced CPT soundings and within 25 feet from SPT borings.

- Drilling fluid loss and grout take may be used as indirect methods of determining the presence of soft zones. These methods are unreliable for determining the extent of soft zones, since the pressure required to introduce fluids into the subsurface may hydrofracture the geologic materiais past the extent of the soft zones.

- There are no documented occurrences of surface depressions (sinks) developing as a result of soft zone collapse at K-Area.

\subsubsection{K-Area Soil Stabilization Program (1992)}

Reference: Westinghouse Savannah River Company (1992), "K-Area Soil Stabilization Program (KASS)," Summary Overview and Volume 1, Systems Engineering Department, Document No. WSRC-TR-92-299, Rev. 0, July, 1992. 
The purpose of this program was to provide stabilized foundation soils for the critical sections of cooling water piping in $K$ Reactor area. This was accomplished by injecting a cement-sand grout mixture into the soil zones underlying the buried cooling water system piping from approximately elevation 110 to $210 \mathrm{ft}$ (160 to $60 \mathrm{ft}$ depths). The grouting operation included 260 to 330 primary and secondary grout holes.

As part of the verification process, and prior to grouting, additional soil information concerning the existing condition of the soft zones was obtained by CPTU along the alignment of the cooling water piping. After the grouting operation was completed, another limited series of CPTU data in the same vicinity was planned to be collected to verify that the known soft zones had been sufficiently stabilized. This included $9 \mathrm{CPT}$ paired holes in area L3, with locations adjacent to lower-grout-take holes and those adjacent to higher-grout-take-holes.

Major findings from this very extensive program include:

- Soft zones (intervals of low resistance to penetration) are not interconnected, average about 6 feet in thickness, and have an average lateral extent of less than $\mathbf{5 0}$ feet in any direction. Soft zones comprise less than 10 percent of the area that was grouted based on the distribution of holes taking more than 300 cubic feet of grout during the COE and KASS Programs. The injected grout propagated by means of hydrofracturing that was initiated during drilling and continued during grouting. Grout is estimated to have traveled at least 40 feet horizontally.

- Grout takes did not appear to vary significantly due to any of the following factors, within the limited ranges used:

- Use of sanded versus neat grout,

- Use of bentonite versus Revert drilling fluid,

- Use of casing advancer versus open hole drilling techniques,

- Short interruptions (20 minutes or less) during grouting, or

- Variation of grout age, temperature, or viscosity.

- Individual in situ grout seams from the KASS Program ranged from less than 0.5 inch to 6 inches in thickness. More than 80 percent of the injected grout, in both the COE and KASS Programs, is in thin seams less than 2 inches thick. Exploratory drilling and in situ testing showed that the soft zones remain essentially unaltered after grouting.

- Based on an average thickness of soft zones of six feet in the grout zone and the fact that less that $10 \%$ of the grout holes in K Area encountered a soft zone, it is estimated that less than one percent of the soil volume beneath $\mathrm{K}$ Area will accept a significant amount of grout (i.e. more that $300 \mathrm{cf}$ per hole).

- The benefit of compression due to grouting is very localized. The injected grout has had only a limited effect on the compressibility of the soft zones. In high take areas, in addition to a limited reduction in the compressibility, any potential pre-grouting settlement would be reduced, after grouting, by the thickness of the in situ grout.

- The results of the post-grout investigation program indicated the presence of load transfer or arching around the soft-zone soils. 
- The soft zones follow an apparent NE-SW trend; however, the trend is not established well enough for precise prediction of soft zone locations.

- The dritling and grouting program was an effective method of testing the response of the subsurface material and demonstrated its ability to resist deformation. Both the COE and KASS Programs subjected the subsurface soils to drilling and grouting fluid pressures higher than existing in situ pore pressures with no evidence of arch collapse or surface settlement.

- Site specific exploration and independent analytical studies have indicated that the previous upperbound estimate of soft zone compression of 42 inches is unduly conservative. Maximum compression due to complete collapse of the soil arches of the worst case soft zone encountered in the KASS Program is calculated conservatively as 17 inches.

- Potential pipe settlement resulting from 17 inches of compression for both the upper bound soft zone width of 35 feet (plane strain condition), and the upper bound diameter for a circular soft zone of 50 feet (axisymmetric conditions), is estimated to be less than 1.5 inches. The corresponding pipe flexural strain is less than $0.008 \%$.

- The results of the analysis of induced pore pressures from a design basis earthquake (DBE) and a seismic event with accelerations 50 percent greater than the DBE showed that the arching effect would be maintained. Resulting cooling water piping settlement will be 2.4 and 3.8 inches, respectively, and the corresponding pipe strains will be $0.005 \%$ and $0.0065 \%$, respectively, for a continuous (plane strain) soft zone 50 feet wide.

- This program demonstrated that it is neither necessary nor desirable to do more grouting at K Area.

\subsubsection{PAR Pond Dam Seismic Evaluation (1992)}

\section{Reference: Ebasco Services Inc. (1993), “Par Pond Dam Supplemental Seismic} Evaluation Final Report", Task 061, March, 1993.

Par Pond Dam is an embankment structure located on the Lower Three Runs Creek at the Savannah River Site, near Aiken, South Carolina. Based on the criteria for dam safety evaluation established by the U.S. Army Corps of engineers, the dam is classified as a high-hazard structure. This program included three major components: (1) a geotechnical field investigation, (2) laboratory testing program and (3) engineering evaluation of seismic stability. Major findings are as follows:

- The critical zone sands and silty sands comprising Par Pond Dam foundation materials are very loose at depth and the potential for liquefaction under seismic loading exists. The critical zone extends upward from approximately EL $37 \mathrm{ft}$ to the base of the dam except in those cases where the dense upper foundation or the organic layer intervenes. Both zones include green, greenish gray, brown and yellowish brown clayey sand (SC), silty sand (SM), poorly graded sand (SP), well-graded sand (SW), silt (ML), and mixtures of these soils. Inorganic clays of low and high plasticity were also found occasionally. Corrected Standard Penetration Resistance within the Critical Zone ranged from 0 to 40 blows per foot with the higher blow counts occurring where cementation was present. The majority of values fell between 1 and 10 blows per foot.

- Cone penetration tests indicated that the Critical Zone had tip stresses that typically ranged from 10 to 200 tsf, with a few harder layers with tip stresses up to 800 tsf. Plots of the in situ undrained steady 
state strength of critical zone soils versus elevation indicated there was no apparent relationship between the elevation at which the material was found and the strength of the material.

- Preliminary seismic stability analyses indicated that both the downstream and upstream slopes might be susceptible to a seismically induced liquefaction flow slide. However, these previous studies were preliminary in nature and did not include an assessment of the earthquake intensity required to trigger failure.

- Settlement analyses indicated the following:

- The maximum dynamic settlement of Par Pond Dam after the design earthquake is estimated to be less than one foot.

- Virtually all the calculated settlements were found to be related to settlement accumulated within the loose foundation sands.

- The maximum settlement is expected to occur at the east and west abutment areas where the embankment overlays thicker deposits of loose saturated foundation sands. The settlement along the conduit at Station $41+40$ is estimated to be less than six inches.

\subsubsection{Replacement Tritium Facility Geotechnical Investigation (1993)}

Reference: Westinghouse Savannah River Company, (1993), "Savannah River Site Replacement Tritium Facility (233H) Geotechnical Investigation (U)", Volume I, Document No. WSRC-RP-93-606, April, 1993.

The scope of work for the RTF geotechnical investigation included a large subsurface investigation and laboratory testing program. The RTF geotechnical investigation was conducted to define the stratigraphy of the foundation materials underlying the facility, obtain engineering properties to assess the competence of the foundation under static and dynamic loads, derive properties for soil structure interaction studies, and relate site-specific geologic features to the general geology of the SRS. Major findings from this study include:

- Soft zones at the RTF were identified based on the following criteria: SPT N-values of 4 or less, sampler advance under weight of rods (with or without hammer), loss of drilling fluid, low hydraulic pressure reading $(<50 \mathrm{psi})$ when pushing a Shelby Tube/Piston Sampler, or low tip resistance $(<200$ psi) from the CPT. It should be noted that the loss of drilling fluid might be an indirect indicator of soft zones; however, using this method to determine the extent of the soft zone is unreliable. Drilling fluid pumped into a boring may hydrofracture the geologic material, causing pathways for the fluid to flow away from the borehole. These pathways may coincide with soft zone intervals; however, it is likely that the hydrofractures may extend past the soft zones, yielding inaccurate estimates of the extent of the soft zone.

- The soft zones at RTF ranged in thickness from 0.5 to 9.5 feet, with an average thickness of 2.2 feet. The thickness of soft zones at RTF is generally less than those identified at other locations at SRS. The formation of soft zones depends heavily on the amount of carbonate material that was originally present in the deposition of the Santee Formation. The RTF is located in the central portion of the SRS, in which less favorable conditions existed for the development of carbonate bodies than downdip areas, such as K-Area and PAR Pond. The lack of large carbonate deposits produced thinner soft zones that occur less frequently than those encountered in downdip locations of SRS.

- The soft zones at RTF are overconsolidated $(O C R=1.4-1.5)$, indicating that no stress transfers, such as arches, have developed at this location. 
- A number of laboratory tests were performed to determine the physical properties of samples recovered from the Santee interval at RTF. The natural water content of the material was $29 \%$, the total unit weight was 117 pcf, the liquid limit was $38 \%$, and the plasticity index was $14 \%$. The shear wave velocity as determined by crosshole and downhole methods was determined to be 1150 feet/second.

\subsubsection{ITP Facility Final Report - Phase I and II CPT Studies (1994)}

Reference: Raytheon Engineers and Constructors, Ebasco Division, (1994), "In-Tank Precipitation Facility, Phase I and II Cone Penetrometer Studies", Final Report, March 10, 1994-

This CPT investigation was conducted to determine the site stratigraphy at the ITP, perform downhole seismic surveys to obtain shear wave velocities for the fill and foundation soils, and determines geotechnical parameters for the geologic formations underlying the site. Special emphasis was placed on the identification of soft zones or voids encountered during the investigation. The scope of work for this investigation called for CPT soundings and dilatometer tests, to be followed by a series of geophysical tests and a remedial alternative study. Important findings from this investigation include:

- Soft zones were defined in CPT soundings where the measured tip resistance was less than 15 tsf over a minimum zone thickness of 6 inches. The sleeve data for these areas was then evaluated to identify zones where the sleeve resistance was less than 1 tsf. The pore pressure plots for zones meeting the three criteria were then examined to determine if these areas were filled with water, slurry, or soil. A pore pressure plot that closely approximates the hydrostatic pressure indicates the presence of water or slurry filled void, rather than a soft zone. A pore pressure plot that is elevated upon pushing the CPT indicates a soil filled zone (soft zone).

- Four soft zones were identified from two CPT soundings within the ITP fill material. One sounding exhibited a single thin zone measuring about 9 inches thick, while the second CPT encountered three thin zones measuring between 7 and 12 inches thick.

- Seven CPT soundings penetrating the ITP foundation soils encountered a total of 19 soft zones and four voids. The thickness of the soft zones ranged from 0.62 to 5.32 feet and the cumulative void thickness ranged from 1.16 to 6.95 feet. The largest interval $(6.9 \mathrm{ft})$ which contained voids (identified on the basis of measured CPT pore pressure equals hydrostatic pressure) was located in CPT-26 at approximately El 169 (157 ft depth). The great majority of soft zones were identified in the eastern portion of the ITP area, where the total thickness of "soft zones" at individual test locations was over $10 \mathrm{ft}$.

\subsubsection{ITP and H Tank Farm Geotechnical Investigation Report (1995)}

Reference: Westinghouse Savannah River Company. (1995), "In-Tank Precipitation Facility (ITP) and H-Tank Farm (HTF) Geotechnical Report", Site Geotechnical Services Department, Document WSRC-TR-95-0057, Rev. 0, September, 1995). 
The scope of the In Tank Precipitation (ITP) investigation was to define the site-specific geological conditions at the In Tank Precipitation (ITP) facility (including Tanks 48, 49, 50,51 and 21) and the general $H$-Tank Farm (HTF) area; obtain engineering properties for the assessment of the stability of the native soils and embankment under static and dynamic loads (i.e., slope stability, liquefaction potential, and potential settlements); and derive properties for soil-structure interaction studies. Primarily due to scheduling, but also due to funding, the report focused on the ITP Facility. Thus, the bulk of the analyses described were performed for the area immediately around and near the ITP. The geotechnical strategy was to perform analyses for ITP and apply the results to the HTF by comparing subsurface conditions at ITP with those in the balance of the HTF. General soft zone observations of this study include:

- At ITP, soft zones (i.e., SPT-N $<5$ bpf or CPT tip resistance $<15$ tsf) are generally restricted to the lower Dry Branch Formation (DB4/DB5 layer) and the Santee/Tinker Formation (ST layer).

- Consolidation properties of the DB4/DB5 layer show that the highly plastic clays $(\mathrm{CH})$ are compressible, but on average, are normally consolidated to slightly overconsolidated. Thus, it was concluded that the soft zones in the DB4/DB5 layer pose no significant settlement threat to the ITP tanks.

- Underconsolidated zones are also present in the predominately sandy soils of the Santee/Tinker Formation. Often, in conjunction with these soft zones, intervals of hard drilling, high penetration values (SPT-N $>50 \mathrm{bpf})$, and high tip resistances $\left(q_{c}>200 \mathrm{tsf}\right.$ ) were also found in the Santee/Tinker Formation. The hard zones appear to be a result of silicified and/or carbonate-cemented sediments that typically cap or are interlayered with the soft zones.

-. - To determine the size and location of the soft zones in the Santee Formation at ITP for engineering analyses, CPT and SPT logs were reviewed for all intervals meeting the following criteria: (1) CPT $q_{c}$ $<15$ tsf or (2) SPT-N $<5$. This review showed that the soft zones were stratigraphically/facies controlled (along the flanks of the moldic limestone facies).

- Near the ITP tanks, the upper soft zone horizon has a maximum thickness of about 10 to 15 feet and is typically found between elevations 160 to 175 feet (about 110 feet below the tank mudmat). The lower horizon is thinner, less continuous, and has a maximum thickness of about 5 feet. It is typically found between elevations 133 to 138 feet.

- Soft zones appear to occur as discontinuous pockets, lenses, or stringers. The high degree of variability in penetration resistance is probably a result of rapid lateral and vertical changes in the carbonate deposits and subsequent diagenetic changes such as dissolutioning/solutioning and silicification.

- Statistics performed on the Santee/Tinker Formation shows that the soft zones are relatively thin (less than 4 feet on average) and are not laterally continuous for distances greater than a few tens of feet (smaller than 35 feet on average, and likely on the order of 10 to 20 feet).

- To check the conclusions of the geostatistical analyses, penetration resistances from paired CPT-SPT boreholes were also analyzed. The CPT tip resistances, $q_{c}$, and SPT $N$-values were paired by elevation for all CPT and SPT boreholes that are separated by approximately 10 feet (or less) horizontal distance. In pairing the CPT data with the SPT $N$-values, measurements of $\mathrm{q}_{\mathrm{c}}$ were averaged over a 2-foot interval, starting 6 inches above the top of the SPT sampling interval. The results indicated that there is poor lateral correlation, even for these closely spaced boreholes and indicates large heterogeneity in penetration resistance over relatively short horizontal distances. 


\section{Observations of potential voids in relation to soft zone intervals at ITP are:}

- The ITP void criteria was established as: CPT $q_{c}<3$ tsf, CPT sleeve $<1 \mathrm{tsf}$, and piezocone pore pressure measurements approximately equal to hydrostatic pressure. Five CPT soundings measured relatively thin intervals of potential void, four of which were on the eastern side of the ITP (where carbonate sediments are present). The interval at which these conditions are noted corresponds to the top of the Santee Limestone and the bordering Facies 2 . Individual thicknesses of potential void range from 0.5 feet to $4-3$ feet thick.

- It is impossible to determine the lateral extent of a possible void from the existing borehole data. However, it is possible to generalize about a maximum likely dimension using statistical analyses, which suggests that the maximum lateral dimension of a soft zone is no greater than 35 feet and is probably between 10 and 20 feet.

- Boring and CPT data (SPT N-values and $\mathrm{q}_{c}$ ) pertinent to the HTF were reviewed, applying the same soft zone and void criteria as described for ITP. It was determined that soft zones are present in the remainder of HTF, and that these zones occur in the same horizons as found at ITP. Also, the relationship between carbonates and soft zones appears to be analogous to that of ITP.

\section{Findings and assumptions of soft zone modeling at ITP were:}

- Site-specific investigations at ITP have revealed that soft zones within the Santee/Tinker Formation are found at depths approximately 130 to 170 feet below natural ground surface (about 110 to 150 feet below the foundations of the ITP tanks). These soft zones act as local, underconsolidated pockets with overburden stresses arching around the underconsolidated zones. Because the soft zones have formed over a considerable period of time (late-Eocene, or about 40 mybp) and have survived for millions of years and have apparently persisted through several pre-historic earthquakes, it is reasonable to assume that for all practical purposes, they are of no engineering concern to the dynamic stability of the ITP tanks.

- However, settlement analyses have been done at other SRS facilities assuming that these underconsolidated zones are "arched" by more competent material and that the arch is broken during an earthquake. The KASS analyses suggest that the matrix sandy soils are incapable of arching zones larger than about 50 feet in diameter.

- In this report the initial dynamic settlement modeling was done assuming a constant soft zone thickness of 10 and 15 feet. However, as the development of the geological model proceeded, it became clear that a variable thickness representation of the soft zones was more realistic. For these analyses, it was assumed that the entire soft zone thickness was underconsolidated and that a complete transfer of effective vertical stress would occur after the earthquake (i.e., the arch would break). Post-earthquake compressions at depth using best-estimate values of the compressibility and consolidation state of the soft zone material and analytical modeling were used to estimate the resulting differential settlement by numerically propagating the deep-seated compressions to the tank foundation level.

- In the numerical analyses, a best estimate OCR of 0.7 was used for the soft zones. Data showed average moisture content for the soft zones and matrix material of 44.3 percent and 30.2 percent, respectively. A site-specific void ratio versus moisture content relation was used to estimate average void ratios of 1.285 and 0.928 , respectively, for the soft zone and matrix material. A site-specific compression ratio versus moisture content relation was used to estimate an average compression ratio of 0.24 for the soft zone material. Calculated soft zone compressions at depth of 4-5 and 7 inches were indicated using these parameters. 
- Total and differential settlements of the tanks at ITP due to dissipation of excess pore pressure and potential compression of the soft zones as a result of the Evaluation Based Earthquakes (EBE) and the 84th percentile motion were computed. In areas where soft zones were indicated by the borehole data these zones were assumed to be laterally continuous, underconsolidated, and were compressed using full effective vertical stresses (i.e., no post-earthquake arching was assumed). These worst case analyses assumed a soft zone thickness of up to 15 feet thick, resulting in a maximum soft zone compression at depth of 7 inches. Based on this result, estimated total settlements at the tank foundation level range up to 5 inches for variable soft zone thicknesses and up to 7 inches for a constant soft zone thickness of 15 feet thick. However, in all cases reported, the maximum differential settlement across a half-width of a tank (i.e., center to edge) is about 1 inch or about 2 inches across a full tank diameter (i.e., edge to edge).

\subsubsection{TEF Geotechnical Summary Report (1998)}

Reference: Westinghouse Savannah River Company, (1998), "Commercial Light Water Reactor Tritium Extraction Facility Geotechnical Summary Report (U)", Site Geotechnical Services Department, Document No. K-ESR-H-00010, Rev. 0, May, 1998.

The purpose of the investigation was to establish site-specific geologic conditions at the TEF site, obtain representative engineering properties of the subsurface and potential fill materials, evaluate the lateral and vertical extent of soft zones encountered, and perform engineering analyses for slope stability, bearing capacity and settlement, and liquefaction potential. The program included a subsurface investigation, laboratory testing, and engineering analyses. Major findings include the following:

- The soft zone criteria at TEF was SPT N-values less than 5 or CPT tip resistances less than 15 tsf over an interval of two feet or greater. Of the seven boreholes and 17 cone soundings only one SPT borehole and one CPT sounding indicated soft zones greater than two feet thick.

- One SPT boring (HTEF-B2) had a 36 inch interval of rod drop at El $148 \mathrm{ft}$ (depth of approximately 144 feet). Confirmatory CPTUs were pushed approximately 20 feet away in three opposing locations to attempt to delineate the extent of the soft zone. The two CPTUs to the south showed no indication of soft material and the CPTU to the north encountered early refusal. Two additional CPTUs were pushed at distances of 10 and 30 feet from the boring. The one at $10 \mathrm{ft}$ distance showed a soft zone 2.6 feet thick, and the other showed no signs of a soft zone. Based on these CPTUs, the soft zone was constrained, fairly small in size ( $3 \mathrm{ft}$ thick by $40 \mathrm{ft}$ diameter), and consistent with soft zones seen at RTF, In-Tank Precipitation Facility (ITP), and the Actinide Package and Storage Facility (APSF).

- A total of 6 SPT and 13 CPT intervals were identified at TEF which contained soft material, but failed to meet the two-foot length criteria for recognition as soft zones. These intervals ranged from 0.16 to 1.62 feet in thickness and occurred in three distinct horizons within the soil profile: the "tan clay" interval of the Dry Branch Formation, upper Santee Formation, and lower Santee Formation.

- Assumptions for TEF settlement calculations were that the soft zone materials were underconsolidated isolated pockets of soil that are bridged by dense overconsolidated layers of clayey sand. A compression ratio of 0.24 and overconsolidation ratio 0.7 were used (the same as in soft zone modeling at ITP and APSF). The ratio of the settlement seen at the surface to the soft zone compresșion at depth in the APSF and ITP analyses ranges from approximately 0.5 to 1.0 inch. Using an average ratio of 0.75 , the settlement observed at the surface at CLWR-TEF in the soft 
location will be less than one inch. For the purpose of design, it is recommended that a soft zone total settlement of one inch and a soft zone differential settlement of one half inch be used.

\subsubsection{Actinide Packaging and Storage Facility Geotechnical Report (1998)}

Reference: Westinghouse Savannah River Company, (1998), "APSF Packaging and Storage Facility Soft Zone Settlement Analysis (U)", Site Geotechnical Services Department, Calculation No. K-CLC-F-00034.

During 1998 a geotechnical investigation was undertaken to support design activities at the Savannah River Site (SRS) Actinide Packaging and Storage Facility (APSF). This new facility, located in F-Area, will largely be a below-grade structure requiring removal of soil to a depth of 30-35 ft below grade across the facility footprint. Tasks completed for this project included a large field effort to characterize subsurface conditions (including soft zone delineation), a laboratory testing program, and calculation of soft zone settlement redistribution and propagation through the soil profile to the ground surface during the design basis earthquake. Significant findings related to soft zones from this study are as follows:

- Two weak "soft zones" are located in the Santee Formation (at elevation $140 \mathrm{ft}$ and elevation $170 \mathrm{ft}$ ). They consist of underconsolidated sandy/clayey soils interspersed in a stronger matrix material, with thicknesses varying from $31 / 2$ to $8 \mathrm{ft}$. The in situ principal stress distribution in the matrix material above the soft zones forms a "soil arch" which supports the full overburden pressure and allows the soft zones to remain underconsolidated.

- The areal distribution of APSF soft zones was both highly and moderately well constrained. Soft zones on the southern side of the site were highly constrained, with the largest having a short dimension of between 25 to $45 \mathrm{ft}$ and the long dimension of about $195 \mathrm{ft}$. Soft zones on the northern half of the site was less well constrained, with the largest having a short dimension of about $40 \mathrm{ft}$ and a long dimension of about $230 \mathrm{ft}$.

- APSF soft zones showed a strong bias in orientation, with the long axes trending west-northwest to east-southeast (somewhat perpendicular to the overall northeast-southwest trend of Coastal Plain sediments).

- The major assumption for this report was that during the design earthquake event, the soil arch above the soft zones weakened and the soft zone material was subjected to the full overburden pressure and compressed to the normal consolidation stage.

- Results from the Fast Lagrangian Analysis of Continua (FLAC) analysis showed an average of about 2.2 inches of foundation settlement across the profiles, with a maximum computed settlement of 3.25 inches. The magnitude of settlement was greatly reduced (typically less than 0.1 inch) in this foundation model at horizontal distances of approximately 100 feet from the nearest soft zone.

- To address the potential danger due to uncertainties in the soil and soft zone properties, selected parametric studies on the variation of different property parameters were also performed. It was decided that the profile with the most severe settlement at ground surface would be selected for the parametric studies. For limited cases, the effects of dilation angles and compression ratios were investigated. It appears that dilation angle has no major effect on the ground surface deformation. However, the increase of compression ratio increases quite significantly the ground settlement. It is therefore very critical to determine the properties of the soft zone soils. 


\subsubsection{Use of the Cone Penetrometer at SRS Whitepaper (1998)}

Reference: Westinghouse Savannah River Company, (1998), "Use of the Cone Penetration Test at the Savannah River Site", Site Geotechnical Services Department, Document No. K-ESR-F-00005, Rev.0, May, 1998. Also referred to as the "White Paper".

The purpose of the White Paper was to describe the use of the CPT as it relates to geotechnical evaluations. In particular, this report described the use and history of the CPT during subsurface investigations at the Savannah River Site, and the philosophy of its inclusion in exploration programs (including exploration design and implementation). Although no fieldwork was completed for this task, significant soft zone observations and conclusions of this study include:

- Of particular importance at the SRS is the detection of soft zones usually encountered at depths exceeding 100 feet. These zones have been characterized from previous investigations as SPT "weight of rod" intervals, lost circulation zones, or a CPT tip resistance less than 14-4 tsf (200 psi). "Weight-of-rod" advancement can be a misleading indicator of a soft soil zone. At depth, the weight of the rods alone is imparting a significant stress on the soil at the sampler location. For instance, at a depth of one hundred twenty feet, the weight of the rods alone acting between the soil and the end area of the SPT spoon sampler would be approximately $30 \mathrm{tsf}$. Adding the weight of the hammer (140 Ibs) would increase this pressure to over $35 \mathrm{tsf}$.

- The CPT has provided valuable information within soft zones. The multiple parameters measured by the CPT indicate the presence of material where a mud rotary boring may lose circulation in the interval resulting in no recovery of material. One application in CPT technology, which has recently been used at the SRS, is the CPT sampler, which has attained excellent recovery of soft zone soils where conventional drilling/samplers have failed. However, due to the relatively small diameter of these samples, they are best suited for index testing and visual soil classification. Disturbance issues and the use of a smaller diameter sample must be resolved (possibly by a comparative testing program) prior to their use for other types of strength or compressibility testing.

\subsubsection{F-Area Northeast Expansion Geotechnical Investigation}

Reference: Westinghouse Savannah River Company (1999), "F-area Northeast Expansion Report (U)", Site Geotechnical Services Department, Document No. K-TRTF-00001, Rev.0, May, 1999.

This program investigated the subsurface conditions for the area known as the "northeast expansion" located in the F-Area. The primary focus was to gather subsurface information within the expansion area and tie this information with the detailed studies completed for the Actinide Packaging and Storage Facility (APSF) located southwest and adjacent to the northeast expansion area and the balance of FArea. The program consisted of field exploration including Standard Penetration Test (SPT) borings and Seismic Piezocone Penetration Test (SCPTU) soundings; a laboratory testing program and an evaluation of subsurface conditions. 
One of the specific objectives of the investigation was to evaluate the presence, thickness and stratigraphic position of soft zones. Significant findings relative to soft zones are summarized below:

- Nineteen CPT soundings and five SPT borings had tip resistances and $\mathrm{N}$-values meeting soft zone criteria however thirteen of these CPT soundings were pushed to delineate a soft zone within the APSF area. Four of the remaining six represented isolated hits in the APSF area and the other two were within the northeast expansion area. Of the five SPT borings, one was located in the APSF area while the other four were located in the northeast expansion area.

- Soft zone intervals were noted in only two of the soundings pushed for the F-Area northeast expansion investigation (soundings 103 and 157). Sounding 103 had a soft zone between El. 177.6 and El. 171.2 feet MSL with a cumulative soft zone thickness in this interval of about 2.9 feet thick. Revisions made to the boundary of the northeast expansion area placed sounding 103 outside of the investigation area; therefore this area was not investigated further. SPT boring FB-19 had measured soft zones from El. 189.6 to about E: 186.6 feet MSL. CPT Sounding 114 was pushed adjacent to FB19 (prior to FB-19 being drilled) with no measured soft zones.

- Sounding 157 had two soft zone intervals. The upper most interval was between El. 215.1 and 211.2 feet MSL with a cumulative soft zone thickness of about 3.4 feet thick. The lower soft zone interval was between El. 179.8 and El. 173.5 feet MSL with a cumulative soft zone thickness of about 6.2 feet. SPT boring FB-17 was drilled about ten feet away from sounding 157. The upper soft zone interval between El. 215.1 and 211.2 feet MSL was not encountered in the SPT boring. In fact, N-values of about 10 were measured through this interval. The lower soft zone interval was encountered in FB17. An interval of low blow counts, including weight of rod, corresponding to the lower interval measured in sounding 157 was encountered between El. 183.1 to El. 176.1 feet MSL. In SPT boring FB-17, a lower interval with low blow counts and weight of rods was also encountered from El. 157.6 to 151.6 feet MSL. This interval corresponds to a low tip resistance interval in CPT sounding 157 however tip resistances are higher than 15 tsf (about 20 tsf).

- Additional indications of soft zones were noted in SPT boring FB-20 and FB-20A. FB-20 was drilled adjacent to sounding 179 for the purpose of obtaining a paired sounding and SPT boring. At about El. 179 , a weight of rod over 37 inches was measured in boring FB-20. Drill fluid circulation was lost and the hole was abandoned. FB-20A was drilled adjacent to FB-20 and the interval from El. 194.9 to El. 181.4 was sampled with measured $\mathrm{N}$-values greater than 20. At El. 181.4 however, circulation was lost in FB-20A and the hole was abandoned. These intervals in FB-20 and FB-20A correspond to a low tip resistance interval in sounding 179 which has thin layers of tip resistances measuring less than 15 tsf but have a cumulative thickness less than 2 feet.

- The shallow stratigraphy and average engineering properties determined for the F-Area northeast expansion are directly comparable to those determined for the Actinide Packaging and Storage Facility (APSF) area as well as the balance of the F-Area. Geologic conditions are also directly comparable between these two areas.

Conclusions pertinent to the presence of soft zones included:

- Soft zone intervals detected in the F-Area northeast expansion area are consistent with soft zone sediments encountered at the APSF area. Siting and design of new facilities in this area should account for the presence of these soils either by avoiding the placement of critical facilities where these zones are known to exist, or determining the potential settlement and designing the facility to accommodate the estimated movement. A thorough review of the data included in this report is recommended for planning further investigations.

- Design and construction of new PC-3 and higher facilities, heavily loaded structures or capital investment projects in the F-Area northeast expansion area should not require extensive geotechnical characterization. However, structure specific investigations for foundation design and construction, as well as, proper characterization of soft zone intervals are required. Foundation specific investigations should consider structure size, geometry, foundation type and depth, performance classification and 
functional classification, etc. A limited program of field testing to confirm dynamic soil properties may be required to obtain baseline subsurface information such that a site-specific comparison with results of this investigation can be made.

\subsection{Outside Reviewer Comments For Soft Zone Technical Approach in SRS Reports}

Beginning in the early 1990's, several major geotechnical programs, summarized in the previous sections, were peer reviewed by outside experts. Those reviews pertinent to soft zone investigation and/or analysis are summarized in the following sections.

\subsubsection{K-Reactor Area Geotechnical Report For Seismic Issues (1991)}

Peer Review for: Geotechnical Engineers, Inc. (1991), "K-Reactor Area, Geotechnical Investigation for Seismic Issues, Savannah River Site $(U)$, Volume 1: Seismic Structural Engineering," WSRC-TR-91-47, March 1991.

An outside technical review of the adequacy and completeness of the geotechnical investigation at K-Area (see Section 3.0.8) was conducted by W. Clough (professor) and J. Martin (Ph.D. student) at Virginia Polytechnic Institute and State University. The Clough and Martin review found that the 1990-91 geotechnical investigation of the KReactor Site was generally thorough and accurate. The writers found some issues that bear further study, but is doubtful that the primary conclusions of the report would be affected since most of the assumptions used in the design studies were conservative. A summary of the issues that they concluded could gain from further study included:

- An attempt should be made to assemble data on the existing depressions and sinkholes at the SRS to determine if this information is consistent with the postulated effects from the analytical studies:

- The predictions of the one-dimensional study of potential seismic settlements should be reassessed in view of the fact that the lowest density sample in the cyclic load tests (73 pcf) was in the upper range of those reported for the soft zone (46-76 pcf). Notably, consolidation tests, which were not used for the settlement calculations, showed the low density soils from the soft zone were considerably more compressible than those at higher densities. The issues are how much more compression would be found in the cyclic tests using low density soils, and how much of the soft zone is in the low density range?

- As to the latter issue, it was suggested that a histogram format be used for display of the blow count and cone tip resistance data. This would be useful in assessing the relative amounts of different levels of densities in the soft zone.

- The need for additional grouting at the site was considered unlikely. However, in the event that additional grouting is recommended, the original procedures are not appropriate. Compaction grouting should be considered. Even this procedure would likely only be effective in localized areas where critical facilities are located and the soft zones can be reasonably defined. In larger areas, the random location of the soft zones makes grouting of any kind ineffective. 


\title{
2.1.2 Replacement Tritium Facility Geotechnical Investigation (1993)
}

\author{
Peer Review (W.F. Marcuson III, Ph.D.; J.K. Mitchell, Sc.D.): Westinghouse Savannah \\ River Company, (1993), “Savannah River Site Replacement Tritium Facility (233H) \\ Geotechnical Investigation (U)", Volume I, Document No. WSRC-RP-93-606, April, \\ 1993.
}

A review of the investigation techniques, subsurface characterization and engineering analysis was performed for the Replacement Tritium Facility (RTF). See Section 3.0.12. The review as submitted is summarized below:

We have reviewed the general approach that the Department of Energy (DOE), Westinghouse, and Bechtel used for evaluation of seismically induced liquefaction potential and associated settlements under the Replacement Tritium Facility (RTF) at the Savannah River Site, South Carolina. Overall, we agree with Bechtel's method to evaluate the potential for seismically induced liquefaction and associated settlements in the Tobacco Road (TR) formation under the RTF and the conclusions that have been developed. Specific comments follow:

\section{Methods Used}

In order to evaluate the liquefaction potential of a deposit, one must determine both the strength of the material under cyclic loading and the stresses induced in the material by the postulated design earthquakes. Bechtel used both laboratory test data and empirical correlations to evaluate the strength of the TR formation. We believe that the laboratory data are more useful for evaluation of the TR formation based on factors that are discussed later in this letter report.

Bechtel used the computer program, SHAKE, to evaluate potential earthquake-induced stresses. We consider the soil parameters used for the SHAKE analyses, which were derived from comprehensive boring and sampling operations and shear wave velocity ${ }^{--}$ measurements, to have provided reasonable estimates of these stresses. For purposes of this evaluation, the lower-bound strengths determined by the laboratory cyclic load tests were chosen, as representative of the TR deposit, which we believe, is conservative. The upper-bound stresses produced by SHAKE were also used by Bechtel. Again, we believe this is conservative.

During all stages of the analyses, we believe either reasonable or conservative assumptions were made during this evaluation. In general, factors of safety are satisfactory, indicating that initial liquefaction will not occur in the TR formation except in some small localized zones if the postulated design earthquakes occur.

It is important to note that for purposes of this project. Bechtel has defined liquefaction as 100 percent pore pressure response measured in stres controlled, undrained cyclic triaxial tests. Post-liquefaction, undrained triaxial shear tests indicate that the TR material is expected to dilate during undrained shear. Thus, we conclude that large strains and flow will not occur, even if high pore water pressure is developed during the design earthquake.

To estimate seismically induced settlements, Bechtel assumed 100 percent pore pressure buildup if the factor of safety against liquefaction was $<1.15$. If the factor of safety was $>1.15$, Bechtel followed an upper-bound pore pressure versus factor-of -safety 
curve. Differential settlements under the RTF are predicted to be less than a couple of inches. We believe this to be conservative since the computed values are, in genera!, less than 1 in.

Why do we believe the lab data are more useful than the empirical correlations?

The database used to develop the widely used empirical correlation developed by Seed and his colleagues is based on recent (Holocene) deposits. The TR material is of Miocene age. The empirical correlations are based on data for transported material with non-plastic fines. The TR material is gap graded with primarily plastic fines. The TR material has been formed by weathering. Mineralogical and petrographic studies indicate that the TR formation is composed of quartz particles surrounded by clay (kaolinite and illite). This partially explains the relatively low $N$ values and high shear-wave velocities obtained in the TR formation under the RTF. To use the empirical correlations for the TR deposit at the RTF would be an extrapolation of the method to materials and conditions for which it was not derived, which we believe would be inappropriate.

\section{Discussion of Sample Disturbance}

In any subsurface, undisturbed sampling investigation, some sample disturbance is unavoidable. Owing to their significant clay content, the TR formation samples possessed a substantial cohesion. This permitted sampling and specimen preparation for cyclic load testing with much less disturbance than is experienced by most liquefiable sands. During this investigation, special care was taken to minimize sample disturbance. The criteria used for electing specimens for cyclic load testing in the laboratory included:

- Low $\mathrm{N}$ values in adjacent borings.

- More sandy (less clayey) material.

- Volume change calculations that indicated the samples used for laboratory specimens expanded (as opposed to consolidated) during sampling and shipment.

Except for sample consolidation, which we believe was small in the specimens tested, all other sample disturbance should reduce the material strength. Additionally, Bechtel drew curves through the lower bound of the test data. As a result of these criteria, we believe Bechtel's use of these laboratory test data is a conservative estimate of the cyclic strength of TR material.

In summary, we agree with the approach Bechtel used to evaluate the potential for seismically induced liquefaction and associated settlements in the TR soil under the RTF.

\subsubsection{Senior Seismic Advisory Panel (1994)}

Peer Review (R.J. Budnitz, J.W. Reed; J.M. Roesset; J. Schmertmann): Letter Following First Meeting of the "Senior Seismic Advisory Panel", December, 19-20. 1994-

In 1994, a panel of experts was assembled to provide as needed review and consultation of geotechnical issues at the SRS. A summary of comments relative to soft zone issues are provided below. 


\section{The potential effects of soft zones at depth}

The evidence seems convincing that the so-called "soft zones" found primarily in the Santee Formation, at depths of approximately 100 to 150 feet, are the result of millions of years of dissolution of the shells found therein. This has resulted in zones of lower density and strength, with consequent higher compressibility, surrounded by still relatively intact parts of the formation. These areas act as local, underconsolidated, "soft zones", with the overburden stresses arching around these weakened zones. The extensive exploration seems to indicate convincingly that they are very local, and not extensive either vertically or horizontally. The concern is that during an earthquake the stress arching over these zones might collapse and reintroduce the overburden stresses with the resulting settlements migrating to the surface to cause differential settlement of the tanks.

Our review of the methodology used by WSRC to investigate the above problem indicates that they have taken a very conservative approach, perhaps overly conservative. They defined a "soft zone" as sands with $N \leq 5$ or $q_{c}, \leq 15 . N \leq 5$ is very conservative considering the weight of rods + hammer. $q_{c} \leq 15$ seems suitable. They used a reasonable best-estimate $\mathrm{OCR}=0.7$ in a larger-than-measured-anywhere soft zone layer $15 \mathrm{ft}$ thick and of large lateral extent, located at various potentially critical locations under the tanks. They then assumed that the arching collapsed completely to reestablish the overburden pressure, and used "FLAC" to force the resulting settlement at depth to distribute upward to the level of the base of the tanks. The combined effect is very conservative and is only justified because the resultant contribution to the tank differential settlement is small. We therefore believe that the "soft zones" issue is relatively unimportant and agree that it probably does not justify any less conservative refinements in the overall ITP investigation.

\subsubsection{ITP and H Tank Farm Geotechnical Investigation Report (1995)}

Peer Review (W.F. Marcuson III Ph.D., P.E.; James K. Mitchell, Sc.D., P.E.; G.F. Sowers, P.E., P.G.): Westinghouse Savannah River Company, (1995), "In-Tank Precipitation Facility (ITP) and H-Tank Farm (HTF) Geotechnical Report", Site Geotechnical Services Department, Document WSRC-TR-95-0057, Rev. 0, September, 1995).

This panel was assembled to review the characterization and analysis of soft zones relative to the ITP facility in the $\mathrm{H}$-area. Results of the review are summarized below.

In accordance with the memorandum from the U.S. Department of Energy (DOE) Savannah River, geotechnical peer review panel was established for the geotechnical investigation at the In Tank Precipitation Facility (ITP) and H-Tank Farm (HTF) Savannah River Site (SRS), South Carolina. Our panel's general assignment was to review the approach, methods, and results of the seismic stability evaluation of the facilities' foundation and embankments performed by DOE. Westinghouse, and Bechtel for the Seismic Safety Issues Resolution Program.

During the period October 1993 through September 1995 six peer review meetings were held. The first two meetings were held at SRS, October 13,1993, and December 6-7, 1,993. Professors Mitchell and Sowers attended an ad hoc program meeting in San Francisco, April 12-13, 1994, which preceded the third peer review meeting held in Atlanta, April 26-27, 1994- The fourth meeting was at SRS, September 27-28, 1994. The fifth and then the final meeting were held in Atlanta, December 20, 1994 and September 
11, 1995, respectively. These meetings and resulting correspondence allowed us to adequately review the approach, methods, and results developed throughout this investigation, culminating with our review of the final Draft report, "In Tank Precipitation Facility (ITP) and H-Tank Farm (HTF) Geotechnical Report", WSRC-TR-95-0057.

\section{Review Summary}

The specific objectives of our panel were to review (1) characterization of the subsurface, with special attention to the carbonate feature, (2) sampling. (3) testing, (4) interpretation of results, (5) liquefaction potential analyses, (6) settlement estimates, and (7) stability of the fill surrounding the tanks. During the two year duration of this project, we have visited the site, examined outcrops of the upper formations, listened to verbal presentations of the methods adopted, and have been furnished interim reports addressing the objectives of the ITP/ HTF investigation. We have responded verbally in the meetings and in writing to the reports submitted and to the draft of the final report. Our criticisms and comments have been acted upon and many of our recommendations have been incorporated in the final report.

We agree with the approach, methods, and findings presented in the final report. The approach used state-of-the-knowledge and state-of-the-art engineering, with appropriate and reasonably conservative assumptions where needed. 


\subsection{SOFT ZONE INDICATORS AND CRITERIA}

As outlined in the summaries of subsurface investigations summarized in Section 2.0, loss of drilling fluid, grout take volumes, weight of rod, rod drops, low SPT N-values, and low CPT tip resistances have been used to identify soft zones in various geologic/geotechnical reports for the SRS. Some of these changes reflect the nature of the program, such as whether it is a pure subsurface characterization or a remedial effort where foundation grouting takes place (thus allowing for grouting parameters/results to be used as a soft zone criteria). Other changes in soft zone criteria are related to improvements in technology, such as the introduction of the CPT in geotechnical investigations during the past decade. Some suggested changes in soft zone criteria involve a rethinking of whether conventional drilling techniques provide a $\mathrm{good} / \mathrm{bad}$, direct/indirect method of soft zone delineation.

Historically and typically, soft zones have been identified by one or more of the following critieria:

- Partial or total loss of drilling fluids

- Grout take volumes

- Rod drops (observed during drilling of the borehole)

- Low SPT blow counts (including weight of rods and/or weight of hammer)

- Low CPT tip resistances

A discussion of these criteria including the history and current criteria, is given in the following sections.

\subsubsection{Loss of Drilling Fluid}

Borings deeper than about 75 feet deep at the SRS are typically drilled using mud rotary techniques. Loss of drilling fluid or lost circulation was one of the indicators of soft zones noted by the COE during the initial subsurface investigations. Significant water losses occurred in 52 of the 418 K-Area grout holes drilled in the COE 1951-1952 grouting program ( $11 \%$ of the total number of holes drilled). These holes were drilled using a tricone bit and drilling fluid injected into the drill string. Drilling operations during KASS (see Section 2.0.10) recorded surface pressures as high as 70 to $100 \mathrm{psi}$, and the 1951-1952 COE program was likely performed in a similar fashion.

Once fluid losses start, they generally continue until the hole is completed. Drilling fluid loss generally occurs at depths of 100 feet or more, which corresponds to intervals within the Dry Branch and Santee Formations. This continued loss of fluid is interpreted to indicate that hydrofracturing of the formation has commenced and continues throughout drilling of the hole.

Zones in which water losses were noted in the 1951-1952 grout program appear to correspond to depths at which soft zones occur. This is due most likely to bottom hole 
pressures exceeding the effective vertical stress. Based on consolidation test results the calculated effective vertical stress at the general level of the soft zones is about 3,800 psf (Geotechnical Engineers, Inc., 1991). Assuming a pump pressure of only 20 psi, the net effective bottom hole pressure at the depth of the soft zones (100-150 ft) would be approximately $6,700 \mathrm{psf}$, which is significantly higher than the effective vertical stress. By exceeding the vertical stress, hydrofracturing of the section would likely occur.

Since hydrofracturing occurs with the application of significant and continued pressure, the fracture zone may extend well beyond the boundaries of the soft zone. Therefore, the volume of lost fluids does not accurately represent the amount of additional pore space or extent of the underconsolidated sediments. Thus, the current position regarding the use of loss of fiuid as an indicator of soft zones is that it is only a tertiary indicator at best. It is not recommended for primary identification of soft zone intervals.

\subsubsection{Grout Take Volumes}

Borings drilled at the SRS to depths that penetrate the water table are abandoned by tremie grouting the borehole. The amount of grout used to abandon the hole as well as the amount of grout pumped during past grout remediation programs have been used in various investigation/remediation reports as indications of soft zones. Although no specific grout volume criteria was reported, the COE made numerous observations of grout communication between boreholes during grouting operations.

Some soft zone criteria were developed during the DWPF and Saltstone remediation programs for grout take ratios. For these programs, the following ratio of actual grout take to theoretical grout take $\left(G_{A} / G_{T}\right)$, were used:
$>6 \quad$ voids or leached zones
3-6 thin leached zones
$<3$ slightly enlarged borehole and waste/ overflow

Mueser Rutledge Consulting Engineers developed a "significant void" criteria based on their grouting experiences at the K-Area Cooling Tower (1988-1990). Voids were defined as holes in which grout takes were more than 100 cubic feet (cf). A grout take of 100 cf represents a grout take ratio of approximately 10 , based on a four-inch diameter drill hole about $125 \mathrm{ft}$ deep. When this value (100 cf grout take) was observed in two adjacent primary holes it was considered a "conservative trigger" for adding secondary grout holes. During the 1992 KASS studies, areas with grout takes of $300 \mathrm{cf}$ or more were interpreted to be associated with well developed soft zone complexes in the subsurface and required secondary grout holes be added.

Hydrofractures induced by grouting exhibit the same behavior as those induced by the drilling fluids. The presence of the thin seams indicates that the grout initiated hydrofractures immediately above the soft zone and propagated for considerable 
distances along horizontal bedding surfaces, with no apparent benefit to the soft zone itself. The fact that grout behaves in this fashion is evident from the confirmatory borings drilled during the KASS program. Numerous thin seams of grout were observed in split spoon and core samples directly above identified soft zones.

The calculated effective grout pressure at the depth of the soft zones, based on information from the COE 1952 grouting report, was about 14,400 psf (100 psi). This calculation assumes a grout pressure of $40 \mathrm{psi}$ at the ground surface (surface pressures actually ranged up to $100 \mathrm{psi}$ ), a total unit weight of $109 \mathrm{pcf}$ for the grout, and a ground water depth of 40 feet. As stated, the effective vertical pressure in the soft zone averages $3800 \mathrm{psf}$, therefore the computed bottom hole grout pressure is approximately 3.8 times the effective average vertical stress. The observation by the $\mathrm{COE}$ that grout vented from nearby borings when grout was being injected in a given boring is, therefore not considered a direct indication of either the interconnectedness or the volume of a soft zone. As with drill fluid loss, the volume of grout does not necessarily represent the amount of pore space filled by the grout since it may be traveling great distances in thin seams along planes of weaker material. Therefore, our current position regarding the use of grout take volume as an indicator of soft zones is that like fluid loss, it is a tertiary indicator at best. It is not recommended as a primary indicator, or remedial technique at the SRS.

\subsubsection{Rod Drops}

Rod drops pertain to relatively quick advance of the drill string through some interval while actually drilling mud rotary borings. Not to be confused with "weight of rod" from Standard Penetration Tests. Drill rigs which are not chain drive derricks probably note this occurrence more often. The fact that drill fluid is being injected at a pressure to circulate the fluid from the bottom of the hole to the surface means the exit pressure at the drill bit is relatively high. The force of the drill fluid most probably jets loser material ahead of the bit resulting in a perceived drop in the drill string or the weight of the drill string exceeds the shear strength of the soil and the rods fall.

Because rod drops during mud rotary drilling are a factor of the down pressure applied, rotary force and fluid pressure, it is considered a secondary indicator of soft zones at best.

\subsubsection{Low SPT N-Values or Blow Counts}

The Standard Penetration Test (SPT), has been used extensively in geotechnical and characterization studies at SRS since the early 1950's. The SPT soft zone criteria has been modified numerous times. Table 3-1 below shows how various investigations have used this criterion. 
Table 3-1. SPT Criteria Used During Various SRS Geologic/Geotechnical Investigations.

\begin{tabular}{|c|c|}
\hline Author/Report & SPT/N-Value Criteria \\
\hline $\operatorname{COE}(1952)$ & Low SPT blow count (no specific value given) \\
\hline MPMRCE (1963) & $\mathrm{N} / \mathrm{A}$ \\
\hline Rutledge (1976) & N/A \\
\hline MRJD (1984)-DWPF & No specific value/criteria \\
\hline MRCE (1986) - Salt & No specific value/criteria \\
\hline MRCE $(1986-1990)-\mathrm{K} \mathrm{COOI}$ & No specific value/criteria \\
\hline Law (1991)-HWRF & SPT blow count $=0$ (including rod drops and weight of hammer) \\
\hline GE] $(1991)-K$ & $\mathrm{~N}$-value $=0$ (including weight of rods or weight of hammer) \\
\hline WSRC (1992) - K & Direct indication of soft zone $=$ rod $\cdot$ drop \\
\hline WSRC (1992)-KASSS & $\begin{array}{l}\text { Rod drops (evaluated but determined to be poor soft zone } \\
\text { criteria) }\end{array}$ \\
\hline Ebasco (1992) - Par Pond & $\begin{array}{l}\text { Corrected } N_{1-60} \text { SPT values less than or equal to } 10 \text { blows per } \\
\text { foot }\end{array}$ \\
\hline WSRC (1993) - RTF & $\begin{array}{l}\text { SPT } N \text {-value } \leq 4 \text { or sampler advance due to weight of } \\
\text { rods/hammer }\end{array}$ \\
\hline Ebasco (1994) - ITP & N/A \\
\hline WSRC (1995) - ITP & SPT $N$-Value $\leq 5$ \\
\hline WSRC (1998) - TEF & SPT $N$-Value $<5$ \\
\hline WSRC (1998)-APSF & SPT N-Value < 5 \\
\hline WSRC (1998) - Whiter & $\begin{array}{l}\text { Use of SPT N-Value as soft zone criteria considered to be } \\
\text { misleading. }\end{array}$ \\
\hline WSRC (1999) -NEC & SPT N-Value $<5$ \\
\hline
\end{tabular}

Sections of strata in which these low SPT blow counts or rod drops occurred were noted as being substantially softer (less consolidated) than overlying/underlying materials, thus earning the designation of "soft zone" or "weak zone". Most of the soft zones were thought to be filled with low strength soils, and even open spaces ("voids" or "cavities") were described. These observations seemed to suggest the presence of very poor ground conditions, and were the primary criteria for identification of soft zones for several decades.

Most soft zones at SRS lie at approximately 100 to 150 feet below the ground surface. At a depth of 130 feet, the effective unit bearing pressure at the end (over the cross sectional area) of a standard split spoon sampler (using $\mathrm{N}$ drill rods) is more than 80 $\mathrm{ksf}$. It is not surprising that settlement of the drill string occurs under its own weight resulting in a weight of rod or weight of hammer during an SPT. Thus, very low $\mathrm{N}$ values or weight of rod or weight of hammer may exaggerate, albeit in a dramatic fashion, the subsurface conditions of soft materials. Most likely this represents the condition where the weight of the drill string simply exceeds the strength of the soil.

Because the SPT is a standard test, and much data for the SRS and published engineering properties exists, the SPT N-value, weight of rod and weight of hammer are considered a primary indicator of soft zones. Currently, N-values of 5 and less, weight of rod and weight of hammer are considered as soft zone criteria. Further, when these criteria are met in the field, SPT measurements are taken continuously until the soft zone interval is fully penetrated. 


\subsubsection{Low CPT Tip Resistances}

During the past decade the CPT technique has been used extensively for SRS subsurface investigations. This technique has proven very useful for the identification ad characterization of foundation soils, and particularly soft zone intervals. The attributes include:

- high frequency of data collection,

- automatic and continuous depth control.

- lower cost as opposed to conventional drilling.

- high degree of reproducibility with minimal operator dependent variability, and

- a variety of measurements to determine physical and mechanical properties of insitu soils (tip and sleeve resistance, pore pressure, soil velocities, resistivity, etc.).

Table 3-2 shows how the CPT soft zone criteria have evolved during the past decade. Currently, the tip resistance measurement is considered the primary soft zone indicator, however, relative measurements of sleeve resistance, pore pressures and shear wave velocity are also considered when evaluating soft zone intervals.

Table 3-2. CPT Criteria Used During Various SRS Geologic/Geotechnical Investigations.

\begin{tabular}{|c|c|}
\hline Author/Report & CPT Criteria \\
\hline $\operatorname{COE}(1952)$ & N/A \\
\hline MPMRCE (1963) & N/A \\
\hline Rutledge (1976) & N/A \\
\hline MRJD (1984) - DWPF & N/A \\
\hline MRCE (1986) - Salt & N/A \\
\hline MRCE (1986-1990) - K Cooli & N/A \\
\hline LaW (1991)-HWRF & Tip resistance of $\leq 15 \mathrm{tsf}$ for at least a $1 \mathrm{ft}$ section. \\
\hline Geotech Engrs (1991) - K & Tip resistance $<200 \mathrm{psi}$ (14-4 tsf) for a distance $>1 \mathrm{ft}$ \\
\hline WSRC (1992)-K & Low tip pressures and sleeve resistance \\
\hline WSRC $(1992 \mathrm{~b})-\mathrm{KASS}$ & Tip resistance $<200 \mathrm{psi}$ \\
\hline Ebasco (1992) - Par Pond & No CPT soft zone criteria indicated \\
\hline WSRC (1993)-RTF & Tip resistance $<200 \mathrm{psi}(13.6 \mathrm{ts}$ ) \\
\hline Ebasco (1994)-ITP & $\begin{array}{l}\text { Tip resistance }<15 \text { tsf, and } \\
\text { Sleeve resistance }<1 \text { tsf, and } \\
\text { Zone thickness }>6 \text { inches }\end{array}$ \\
\hline WSRC (1995)-ITP & Tip resistance $<15$ tsf \\
\hline WSRC (1998) - TEF & $\begin{array}{l}\text { Tip resistance }<15 \mathrm{tsf} \text {, and } \\
\text { Zone thickness }>=2 \mathrm{ft} \\
\text { (Some judgement used for layers approaching } 2 \mathrm{ft} \text { in thickness). }\end{array}$ \\
\hline WSRC (1998)-APSF & $\begin{array}{l}\text { Tip resistance }<15 \mathrm{tsf} \text {, and } \\
\text { Zone thickness } \geq 2 \mathrm{ft} \\
\text { (Some judgement used for layers approaching } 2 \mathrm{ft} \text { in thickness). }\end{array}$ \\
\hline WSRC (1998) - White & N/A \\
\hline WSRC (1999) - NEC & $\begin{array}{l}\text { Tip resistance }<15 \mathrm{tsf} \text {, and } \\
\text { Zone thickness } \geq 2 \mathrm{ft} \\
\text { (Some judgement used for layers approaching } 2 \mathrm{ft} \text { in thickness). }\end{array}$ \\
\hline
\end{tabular}


The CPT is a quasi-static test meaning the measurements are independent of the push stress. This is accomplished by the cone tip resistance being measured by a load cell located directly above the tip. Therefore, the CPT does not have the same inherent problems that the SPT has with the weight of the drill rods bearing on the sampler end. Also, the electronic sampling rate, during penetration, results in a vertical resolution of about 1.2 inches. The quasi-static measurements, vertical resolution and other attributes of the CPT result in it being a primary indicator of soft zones. The current criteria for soft zone intervals are:

- Tip resistance measurements $\leq 15$ tsf

- Continuous intervals $\leq 2$ feet thick

\subsubsection{Miscellaneous Indicators}

Several other techniques associated with conventional drilling techniques have been used as soft zone criteria. These include:

- a hydraulic pressure of less than 50 psi to push a thin walled sampler (shelby) tube,

- borehole compensated density logs,

- cross-hole shear wave velocity survey, and

- cross-hole seismic tomography.

Although these criteria can be used to provide information regarding the in situ properties of subsurface soils, they suffer from short fallings. The shelby tube criteria (used during K-Area investigations in 1991) is not a rapid technique that can be easily applied over the complete length of the soft zone interval (much less the entire boring). It is a selective sampling tool ordinarily used when some other.criterion has indicated that soft soils are present.

The density log can quickly generate a complete borehole profile but it is infrequently used on geotechnical jobs thus there is not a base of experience to make a reliability assessment of the technique.

Cross-hole shear wave velocity survey cannot be easily or rapidly applied as a screening tool in a large number of borings since the investigation is limited to the area between the cross-hole borings. In addition, it requires drilled and cased borings which result in some degree of damage to the formation especially soft zone intervals.

Another cross-hole technique is seismic tomography. This has been used on three investigations at the SRS. First during the K-Reactor Soil Subsidence Program where it was used to image the extent of a construction mud mat and loss materials. Second, it was used during the KASS investigation where it was utilized to identify grout location or plumes in order to help determine grouting effectiveness. The large number of sampled borings and high contrast between the cured grout $P$-wave velocity and that of the surrounding soils made for good conditions to test the technique. The seismic 
tomography program effectively imaged some of the details of the grout plumes and detected changes in before-and-after surveys. The most sensitive results of tomography were visible in the difference image created by subtracting velocity tomograms after grouting from those taken before grouting. However, very thin layers of grout $(<3 \mathrm{in})$ were undetectable because of the relative dimensions of grout layer thickness and the wavelength of the seismic energy used to sense the grout layer. The latest application of the tomographic technique was for the ITP investigation where it was used to image soft zone intervals beneath existing tank structures where other exploratory methods like borings and CPT's were not possible. The tomographic images acquired from this investigation were directly correlated with pre-construction SPT borings.

Depending on the field conditions of the investigation area, some of the above techniques may be useful. However, calibration with CPT and SPT measurements is required.

\subsection{Current Soft Zone Identification Criteria}

Although most investigations have relied extensively upon, fluid losses, grout takes, rod drops, low SPT N-values and low CPT tip resistances as primary soft zone criteria, the above discussion leads to the following general conclusions:

1. The loss of drilling fluids is not a reasonable indicator that soft materials have been intercepted by the borehole. Also, it is not a reliable indicator of soft zone size or extent. Fluid losses are a routine occurrence in sediments below 100 feet depth, and likely indicate hydrofracturing has occurred. In addition, identifying the location of leakage into the formation is notoriously difficult. Typically the only definitive information that can be obtained from fluid loss is the depth to its first occurrence and the depth of any marked increases in loss (or total loss of circulation).

2. During grouting programs it has been found that while significant quantities of grout were injected into the sediments, a substantial quantity of the grout resides probably in thin seams. Thus, the volume of grout-take in a boring is not a reliable indicator of the location or extent of a soft zone.

3. Rod drops recorded from historical drilling accounts require some knowledge of the drilling rig, type of bit and pump pressure. Therefore, rod drops during drilling operations are not considered primary indicators of soft zones

4. SPT N-values less than 5 (including weight of rods and weight of hammer) are considered to be primary indicators of soft zones. Also, when these criteria are met during SPT sampling, continuous SPT sampling is required until the soft zone interval is passed. 
5. The CPT has none of the limitations associated with sampler mass or fluid injection into the formation. Because of its high data sampling frequency and array of test parameters and reliability of the measurements, it is the primary.tool for detecting and locating soft zone intervals. The primary criterion is a tip resistance less than 15 tsf over a continuous 2 feet thick interval. Further, the sleeve resistance, pore pressure and shear wave velocity measurements should be acquired and evaluated.

6. Depending on the type of investigation, field conditions and other circumstances, other techniques including cross-hole seismic tomography or other geophysical techniques may be used. These techniques must, however, be calibrated to more standard soft zone identification criteria such as the CPT and SPT measurements. 


\subsection{ORIGIN AND EXTENT OF SOFT ZONES}

This section will present past and present understanding of the origin and extent of both carbonates and soft zones found in the Tinker/Santee (Utley) sequence at SRS. The primary focus will be on the General Separations Area (GSA) with a limited discussion of the remainder of SRS (Figure 4-1). Specifically the following will be presented.

- Background of soft zones and carbonates.

- Geologic setting of the carbonate and soft zone sequence at SRS and the GSA in particular.

- The depositional environments of the carbonate-rich sediments.

- The post-depositional diagenetic alteration of the carbonate-rich sediments, and the timing of the alteration events.

- Review of past hypotheses for the origin of soft zones

- Hypothesis for the origin of soft zones based on current studies.

- Analysis of the extent (stratigraphic and geographic distribution) of the areas of carbonate concentrations and attendant soft zones in the GSA.

- $\quad$ Significant findings and observations

\subsection{Background}

Rod drops, during drilling, commonly occur in the carbonate-rich sediments in the Tinker/Santee (Utley) and Dry Branch formations (Figures 4-2 and 4-3). Historically the rod drop (including low blow counts in SPT borings) was assumed to indicate the presence of a "soft zone." The prevailing assumption of the causal mechanism for the "rod drops" has been dissolution of the carbonate-rich sediments in the zone, resulting in vugular porosity where the drill rod meets little or no resistance to penetration. An alternative hypothesis for this phenomenon is that the drill rod was pushed into uncemented sands where the overburden is supported by dense or semi-cemented beds that overly the uncemented sands. A third alternative hypothesis from data accumulated in this study (Parker, 1999) is that soft zones form where carbonate has been largely replaced by opal-CT (amorphous silica). The uncertainty of the origin and extent of soft zones has lead to very conservative engineering analyses of this subsurface condition.

Due to the depth at which soft zones occur (typically greater than $100 \mathrm{ft}$ below the ground surface) there has been no opportunity for direct visual observations of their nature and geometry. Conclusions that have been drawn on soft zone size are based on the limited penetrations of geotechnical/geophysical borings and CPT's. Despite these limitations, there has been a remarkable amount of data collected from a variety of sources that serve to outline soft zone geometry, distribution, and genesis. Table 4-1 presents, in summary form, the findings of major geotechnical investigations with respect to soft zone characterization. 


\section{Table 4-1 Historical Observations of Soft Zone Geometry and Distribution.}

\begin{tabular}{|c|c|}
\hline Report & Observations of Soft Zone Noid Geometry and Distribution \\
\hline COE $(1952)$ & $\begin{array}{l}\text { Soft zones reflect a skeletal structure resulting from leaching; mud losses reflect cavemous conditions. } \\
\text { Cavities (voids) are unlikely to be "many feet in diameter"; likely they are characterized by a } \\
\text { honeycombed structure of numerous small "rat holes" and are probably partly filled with soft semiliquid } \\
\text { clays or loose silts and sand. Report related soft zone collapse to surface depressions. }\end{array}$ \\
\hline MPMRCE (1963) & $\begin{array}{l}\text { Most severe common subsoil condition in solution zone is a porous, spongy, relatively open strata that } \\
\text { has substantial structural competence. }\end{array}$ \\
\hline Rutledge (1976) & N/A \\
\hline MRJD (1984)-DWPF & $\begin{array}{l}\text { No soft zone geometry discussion given. Numerous instances of low SPT counts, fluid losses, and 2-8 } \\
\text { feet thick rod drop zones observed. However, continuous layers of loose material were not identified. } \\
\text { Voids/eached zones identified where grout take ratios were between } 3 \text { and } 6 \text {. }\end{array}$ \\
\hline MRCE (1986) - Salt & $\begin{array}{l}\text { An isolated highly plastic clay layer with an } N \text {-value of weight of hammer was encountered in Boring } Z- \\
211 U \text { at Elev. } 195 \text {. In Boring } Z-210 \text {, at Elev. } 193, \text { a void was encountered with a three feet thick rod drop } \\
\text { and loss of drilling fluid. However, in subsequent borehole grouting at completion, the grout take was } \\
\text { only slightly greater than nomal indicating the lateral extent of the void is small. } \\
\text { Of the } 23 \text { borings extended through the calcareous layer, one significant void was encountered at the top } \\
\text { of Stratum } S 4 \text { in Boring Z-217 at Elev. } 180 \text {. The void was evidenced by an initial loss of drilling fluid } \\
\text { followed by a drill rod drop of four feet. At completion, } 1000 \text { gallons of cement-bentonite grout were } \\
\text { pumped into the borehole without grout retum to ground surface. After allowing the grout to set, the } \\
\text { borehole was filled with grout. A six inch rod drop occurred in Boring Z-210 at Elev. 169; however there } \\
\text { was no significant loss of drilling fluid nor unusual grout take. }\end{array}$ \\
\hline MRCE (1986-1990)- K CoOl & $\begin{array}{l}\text { Several. K-Area sites were characterized during these three studies. The first found encountered virtually } \\
\text { no soft ground, with only an isolated weight of rods interval in the McBean [Santee] Formation. The } 1988 \\
\text { investigation identified only a few rod drop, lost circulation, and high grout-take ratio intervals. The last } \\
\text { (and largest) investigation found extensive soft zone conditions within the McBean [Santee] Formation. } \\
\text { These soft zones were identified on the basis of low N-values, rod drops (up to } 13 \text { feet). drilling fluid } \\
\text { losses, and high grout take ratios, and occurred between EI } 175 \text { and El } 100 \text {. No real analyses of soft } \\
\text { zone geometry or size were completed, although the problem areas were not uniformly distributed, and } \\
\text { were mostly confined to the southwest portion of the site. }\end{array}$ \\
\hline Law (1991)-HWRF & $\begin{array}{l}\text { Very little stated on soft zone dimensions. Some general statistics on soft zone materials encountered } \\
\text { are as follows: } \\
\text { - NW site had } 32 \text { linear } \mathrm{ft} \text { of soft soils in } 2040 \text { linear feet of drilling (2 percent) } \\
\text { - } \quad \text { SW site had } 69 \text { linear ft of soft soils in } 4010 \text { finear feet of drilling ( } 2 \text { percent) } \\
\text { - Aggregate (total) linear feet of zero blow materials in a single boring ranged from } 4 \text { to } 21 \text { feet } \\
\text { - Appx. } 5 \% \text { of CPT's had blow counts of zero, while } 7-8 \% \text { had blow counts of } 5 \text { bpf or less. } \\
\text { - NW site had circulation tosses in } 6 \text { of } 7 \text { soil test borings ( } 86 \text { percent). } \\
\text { - SW site had circulation losses in } 8 \text { of } 14 \text { borings ( } 57 \text { percent). } \\
\text { NW site had complete circulation loss during installation of } 2 \text { of } 5 \text { piezometers. } \\
\text { CPT softhoose soils (defined as < }<=15 \text { tsf over a minimum of one foot) were identified in } 3 \text { CPT's. }\end{array}$ \\
\hline GEI (1991) - K & $\begin{array}{l}\text { Significant efforts made to determine soft zone geometry. Results include: } \\
\text { CPT Data } \\
\text { - Soft zones encountered between El } 152 \text { and } 123 \text { (depth of about } 117 \text { to } 146 \text { feet below ground } \\
\text { surface). } \\
\text { Of } 32 \text { CPT's, about half (14) encountered soft zones. Fifteen of the CPT's were performed in a } \\
\text { closely spaced pattern to investigate the lateral and vertical distribution of soft zones. Seven out of } \\
15 \text { CPT soundings encountered soft zones. The areal and vertical distribution of soft zones appears } \\
\text { to be erratic. } \\
10 \text { CPTs were performed in the area surrounding the reactor. Only } 3 \text { penetrated the critical layer, } \\
\text { and } 1 \text { encountered a soft zone. There are no indications that soft zones are concentrated in the } \\
\text { upper or lower portion of this depth range. Soft zones appear to occur at random within the critical } \\
\text { layer. For analyses, the critical layer was assumed to be } 30 \text { feet thick. Soft zone size and elevation } \\
\text { varies even within horizontal distances of } 5 \text { feet. } \\
\text { Soft zone thickness ranged from } 3 \text { to } 15 \text { feet, with an average thickness of about } 6 \text { feet. The shorter } \\
\text { lateral dimension of soft zones does not appear to exceed } 15 \text { feet. The longer lateral dimension is, } \\
\text { however, undefined. Observations made during the grouting program in } 1951 \text { indicated that grout or } \\
\text { water sometimes vented from boreholes located hundreds of feet from the location being grouted. } \\
\text { Thus the soft zones appear to be elongated, "channel-like" features and not isolated spheres or } \\
\text { spheroids. The channel-like shape is consistent with the geologic history of the deposit. } \\
\text { Concentrations of shells that probably led to the development of the soft zones would tend to occur } \\
\text { in elongated depressions in the surface of the coastal deposits. } \\
\text { The chances of encountering a soft zone at any particular exploration location is about } 50 \text { percent, } \\
\text { regardless of whether the explorations are performed hundreds of feet apart or only } 5 \text { feet apart. }\end{array}$ \\
\hline
\end{tabular}




\begin{tabular}{|c|c|}
\hline & $\begin{array}{l}\text { - The total thickness of soft zones encountered in CPT's divided by the total of CPT penetration } \\
\text { depths into the critical layer is } 84 \text { feet } 790 \text { feet, or } 10.6 \text { percent. } \\
\text { Assuming that the soft zones are elongated "channel-like" features, it appears that the soft zones } \\
\text { comprise about } 10 \text { to } 15 \text { percent of the critical layer by volume. A "best estimate" value of } 13 \\
\text { percent was used for analysis. Thus the matrix material comprises about } 87 \text { percent of the critical } \\
\text { layer. } \\
\text { Boring Data } \\
\text { Indications of soft zones were usually seen in borings at about the same elevation range as soft } \\
\text { zones encountered in adjacent CPT soundings. This is additional evidence that the critical layer } \\
\text { thickness and depth indicated by CPT's is reasonable. Soft zones were not encountered } \\
\text { consistently within a localized area, with some CPT/SPT pairs located } 20-30 \text { feet apart not } \\
\text { encountering the same soft zone. } \\
\text { Soft zones still exist in areas which have been grouted. }\end{array}$ \\
\hline WSRC (1992) K & $\begin{array}{l}\text { Significant efforts made to determine soft zone geometry. Results include: } \\
\text { - Soft zones under K Reactor occur primarily in three intervals (interpreted to be originally carbonate- } \\
\text { rich) of the Santee Formation, at depths of } 120 \text { to } 130,135 \text { to } 150 \text {, and } 155 \text { to } 170 \text { feet below the } \\
\text { present surface grade of } 270 \text { feet. } \\
\text { - Soft zones are distributed sporadically along three southwest trends. Direct indications of soft } \\
\text { zones are encountered in approximately } 10 \% \text { of the deep penetrations in the study area. } \\
\text { The most well developed soft zone complexes are approximately } 15 \text { feet thick composed of an } \\
\text { upper soft zone } 3 \text { to } 5 \text { feet in thickness, and a lower zone of underconsolidated silty sands } 8 \text { to } 10 \\
\text { feet thick. } \\
\text { The areal extent of the most well developed soft zone is approximately } 200 \text { feet long by } 50 \text { feet } \\
\text { wide and exhibits a strong southwest orientation. } \\
\text { Soft zones in the K Reactor area are poorly developed, limited in size and areal extent and poorly } \\
\text { interconnected. } \\
\text { Five of } 14 \text { SPT borings drilled in the GEINSRC program encountered intervals in which the drill } \\
\text { string advanced with the weight of the rods or hammer. The GEIMSRC program was specifically } \\
\text { targeted at sampling these zones and yet had only a } 36 \% \text { contact ratio. } \\
\text { No open voids or cavities were encountered in any of the borings. }\end{array}$ \\
\hline WSRC (1992)-K & 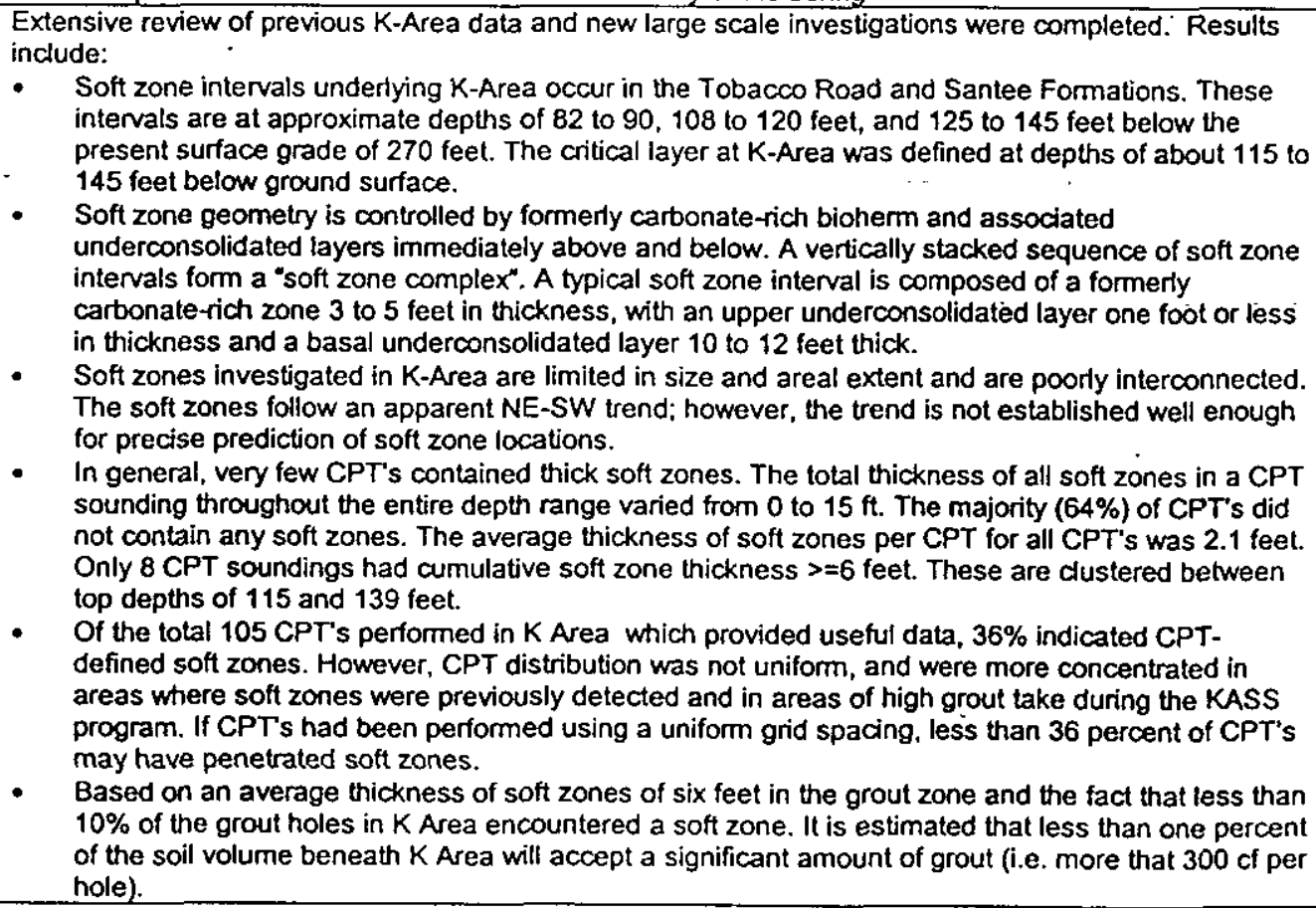 \\
\hline Ebasco (1992) - Par Pond & $\begin{array}{l}\text { "Critical zone" identified as being between } 70 \text { and } 135 \text { feet in thickness; dimensions of soft zones within } \\
\text { the critical zone not discussed. Rod drops, low SPT N-values, and low CPT sleeve/tip observed. }\end{array}$ \\
\hline WSRC (1993)-RTF & $\begin{array}{l}\text { Fifteen individual soft zones were identified within the Santee formation. Thicknesses ranged from about } \\
0.5 \text { feet up to } 9.5 \text { feet. The average soft zone thickness was } 2.2 \text { feet with a standard deviation of } 2.2 \\
\text { feet. }\end{array}$ \\
\hline Ebasco (1994) - ITP & $\begin{array}{l}\text { Numerous soft zones identified via CPT, particularly in eastem portion of ITP site. Total thickness of } \\
\text { "soft zones' within individual CPT soundings were over } 10 \mathrm{ft} \text {. }\end{array}$ \\
\hline WSRC (1995) - ITP & Soft zone maximum thickness of 20-30 feet (clay layer): $10-15 \mathrm{ft}$ thickness near ITP tanks. Geostatistical \\
\hline
\end{tabular}




\begin{tabular}{|l|l|}
\hline WSRC (1998)-TEF & $\begin{array}{l}\text { analyses suggest lateral continuity of soft zones smaller than } 35 \text { feet, more likely on the order of } 10 \text { to } 20 \\
\text { feet. }\end{array}$ \\
\hline WSRC (1998)- APSF & $\begin{array}{l}\text { Soft zone identified with dimensions of about } 40 \text { feet diameter by } 3 \text { feet thick. No voids identified. } \\
\text { Soft zones on the southem side of APSF site were highly constrained, with the largest having a } \\
\text { short dimension of between } 25 \text { to } 45 \mathrm{ft} \text { and the long dimension of about } 195 \mathrm{ft} \text {. Soft zones on the } \\
\text { northem half of the site were less well constrained, with the largest having a short dimension of } \\
\text { about } 40 \mathrm{ft} \text { and a long dimension of about } 230 \mathrm{ft} .\end{array}$ \\
$\begin{array}{l}\text { APSF soft zones showed a strong bias in orientation, with the long axes trending west-northwest to } \\
\text { east-southeast (somewhat perpendicular to the overall northeast-southwest trend of Coastal Plain } \\
\text { sediments). } \\
\text { Soft zones were modeled along sections with maximum width set to appx. } 50 \text { feet and thickness of } \\
\text { 3-8 feet. } \\
\text { No voids were identified. }\end{array}$ \\
\hline WSRC (1998)-White & N/A. No investigations conducted. \\
\hline WSRC (1999)-NEC & N/A No investigation conducted for soft zone geometry \\
\hline
\end{tabular}

Issues specific to the soft zones delineated in the GSA and their relationship to the nearby and enclosing carbonate sediment that are addressed in this section include the following:

- Typically soft zones occur within or proximate to carbonate bearing sediments. Therefore understanding the distribution, relative stratigraphic position and carbonate sediment type associated with the soft zones is addressed.

- Geologic and depositional setting of the soft zones and enclosing sediments are generally constrained to the middle Eocene Dry Branch-Tinker/Santee (Utley) (Figure 4-2) portion of the geologic section. Understanding the depositional setting in which these sediments were deposited is critical to understanding the distribution, thickness and continuity of the soft zones and their enclosing sediments. It is also necessary for evaluating post depositional alteration (dissolution/mineral replacement) of the calcareous sediments commonly associated with the soft zones.

- A perplexing problem with the distribution of soft zones is the limited lateral extent of individual soft zones. Resolving this issue requires an understanding of the depositional and diagenetic history of the soft zone and enclosing sediments. The type and degree of dissolution/recrystallization/replacement of different mineral phases is discussed using existing data and data acquired in two petrographic studies that detailed the lithologies, environments of deposition and diagenetic alteration of the sediments.

- To assist in addressing the above issues, a data base was established that includes all data retrieved from core, geophysical logs, CPT logs and geotechnical (SPT) borings related to the stratigraphy and presence of carbonate and soft zones in the GSA. The data base was queried in order to map the extent (stratigraphic and geographic distribution) of the carbonate zones and soft zones.

\subsection{Geologic Setting}

The Savannah River Site (SRS), covers approximately $300 \mathrm{mi}^{2}$ in the upper Atlantic Coastal Plain of southwestern South Carolina (Figure 4-1). Sediment underlying the SRS forms a wedge of sedimentary strata that thickens from about $700 \mathrm{ft}$ in the northwest to almost $1400 \mathrm{ft}$ at the southeastern boundary of the site (Plate 4-1). 
measuring, on average, $900 \mathrm{ft}$ in thickness in the GSA. Regional dip is to the southeast and decreases upward from about $48 \mathrm{ft} / \mathrm{mi}$ at the base of the Cretaceous-aged strata to about $15 \mathrm{ft} / \mathrm{mi}$ at the top of middle Eocene-aged strata.

Three distinct geologic provinces are delineated beneath the SRS: Paleozoic metamorphic and igneous rocks; a Mesozoic rift-basin (Dunbarton Basin) sequence comprising lithified mudstones, sandstones, and conglomerates of probable Triassic age; and unconsolidated Atlantic Coastal Plain sediments of Late Cretaceous and Tertiary age (Figure 4-2).

The Paleozoic basement rocks and the Triassic/Jurassic-age sedimentary rocks (Dunbarton Basin) have been leveled by erosion (Plate 4-1) and are unconformably overlain by unconsolidated to poorly consolidated Late Cretaceous and Tertiary Coastal Plain sediments. The Coastal Plain sediments form a mostly clastic wedge that thickens, and dips to the southeast. The sedimentary wedge represents depositional environments ranging from fluvial to shallow marine shelf (Figure 4-4). Fluctuating depositional conditions account for the observed complex variations in sediment lithology in the area.

In the GSA the Upper Cretaceous sediments (91 to 66 mybp) overlie Paleozoic crystalline basement rocks (Figure 4-2). The Cretaceous sequence is about 550 feet thick in the GSA, and consists of quartz sand; pebbly sand and sandy clay generally deposited in lower to upper delta plain environments (Figure 4-4). Following a drop in sea level that resulted in erosion of the underlying exposed Cretaceous section at the Cretaceous/Tertiary unconformity, Tertiary sediments were deposited when sea level rose onto the unconformable erosion surface.

Tertiary sediments average about 350 feet in thickness in the GSA (Figure 4-2), range in age from Early Paleocene to Miocene (?)/Oligocene (?) and were deposited in fluvial to marine shelf environments (Figure 4-4). The soft zone and calcareous sediment in the GSA, is specifically concentrated in the Tinker/Santee (Utley) interval, with minor occurrences noted in the Dry Branch Formation beneath the Tan Clay (Figure 4-3). Thus the distribution of carbonate and attendant soft zones is stratigraphically confined to an interval averaging approximately 80 feet in thickness in the GSA and constrained geographically to the areas where the depositional environments were conducive to carbonate sedimentation (Figure 4-4).

\subsubsection{Chronology of Tertiary Geologic Events in the GSA}

The chronology of events and the depositional setting that characterized deposition of the Tertiary sequence in the GSA is presented here. 


\section{Oldest}

- The Snapp Formation (Figures 4-2 and 4-3) and older Paleocene sediments (Sequence Stratigraphic unit I) were deposited in shallow clastic shelf and delta plain environments (Figure 4-4). Shallow shelf (platform) carbonate deposition was restricted to coastal areas of South Carolina at this time.

- Sequence I deposition was followed by erosion of the section (Lang Syne/Sawdust Landing unconformity) (Figure 4-3).

- A rise in sea level initiated deposition of the Congaree/Fourmile sands (Sequence Stratigraphic unit II) in shoreline to shallow shelf depositional environments (Figure 4-4). Shallow shelf (platform) carbonate deposition rapidly expanded landward and reached the southern boundary of SRS, but remained to the south and east of the GSA.

- Sea level continued to rise resulting in deposition of the Warley Hill clays (Sequence Stratigraphic unit II) in deeper shelf depositional environments (Figure 4-4).

- A lowering of sea level and/or the increased rate of sediment supply into the environment resulted in deposition of the Santee (and Utley) carbonates and clastics in shallow shelf depositional environments. This completed deposition of the Sequence Stratigraphic unit II sedimentary package (Figures 4-2 and 4-3).

- A retreat of the sea resulted in substantial erosion of the Tinker/Santee (Utley) (Sequence II) section (Santee unconformity).

- Deposition of the Dry Branch Formation (Sequence III) including the Griffins Landing limestone member was deposited over the Tinker/Santee (Utley) section, in shoreline to lagoonal/marsh depositional environments. Thus the shoreline depositional setting shifted southward from its position in Santee time (Figure 4-5). This was followed by deposition of the Tobacco Road Formation. (Sequence III) probably in a moderate to high-energy lagoonal/open bay environments (Figures 4-4 and 4-5). The shallow shelf (platform) carbonates that had reached their most northwesterly updip position in Santee (Utley) time retreated far to the south and east of SRS in Tobacco Road/Dry Branch time.

- A dramatic increase in sediment supply and a retreat of the shoreline towards the southeast, resulted in deposition of the "upland unit" sand and gravel (Sequence IV) in fluvial to upper delta plain environments (Figure 4-4).

\section{Youngest}

In conclusion, the deposition of shallow shelf carbonates generally remained to the south and east of the Savannah River Site during the Tertiary with the exception of middle Eocene Santee/Utley time when deposition of the carbonates extended as far inland as the GSA (Figures 4-3 and 4-5). 


\subsubsection{Distribution and Depositional Environments of Carbonates at SRS}

The regional distribution of the Tinker/Santee (Utley) carbonate-rich sequence is illustrated in Figure 4-6. Carbonate content in the sequence is minimal in northwestern SRS and predominates near the southeast boundary of the site. The GSA is in that part of the mixed clastics/carbonate zone where the clastic sediments generally constitute a greater percentage of the section than the carbonates. Figure 4-5 illustrates the environments of deposition of the Tinker/Santee (Utley) sediments in the SRS region. In northern SRS the Tinker/Santee (Utley) sediments are mostly sands and muddy sands deposited in shoreline to lesser lagoonal and tidal marsh environments. In the central SRS the sequence was deposited in middle marine shelf environments resulting in a varied mix of lithologies from carbonate-rich sands and muds to sandy and muddy limestones (Figure 4-7). In southern SRS the Tinker/Santee (Utley) sediments were deposited further offshore, further removed from riverine clastic input into the shelf environment resulting in deposition of carbonate muds.

\subsubsection{Stratigraphy of the Carbonate Sediments in the GSA}

The carbonates and carbonate-rich clastics are restricted essentially to two horizons in the GSA, the Dry Branch Formation and the Tinker/Santee (Utley) interval. The upper most horizon includes the carbonates of the Griffins Landing Member of the Dry Branch Formation found below the "tan clay" interval that occurs near the middle of the Dry Branch (Figures 4-2 and 4-3). The isolated carbonate patches of the Griffins Landing are the oyster banks that formed in the back barrier marsh zone behind the barrier island system (Figures 4-4 and 4-5). Underlying the Dry Branch, directly below the regionally significant Santee unconformity, is the Utley Limestone Member of the Clinchfield Formation. Without the benefit of detailed petrographic and paleontological analysis, the Utley carbonates cannot be systematically distinguished from the carbonates of the underlying Tinker/Santee Formation. Thus the carbonate-rich sediments between the Santee unconformity (Figure 4-3), and the Warley Hill Formation are referred to as the Tinker/Santee (Utley) sequence in this report.

Approximately $40-50 \%$ of the wells that drilled through the Tinker/Santee (Utley) interval in the GSA penetrated quantities of carbonate ranging from $5-78 \%$ of the sediment sampled. The calcareous sediment in the GSA consists of calcareous sand, calcareous mud, limestone, sandy limestone, muddy limestone, and sandy muddy limestone.

The Dry Branch sediments overlying the Tinker/Santee (Utley) interval in the GSA, were deposited in shoreline/lagoonal/tidal marsh environments (Figure 4-5). The shoreline retreated from its position in northern SRS during Tinker/Santee (Utley) time to the central part of SRS in Dry Branch time. Progradation of the shoreline environments to the south resulted in the sands and muddy sands of the Dry Branch being deposited over the shelf carbonates and clastics of the Tinker/Santee (Utley) sequence. 


\subsection{Origin of Carbonate Sediments in the GSA}

The average carbonate content of the Dry Branch-Tinker/Santee (Utley) sediments sampled in the GSA is approximately 31 percent with a large standard deviation of \pm 25 percent (Thayer and others, 1994). The carbonate content ranges from zero to 87 percent. The presence of glauconite along with a normal marine fauna including foraminifers, molluscs, bryozoans, and echinoderms, indicates that the limestones and limy sandstones were deposited in clear, open-marine water of normal salinity on the inner to middle shelf (Figure 4-5). The abundance of carbonate mud (micrite) in the limestones suggests deposition in quiet water below normal marine wave base. The presence of abraded and well-worn skeletal grains indicates that bottom transport by currents or storm-generated waves alternated with quiet-water conditions in which the sediments accumulated.

The presence of varying percentages of fine, subangular quartz sand and terrigenous mud in the carbonate lithologies indicates the varying but ever presence proximity of the carbonates to riverine input (Figures 4-4 and 4-5). Occasionally the Warley Hill Formation includes calcareous mud in isolated patches that were deposited in the deeper shelf environments (Figure 4-3).

Viewing the Tinker/Santee (Utley) sedimentary package parallel to the shoreline (Figures 4-4 and 4-5), the carbonate-rich sediments would be concentrated in the areas furthest removed from the tidal inlets at the shoreface where clastic sediments supplied by riverine input is concentrated. The clastic-rich sediments on the other hand would concentrate opposite the tidal inlet areas where clastic sediment is more readily available. The lateral facies transition of the sediments in the subtidal shelf environment from carbonate-rich to clastic-rich lithologies is therefore gradual and measures in the thousands of feet. Shifting locations of the tidal inlets at the shoreline has resulted in a complex sedimentary package (Figure 4-7) where facies gradually transition from one lithology to another both laterally and vertically. Therefore both vertical and lateral lithologic variability in the Tinker/Santee (Utley) sequence is the rule rather than the exception.

Locally the contact between carbonate sediments and laterally comparable clastic sediments is often sharply drawn, occurring over distances of only a few feet. In the past three hypotheses have been invoked to explain the rapid lithologic transition.

- First, the carbonate was deposited as discrete bioherms i.e., carbonate buildups surrounded by clastic sediments. The subtidal marine shelf environment of deposition of the Tinker/Santee (Utley) carbonates and clastics precludes the hypothesis that the sediment was deposited as discrete bioherms since bioherms are deposited in back barrier marsh environments (Figure 4-5).

- Second, rapid changes in sea level and the relative position of the shoreline resulted in erosion of the carbonate-rich sediments and deposition of channel clastics prior to deposition of the overlying Dry Branch and Tobacco Road clastics. Sediments 
typical of channel environments have not been demonstrated in the Tinker/Santee (Utley) sequence in the GSA.

- Alternately the carbonate is interpreted to be the remains of more continuously deposited beds (Thayer and others, 1994: Parra and others, 1998) where post depositional dissolution and removal of carbonate left isolated remnants over time. Here the overlying Dry Branch/Tobacco Road ("Upland" unit ?) clastics are interpreted to have slumped downward compensating for the removal of the carbonate (Figure 4-8). Slumping into the lows left by the removal of the Tinker/Santee (Utley) carbonate indicates that the consolidation of the Tinker/Santee (Utley) section post-dates deposition of the Dry Branch and Tobacco Road sands.

\subsubsection{Diagenesis of the Carbonate Sediments and Formation of Soft Zones}

Diagenesis is the sum of the physical, inorganic, chemical or biochemical changes that occur in a sedimentary deposit after its initial accumulation. The carbonate-bearing and carbonate-rich Tinker/Santee (Utley) sediments underwent extensive diagenesis, being very susceptible to post-depositional alteration due to dissolution and/or precipitation of calcite, silica and other minerals. Post-depositional events affecting the limestones and limey sandstones occurred in both the marine and freshwater phreatic (saturated) environments.

Events occurring in the marine phreatic environment include: 1) boring and micritization of skeletal grains (Figure 4-9), mainly by endolithic algae and fungi; and 2) precipitation of subsea cements, including pyrite and glauconite.

Glauconite precipitates under slightly reducing conditions in water depths greater than $10 \mathrm{~m}$; its presence indicates slow sedimentation rates (Nystrom and others, 1989, 1991) in marine shelf environments. The pervasive presence of glauconite in the Tinker/Santee (Utley) sediments corroborates the interpretation that the sediments were deposited in subtidal marine shelf environments based on fossil content and sediment fabric analysis.

Pyrite precipitates and is associated with organic matter within the carbonate mud (micrite) matrix of the limestones indicating that it formed under localized reducing conditions in areas containing putrifying tissue where sulfate-reducing bacteria were abundant (Scoffin, 1987).

The limestones commonly underwent minor post-depositional compaction within the first few hundred feet of burial as shown by the presence of broken pelecypod and other shells (Figure 4-10).

The Tinker/Santee (Utley) sediments were flushed by fresh water. The first demonstrable episode of fresh water flushing probably occurred soon after burial following the drop in sea level at the Santee unconformity. The diagenetic changes that 
occurred that materially effected the mineralngy and/or the engineering properties of the sediments include the following:

- $\quad$ Skeletal grains, mostly pelecypods (clams), dissolved to create molds (Figures 410, 4-11, 4-12; and 4-13). The molds underwent solution-enlargement to form vugs and channels. This was an important porosity-creating process in the limestones and limey sandstones because pelecypods formed up to 20 percent of the original unconsolidated sediment (Thayer and others, 1994). Locally the molds and vugs collapsed due to compaction following the dissolution of the fossil debris (Figures 4-14 and 4-15).

- $\quad$ Some of the carbonate derived from dissolution of the fossil shell debris described above was precipitated nearby as pore-reducing or pore-filling calcite cement (Figure 4-16). This was a minor process in the limestones and limey sandstones. Most of the carbonate material released from dissolution of fossil shells was exported out of the system as indicated by the small number of pores that are lined or filled with sparry calcite cement (Moore, 1979). Where it occurred however, the carbonate was often lithified (cemented) into hard limestone.

- Biogenic opal-A in the form of sponge spicules and diatom valves dissolved to create silica-rich pore water. Some of the silica was precipitated as $2-5 \mu \mathrm{m}$ sized opal-CT lepispheres that replace carbonate mud (micrite) matrix (Figure 4-10), precipitated within molds and vugs and in micropores in the lime mud matrix. OpalCT formation generally postdates solution of skeletal grains because the silica lines the interiors of some molds [rare to pervasive].

The amount and selectivity of the Opal-CT and chalcedony precipitation and replacement of carbonate is variable in the Tinker/Santee (Utley) sediments. Precipitation of the opal-CT silica varies from rare to pervasive where the entire precursor carbonate sediment was 100 percent replaced by silica (Figures 4-17 and 418). The main limiting factor for silica precipitation and replacement of carbonate depends on the quantity and availability of amorphous biogenic opal-A (sponge spicules and diatom valves) that dissolved to create silica-rich pore water for mobilization and precipitation of the silica into the nearby sediment (Figure 4-10). The silicification process ceased when the silica supply (diatom and sponge-spicule biogenic opal-A) was exhausted.

Fibrous chalcedony precipitates locally as rim cements on detrital quartz grains (Figures 4-17 and 4-19). Cement stratigraphy indicates that chalcedony formed after precipitation of opal-CT.

The carbonates and limey sands of the Tinker/Santee (Utley) sequence underwent a complex combination of deposition of diverse lithologies, post-depositional dissolution/precipitation/replacement of calcite, silica and other minerals. The result is sediment often far removed from its initial depositional fabric and mineralogy. Local dissolution is so pervasive that the precursor sediment is no longer identifiable. 
For a more comprehensive review of the carbonate sediments and their diagenesis the reader is referred to Thayer and others, 1994; Rine and Engelhardt, 1999; and Parker, 1999.

\subsubsection{Timing of Diagenetic Events}

The Tinker/Santee (Utley) sediments were deposited in the subtidal "normal" marine environment where marine phreatic waters bathed the newly deposited sediment. Diagenetic events occurring in the marine phreatic environment included: 1) boring and micritization of skeletal grains to form micrite envelopes (Figures 4-9 and 4-13), mainly pelecypods, and 2) precipitation of subsea cements, including pyrite and glauconite.

The initial dissolution/erosion of the middle Eocene Tinker/Santee (Utley) sediments occurred soon after burial, when sea level dropped (Santee unconformity) resulting in fresh water flushing of the Tinker/Santee (Utley) sediments (Figure 4-26). This is also the probable time frame when siliceous replacement and cementation of the clastics and carbonates in the Tinker/Santee (Utley) section was initiated. With dissolution of carbonate and precipitation and replacement of carbonate by silica, soft zones began forming.

The clastic sediments of the Dry Branch Formation (Sequence III) including the Griffins Landing limestone member were deposited over the Tinker/Santee (Utley) section in shoreline to lagoonal/marsh depositional environments. This was followed by deposition of the Tobacco Road Formation (Sequence III) probably in a moderate to high-energy lagoonal/open bay environment (Figures 4-4, and 4-5).

During deposition of the Tobacco Road and Dry Branch sequence, where the sediments were deposited in the shoreline environments, the underlying Tinker/Santee (Utley) section would be alternately flushed by the meteoric phreatic zone (fresh water)/marine phreatic zone (salt water) mixing zone (Figure 4-20). Here further dissolution of the Tinker/Santee (Utley) carbonates occurred albeit at a reduced rate, and siliceous replacement and cementation of the clastics and carbonates progressed, and soft zones continued to develop until the supply of silica was exhausted.

Eventually, as Dry Branch and especially Tobacco Road sedimentation continued, the Tinker/Santee (Utley) sediments were buried more deeply and the mixing zone waters could no longer reach the section (Figure 4-26). Here the sequence remained in the marine phreatic environment for extended lengths of time and diagenetic alteration of the sediments was reduced to a minimum or essentially ceased.

A dramatic increase in sediment supply and a retreat of the shoreline seaward to the southeast, resulted in deposition of the "upland unit" sand and gravel (Sequence IV) in fluvial to upper delta plain environments (Figure 4-4). This is the time frame of the further dissolution and removable of the Tinker/Santee (Utley) carbonate due to renewed fresh water flushing of the sequence. Here the overlying Dry Branch/Tobacco Road ("Upland" unit ?) clastics are interpreted to have slumped downward 
compensating for the remcval of the carbonate (Figure 4-8). Slumping into the lows left by the removal of the Tinker/Santee (Utley) carbonate corroborates the assertion that the consolidation of the interval post-dates deposition of the Dry Branch and Tobacco Road sands.

Rine and Engelhardt, 1999, noted that at least two generations of spar cements appear to be present in the carbonates in HBOR-50 at the ITP in H Area, both related to separate episodes of dissolution. They noted vugs containing sand and silt sized limestone fragments and quartz grains are present in thin sections from HBOR-50 (Figure 4-22) and concluded that the detritus was probably derived from leaching and collapse of rock adjoining the vug. The voids not containing the detritus are probably molds of single shells and are not connected to other large pores. These limestone and quartz debris filled vugular limestones formed during the "collapse" and consolidation of the Tinker/Santee (Utley) carbonates in "upland unit" time.

Today, the Tinker/Santee (Utley) section is generally in the saturated zone in the GSA (except near Upper Three Runs Creek) well below the water table. Here the sediments are in a stable chemical environment, and carbonate dissolution is minimal. The further dissolution and removable of the Tinker/Santee (Utley) carbonate (in the engineering sense i.e., the next 100 years) is a non-issue.

In conclusion, two primary episodes of freshwater flushing of the Tinker/Santee (Utley) section resulting in two (or more) stages of fossil shell dissolution are hypothesized based on the multiple episodes of erosion/dissolution of the section. The first occurred at the time of the Santee unconformity, the second at the time of deposition of the "upland unit" following the Upland unconformity. During the interim period between the two primary episodes of fresh water flushing of the Tinker/Santee (Utley) section, dissolution of carbonate and precipitation and replacement of carbonate by silica continued albeit at a slower rate during deposition of the Dry Branch and Tobacco Road sands.

\subsection{Origin and Delineation of Soft Zones}

Until recently, sediment from soft zones as defined by SPT N-values, rod drops and lost circulation are never recovered. Conventional coring methods were unable to recover sediment from the intervals. Therefore, the soft zone sediment, and certainly the precursor sediment to the final soft zone sediment was unknown.

Nearby sediments (often fossiliferous) to the soft zones, whether they are carbonatebearing to carbonate-rich clastics or limestones have been observed to have undergone minor to extensive carbonate dissolution. Often, the result is the fossils (especially mollusks) were dissolved leaving voids that were often enlarged to form vugs (Figures 4-11 and 4-12). Silicification was commonly noted where the precipitation of silica was minor to extensive (replacing and cementing much of the original sediment). Only minor 
carbonate cementation has been noted in near-by sediments (Thayer and others, 1995; Rine and Engelhardt, 1999 and Parker, 1999).

It has generally been assumed that the carbonate in the sediment in the soft zones has undergone extensive if not complete carbonate dissolution leaving behind vugular, moldy clastic debris. Thus a soft zone occurs in the "end member" sediment where the carbonate dissolution noted in varying degrees in the nearby non-soft zone sediments was complete.

\subsubsection{Soft Zone Study at APSF}

It has often been observed in the GSA and elsewhere, that rod drops, "soft zones" and zones of no conventional core recovery occurred beneath carbonate cemented and/or silica replaced/cemented hard layers that are difficult to penetrate with the drill (Figure 4-23). Once through the hard cemented layer the drill rod was pushed into what was assumed to be uncemented silts and sands that were supported by the overlying indurated beds and/or by laterally competent beds.

Localized zones of silica cementation of sand sequences and of indurated limestones are common in the Tinker/Santee (Utley) section and the overlying lower Dry Branch Formation. Silica cementation varies from a trace to more than $30 \%$ of the sediment analyzed, and individual hard silica cemented layers can vary from less than 1 foot to more than 10 feet in thickness. The silica cementation occurs in all the various lithologies found in the Santee and Dry Branch sections.

Evidence from the soft zone study at the APSF suggests that the sediment in the rod drop/no recovery zone had not undergone extensive carbonate dissolution. Instead, the precursor carbonate sediment underwent extensive opal-CT (amorphous silica) replacement much like the silica replacement/cementation that commonly occurs in overlying and nearby indurated layers.

A series of closely spaced CPT's were pushed at the APSF Site in the northern portion of $F$ Area (Figure 4-21). One purpose of the investigation program was to aid in establishing the stratigraphic and lateral distribution of soft zones in the area. Using the defining criteria of tip stress values less than 15 tsf to define the presence of soft zones, it was determined that soft zones vs. non-soft zones occurred at comparable stratigraphic horizons in CPT pushes spaced less than 10 feet apart. A 8 feet thick soft zone occurred in CPT-157S3 at the top of the Tinker/Santee (Utley) section immediately beneath the Santee unconformity that could not be carried to the surrounding CPT pushes only a few feet away. The soft zone was continuously cored and the interval was analyzed in detail in the SGS core Analysis Lab. Three sediment types were delineated under petrographic microscope examination of the soft zone sediment (Parker, 1999); sandy, biomoldic chert; siliceous sandy mud and terrigenous sand. 
The sandy, biomoldic chert and the siliceous, sandy mudstone were originally sandy lime mud (micrite)-supported fossiliferous limestone and sandy, lime mudstones. The carbonate mud was replaced molecule for molecule with authigenic opal-CT lepispheres and chalcedony without any loss in sediment volume (Figures 4-10, 4-17, 4-18, 4-24 and 4-25). The original sandy fossiliferous limestone sediment was deposited in clear, open-marine water of normal salinity on the inner to middle shelf (Parker, 1999). The opal-CT matrix was originally lime mud (micrite) matrix, and its abundance indicates deposition in quiet water below normal marine wave base. In short the precursor soft zone sediment was typical of the Tinker/Santee (Utley) carbonate deposited in the GSA.

Thus this sediment in the soft zone is not a distinct microfacies separate and distinct from the sediments that comprise the surrounding carbonate, but is diagenetically altered where the initial carbonate matrix was completely replaced with opal-CT (Figures 24 and 4-25). The silica was precipitated as 2-5 $\mu \mathrm{m}$ opal-CT lepispheres that replaced carbonate mud (micrite) matrix, and precipitated as linings within molds and vugs and in micropores in the lime mud matrix (Figures 4-10 and 4-17). The opal-CT formation postdates solution of the fossil shells because the opal-CT and chalcedony line the interiors of some molds.

Since the carbonate in the soft zone sediment defined in CPT-157S3 at the APSF area underwent complete siliceous replacement, the working hypothesis would be that opalCT silica replacement of carbonate sediments may be one of the crucial events in the formation of the soft zones. Where carbonate has been replaced by silica the soil -.properties of the resulting diagenetically altered sediment is such that it has neither cohesion nor very much compressive strength. Here the tip resistance to the CPT push would be low (less than 15 tsf over a two foot interval), rod drops would be encountered during conventional drilling and the surrounding unaltered carbonate sediment supports the overburden. The soil properties and characteristics of the opal-CT silica "mud" is currently under investigation (Miles Denham, personal communication)

If the replacement of carbonate by amorphous silica was a controlling factor in the development of soft zones, then the controlling mechanisms for soft zone development would include (Folk and Pitman, 1971):

- Adequate supply of amorphous silica in the form of sponge spicules and diatoms for the continued precipitation of the opal-CT.

- $\quad$ Adequate permeability to flush the sediment with the volumes of silica saturated pore waters needed to maintain the precipitation of the silica.

- $\quad$ Chemistry and mineralogy of the host sediment.

- Bulk pore-water ph.

- Presence of organic matter.

- Concentration of silica and certain other ions, such as sulfate. 
Assuming the above mentioned controls are available for silica replacement/cementation to occur; the spatial geometry of the silicified "areas" would be very irregular (Figure 421). The silicification of the enclosing sediment would follow and spread along bedding planes, along microfractures of varied orientations, along corridors of locally enhanced permeability etc. The resulting "soft zone" could be in the form of irregular isolated pods, extended thin ribbons or stacked thin ribbons separated by intervening unsilicified parent sediment. Soft zones encountered in one CPT could be absent in the neighboring CPT only a few feet away. Only where silicification has spread far enough away from the bedding planes and/or fractures along which the silica replacement has taken place, where all the intervening sediment is replaced, would the soft zones be large enough and coherent enough to pose a question for the siting of new facilities. In all likelihood this would be a most uncommon event.

\subsection{Extent of Carbonate Zones and Soft Zones}

A database was established that cataloged all data retrieved from core, geophysical logs, CPT logs and geotechnical (SPT) borings related to the stratigraphy and the presence of carbonate and soft zones in the Dry Branch-Tinker/Santee (Utley) interval.

\subsubsection{Stratigraphy of Dry Branch-Tinker/Santee (Utley) interval}

The stratigraphic data from the 158 cored and geophysically logged wells analyzed in the Site Geotechnical Services (SGS) Core Analysis laboratory and 375 CPT logs were queried to map the stratigraphy of the Dry Branch-Tinker/Santee (Utley) interval. Three geologic top maps, the top surface of the Dry Branch, the top surface of the Santee Unconformity and the top surface of the Warley Hill, were created to constrain the stratigraphic and geographic distribution of the carbonate and soft zones to the lower Dry Branch/Warley Hill interval.

\section{4-5.2 Delineation of the Extent of The Carbonate Zones}

The primary sources of data for mapping the extent (stratigraphic and geographic distribution and "concentration") of the carbonate zones were the Core Laboratory core descriptions, CPT logs and borehole geophysical logs. The percentage of carbonate was recorded on a foot by foot basis from core described in the core lab. The thickness, distribution and percentage of carbonate were mapped from the core data. Mapping the stratigraphic and lateral extent of the carbonate was augmented with lithologic data interpreted from the geophysical logs.

Due to the absence of a common standardized descriptive format, lithologic data from the geotechnical (SPT) field logs were not used for estimating carbonate content (percentage) in this investigation. Lithologic data from the geotechnical (SPT) boring reports were used to supplement the borehole geophysical and core description data to further delineate the geometry of the carbonate zones. 
Lithologic information gleaned from 525 SPT logs includes indications of the presence of carbonate from positive $\mathrm{HCl}$ reactions, and other lithologic characteristics indicative of carbonates, such as the presence of calcareous sediment, and the presence of calcareous fossils. Since the reliability of the data varied according to the quality of the field data recorded by the logger, the database includes a ranking from 1 through 4 with 1 having the most reliable lithologic descriptions.

Generally those SPT logs considered most reliable were used to augment the query of the core data. Where carbonate was indicated the interval was given a designation of 1 for the data base query and 0 where carbonate was not indicated.

\section{4-5.3 Delineation of Soft Zones}

CPT logs were the primary data source queried to determine the presence, geographic distribution and stratigraphic position of the soft zones in the GSA. Where the tip stress was less than $15 \mathrm{tsf}$, a soft zone was defined. In addition, a search of the data from the field logs from the SPT boring reports was conducted for indications of "soft zones" encountered during drilling in the GSA. These data included blow count N values, where $\mathrm{N}$ values less than 5 are considered evidence of soft zones. In addition, rod drop intervals, lost circulation zones were considered to further delineate the areal extent of the soft zones. These last two, rod drop intervals and lost circulation zones proved of little value in delineating soft zones and were not included in the final data base queries. The blow count data from the SPT boring logs were queried as backup to the primary data source, namely the tip stress measurements from the CPT pushes.

All CPT pushes in the GSA that penetrated most of the Tinker/Santee section down to the Warley Hill Formation were queried for tip stress values less than 15 tsf. The CPT pushes are generally limited to a shorter vertical interval than the SPT borings, monitoring wells and geophysically logged borings due to the depth limitation of the direct push technology. CPT's will not penetrate lithified clastic or carbonate sediments, or stiff "fat" clays. Consequently, the CPT logs generally bottom in the Tinker/Santee Formation without reaching the green clays of the Warley Hill Formation. The stratigraphic and geographic distribution of the soft zones was established by querying simply for the presence of soft zone material (designated 1), and for the absence of soft zone material (designated 0 ).

The blow count data derived from the SPT borings were queried and blow counts less than 5 blows/ft (designated one 1) were flagged as indicators of soft zones. The blow count data is considered complementary to the establishment of the soft zones based on and defined by tip stress data derived from the CPT pushes. The results of the blow count query were compared with the data from the CPT pushes for consistency (i.e., are the same stratigraphic horizons and geographic areas delineated by the two methods). The blow count data further refined the geographic distribution of the soft zones, and added to the delineation of soft zones especially in the lower part of the Tinker/Santee where CPT pushes often could not penetrate. 


\subsubsection{Delineation of the Extent of Carbonate Zones/Soft Zones}

The lithostratigraphic and hydrostratigraphic position of the "calcareous zone(s)" in the GSA was first documented in the U.S. Department of Energy (DOE) 1990 application for a hazardous waste post-closure permit for H-Area (Aadland and others, 1990). The DOE report (1990) listed all wells and boreholes penetrating carbonate strata in the GSA and provided isopach maps of the calcareous sediments, dividing the distribution into upper and lower zones relative to hydrostratigraphic units in the area (Figure 4-27). The maps only illustrate the gross thickness of the carbonate present not the percentage or concentration of carbonate on a foot by foot basis. The isopach maps in the DOE (1990) report indicate a somewhat irregular areal distribution of the "calcareous zone" in the GSA. The lower zone, which includes the Tinker/Santee (Utley) carbonates is present in three separate areas of the GSA and follows a northeast-southwest trend. Beds within this zone were thought to thicken and thin over short distances.

Recent work by Richardson (1995) confirms the irregular distribution of calcareous strata in the GSA (Figure 4-28). He suggests that the distribution is the result of postdepositional, subsurface leaching of carbonate sediment. An isopach map of calcareous sediment within the "lower" aquifer zone (Thayer and others, 1994) shows that the carbonate strata are laterally discontinuous and are present as isolated patches in the central, eastern and western parts of the GSA (Figure 4-29). Aadland and others, 1995, mapped the distribution and thickness of the calcareous sediment in the GSA (Figure 4-30) further refining the geometry of carbonate sediment in the GSA. Comparison of the various isopach maps suggests a lack of understanding of the distribution and causal mechanisms that contributed to the stratigraphic and geographic distribution of the calcareous sediment in the GSA. As more data has accumulated, the configuration of the calcareous zone(s) has changed and continues to change dramatically.

\subsubsection{Present Study}

A series of maps were created to illustrate the extent (stratigraphic and geographic distribution) of soft zones and carbonate zones in the GSA. Plate 4.2 is the base map of the GSA and includes the location of all CPT pushes, geotechnical (SPT) borings, cored and geophysically logged wells and borings queried for the study. The color filled core and boring (SPT) symbols encountered carbonate.

A file was assembled with stratigraphic information from core and geophysical log data that includes picks for the top of the Dry Branch Formation, top of the Tinker/Santee (Utley) section (i.e., top surface of the Santee unconformity) and top of the Warley Hill Formation for the GSA area. The top surfaces were mapped and used to constrain the data query for the presence of calcareous zones and soft zones to the stratigraphic 
interval between the top of the Santee unconformity and the top of the Warley Hill Formation where the zones are located.

\subsubsection{Results}

The initial pass used to establish the geographic distribution, and concentration of carbonate sediment in the Tinker/Santee (Utley) section in the GSA was by querying the footage of carbonate greater than or equal to $5 \%$ found in the cored wells and SPT borings (Plate 4.3). Three areas stand out where several cored wells indicated appreciable thicknesses of carbonate. From east to west they include the ITP area (\#1 on the map), the "H" Basin area (\#2 on the map) and the Burial Grounds area (\#3 on the map). In "F" Area at the APSF site (\#4 on the map) and the F Basin area (\#5 on the map) extensive SPT boring data is available indicating concentrations of carbonate. Neither area has concentrated core data that is needed to verify the SPT findings. In other areas carbonate is encountered in isolated cored wells. Here the extent of the carbonate is indeterminate.

The color filled core and boring (SPT) symbols on the base map (Plate 4.2) indicated locations where carbonate was encountered. Locally, e.g. at ITP (area \#1) where the SPT data overlaps with the core data (Plates 4.2 and 4.7) the constraints on the lateral extent of the carbonate is greatly improved. Here the distribution of carbonate cannot be construed to be an artifact of the data distribution and reflects the actual geographic extent of the carbonate in the area. In areas \#2 and \#3 SPT data is sparse and did not help further constrain the lateral extent of the carbonate-rich areas delineated with core data. Large areas of sparse data precludes making the assumption, as was done in the past, that the carbonate is concentrated only in the areas indicated on the map. Historically these were assumed to be the areas where carbonate was concentrated (Figures 4-27, 4-28, 4-29 and 4-30).

The average percentage of carbonate in each core was mapped (Plate 4.4). In general where the carbonate is thickest, as in areas \#1,\#2 and \#3 the average carbonate percentage is greatest. Again isolated cored wells include carbonate-rich zones in areas other than those noted above. These may indicate sizeable carbonate concentrations but they cannot be confirmed at this time.

Plate 4.5 is a hybrid map of the "total percent" carbonate present. Here the total thickness of the carbonate in the core was multiplied by the average percent carbonate in the core, and the resulting value was delineated. Carbonate concentrations concur with the observations noted on Plate 4.3 in areas \#1, \#2 and \#3 that the concentrations are directly related to total thickness of the carbonate.

The extent and distribution of soft zones based on CPT data was mapped (Plate 4.6). Comparing the extent and lateral distribution of the soft zone "hits" with the distribution of carbonate (Plates 4.3, 4.4 and 4.5) from both core and SPT data indicates that soft zones are generally thicker and more concentrated where carbonate is thickest and 
most concentrated (highest average percentages). Where the various data types (core, CPT and SPT) overlap as at ITP in map area \#1 the concentration of soft zone hits (Plate 4.8) overlaps with the areas of carbonate concentration (Plate 4.7).

The thickness of the Tinker/Santee (Utley) interval in the GSA is variable. The thickness and concentration of carbonate is directly related to the thickness of the Tinker/Santee (Utley) interval. Where the Tinker/Santee (Utley) interval is thick carbonate is more concentrated, where the interval is thin carbonate thickness and concentration is reduced. It is further observed that where carbonate is concentrated in the Tinker/Santee (Utley) section, the overlying "upland unit" and Tobacco Road/Dry Branch section are generally structurally high (Figure 4.8). Where the carbonate content are reduced or absent, the overlying "upland unit" and Tobacco Road/Dry Branch section are generally structurally low. This indicates that the removal of carbonate and the thinning of the Tinker/Santee (Utley) interval occurred in post Tobacco Road time.

Since the thickness and distribution of soft zones is closely linked to the thickness and distribution of carbonate those structurally low areas where a great deal of carbonate has been removed would be areas where soft zones are less likely to be present.

\subsection{Significant Findings and Observations}

- $\quad$ The CPT is the preferred method for identifying soft zones.

- Soft zones are pervasive throughout the GSA and typically occur within or proximate to carbonate bearing sediments.

- Geologic and depositional setting of the soft zones and enclosing sediments are generally constrained to the middle Eocene Dry Branch-Tinker/Santee (Utley) portion of the geologic section.

- The carbonates and limey sands of the Tinker/Santee (Utley) sequence underwent a complex combination of deposition of diverse lithologies, postdepositional dissolution/precipitation/replacement of calcite, silica and other minerals. The result is a sediment often far removed from its initial depositional fabric and mineralogy. Local dissolution is sometimes so pervasive that the precursor sediment is no longer identifiable.

- All degrees of carbonate dissolution from minor to complete are observed in the Tinker/Santee (Utley) sediments.

- Two primary episodes of freshwater flushing of the Tinker/Santee (Utley) section resulting in two (or more) stages of fossil shell dissolution are hypothesized based on the multiple episodes of erosion/dissolution of the section. The first occurred at the time of the Santee unconformity, the second at the time of deposition of the "upland unit" following the Upland unconformity. During the interim period between the two primary episodes of fresh water flushing of the Tinker/Santee (Utley) section, dissolution of carbonate and precipitation and replacement of carbonate by silica continued albeit at a slower rate during deposition of the Dry Branch and Tobacco Road sands. 
- Today, the Tinker/Santee (Utley) section is generally in the saturated zone in the GSA (except near Upper Three Runs Creek) well below the water table. Here the sediments are in a stable chemical environment, and carbonate dissolution is minimal. The further dissolution and removable of the Tinker/Santee (Utley) carbonate (in the engineering sense i.e., the next 100 years) is a non-issue.

- Evidence from the soft zone study at the APSF site suggests that the carbonate sediment in the soft zone defined by CPT tip stress underwent extensive opal-CT (amorphous silica) replacement much like the silica replacement/cementation that commonly occurs in overlying and nearby indurated layers. Elsewhere, carbonates and carbonate-rich clastics have been described that have undergone minor to extensive, to complete amorphous silica replacement/cementation.

- The original sediment in the soft zone at the APSF Site was sandy lime mud (micrite)-supported fossiliferous limestone and sandy, lime mudstones where the carbonate mud was replaced molecule for molecule with authigenic opal-CT lepispheres and chalcedony. Thus this sediment in the soft zone is not.a distinct microfacies separate and distinct from the sediments that comprise the surrounding carbonate. The soft zone sediment is typical of the surrounding sediments, but was diagenetically altered where the initial carbonate matrix was completely replaced with opal-CT.

- $\quad$ The silica was precipitated as $2-5 \mu \mathrm{m}$ opal-CT lepispheres that replaced carbonate mud (micrite) matrix, and precipitated as linings within molds and vugs and in micropores in the lime mud matrix. The opal-CT formation postdates solution of the fossil shells because the opal-CT and chalcedony-line the interiors of some molds.

- Since the carbonate in the soft zone sediment defined in the APSF area underwent complete siliceous replacement, the working hypothesis would be that opal-CT silica replacement of carbonate sediments may be one of the crucial events in the formation of the soft zones.

- The spatial geometry of the silicified "areas" would be very irregular and the lateral and vertical extent of the silicified zone (s) would not conform to any rational geometric pattern. The silicification of the enclosing sediment would follow and spread, for example, along bedding planes, and along microfractures of varied orientations, and along corridors of locally enhanced permeability.

- The resulting "soft zone" can be in the form of irregular isolated pods, extended thin ribbons or stacked thin ribbons separated by intervening unsilicified parent sediment. Soft zones encountered in one CPT could be absent in the neighboring CPT only a few feet away.

- Where carbonate has been replaced by silica the soil properties of the resulting diagenetically altered sediment is such that it has neither cohesion nor very much compressive strength. Here the tip resistance to the CPT push would be low (less than $15 \mathrm{tsf}$ ), rod drops would be encountered during conventional drilling and the surrounding unaltered carbonate sediment supports the overburden. 
- In general where carbonate is thickest in cores the average carbonate content (percentage) is greatest.

- Where carbonate is concentrated in the Tinker/Santee (Utley) section, the overlying "upland unit", Tobacco Road/Dry Branch section is generally structurally high.

- Where the carbonate content is reduced or absent the overlying "upland unit", Tobacco Road/Dry Branch section is generally structurally low.

- Structurally low areas where a great deal of carbonate has been removed would be the location where soft zones are less likely to be present.

- The size and distribution of soft zones appears to be geographically and stratigraphically associated with the presence and concentration of carbonate;

- The formation of soft zones appears to be closely linked to the diagenetic alteration of carbonate whether the development of soft zones is attributed to either carbonate dissolution and/or to silica replacement/cementation.

- As a preliminary screening tool where soft zones are an issue when siting new facilities in the GSA, those areas that are structurally low at the "upland unit", Tobacco Road/Dry Branch level, and/or where the presence of carbonate is minimal, would be favored.

- It is observed that the concentration of carbonate is directly related to the total thickness of the carbonate. 


\subsection{STABILITY OF SOFT ZONES}

\section{Engineering practice at the SRS has had two clearly distinct phases of thought} regarding soft zone investigation, analyses, and treatment. The first phase stretches from 1951 to about 1991, and the second phase from about 1991 to the present. Differences between these two phases reflect advances in technology brought about by advances in subsurface investigation techniques and computer-based solutions. A summary of the major differences in these phases is given below:

Table 5.0 Comparison of Investigation Methods and Analysis of Soft Zone Sediments

\begin{tabular}{|c|c|c|}
\hline Category & 1951-pre 1991 & About 1991 to present \\
\hline $\begin{array}{l}\text { Nature of } \\
\text { subsurface } \\
\text { investigation } \\
\text { tools. }\end{array}$ & $\begin{array}{l}\text { Geotechnical penetrations consist largely of } \\
\text { mud rotary borings with SPT and UD } \\
\text { sampling, with a limited suite of downhole } \\
\text { geophysical tools. }\end{array}$ & $\begin{array}{l}\text { SPT/UD boring technique remains virtually } \\
\text { unchanged; however the CPT method greatly } \\
\text { expands the quantity and quality of subsurface } \\
\text { data that can be collected. An extensive array of } \\
\text { new sensor technology e.g. (SCPTU, cross hole } \\
\text { tomographic arrays and dilatometer) allows for } \\
\text { collection of physical property data of in situ. } \\
\text { soils. }\end{array}$ \\
\hline $\begin{array}{l}\text { Type of } \\
\text { engineering } \\
\text { analyses }\end{array}$ & $\begin{array}{l}\text { Engineering analyses largely consist of hand } \\
\text { calculations of a limited number of cases. } \\
\text { Liquefaction and settlement analyses, if } \\
\text { conducted, rely upon empirical relationships. }\end{array}$ & $\begin{array}{l}\text { A large number of computer programs are } \\
\text { developed for desktop computers, including } \\
\text { highly specialized programs such as SHAKE, } \\
\text { FLAC, PCSTABL 5M; DESRA-2C, etc. These } \\
\text { programs allow for development of much more } \\
\text { detailed, realistic, and site-specific models. } \\
\text { Parametric analyses become possible, with } \\
\text { variables that traditionally were held constant } \\
\text { now open to bounds/range checking. }\end{array}$ \\
\hline $\begin{array}{l}\text { Understanding } \\
\text { of soft zones }\end{array}$ & $\begin{array}{l}\text { Understanding of soft zone genesis and } \\
\text { properties were somewhat understood. Soft } \\
\text { zones correctly attributed to carbonate } \\
\text { dissolution and distribution/association across } \\
\text { the SRS in discrete stratigraphic horizons } \\
\text { pretty well established. However, low SPT N- } \\
\text { values (weight of rods, weight of hammer), } \\
\text { loss of drilling fluids, rod drops, and high grout } \\
\text { takes/grout take ratios were incorrectly } \\
\text { interpreted as being related to presence of } \\
\text { cavities/voids. }\end{array}$ & $\begin{array}{l}\text { Extensive soft zone characterizations, including } \\
\text { field studies, laboratory testing, and modeling of } \\
\text { soft zones, greatly refines the genesis, } \\
\text { geometry, and physical properties of soft zone } \\
\text { materials. Although true voids spaces are } \\
\text { confirmed, they probably represent a small } \\
\text { fraction of instances where low SPT N-values } \\
\text { (weight of rods, weight of hammer), loss of } \\
\text { drilling fluids, rod drops, and high grout } \\
\text { takes/grout take ratios are observed. }\end{array}$ \\
\hline $\begin{array}{l}\text { Understanding } \\
\text { of soft zone } \\
\text { collapse }\end{array}$ & $\begin{array}{l}\text { Soft zones and associated voids may present } \\
\text { a collapse condition; they are hypothesized to } \\
\text { have failed in the past, and strained the } \\
\text { overlying sediments to the extent that shallow } \\
\text { depressions "sinks" formed on the ground } \\
\text { surface. }\end{array}$ & $\begin{array}{l}\text { Soft zones are considered to represent clusters } \\
\text { of relatively small areas where extensive } \\
\text { dissolution of oyster banks/shell material took } \\
\text { place. Soft zone materials are shown to be in } \\
\text { various states of consolidation, and } \\
\text { modeling/laboratory tests indicate that arching } \\
\text { effects, where present, will not fail under the } \\
\text { Design Basis Earthquake or under static loading } \\
\text { conditions. Nonetheless, conservative models } \\
\text { for soft zone performance postulate soft zone } \\
\text { failure to compute settlements. }\end{array}$ \\
\hline $\begin{array}{l}\text { Overall } \\
\text { approach to } \\
\text { foundation fix }\end{array}$ & Grout It & Do Nothing \\
\hline $\begin{array}{l}\text { Understanding } \\
\text { of grouting } \\
\text { results }\end{array}$ & $\begin{array}{l}\text { Grouting is assumed to compact soft zone } \\
\text { materials and fill in voids. No definitive } \\
\text { verification of grouting results is possible. }\end{array}$ & $\begin{array}{l}\text { Understanding of results of grouting significantly } \\
\text { improved due to extensive post grout verification } \\
\text { programs. Grout is largely found to travel along }\end{array}$ \\
\hline
\end{tabular}




\begin{tabular}{|l|l|l|}
\hline Category & 1951 -nre 1991 & About 1991 to present \\
\hline & $\begin{array}{l}\text { weak interfaces resulting in thin ribbons to sheet } \\
\text { like emplacements. Improvement to soft zone } \\
\text { materials (overall consolidation) is considered to } \\
\text { be minimal. }\end{array}$ \\
\hline
\end{tabular}

The three sections that follow build upon the information contained in the above table and focus on the engineering properties and analytical techniques that are recommended for use, and the techniques and methodologies to be used for future subsurface investigations for soft zones at the SRS.

\subsection{Properties}

Sampling soft zone soils has been a difficult task. On one hand, obtaining an undisturbed sample has been problematic. On the other hand, once a sample has been obtained we continually ask ourselves "is this sample representative, or were we able to obtain a sample because it was the most competent soil within the soft zone and therefore not representative of the entire soft zone interval?" What we have seen however, is that the measured properties (index and mechanical properties) of soft zone soils have been remarkably consistent.

The results indicate the following;

- Soft zones consist predominately of silty and clayey fine sands to fine sand, SM, SC and SP-SC, SP-SM, however, there can be very fine-grained clays (CL) and occasional shell fragments

- The fines content ranges from less than $10 \%$ up to about $50 \%$

- The liquid limit (LL) ranges from about 50 to $100 \%$

- The plasticity index (PI) ranges from 20 to $90 \%$

- The moisture content ranges from about 25 to $75 \%$

- The total unit weight is about 90 to 110 pcf

- The dry unit weight ranges from about 50 to 80 pcf

- The compression index $\left(\mathrm{C}_{\mathrm{c}}\right)$ ranges from 0.15 to 1.2

- The void ratio $\left(e_{0}\right)$ ranges from 0.3 to 1.4

- The recommended compression ratio $\left(C_{d} 1+e_{0}\right)$ is 0.24

- The soft zones are underconsolidated; values of OCR range from about 0.3 to 1.0. A best estimate value of 0.7 is recommended.

The single breakthrough that has occurred over the past 1 to 2 years is the use of the CPT sampler. The sampler is a nominal 1.4-inch diameter tube, made of either clear plastic (lexan), brass or stainless steel. The sampler is up to 4 feet in length and results to date have shown that very good recoveries of soft soils have been obtained, nearly a $100 \%$ recovery rate. 
The sampler has allowed us to obtain more and better quality samples of the soft zone soils. Although the sample diameter is smaller than required for undisturbed sampling and testing, we have performed a consolidation test on material recovered from the APSF project area. Also, numerous index tests that have been performed. The results confirmed the consolidation parameters given above. However, because conventional laboratory testing is performed on nominal 3-inch diameter undisturbed samples, additional testing is recommended as an effort to correlate the results of strength and consolidation testing from small diameter (nominal 1.4 inch) samples to the results from larger diameter (nominal 3 inch) samples.

Site-wide correlations relating the results of index tests with compressibility parameters have been generated. Index testing of the soft zone soils has shown the same strong correlation with compressibility parameters, although the data is limited. For example, Figure 5-1 shows the relationship between the Compression Index $\mathrm{Cc}$ and moisture content. Although the results are no substitute for actual compressibility tests on soft zone soils, the correlations have proven to be very representative, as evidenced by the results of the recent consolidation test performed on the CPT sample (referenced above) for the APSF project. The laboratory determined results and the calculated values from the site-wide correlations are shown below:

Table 5-1 CPT Sample at APSF Laboratory Data Compared to Calculated Data

\begin{tabular}{l|llll} 
Parameter & $\begin{array}{l}\text { Laboratory } \\
\text { Measured } \\
\text { Value }\end{array}$ & $\begin{array}{l}\text { Moisture: } \\
\text { Calculated } \\
\text { Values }\end{array}$ & $\begin{array}{l}\text { Fines: } \\
\text { Calculated } \\
\text { Values }\end{array}$ & $\begin{array}{l}\text { Pl: } \\
\text { Calculated } \\
\text { Values }\end{array}$ \\
\hline Moisture content & $25 \%$ & $25 \%$ & - & - \\
Fines content & $51.7 \%$ & - & $51.7 \%$ & - \\
Plasticity index & $24 \%$ & - & - & $24 \%$ \\
$e_{0}$ & 0.59 & 0.77 & 0.94 & 0.87 \\
$C_{c}$ & 0.26 & 0.21 & 0.36 & 0.3 \\
$C_{d} / 1+e_{0}$ & 0.16 & 0.12 & 0.18 & 0.16
\end{tabular}

The results show that the calculated values of compression index $(\mathrm{Cc})$ and compression ratio $\left(\mathrm{C}_{d} / 1+\mathrm{e}_{0}\right)$ closely match the laboratory measured values, while the calculated values for void ratio $\left(e_{0}\right)$ all overpredict the laboratory values. Overall however, the results are very encouraging. As budgets allow, additional laboratory testing will be performed to further refine these relationships and, as discussed previously, to correlate the small diameter CPT sampled soils with the larger diameter undisturbed sampled soils.

\subsection{Analysis}

The soft zones in question are at depths greater than 100 feet below the ground surface. As such, they are not subject to significant static loads, based on the size and 
loading of structures historically constructed at the SRS. Thus, issues such as bearing capacity and static settlement are generally not a concern.

As indicated in Table 5-2, analyses of soft zone soils have evolved over the years from essentially no analysis to very sophisticated modeling using the latest techniques. The current analysis has focused on settlement due to a seismic event, which can manifest itself in one of two ways. First, dynamic settlement due to liquefaction or partial liquefaction of the soils, and second, static consolidation settlement due to full overburden pressure coming to bear onto the soft zone soils. The second scenario is a result of a seismic event, which weakens the postulated arch and causes the full weight of the overburden soils to act on the soft zone soils. The current methodology for each scenario is discussed below.

Table 5-2. Summary of Analytical Methods Used To Determine Soft Zone Stability During SRS Geologic/Geotechnical Investigations.

\begin{tabular}{|c|c|c|}
\hline Author/Report & Analytical Methods Used & $\begin{array}{l}\text { Recommended Soft Zone. } \\
\text { Treatment(s)/Monitoring Programs }\end{array}$ \\
\hline COE (1952) & $\begin{array}{l}\text { - No specific engineering analyses of soft zones } \\
\text { performed. Qualitative results from subsurface } \\
\text { investigations of soft zones and "sinks". }\end{array}$ & $\begin{array}{l}\text { Grout all holes with significant rod } \\
\text { drops or fluid losses. }\end{array}$ \\
\hline MPMRCE (1963) & $\begin{array}{l}\text { Review of previous foundation investigation and } \\
\text { treatment programs at SRS. }\end{array}$ & $\begin{array}{l}\text { Recommended various investigation } \\
\text { and remedial treatments based on } \\
\text { category of structure, geologic } \\
\text { conditions, risk trade-off, and } \\
\text { professional engineering judgement. }\end{array}$ \\
\hline Rutledge (1976) & - Review of previous liquefaction studies & $\begin{array}{l}\text { - No soft zone discussion; most soils } \\
\text { at SRS are not liquefiable. }\end{array}$ \\
\hline $\begin{array}{l}\text { MRJD }(1984)- \\
\text { DWPF }\end{array}$ & $\begin{array}{l}\text { Settlements: estimated assuming one- } \\
\text { dimensional consolidation of the soil profile } \\
\text { under applied loads where excavation was } \\
\text { treated as a negative loading to determine } \\
\text { heave of the excavation bottom. Change in } \\
\text { stresses through the soil mass resulting from } \\
\text { applied loads were computed using a } \\
\text { Boussinesq solution. }\end{array}$ & $\begin{array}{l}\text { - Grout all holes on a grid pattern. } \\
\text { Install settlement monitoring points } \\
\text { on structures. }\end{array}$ \\
\hline $\begin{array}{l}\text { MRCE (1986) - } \\
\text { Salt }\end{array}$ & $\begin{array}{l}\text { Settlements: estimated assuming one- } \\
\text { dimensional consolidation of the soil profile } \\
\text { under applied loads where excavation was } \\
\text { treated as a negative loading to determine } \\
\text { heave of the excavation bottom. Used } \\
\text { consolidation parameters developed for S-Area, } \\
\text { except for two strata where compression } \\
\text { properties were derived from lab testing. }\end{array}$ & $\begin{array}{l}\text { Backfill grouting of boreholes; no } \\
\text { foundation grouting even in light of } \\
\text { expected large settlements because } \\
\text { vaults were not considered sensitive } \\
\text { to settlements and cracking. }\end{array}$ \\
\hline $\begin{array}{l}\text { MRCE }(1986 \\
1990)- \text { K Cool }\end{array}$ & $\begin{array}{l}\text { Liquefaction: analysis conducted for shallow } \\
\text { sands at 20-80 ft depth (not soft zone materials). } \\
\text { Seftlements: assumed one dimensional } \\
\text { consolidation of the soil profile under applied } \\
\text { loads with excavation treated as a negative } \\
\text { loading to determine heave of the excavation } \\
\text { bottom. }\end{array}$ & $\begin{array}{l}\text { Foundation grouting on grid pattern, } \\
\text { with need for secondary holes } \\
\text { determined by grout takes }>100 \\
\text { cu/ft (indicating a "significant void") } \\
\text { in two adjacent primary holes. }\end{array}$ \\
\hline $\begin{array}{l}\text { Law (1991)- } \\
\text { HWRF }\end{array}$ & $\begin{array}{l}\text { No specific engineering soft zones analyses } \\
\text { performed. General characterization study. }\end{array}$ & $\begin{array}{l}\text { - Grouted borings; some required } \\
\text { several stages of grouting over a } \\
\text { period of a few days. }\end{array}$ \\
\hline
\end{tabular}




\begin{tabular}{|c|c|c|}
\hline Author/Report & Analytical Methods Used & $\begin{array}{l}\text { Recommended Soft Zone } \\
\text { Treatment(s)/Monitoring Programs }\end{array}$ \\
\hline GEI (1991)-K & $\begin{array}{l}\text { Many engineering analyses performed, including: } \\
\text { Measuring reaction under simulated cyclic } \\
\text { loading to evaluate the potential for liquefaction } \\
\text { and to compute the estimated settlements of } \\
\text { various soil layers. } \\
\text { Computer program SHAKE used to compute } \\
\text { seismic shear strains throughout the soil profile, } \\
\text { using field measured values of shear wave } \\
\text { velocity. } \\
\text { Strains associated with the Design Basis } \\
\text { Earthquake used to evaluate average ground } \\
\text { surface settlements. Laboratory tests performed } \\
\text { to measure volumetric strains of soft zone and } \\
\text { matrix materials due to reconsolidation after } \\
\text { cyclic loading. } \\
\text { Differential settlement: evaluation used empirical } \\
\text { studies for soft ground tunneling, using worst } \\
\text { case criteria of } 15 \text { foot diameter soft zones } \\
\text { spaced on } 20 \text { ft centers at } 115 \mathrm{ft} \text { depth. } \\
\text { Liquefaction: assessed utilizing two separate } \\
\text { methods, including the Dobry cyclic strain } \\
\text { approach and Seed empirical blow count } \\
\text { assessment. }\end{array}$ & $\begin{array}{l}\text { Grout project borings. } \\
\text { Further soils analysis should be } \\
\text { considered based on a site specific } \\
\text { spectra. This analysis should } \\
\text { incorporate convolution techniques } \\
\text { and parameter variation to } \\
\text { determine the margin to failure for } \\
\text { the reactor facility with respect to } \\
\text { settlement and liquefaction. } \\
\text { No treatment needed for soft zones. } \\
\text { No further grouting necessary. }\end{array}$ \\
\hline $\begin{array}{l}\text { WSRC (1992)- } \\
\mathrm{K}\end{array}$ & $\begin{array}{l}\text { No engineering analyses performed. Summary } \\
\text { geologic analysis. }\end{array}$ & 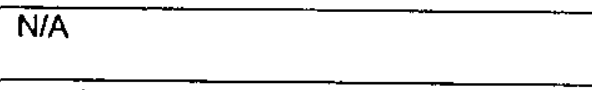 \\
\hline $\begin{array}{l}\text { WSRC (1992)- } \\
\text { KASS }\end{array}$ & $\begin{array}{l}\text { Extensive review of grouting data and post } \\
\text { grouting verification data to assess grouting and } \\
\text { soft zone phenomenon. } \\
\text { Cooling Water Pipe (CWP) ground settlement } \\
\text { analyses based on two empirical relationships, } \\
\text { including: } \\
\text { - Peck soft ground tunneling analogy } \\
\text { - Bals coal mine subsidence analogy } \\
\text { CWP deformation analysis using computer } \\
\text { program FLAC } \\
\text { - Computer program SHAKE used to estimate } \\
\text { pore water pressures during DBE. } \\
\text { Computer program DESRA-2C used to } \\
\text { independently estimate pore water pressures } \\
\text { during DBE. } \\
\text { Qualitative laboratory-model grout tests to study } \\
\text { grout penetration into clay and sand. }\end{array}$ & $\begin{array}{l}\text { - Large scale grouting program } \\
\text { implemented. } \\
\text { Heave monitoring during foundation } \\
\text { grouting included surface surveys, } \\
\text { borros heave monitoring points, and } \\
\text { tiltmeters. } \\
\text { Based on KASS analyses the soft } \\
\text { zone arches were shown to not } \\
\text { collapse under the DBE. The } \\
\text { maximum expected strain in the } \\
\text { straight segments of the CWP } \\
\text { indicated that no foundation } \\
\text { treatment was warranted. }\end{array}$ \\
\hline $\begin{array}{l}\text { Ebasco (1992) } \\
\text { - Par Pond }\end{array}$ & $\begin{array}{l}\text { Seismic stability analysis, including the following: } \\
\text { Preliminary seismic stability evaluation used } \\
\text { static and pseudostatic-type analyses. } \\
\text { Computer program PC STABL5M utilized. } \\
\text { - Liquefaction flow failure analysis followed the } \\
\text { method of Poulos, Castro, and France (1985). } \\
\text { - Dynamic response analysis was performed } \\
\text { using computer program SHAKE. } \\
\text { - Triggering analyses used strain approach of } \\
\text { Castro et al. (1989). } \\
\text { Dynamic settlement analysis following DBE } \\
\text { followed that of Castro (1987). }\end{array}$ & $\begin{array}{l}\text { Conceptual remedial design } \\
\text { considered soft zone soil } \\
\text { improvements via compaction } \\
\text { grouting, vibratory piles, dynamic } \\
\text { compaction, and stone columns. } \\
\text { Stone columns was determined to } \\
\text { be the preferred treatment. } \\
\text { Project boreholes grouted. }\end{array}$ \\
\hline $\begin{array}{l}\text { WSRC (1993)- } \\
\text { RTF }\end{array}$ & $\begin{array}{l}\text { Primary focus of work on liquefaction } \\
\text { susceptibility of } 30-75 \mathrm{ft} \text { depth, Tobacco Road } \\
\text { Formation (not soft zones) }\end{array}$ & $\begin{array}{l}\text { No foundation improvement } \\
\text { necessary. } \\
\text { Project boreholes grouted. }\end{array}$ \\
\hline
\end{tabular}




\begin{tabular}{|c|c|c|}
\hline Author/Report & Analytical Methods Used & $\begin{array}{l}\text { Recommended Soft Zone } \\
\text { Treatment(s)/Monitoring Programs }\end{array}$ \\
\hline & $\begin{array}{l}\text { Santee samples found to be normally to slightly } \\
\text { overconsolidated (no arching), so evaluations } \\
\text { completed only concerned recompression of } \\
\text { material upon dissipation of seismically-induced } \\
\text { liquefaction. Potential for excess pore water } \\
\text { pressure evaluated using data of Dobry et al. } \\
\text { (1982). Settlement phenomenon, including } \\
\text { sensitivity analyses, performed using computer } \\
\text { program FLAC. }\end{array}$ & - \\
\hline $\begin{array}{l}\text { Ebasco (1994) } \\
\text { - ITP }\end{array}$ & No analyses performed; data report & $\mathrm{N} / \mathrm{A}$ \\
\hline $\begin{array}{l}\text { WSRC (1995) - } \\
\text { ITP }\end{array}$ & $\begin{array}{l}\text { - Geostatistical (kriging) analyses were completed } \\
\text { on CPT data. } \\
\text { - Santee/Tinker liquefaction analyses included } \\
\text { use of the Chinese Criteria, and stress and } \\
\text { strain approaches. } \\
\text { Settlement based on dissipation of seismically- } \\
\text { induced pore pressures for the Santee/Tinker } \\
\text { was estimated based on laboratory volumetric } \\
\text { and threshold strain test results. } \\
\text { Future settlement from filling (TP tanks to } \\
\text { maximum were computed using classical one- } \\
\text { dimensional consolidation theory, with vertical } \\
\text { pressure for the soil layer calculated using } \\
\text { Boussinesq theory. } \\
\text { Soil-structure interaction analyses were } \\
\text { performed using the computer program SASSI. } \\
\text { Settlement analyses were performed using the } \\
\text { computer program FLAC. } \\
\text { Ground response analyses utilized the computer } \\
\text { program SHAKE (Schnabel, Lysmer, and Seed, } \\
\text { 1972; Idriss and Sun, 1992) } \\
\text { Probabilistic liquefaction assessment at the ITP } \\
\text { used the Advanced Seismic Hazard/Liquefaction } \\
\text { Evaluation (ASHLE) method (Bechtel, 1991; } \\
\text { Ostadan et al., 1991; Arango, I. And Ostadan, } \\
\text { F., 1995). } \\
\text { Earthquake spectra were generated by the } \\
\text { computer program RASCAL (Silva et al., 1987). } \\
\text { Cross-hole seismic velocity survey, cross-hole } \\
\text { tomography survey and downhole seismic } \\
\text { refraction survey performed. }\end{array}$ & $\begin{array}{l}\text { - Recommended that all tanks in the } \\
\text { HTF, be periodically monitored for } \\
\text { settlement. } \\
\text { - Project boreholes grouted. } \\
\text { - No foundation grouting program } \\
\text { needed. }\end{array}$ \\
\hline $\begin{array}{l}\text { WSRC }(1998)- \\
\text { TEF }\end{array}$ & $\begin{array}{l}\text { Static settlement was calculated based on one } \\
\text { dimensional consolidation theory with } \\
\text { Boussinesq stress distribution to determine } \\
\text { stress increase due to foundation loading. } \\
\text { Liquefaction and dynamic settlements were } \\
\text { evaluated using existing SRS methodology. } \\
\text { This includes use of the computer program } \\
\text { SHAKE and two time histories (PC3 random } \\
\text { phase, and a Charteston } 50^{\text {th }} \text { percentile random } \\
\text { phase). } \\
\text { Qualitative liquefaction evaluation included the } \\
\text { Chinese Criteria for clayey soils and the } \\
\text { empirical shear wave velocity of Seed; Kayen; } \\
\text { and Stokoe and others. } \\
\text { CR and OCR used for settlement analyses were } \\
\text { assurned to be the same as at ITP and APSF }\end{array}$ & $\begin{array}{l}\text { - } \quad \text { Project boreholes grouted. } \\
\text { no foundation grouting program } \\
\text { needed. }\end{array}$ \\
\hline
\end{tabular}




\begin{tabular}{|l|l|l|}
\hline Author/Report & $\begin{array}{l}\text { Analytical Methods Used } \\
\text { (0.24 and 0.7, respectively). Estimates of } \\
\text { settlement at TEF were based on FLAC runs } \\
\text { completed for ITP and APSF studies. }\end{array}$ & $\begin{array}{l}\text { Recommended Soft Zone } \\
\text { Treatment(s)/Monitoring Programs }\end{array}$ \\
\hline $\begin{array}{l}\text { WSRC (1998)- } \\
\text { APSF }\end{array}$ & $\begin{array}{l}\text { Settlement analyses were performed using the } \\
\text { computer program FLAC. } \\
\text { CR and OCR used for settlement analyses were } \\
\text { assumed to be the same as at ITP (0.24 and } \\
0.7, \text { respectively). }\end{array}$ & $\begin{array}{l}\text { Project boreholes grouted. } \\
\text { No foundation grouting program } \\
\text { needed. }\end{array}$ \\
\hline $\begin{array}{l}\text { WSRC (1998) - } \\
\text { White Paper }\end{array}$ & $\begin{array}{l}\text { No analyses completed; summary of CPT usage at } \\
\text { SRS. }\end{array}$ & N/A \\
\hline $\begin{array}{l}\text { WSRC (1999)- } \\
\text { NEC }\end{array}$ & \begin{tabular}{l} 
No analyses completed \\
\hline
\end{tabular}
\end{tabular}

\subsubsection{Liquefaction}

Analyses have demonstrated that the cyclic shear strains calculated as a result of an earthquake in the soft zones soils and the matrix material surrounding the soft zones (depths greater than 100 feet, in the Santee formation) are small, less than $0.1 \%$ (Ref. GEI, 1991 and WSRC, 1995) for the earthquake loading analyzed. Laboratory tests on representative samples of these materials indicate pore pressure ratios generally in the range of 0.1 to 0.2 for these cyclic shear strains, far less than would be required to cause liquefaction. In addition, measured shear wave velocity within the soft zone intervals would indicate that liquefaction would not occur. However, settlement (volumetric strain) will occur once these "excess" pore pressures dissipate.

The current and recommended analysis related to liquefaction for the soft zone soils and material surrounding the soft zones is to assume that volumetric strain (recompression) occurs upon dissipation of excess pore pressures after the design seismic event. A site-speicific shear strain versus pore pressure relationship for the Santee formation was developed specifically for the SRS utilizing data from the ITP and RTF (Ref. WSRC, 1995 and WSRC, 1993, respectively) investigations. The resulting compression is computed using the following relationship (Seed, et al, 1975):

$$
S=(H) \frac{C_{r}}{1+e_{0}} \log \left(\frac{1}{1-r_{u}}\right)
$$

Where: $\quad S$ is the computed settlement in feet

$\mathrm{H}$ is the layer thickness in feet

$\mathrm{C}_{\mathrm{r}}$ is the recompression ratio

$\mathrm{e}_{0}$ is the void ratio

$r_{u}$ is the pore water pressure ratio

The resulting settlement is increased by a factor of 1.2 (site standard 01060, Revision 4 ) and then used for design purposes. 


\subsubsection{Consolidation Due to Full Overburden Pressure}

The underlying premise for this scenario is that an arch actually exists. This is based on two supporting facts. First, laboratory consolidation tests indicate that the soft zone soils are underconsolidated. Second, field SPT and CPT data confirm that these soils are in a very loose or very soft state, incapable of supporting the overburden pressure above. However, there has been no manifestation of surface movement as a result of these soft and loose soils. Thus, an arch of a denser material above the softer/looser soils must exist and must be taking load.

Prior to about 1991, settlement analysis of these soils was not performed. Net foundation loads were kept to a minimum and the zones that contained these soils were remediated with cement grout. As discussed in'earlier sections of this report, beginning in the early 1990's a more critical look was made of these zones in terms of investigation and analysis.

From the analytical point of view, the question has always been "will these soft zones contribute to settlement of facilities near the ground surface?" Two extensive studies were done to answer this question. The first was the work performed for the K Reactor Restart Program and the second for the In Tank Precipitation (ITP) Facility. Analyses included;

- Empirical analysis using a soft ground tunneling analogy

- Empirical analysis using a coal mine subsidence methodology

- Numerical analysis using FLAC

In all cases a fundamental assumption was made; that the arch, or dense soils taking load, would weaken during a seismic event resulting in full overburden pressure being transferred to the softer soils. This is a conservative assumption that we continue to make today even though analyses indicate cyclic shear strains are not high enough to generate pore pressures, which would reduce the strength of the arch or denser soils.

Based on the previous work for K Reactor and ITP, the current recommended approach for settlement analysis of soft zone soils is:

- Determine lateral and vertical extent of soft zones greater than 2 feet thick,

- Assign values of OCR and compression ratio (0.7 and 0.24 , respectively),

- Assume the arch transfers full overburden pressure to the soft zone soils, due to an external load (seismic),

- Compute settlement of the soft zone using conventional Terzaghi consolidation theory, and

- Model and analyze using the finite difference program FLAC and determine surface expression of soft zone settlement at depth. 
The numerical analysis using FLAC has the benefit of being able to account for;

- Large strains,

- Non-linear soil properties,

- Dilation, and

- Soil-structure interaction effects.

The methodology was validated for the ITP project by comparing the measured settlement of 1.5 to 2 inches for the tanks with the predicted settlement of 1.5 to 2.5 inches using FLAC. In our view, the agreement between measured and predicted movement validates the model, including the soil properties and overall methodology.

The resulting settlement is increased by a factor of 1.2 and then used for design purposes.

\subsection{Subsurface Investigations}

Foundation exploration at the SRS consists of a combination of drilling and direct push technology along with surface and downhole geophysical methods. Specific exploration techniques for a given project depend on all or some of the following:

- Data required, e.g. environmental or geotechnical,

- Quantity and quality of existing data,

- Anticipated field conditions, including ground water,

- Performance and functional classification of the facility under investigation,

- Geometry of the facility under investigation

- Anticipated loading,

- Depth of foundation,

- Location of above and below ground obstructions, and

- Type of exploration program, e.g., reconnaissance, preliminary design or final design.

Thus, each investigation program will be unique. However, the goal of all investigation programs is the same i.e., to determine the subsurface conditions for design and construction purposes. In relatively new or unexplored areas exploration programs for large facilities are usually implemented in two phases. The Phase 1 (reconnaissance phase) program is used to determine overall stratigraphy, including any soft zones, and preliminary engineering properties for feasibility studies and order of magnitude cost estimates. The Phase 2 (final phase) program is used to perform detailed sampling and laboratory testing as well as finalize stratigraphy, including thickness and extent of any soft zones encountered for final design.

The primary tool for the Phase 1 investigation program is the CPT, while both the CPT and soil borings are used during the Phase 2 program. The CPT is particularly useful in 
locating and identifying soft zone soils. Currently, soft zone soils are identified as having a CPT tip resistance less than 15 tons per square foot (tsf) over a continuous 2foot interval and SPT $\mathrm{N}$-values less than 5. Additional CPT attributes that can be used to refine the soft zone interval, include;

- Sleeve stress,

- Pore pressure, and

- Shear wave velocity

Other criteria, such as rod/tool drops, and drilling fluid loss, are also used but in a secondary and tertiary role respectively.

Investigations in the future will continue to utilize drilling and direct push technologies. However, the CPT will be the primary tool for locating, identifying and determining the extent of the soft zone soils. Determining the lateral and vertical extent of a soft zone will depend on the facility-specific requirements. For critical facilities every effort will be made to locate the facility in areas where soft zones are not present or where they are at a minimum. If that is not possible, the facility will be designed to accommodate the potential adverse effects of any soft zones encountered. 


\subsection{SUMMARY AND CONCLUSIONS}

Subsurface explorations at the SRS show that soils within about 200 feet of the ground surface consist mainly of sands, clayey sands, silty sands. In less than $50 \%$ of the penetrations, a zone of low penetration resistance, rod/tool drops, and/or drilling fluid loss is encountered. Within the GSA of the SRS this corresponds to a depth of approximately 100 to 150 feet below ground surface. These zones have and still are referred to as "soft zones."

The extent and thickness of these zones vary and are not predictable. In fact, they are erratic. Our experience indicates that they are elongated, channel-like features that range in thickness from less than a few inches up to about 10 feet thick, with an average least dimension of 10 to 20 feet. Based on extensive investigations in the $\mathrm{K}$ area, they make up approximately 10 to $15 \%$ of the soil volume within the geologic layer (Santee formation) where they are found. Typically, these zones consist of very fine silty and clayey sands, with occasional fine shell fragments.

The origin of the soft zones is not precisely known, however several hypotheses exist. The most probable being that these zones consisted of varying amounts of carbonate material that has been altered (solutioned) over geologic time leaving sediments that are now subjected to low vertical effective stresses due to arching of more competent soils above the soft zone intervals. Carbonate material still exists in the subsurface, however solutioning is so slow (if it is occurring at all) that it is not expected to affect any facility, present or future, at the SRS. Further, there is no evidence of surface settlement due to any defects in the subsurface, such as soft zones.

Soft zones occur throughout the SRS, but are more prevalent as you move across the site to the southeast. Detection of soft zones is critical to the siting of new facilities. Where possible, new facilities should be sited in areas of no or little soft zone occurrence. If this is not possible the facility should be designed taking into account the potential effects on a facility.

Exploration to locate soft zones should include soil borings and cone penetration test (CPT) soundings. Our experience indicates the CPT is the best tool to determine the presence of soft zones. However, exploration programs for critical facilities include combinations of soil borings, CPT soundings, surface and downhole geophysical measurements, compression and shear wave velocity determinations, and sampling for laboratory testing. The exploration program depth is designed to penetrate through the layers where soft zones occur. In the GSA, this requires depths of approximately 180 feet below ground surface to be investigated.

It is recommended that initial soft zone identification be determined using the CPT tip resistance and the SPT N-value. For depths between 100 and 150 feet below the 
ground surface, the CPT criteria would be less than 15 tsf and the SPT criteria would be an $\mathrm{N}$-value less than 5 .

For critical facilities it is recommended that a phased investigation program be performed. This could be done in combination with a site selection program, if warranted. The phased program allows for determination of stratigraphy (particularly soft zones) early in the program, then targeting those critical layers that require sampling and laboratory testing. Generally, the initial phase relies heavily on the CPT, and the second phase relies heavily on drilling, sampling and laboratory testing.

Because of the depth of the soft zones (100 to 150 feet in the GSA) there is no static stability issue. Dynamic settlement, on the other hand, requires evaluation. Analyses include dynamic settlement determinations from partial liquefaction and consolidation from load transfer due to a seismic event. Partial liquefaction is evaluated based upon induced cyclic shear strain. Results at K Reactor and ITP (representative of conditions at SRS) indicate the maximum shear strain is in the range of 0.1 to $0.2 \%$. Based on laboratory testing the pore pressure increase in these layers is expected to be about 0.2 times the existing effective stress. Thus, the matrix material is not expected to loose strength as a result of a seismic event.

It is conservatively assumed, however, that the arch does loose strength and consolidation settlements occur. Consolidation of the soft zone soils is evaluated using conventional Terzaghi consolidation theory. The affect this settlement at depth has on surface structures is evaluated using a numerical model (FLAC).

Properties of the soft zone material are well established, however site-specific investigations are required. It is recommended that laboratory testing be done on samples obtained from the CPT sampler and compared to tests performed on larger (shelby) tubes. 


\section{REFERENCES}

Aadland, R. K., Gellici, J. A. and P. A. Thayer, 1995, Hydrogeologic Framework of West-Central South Carolina. State of South Carolina Department of Natural Resources, Water Resources Division Report 5, 200p.

Aadland, R. K., Cumbest, R. J., Howe, K., Lewis, S. E., Price, v. Jr., Richers, D. E., Wyatt, D. E. and K. S. Sargent, 1994, Geological Characterization in the Vicinity of the In-Tank Precipitation Facility (U). Westinghouse Savannah River Co., Site Geotechnical Services Dept., U. S. Department Of Energy Report, WSRC-TR-94-0373, Rev. 0, 88p.

Aadland, R. K., Harris, M. K., Lewis, C. M., Gaughan, T. F. and T. M. Westbrook, 1991 , Hydrostratigraphy of the General Separations Area, Savannah River Site (SRS), South Carolina, USDOE Report WSRC-RP-91-13, Westinghouse Savannah River Company, Aiken, SC., 29808, 114 p.

Attewell, P.B., Yeates, J., and Selby, J., (1986), "Soil Movements Induced by Tunnelling and Their Effects on Pipelines and Structures", Blackie and Son Ltd., Glasgow.

Choquette, P. W. and L. C. Pray, Geological Nomenclature and Classification of Porosity in Sedimentary Carbonates. Am. Ass. Petrol. Geologists Bull 54, p. 207-250.

Geotechnical Engineers, Inc. (1991), "K-Reactor Area, Geotechnical Investigation for Seismic Issues, Savannah River Site (U), Volume 1: Seismic Structural Engineering," WSRCTR-91-47, March 1991.

Ebasco Services Inc. (1993), "Par Pond Dam Supplemental Seismic Evaluation Final Report", Task 061, March, 1993.

Ebasco Division, Raytheon Engineers and Constructors, (1994), "In-Tank Precipitation Facility, Phase I and II Cone Penetrometer Studies", Final Report, March 10, 1994-

Folk, R. L., and J. S. Pittman, 1971, Length-slow chalcedony: a new testament for vanished evaporates: Journal of Sedimentary Petrology, v. 41, p. 1045-1058.

Land, L. S., 1973, Contemporaneous Dolomitization of Pleistocene Limestone, North Jamica. Sedimentology, v. 20, p.64-92.

Law Environmental, Inc., and Law Engineering, Inc. (1991), "Savannah River Site Heavy Water Reactor Facility Phase I Geotechnical Study", Revision 1, SRS DCN PI-GE-210-I, June 10, 1991.

Maliva, R. G., and R. Siever, 1988, Mechanisms and controls of silicification of fossils in limestones: Journal of Geology, v. 96, p. 387-398.

Moran, Proctor, Mueser \& Rutledge Consulting Engineers, (1963), “Foundation Investigations and Treatment at Savannah River Plant", April 19, 1963. 
Mueser Rutledge Consulting Engineers, (1990), "Foundation Investigation and Grouting Program K-Area Natural Draft Cooling Tower", February 5, 1990.

Mueser Rutledge Consulting Engineers, (1988), "K-Area Cooling Tower Eastern Site", December 5, 1988.

Mueser Rutledge Consulting Engineers, (1986), "K-Area Cooling Tower and Pump Pit", January 6, 1986.

Mueser, Rutledge, Johnston, and DeSimone (1984), “Geotechnical Report, Design and Construction, Defense Waste Processing Facility, 200-S Area, Savannah River Plant," Aug. 7, 1984-

Mueser, Rutledge Consulting Engineers, (1986) Saltstone disposal, Z-Area SRP.

Martin, J.R., and Clough, G.W., (1991), Outside Review of "Geotechnical Engineers, Inc. (1991), "K-Reactor Area, Geotechnical Investigation for Seismic Issues, Savannah River Site (U), Volume 1: Seismic Structural Engineering," June 6, 1991.

Nystrom, P. G., Jr., Willoughby, R. H., and L. E. Price, 1989, The Cretaceous and Tertiary stratigraphy of the upper Coastal Plain of South Carolina, in Harris, W. B., Vernon J. H., Nystrom, P. G., Jr., and L. W. Ward, eds., Upper Cretaceous and Cenozoic Geology of the Southeastern Atlantic Coastal Plain: 28th International Geological Congress, Field Trip Guidebook T172, p. 23-42.

Nystrom, P. G., Jr., Willoughby, R. H., and L. E. Price, 1991, Cretaceous and Tertiary stratigraphy of the upper Coastal Plain, South Carolina; in Horton, J. W., Jr., and Zullo, V. A., eds., The Geology of the Carolinas: Knoxville, Tennessee, The University of Tennessee Press, p. 221-240.

Parra, J.O., Price, V., Addington, C., Zook, B.J., and Cumbest, R.J., 1998. Interwell seismic imaging at the Savannah River Site, South Carolina: Geophysics, 63: 1858-1865.

Parker, W. H., 1999. Petrographic Analysis and Microfacies Delineation for a Soft Zone Interval Beneath F-Area, Savannah River Site, Aiken, South Carolina. Report prepared by SAIC under subcontract AB6029N to DOE. 24p.

Prowell, D.C., Christopher, R.A., Edwards, L.E., Bybell, L.M., Gill, H.E., (1985), "Geologic Section of the Updip Coastal Plain From Central Georgia to Western South Carolina".

- Richardson, G. A., 1994, Petrographic and Hydrogeologic Characteristics of Eocene Calcareous Strata of the General Separations Area, Savannah River Site, South Carolina; Masters Thesis, University of North Carolina, Wilmington, 59p. 
Rine, J. M. and D. W. Engelhardt, 1999, Geologic Characterization of Core from Borings HBOR-34 and HBOR-50, In Tank Processing (ITP) Area, Savannah River site, South Carolina. Report prepared for DOE by the Earth Sciences and Resources Institute, University of South Carolina, Columbia South Carolina. ESRI-USC Technical Report 99-3-F143. 16p.

Rutledge. Philip C. of Meuser, Rutledge, Wentworth \& Johnson, (1976), “Danger of Soil Liquefaction Caused by Earthquake at the Savannah River Plant", October, 1976.

Seed, H.B., Arango, 1., and Chan, C.K., (1975), "Evaluation of Soil Liquefaction Potential During Earthquakes", Report EERC 75-28, Earthquake Engineering Research Center, University of California, Berkeley, CA.

Thayer P. A., Smits, A. D., Parker, W. H., Conner, K. R., Harris M. K. and M. B. Amidon, 1994, Petrographic Analysis of Mixed Carbonate-Clastic Hydrostratigraphic Units in the General Separations Area (GSA), Savannah River Site (SRS), Aiken, South Carolina (U). WSRC-RP-94-54, 83p.

Thayer, P.A., Smits, A. D., Parker, W. H., Conner, K. R., Harris, M. K., and M. B. Amidon, 1994, Petrographic Analysis of Mixed Carbonate-Clastic Hydrostratigraphic Units in the General Separations Area (GSA); Savannah River Site (SRS), Aiken, South Carolina, Westinghouse Savannah River Company, Environmental Restoration Department, U. S. Department of Energy Report, WSRC-RP-94-54, 43p.

Westinghouse Savannah River Company, (1992a), "Integrated Geologic Analysis of the KReactor Area (U), " Reactor Engineering Department, Document No. WSRC-TR-9242-004, January, 1992.

Westinghouse Savannah River Company (1992b), "K-Area Soil Stabilization Program (KASS)," Summary Overview and Volume 1, Systems Engineering Department, Document No. WSRC-TR-92-299, Rev. 0, July, 1992.

Westinghouse Savannah River Company, (1993), "Savannah River Site Replacement Tritium Facility (233H) Geotechnical Investigation (U)", Volume I, Document No. WSRC-RP93-606, April, 1993.

Westinghouse Savannah River Company, (1995), "In-Tank Precipitation Facility (ITP) and HTank Farm (HTF) Geotechnical Report", Site Geotechnical Services Department, Document WSRC-TR-95-0057, Rev. 0, September, 1995).

Westinghouse Savannah River Company, (1998a), "Commercial Light Water Reactor Tritium Extraction Facility Geotechnical Summary Report (U)", Site Geotechnical Services Department, Document No. K-ESR-H-00010, Rev. 0, May, 1998.

Westinghouse Savannah River Company, (1998b), "APSF Packaging and Storage Facility Soft Zone Settlement Analysis (U)", Site Geotechnical Services Department, Calculation No. K-CLC-F-00034- 
Westinghouse Savannah River Company, (1998c), "Use of the Cone Penetration Test at the Savannah River Site", Site Geotechnical Services Department, Document No. K-ESRF-00005, Rev.0, May, 1998. Also referred to as the "White Paper".

US Army Corps of Engineers (COE), Charleston District. "Geologic Engineering Investigations, Savannah River Plant", Volumes I and 2, Waterways Experiment Station, Vicksburg, MS, 1952. 


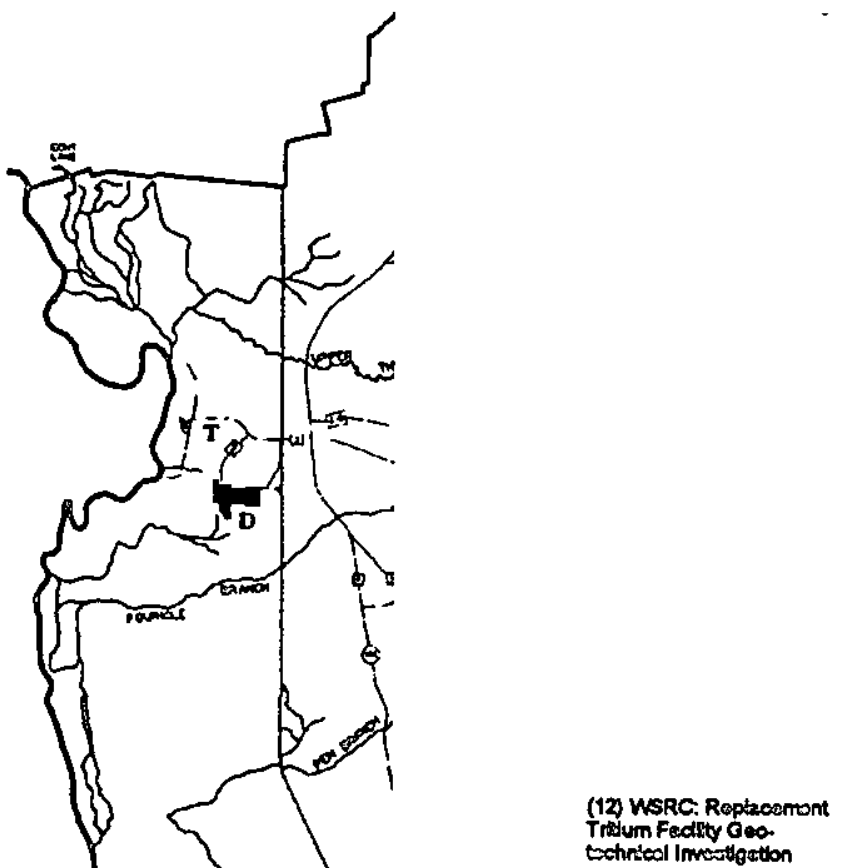

i USRG k Aroos EOll

EaAsco: Per Pond in Golemis Evaluzton

CPT Eudbos

(19) WSRC: TEF coocesctinical (II) WSRC. White Papar

(18) APSF-NE Cheractertietion
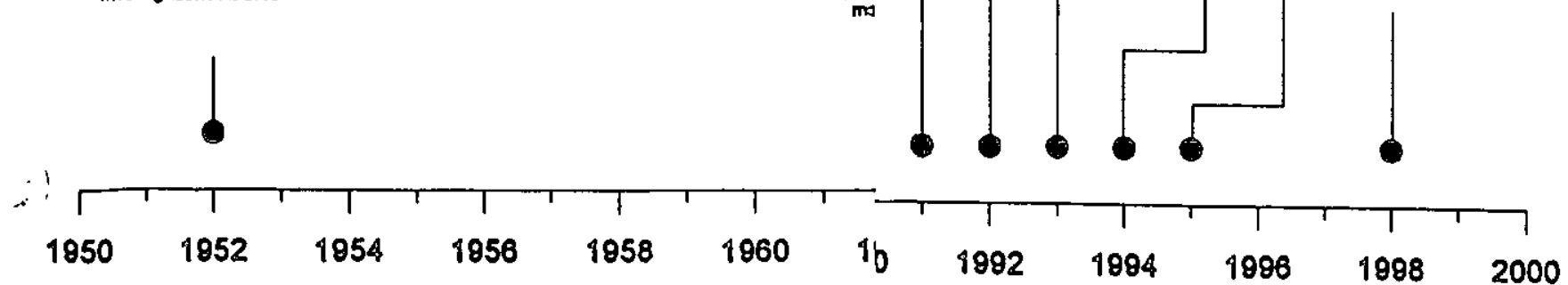


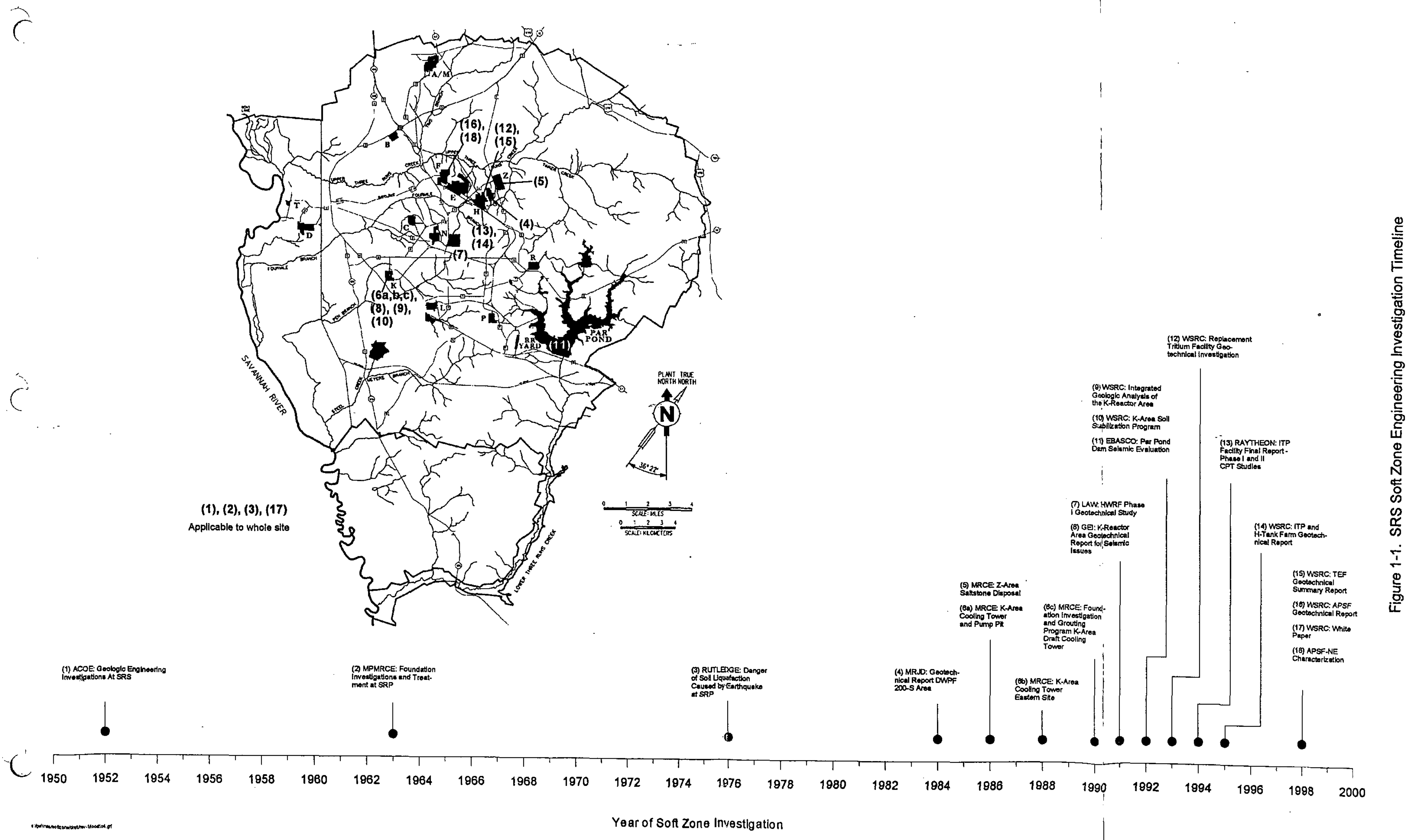




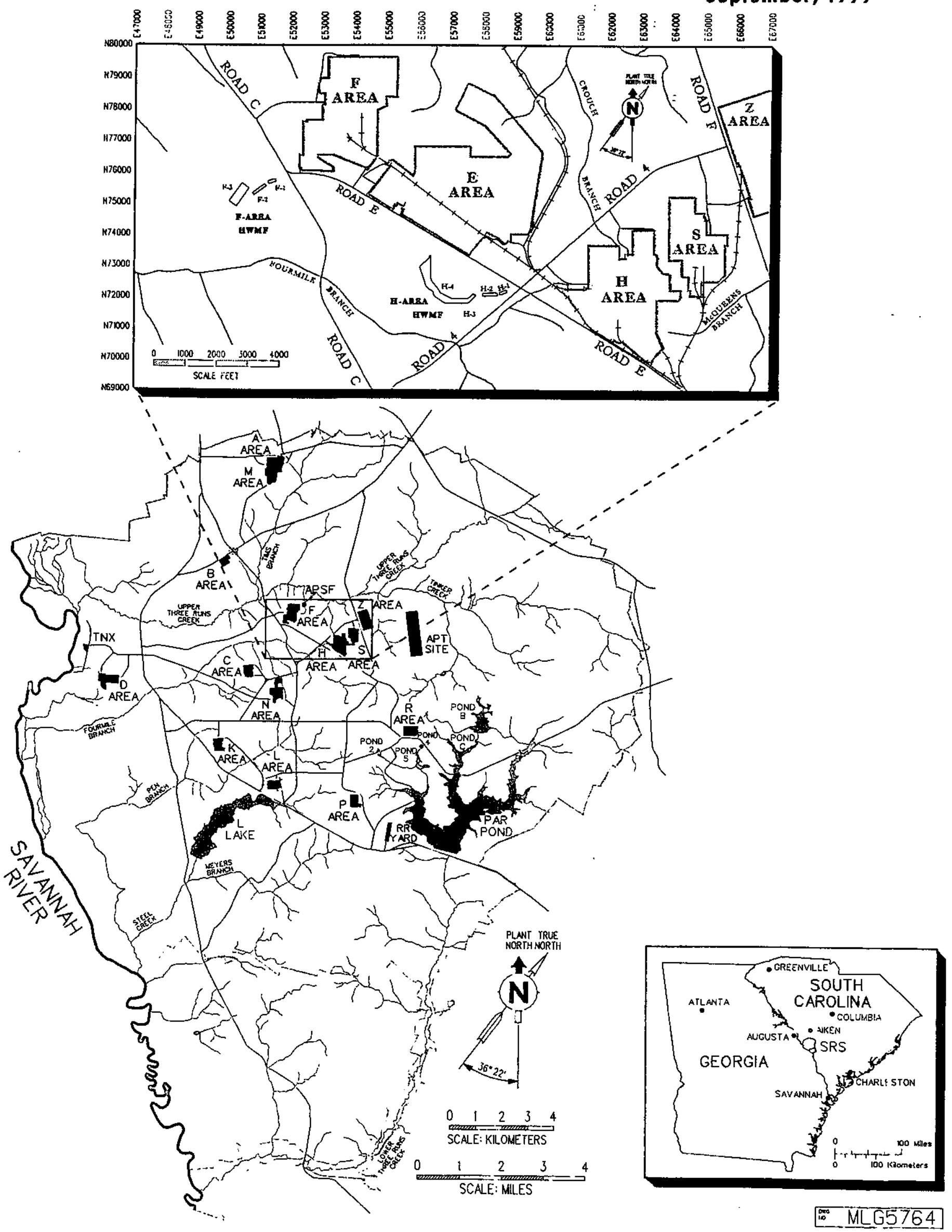

Figure 4-1 Location of General Separations Area at the Savannah River Site Mav 


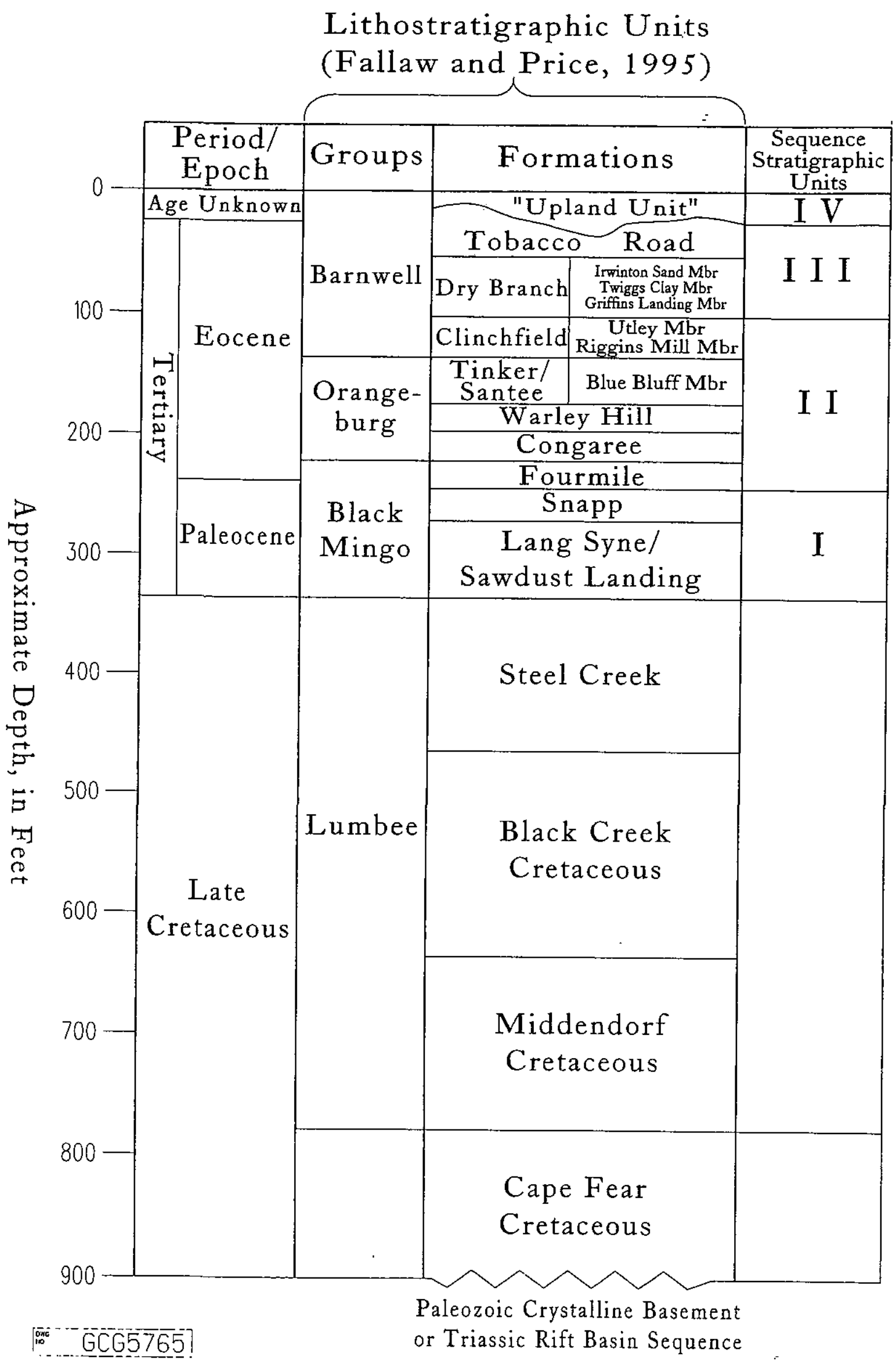

Figure 4-2 Lithostratigraphic and Sequence Stratigraphic Units, at Savannah River Site 
$\mathrm{HSB}-\mathrm{TB}$

GROUND ELEV. 267 EEET :

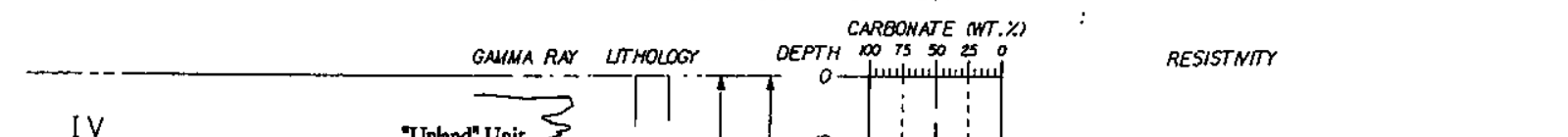

I I I
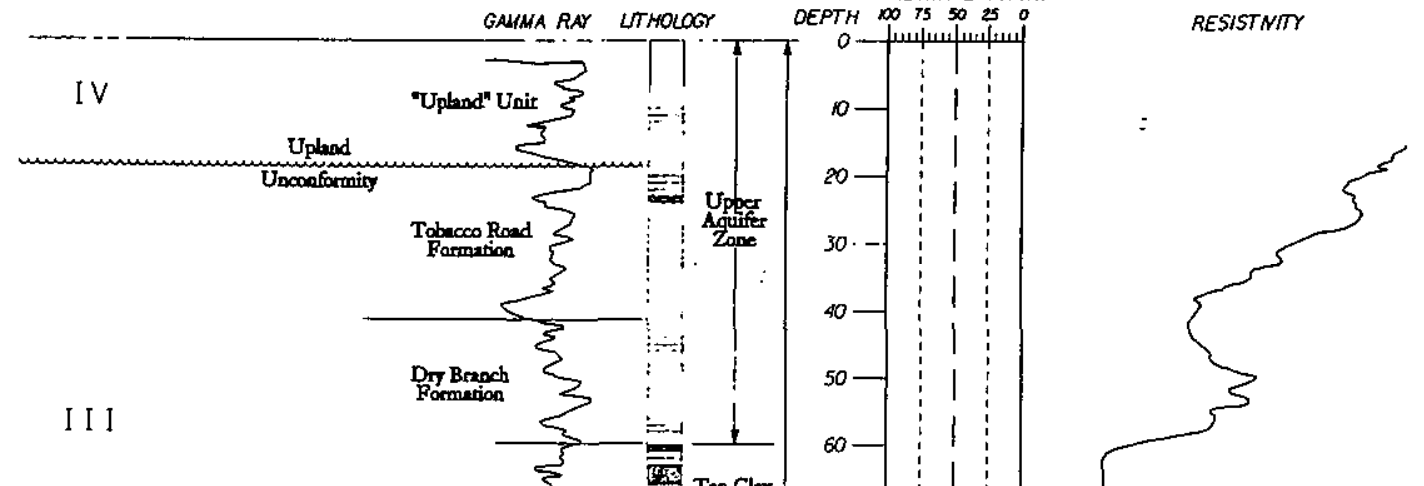

I I

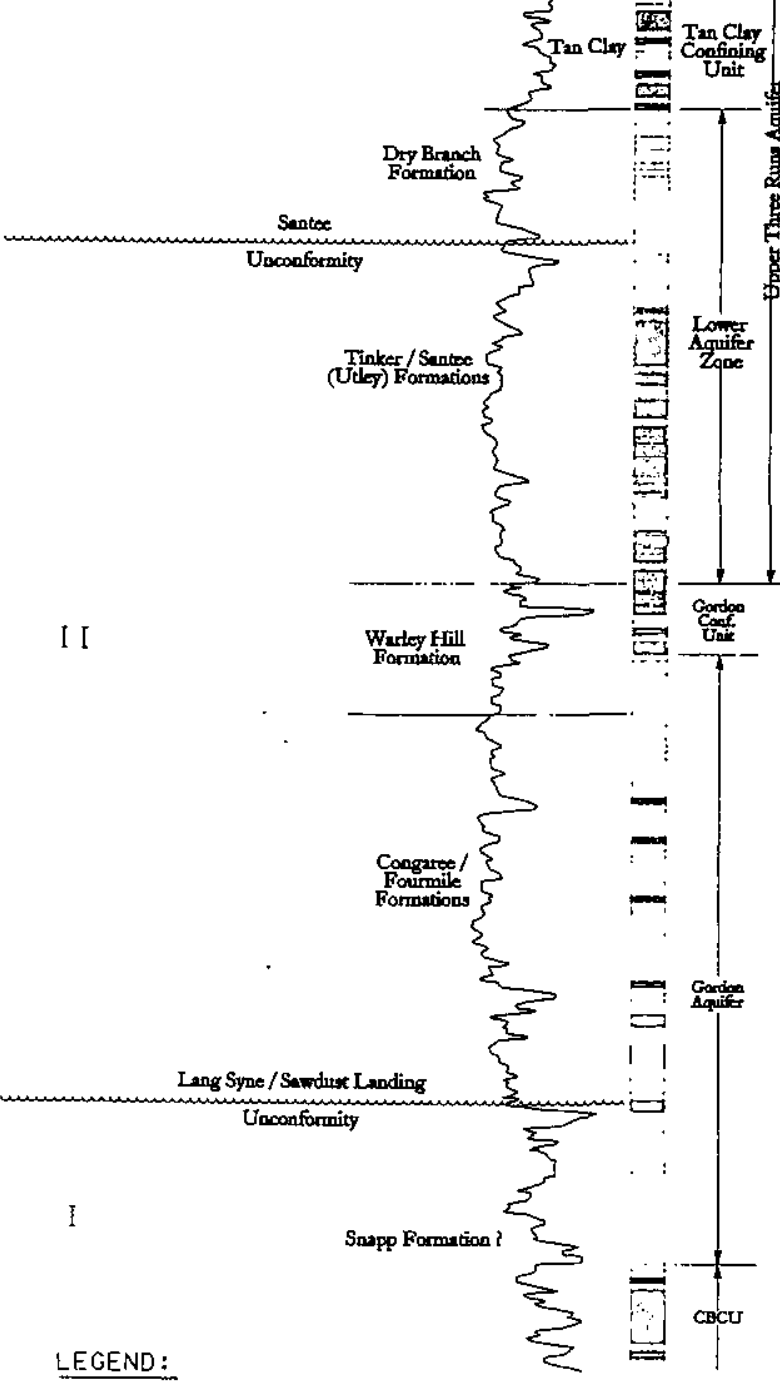

]SAND

B: B CLAYEY SAND

[T]CLAY

BLACK AND WHITE SYMBOLS INOICATE

INFERRED LITHOLOGY IN ZONES OF NO RECOVERY.

U

-inglalcareous SAND

RESULTS OF INSOLUBLE--RESIOUE ANALYSIS

CONNECTING LINES INDICATE CONTINUDUS

SAMPL ING AT DNE -FOOT INTERVALS.

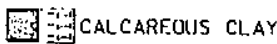

MODIF IED FROM THAYER AND OTHERS. 1994.

M 国LIMESTONE.

GiSANDY R. IMESTIONE

Figure 4-3

Summary of Insoluble Residue Data and Carbonate WT \% 
Mesotidal ( Barrier Island) Shoreline
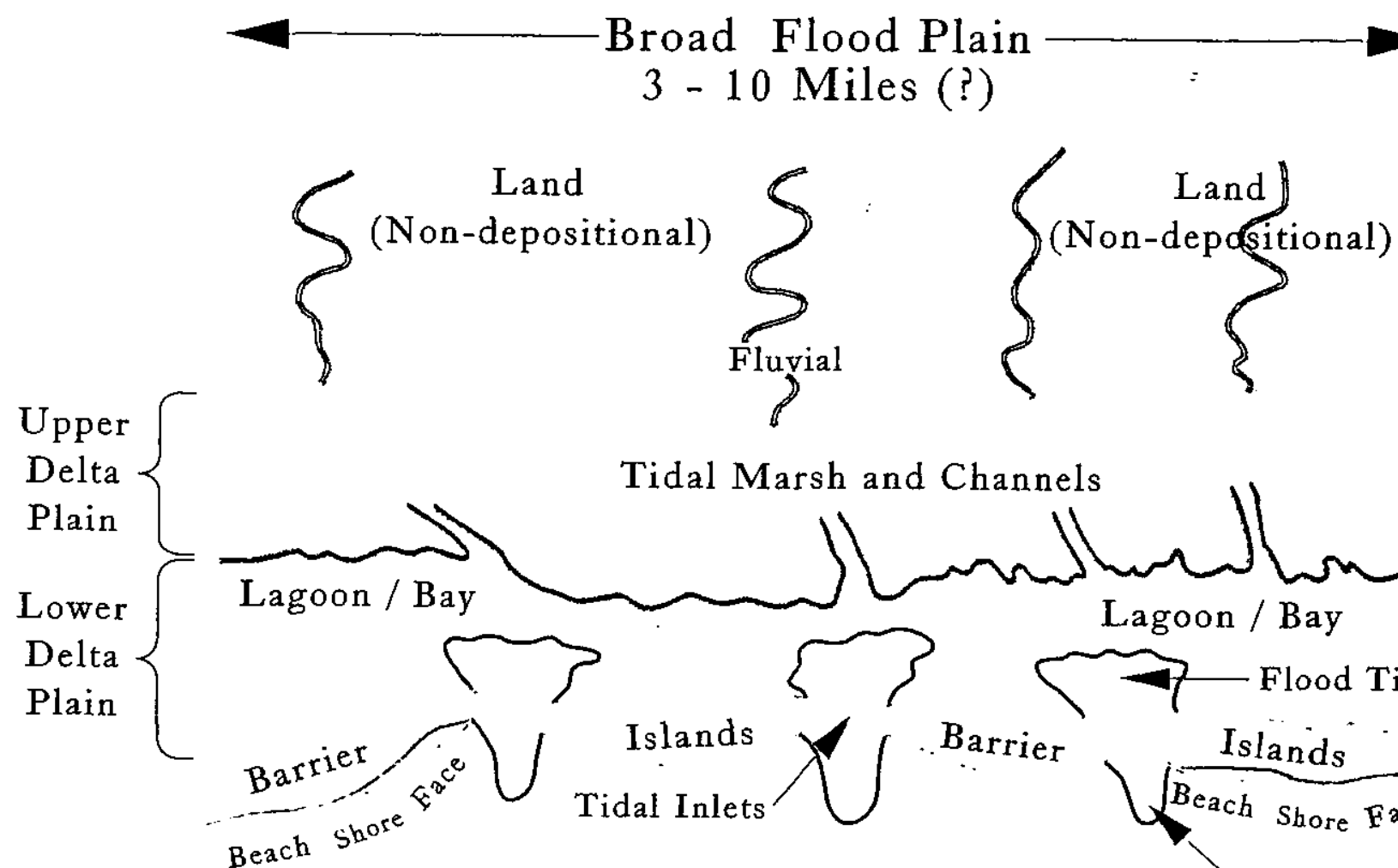

Tidal Marsh and Channels
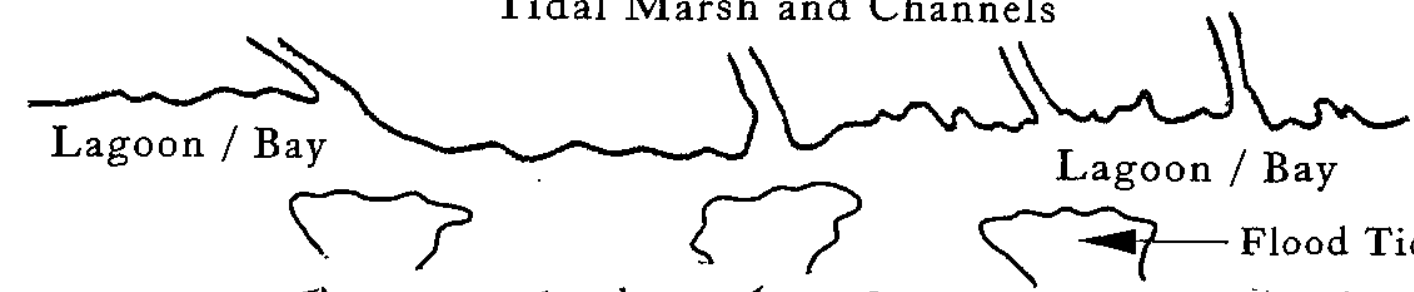

$$
\text { Lagoon / Bay }
$$

Shallow Clastic/Carbonate Shelf

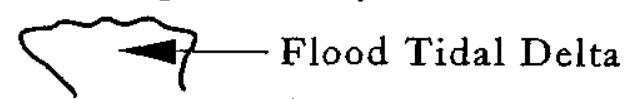

Shallow Shelf Below Storm Wave Base
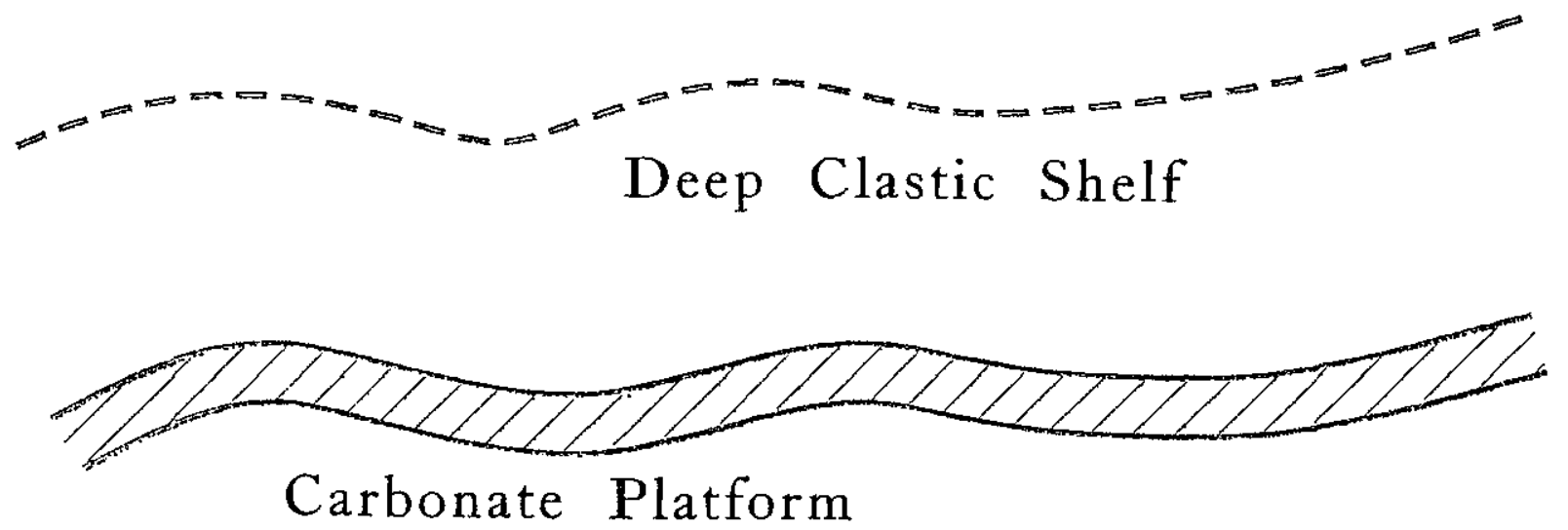


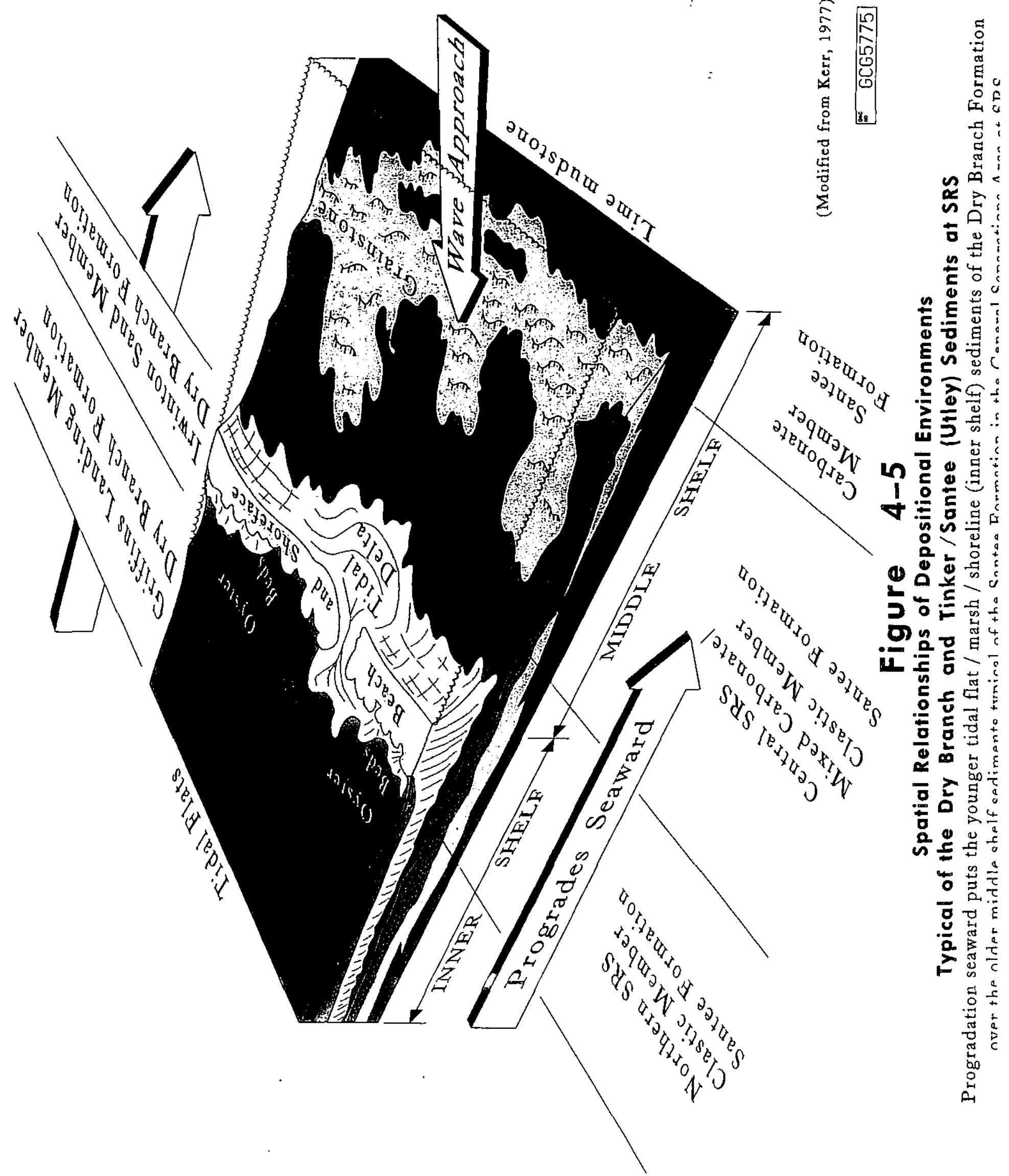




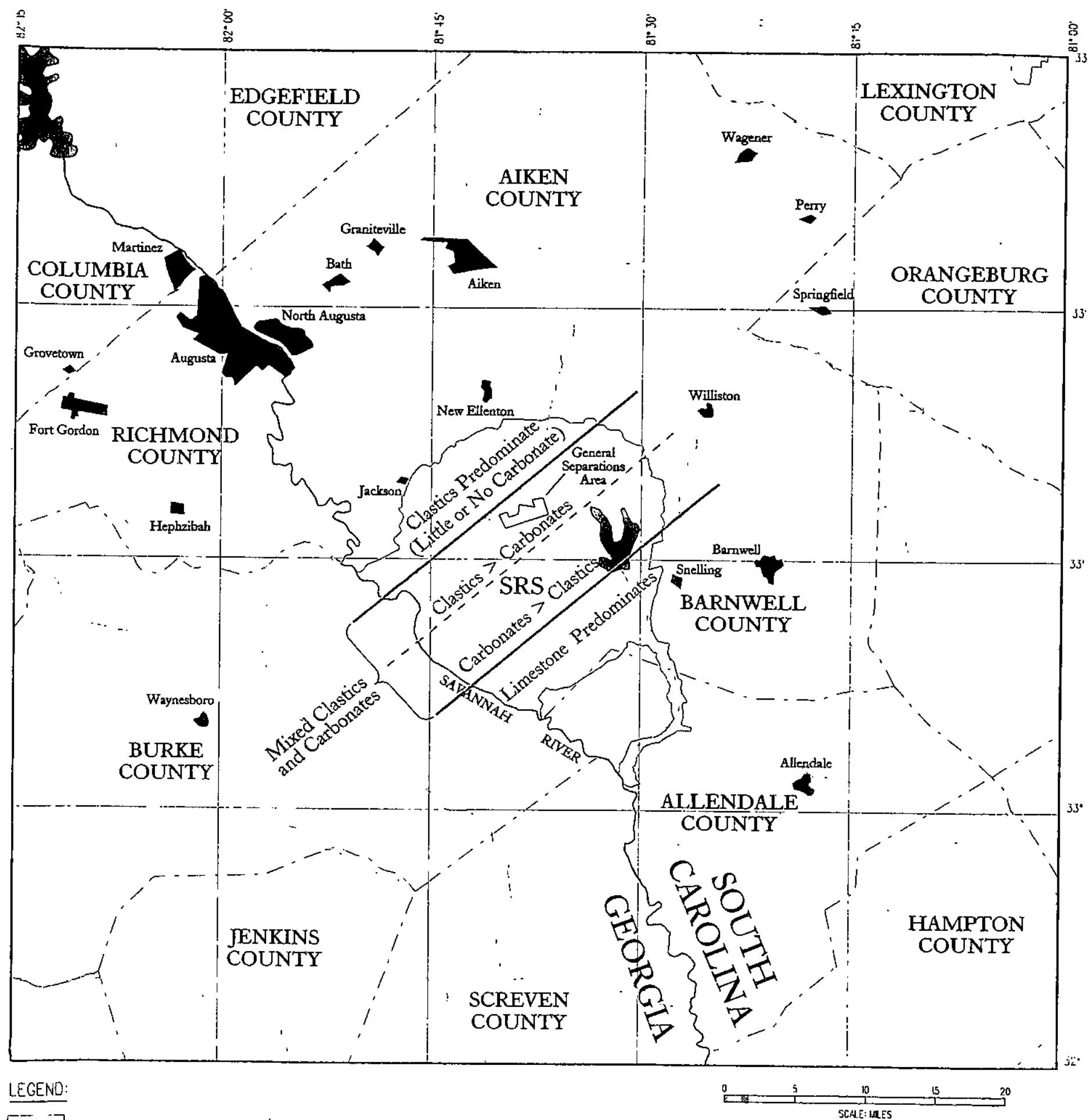

SAVANNAH RIVER SITE BOUNDARY

Figure 4-6

Regional Distribution of Carbonate in the Lower Aquifer Zone of the Upper Three Runs Aquifer (SanteeUtley-Dry Branch Sequence)

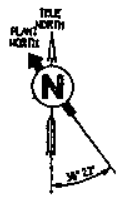


Schematic Diagram of Tinker/Santee (Utiey) Sediments Deposited Parallel to Shoreline.
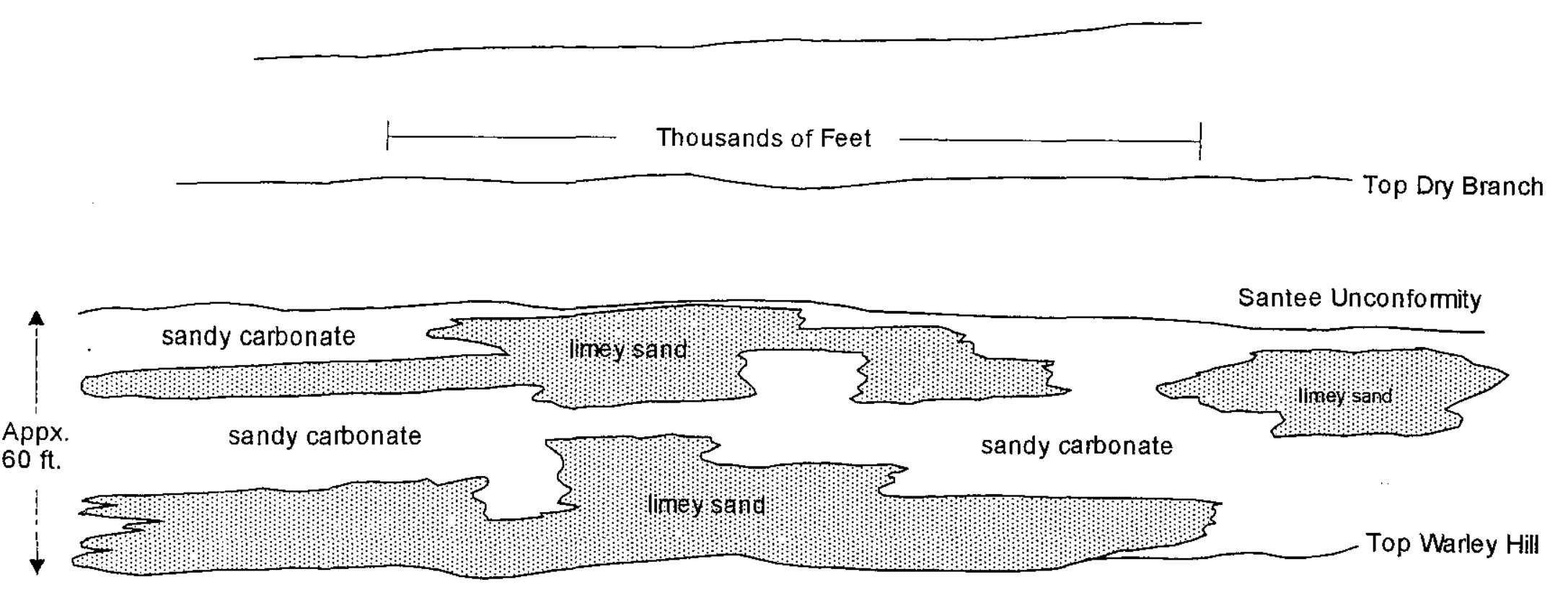

Figure 4-7. Shifting positions of tidal inlets at the shore face would result in shifting positions of the clastic-rich/ carbonate-rich sediments deposited out on the subtidal shelf. The result is a complex mix of sediments that gradually transition from one facies to another. 


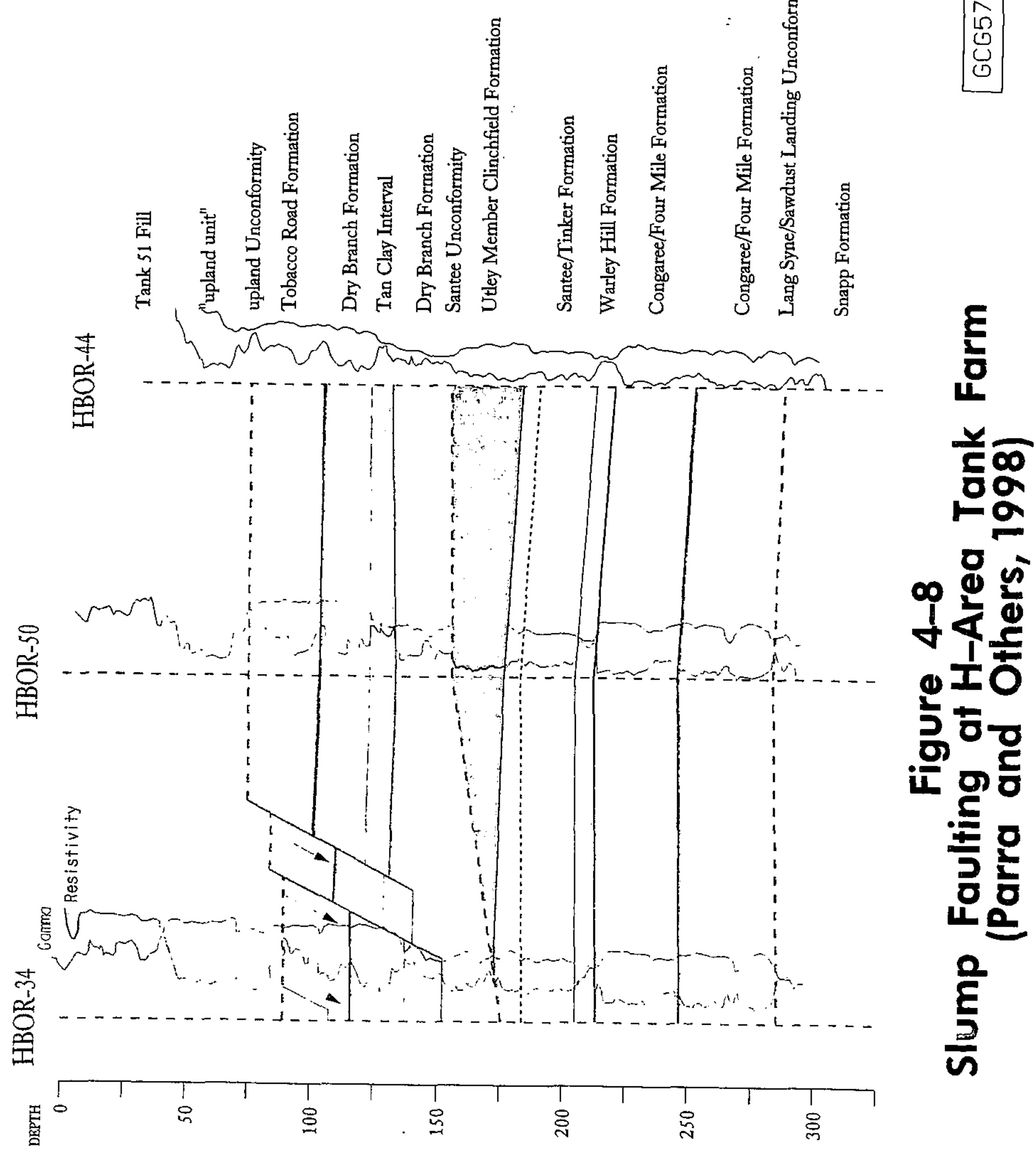




\section{EXPOSEO TO SEAWATER:}
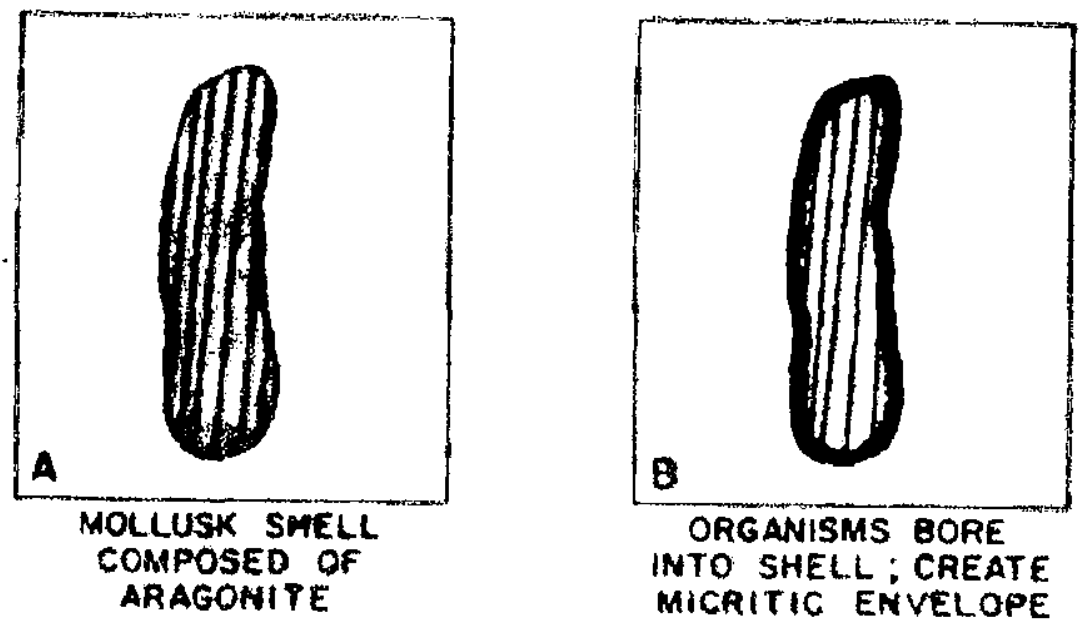

TAKEN OUT OF MARINE ENVIRONMENT EXPOSED TO FRESHWATER:
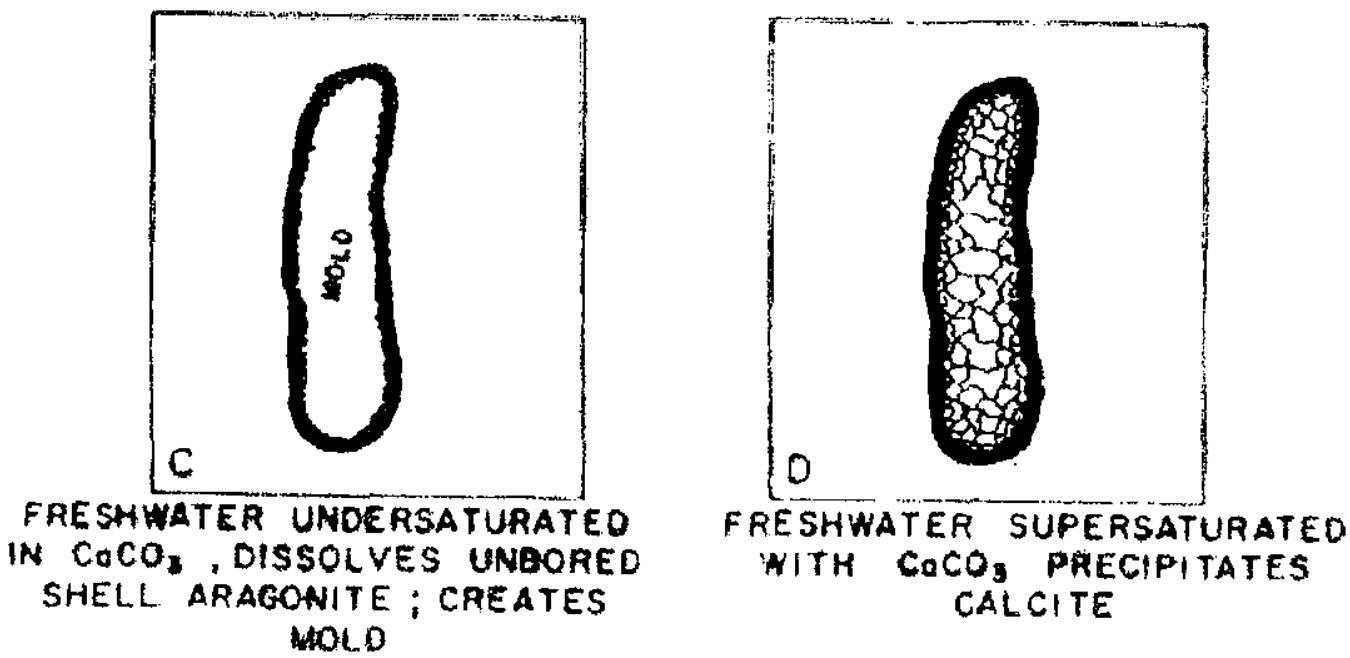

Figure 4-9 Diagrammatic Summary showing Steps in Solution and Precipitation of Calcium Carbonate by Fresh Water. 


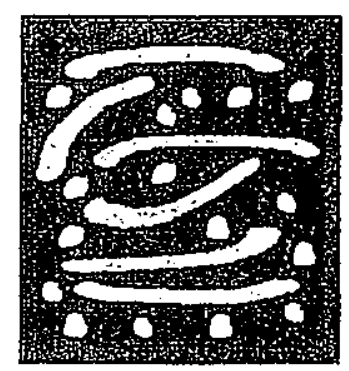

$-1$
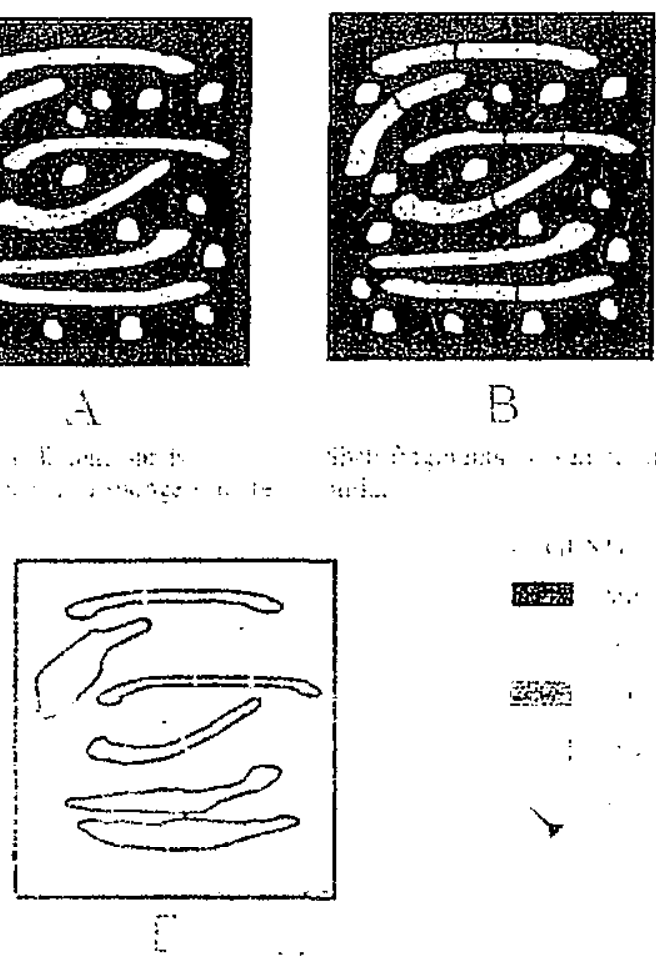

$B$
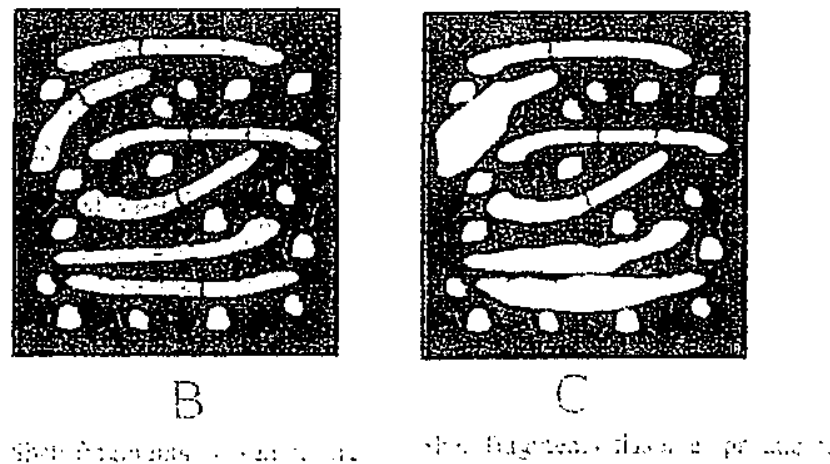

蔡瞥

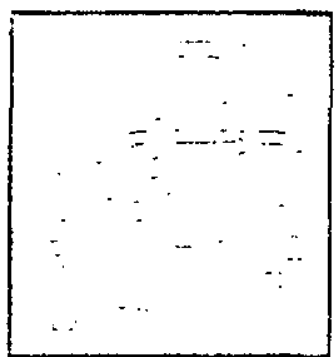

[)
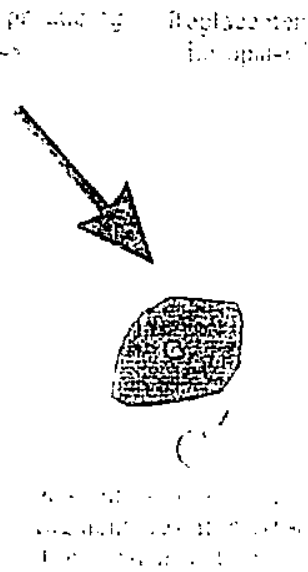

$\because$

Figure 4-10 Diagrammatic Representation of the Interpreted Diagenetic History of the Sandy Biomoldic Chert Microfacies.

\section{BEST AVAAP ABLE COPY}




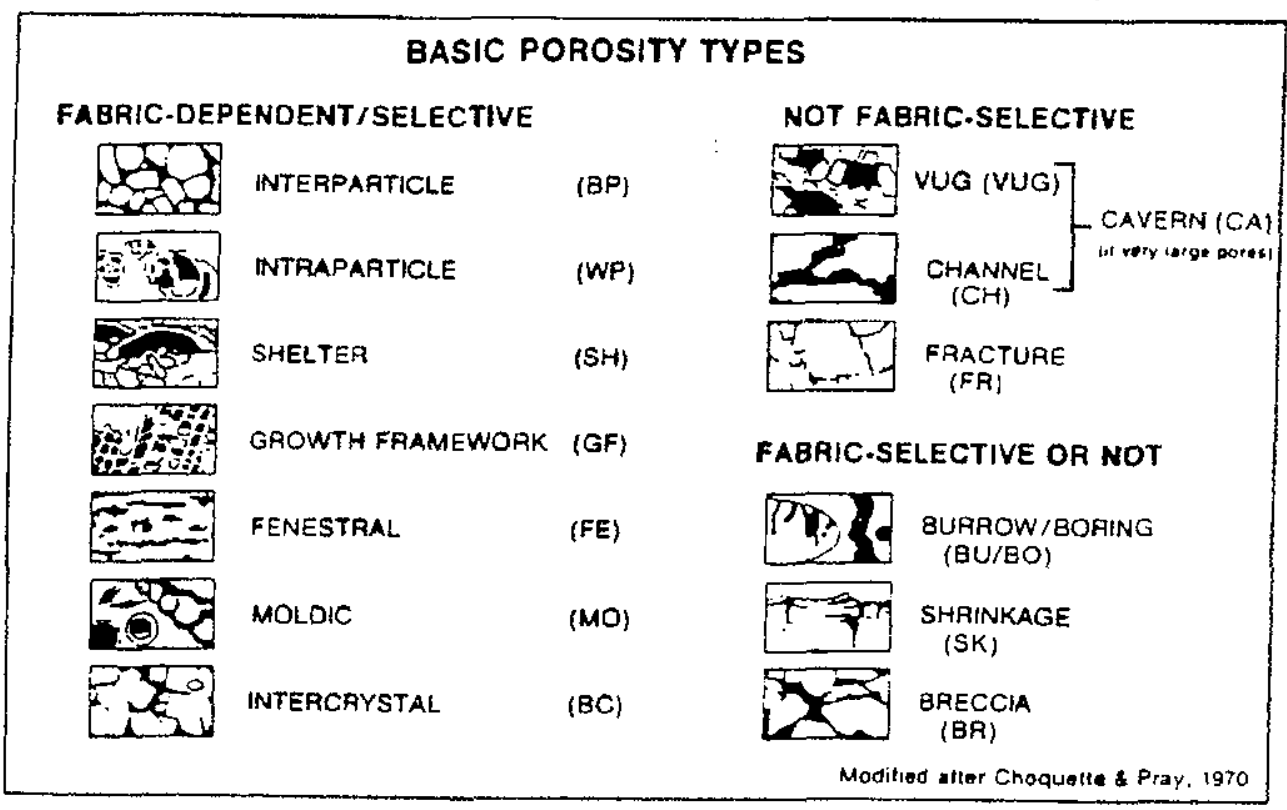

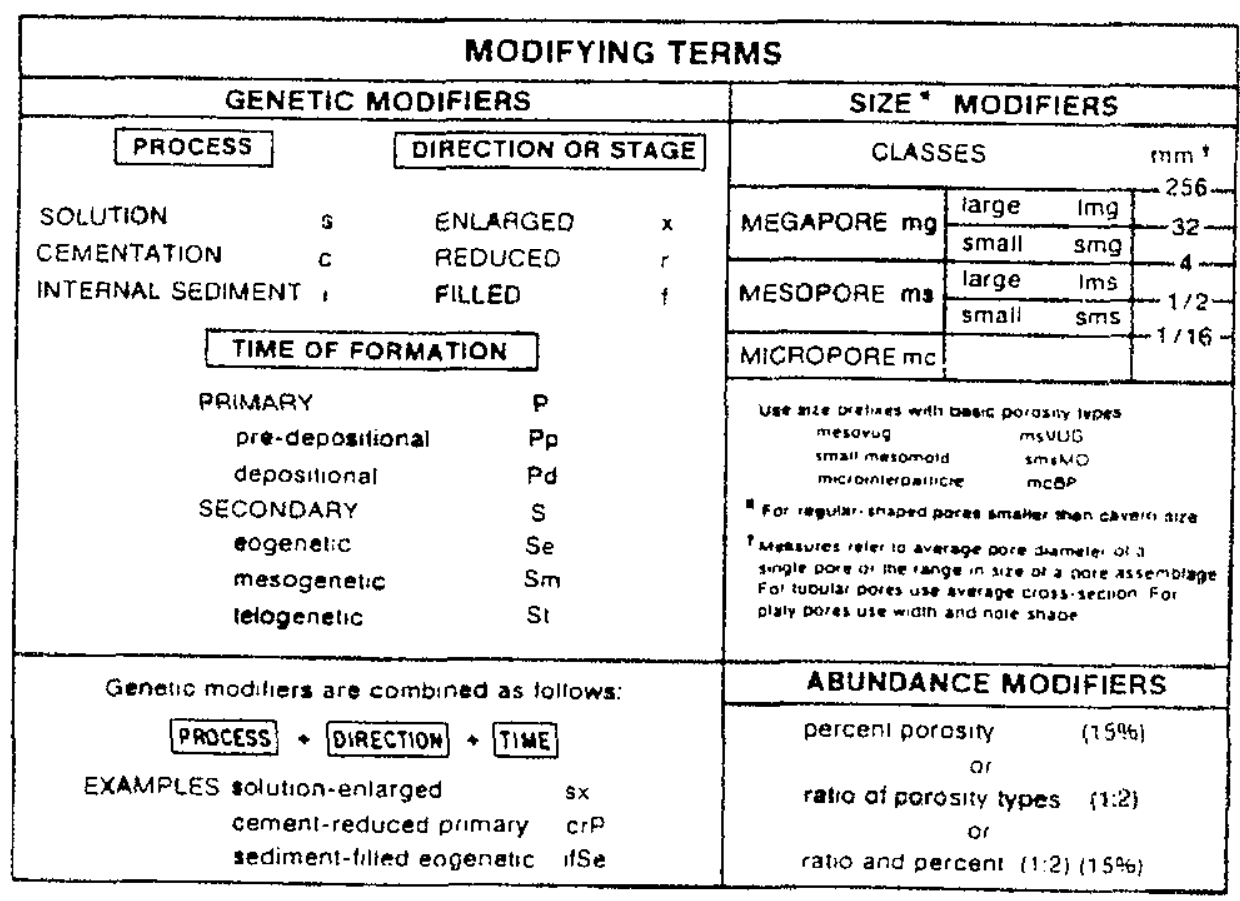

Figure 4-11 Porosity Classification of Choquette and Pray (1970). A. Basic Porosity Types. B. Genetic, Size, and Abundance Modifiers. 

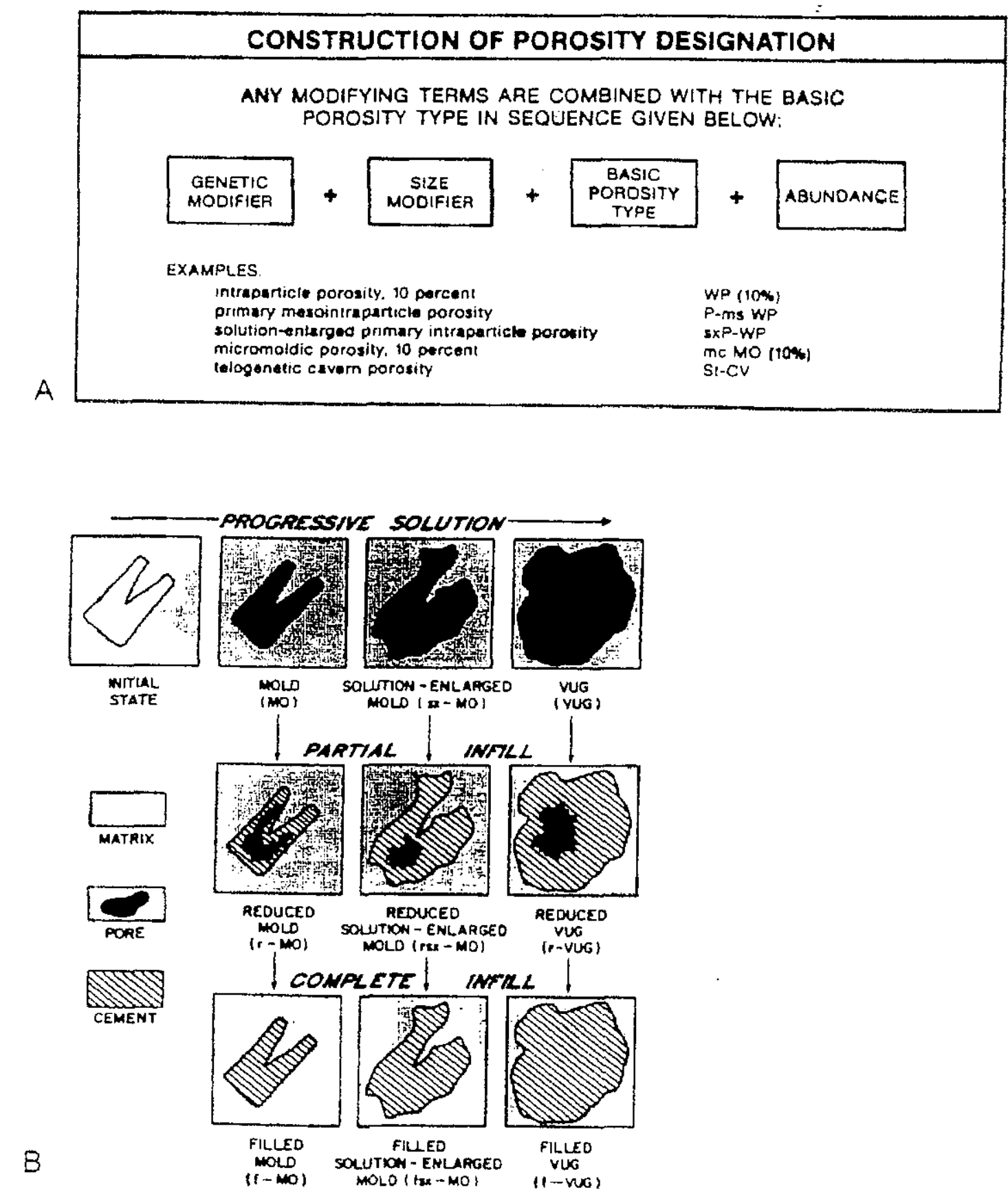

Figure 4-12 Porosity Classification of Choquette and Pray (1970). A. Format for Construction of Porosity Name and Code Designations. B. Common Stages in Evolution of Pore, a Mold, Showing Application of Genetic Modifiers and Classification Code. 


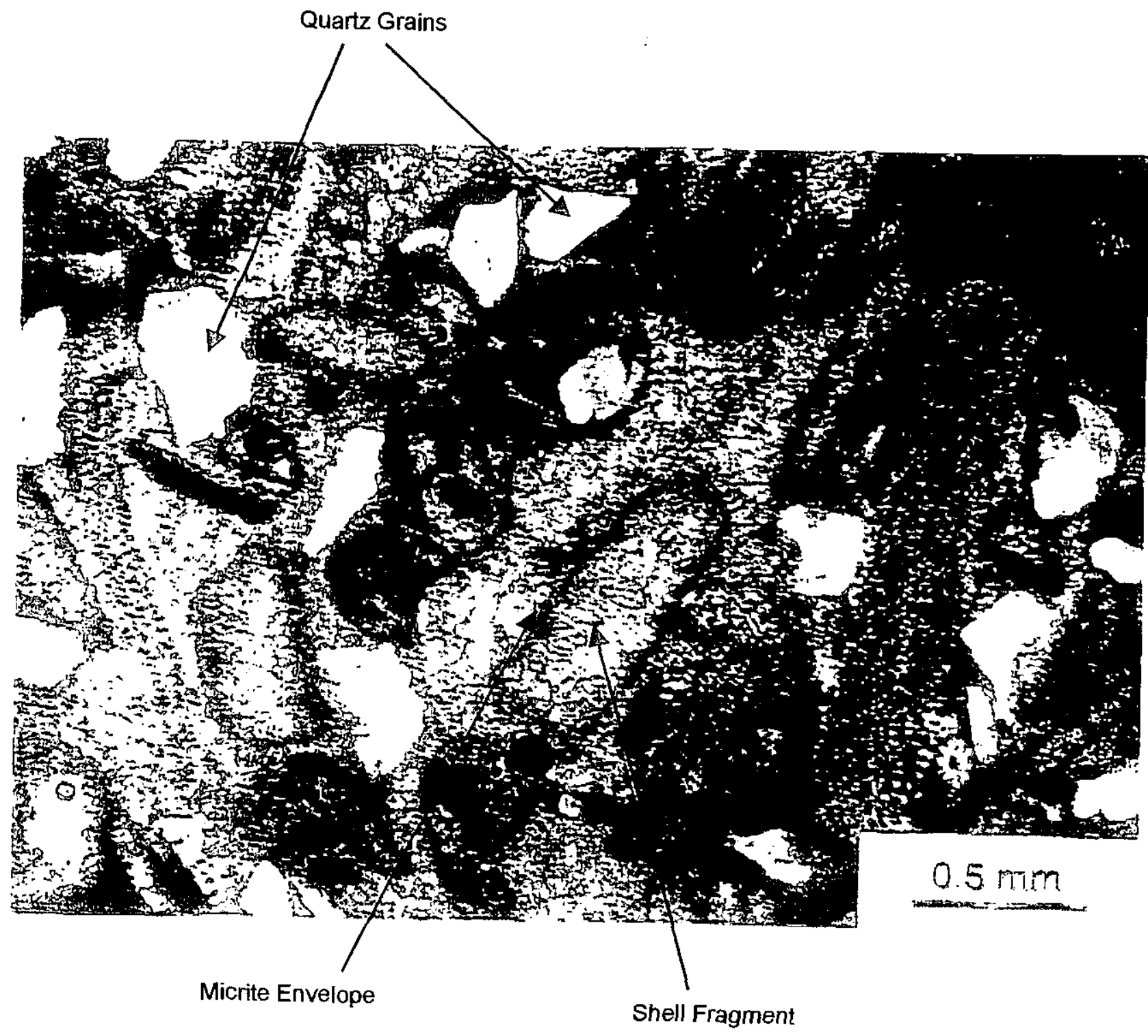

Figure 4-13 Photomicrograph of Quartz-Rich Skeletal Packstone that has been Diagenetically Altered to Sandy, Molluscan-Mold Microsparite. Tinker/Santee (Utley) Section, GSA SRS. Well BGO-14A, $122 \mathrm{ft}$. Crossed Nicols. Note: Micrite Envelopes Around Shell Fragments. Blue Area Void Space Filled with Blue Epoxy Glue. 


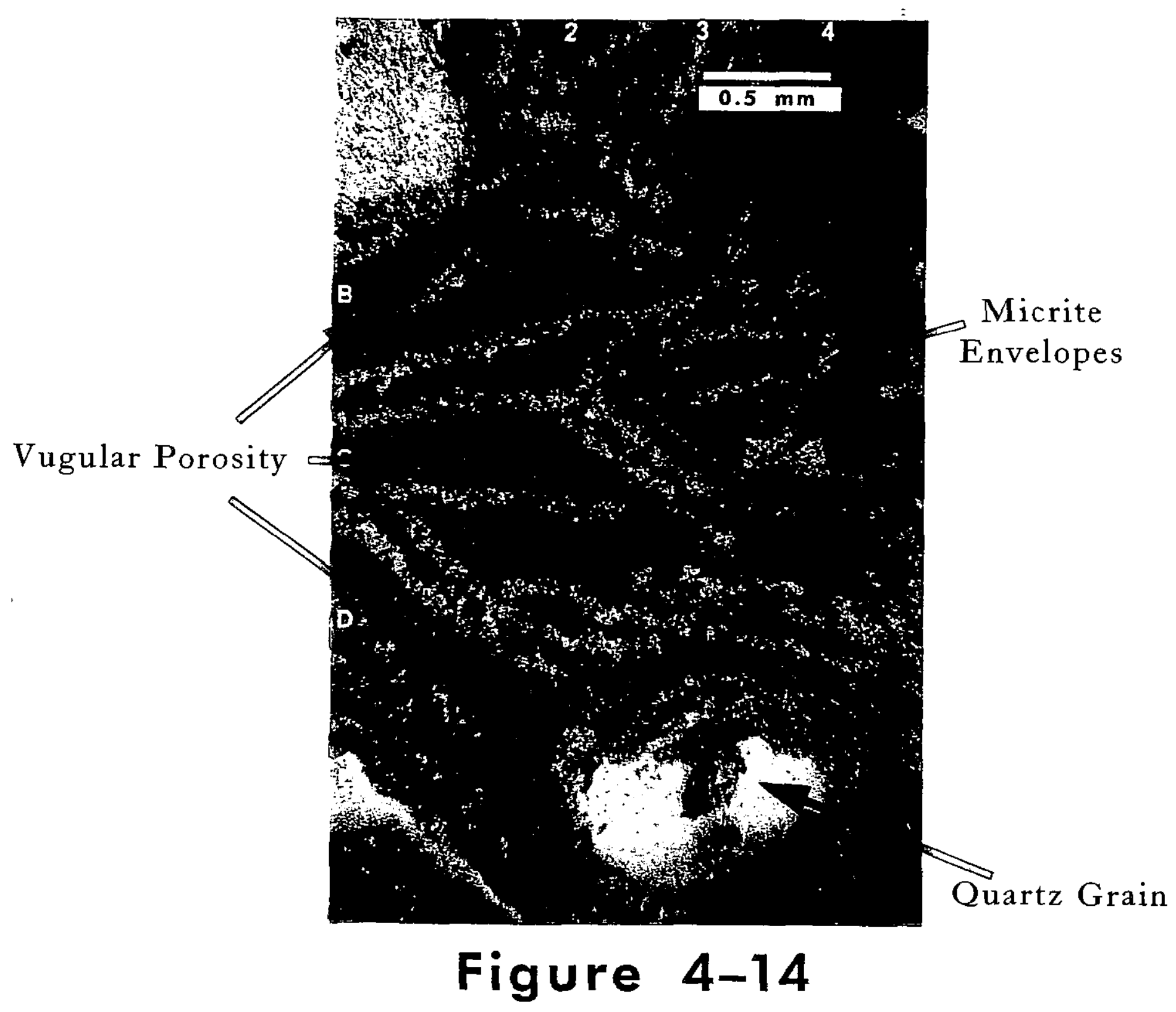

\section{Extensive dissolution of fossil fragments in a Skeletal Grainstone (?) resulting in Vugular Porosity.}

Only micrite envelopes of shell fragments remain. Tinker/Santee (Utley), General Separations Area, Savannah River Site Well HBOR-50@165 ft. Crossed nicols. Void space filled with blue epoxy glue. 


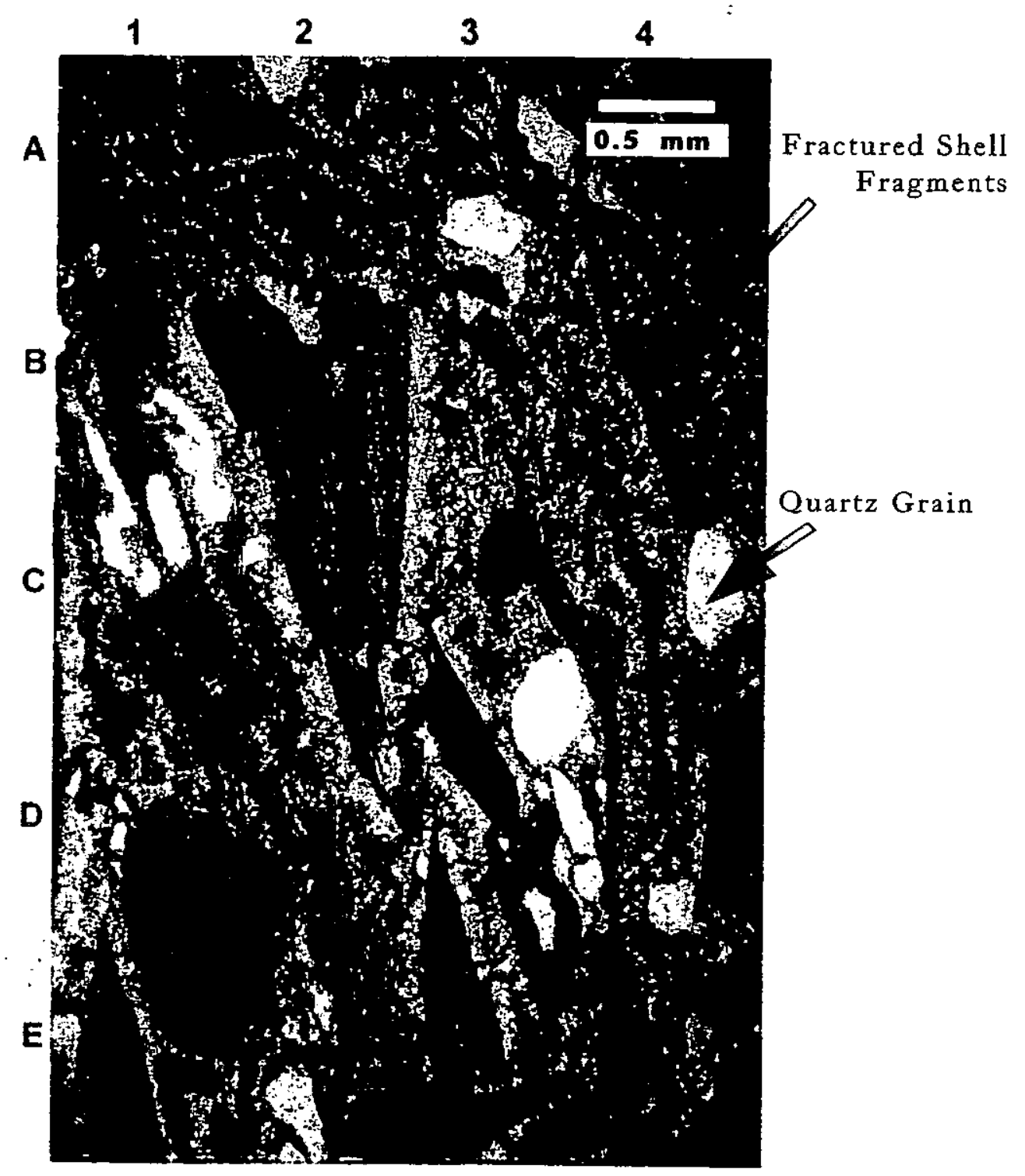

Figure 4-15

Collapsed and fractured Shell Fragments in a Skeletal Grainstone (?).

Tinker/Santee (Utley)

General Separations Area, Savannah River Site

Well HBOR-50.@179 ft. Crossed nicols.

Void space filled with blue epoxy glue. 
Partial infill of

calcite cement in shell mold
Quartz Grain

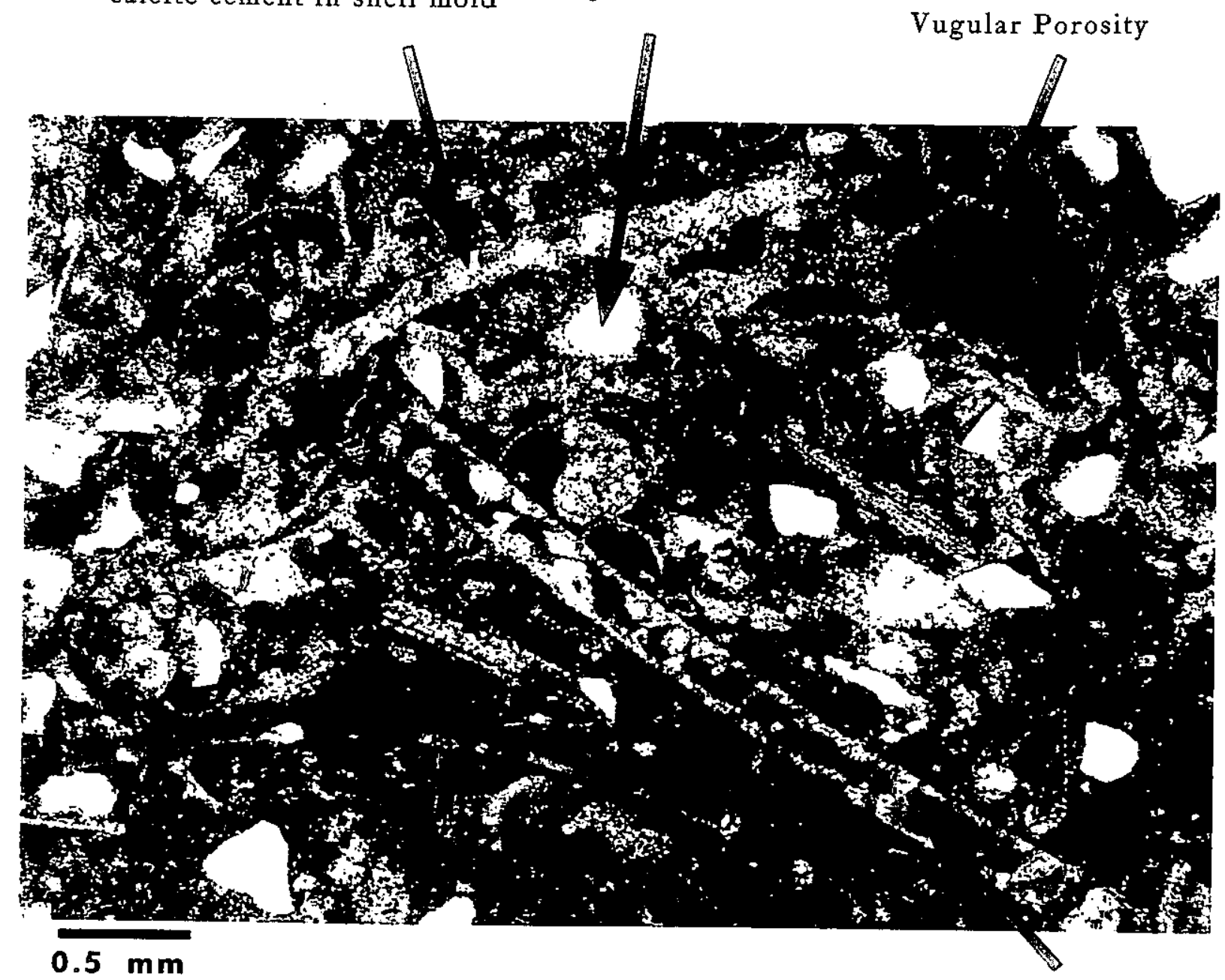

\section{Figure 4-16}

\section{Sandy, Pelecypod, Pellet Packstone,} Skelefal Packstone Microfacies.

Tinker/Santee (Utley) section

General Separations Area, Savannah River Site. Crossed nicols. Void Space filled with blue epoxy glue. 


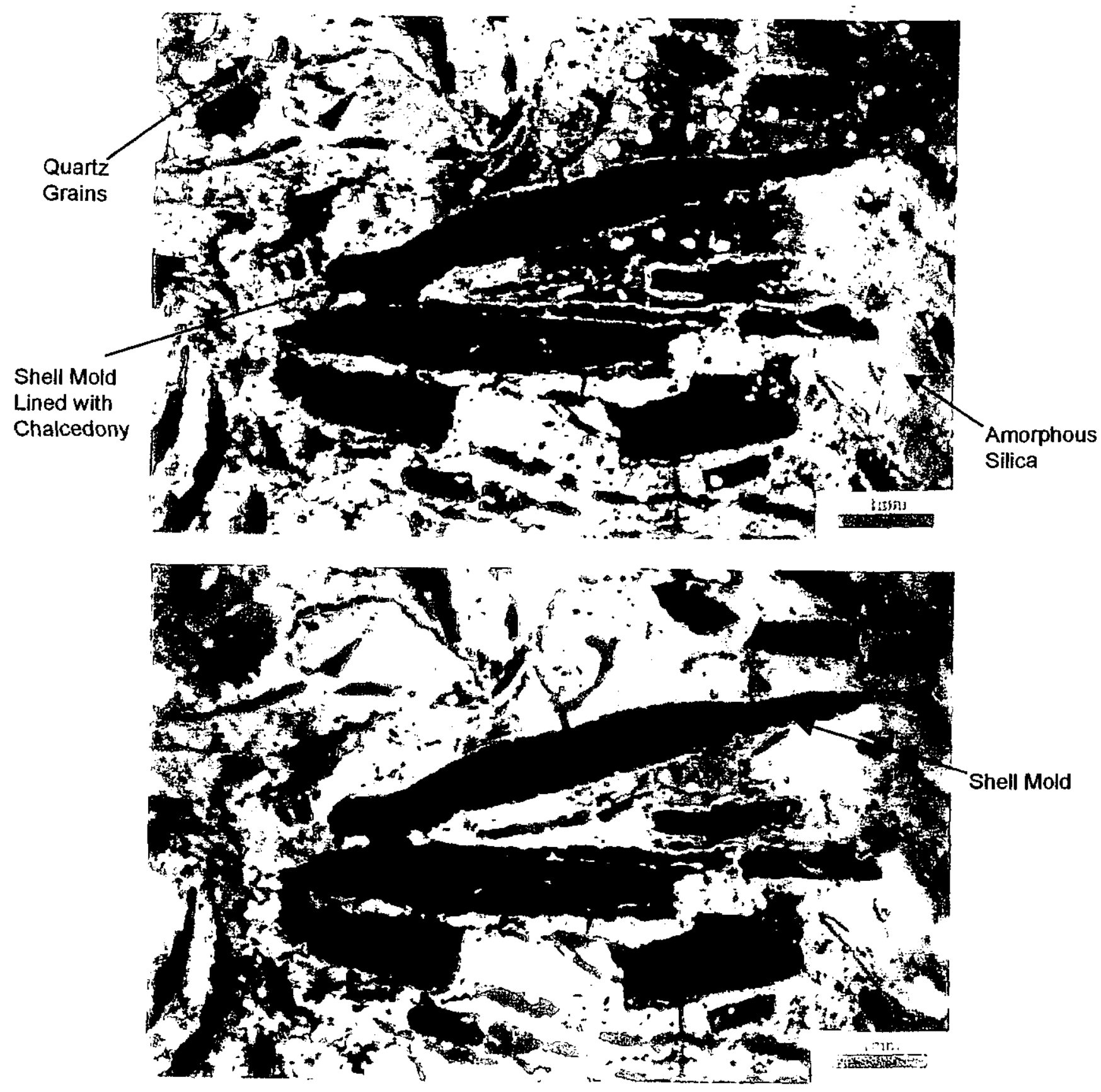

Figure 4-17 Photomicrographs of Sandy Biomoldic Chert Microfacies Tinker/Santee (Utley) section, Core CPT-157S3 at 109.85 Feet Below Land Surface, Top Picture Crossed Nichols, Bottom Picture Plane-Polarized Light. Amorphous Silica (Opal-CT) Replacement of Calcite Micrite (mud) Matrix. 


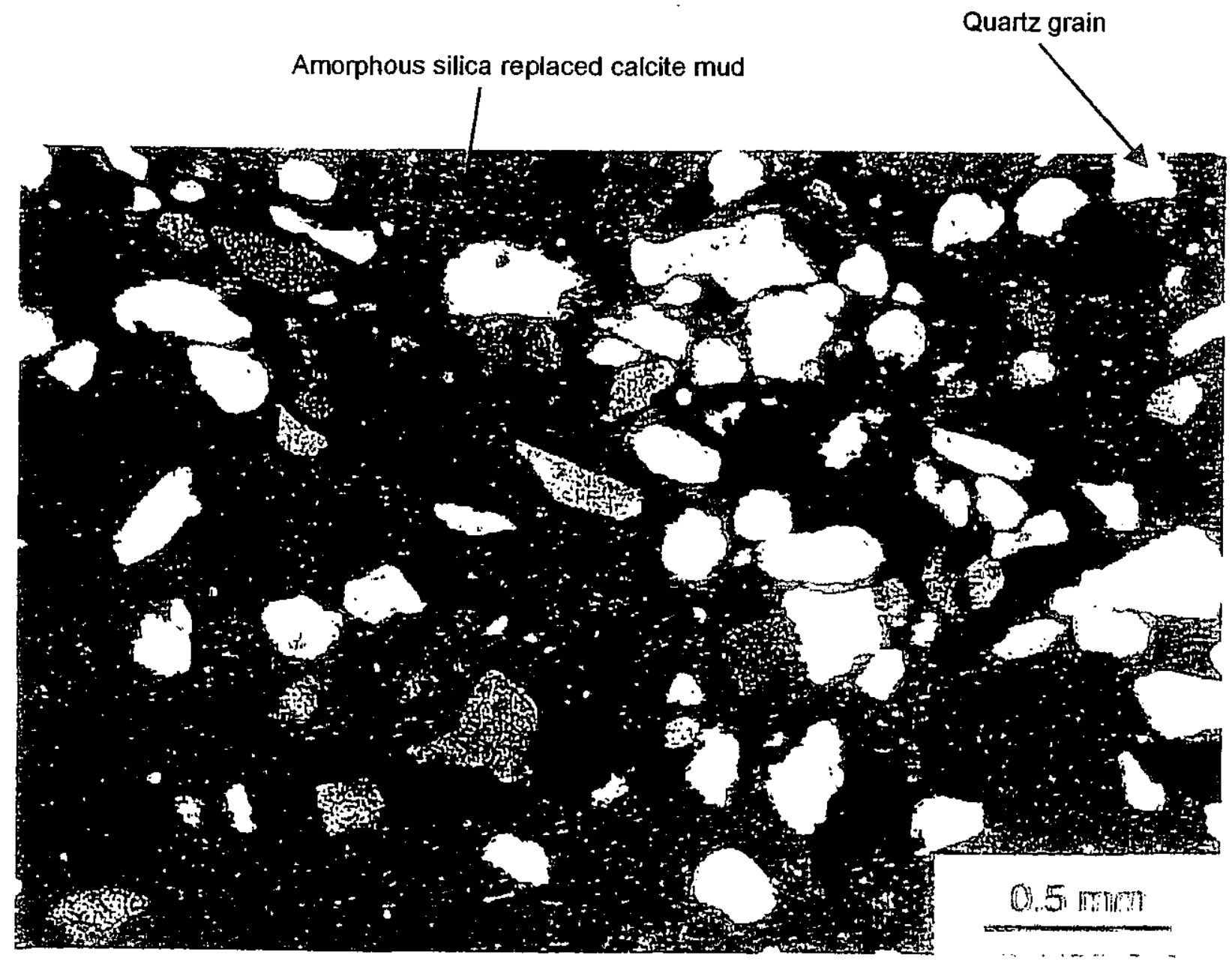

Figure 4-18 Photomicrograph of Sandy Siliceous Mudstone, Siliceous Mudstone Microfacies, Tinker/Santee (Utley) Section, General Separations Area, SRS. Well BGX-2B, 151.2 ft (Thin Section BGX-2B-152A). Crossed Nicols. Tinker/Santee (Utley) Section Calcite Micrite (Mud) Matrix Replaced by Amorphous (Opal-CT) Silica. 


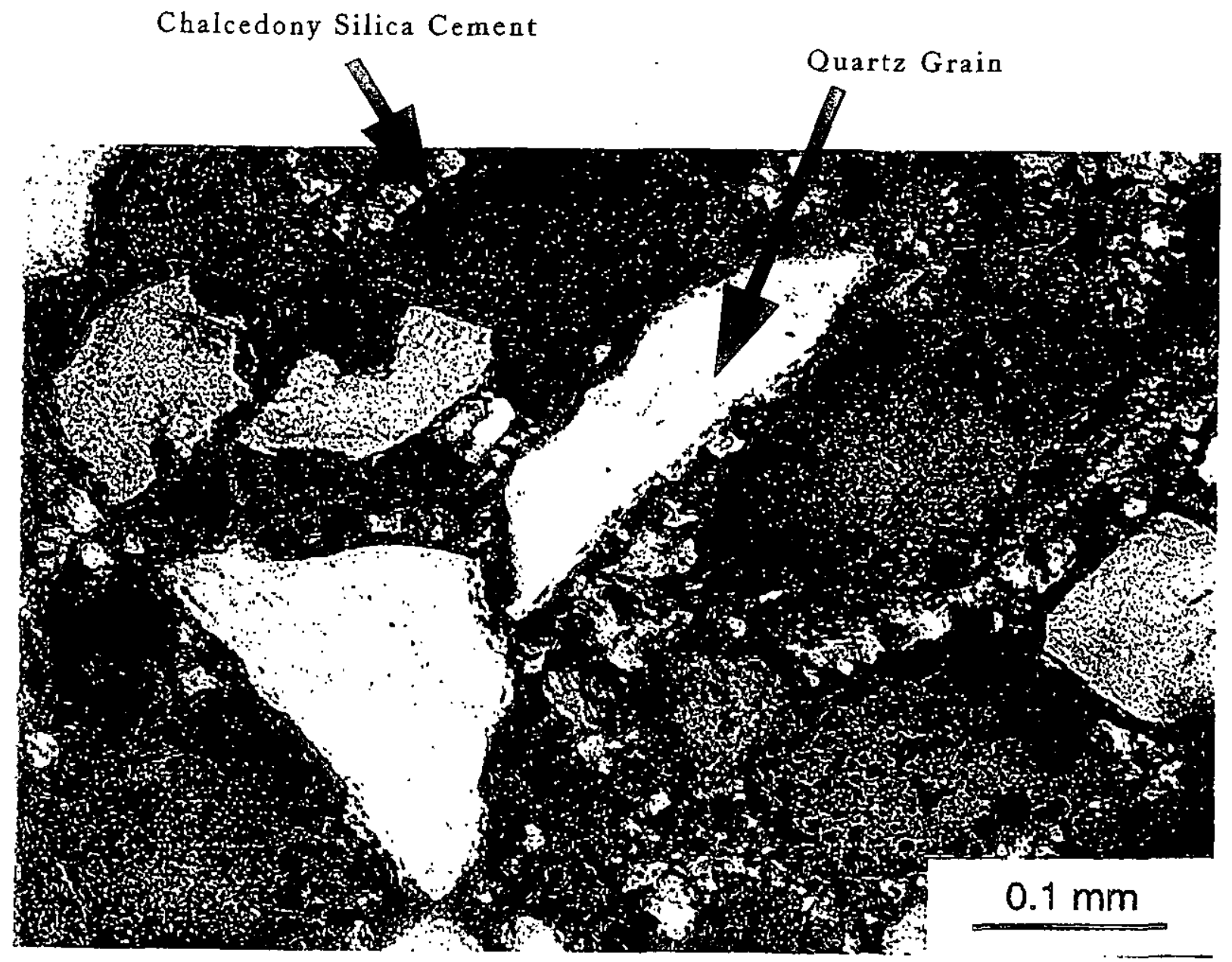

\section{Figure 4-19 \\ Chalcedony-cemented, Quartz Arenite, Terrigenous Sand and Sandstone Microfacies. \\ Tinker/Santee (Utley) section \\ General Separations Area, Savannah River Site Well YSC-2A@109ft. Crossed nicols.}




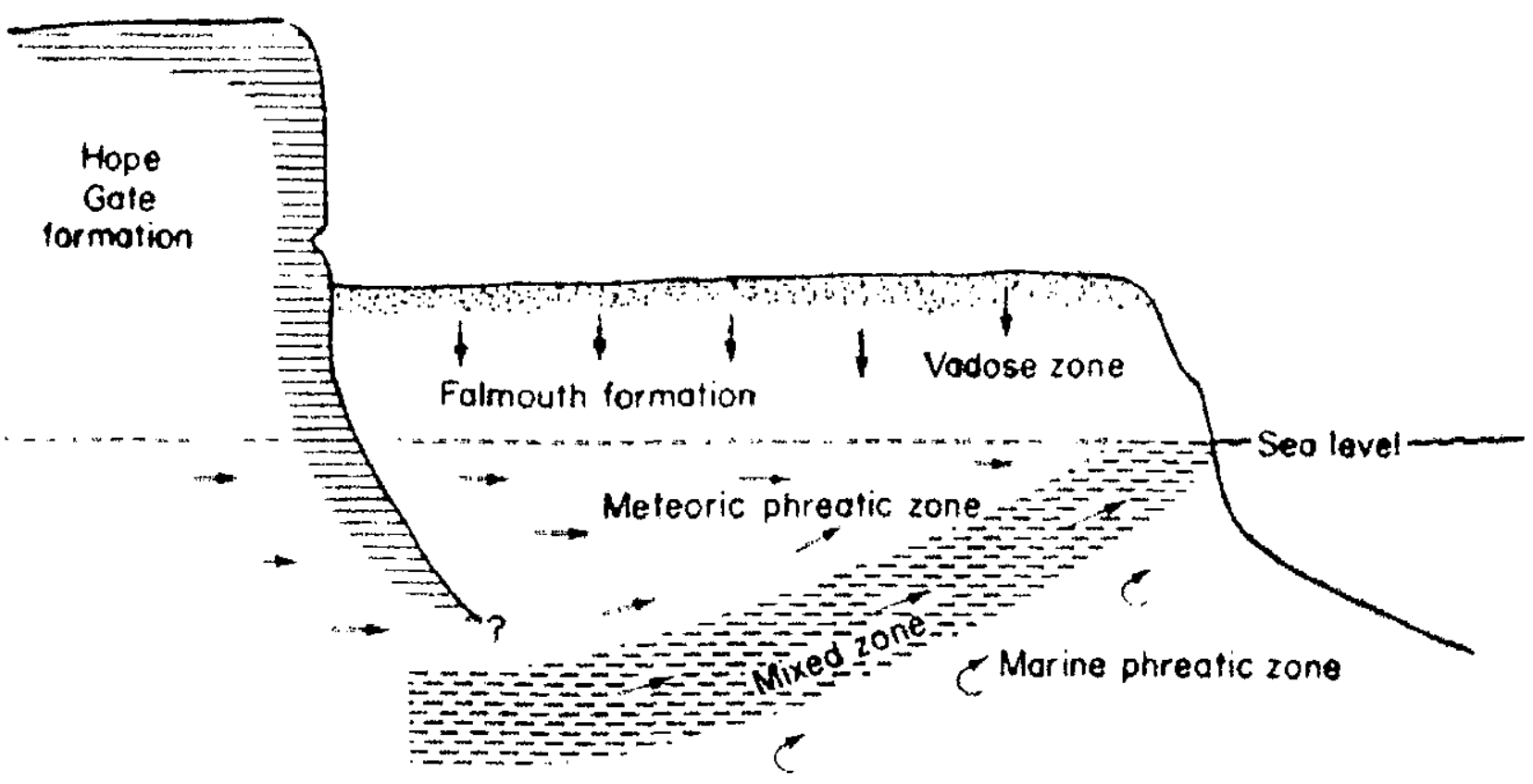

Figure 4-20 Schematic Cross Section Showing the Contact Relations Between the Medeoric Phreatic Zone/Marine Phreatic Zone in the Hope Gate and Falmouth Formations in the Bahamas. The Truncated Marine Terrace Underlain by the Falmouth Formation is Capped by a Well Lithified Caliche-Like "Caprock" (dotted pattern). Small Amounts of Water (Vertical Arrows) Percolate Through the Vadose zone to the Water Table. Most of the Meteoric Water is Derived from the Water Table Aquifer of the Island, however. (After Land, 1973). 

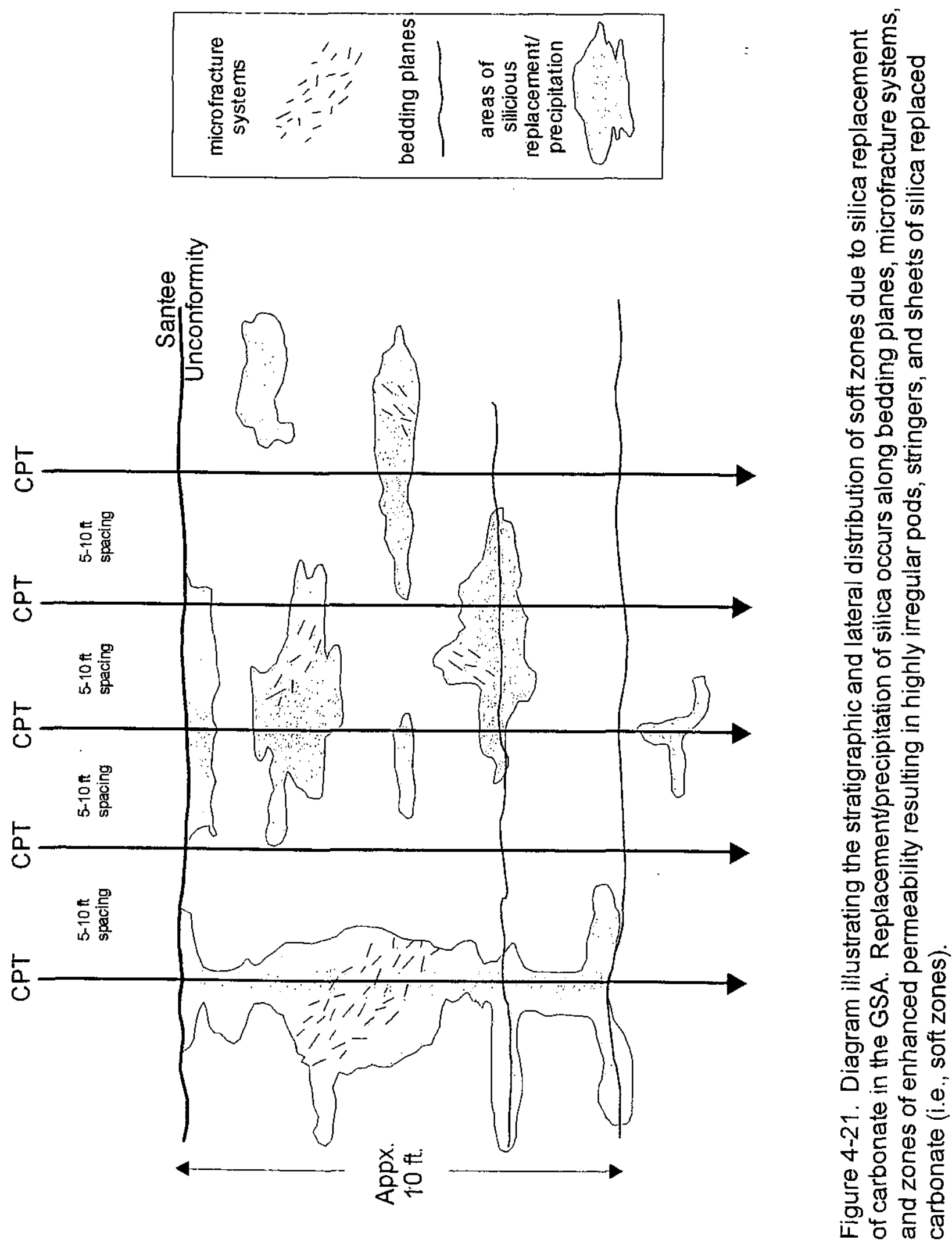


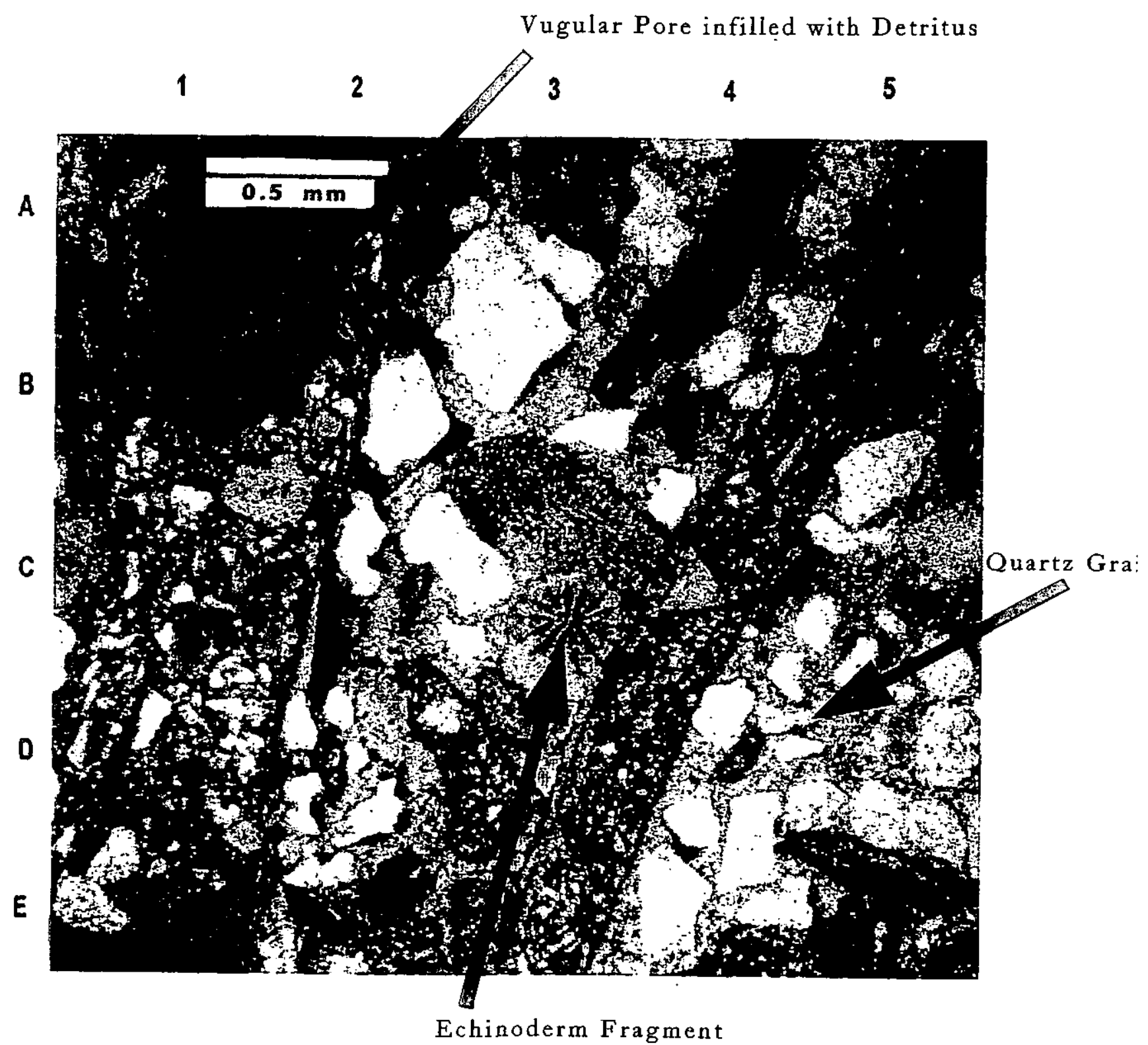

\section{Figure 4-22}

\section{Quartz-rich, Skeletal Grainstone,}

with carbonata/quartz datritus presant in Vuggy Pores. Skeletal Grainstone Microfacies,

Tinker/Santee (Utley) section

General Separations Area, Savannah River Site

Well HBOR-50@166 ft. Crossed nicols.

Void spare filled with blue epoxy glue. 


\section{LEGEND:}

SAND LOCALLY CONGLOMERATIC

CLAYEY/SILTY SAND

\section{CLAY}

CLAY, SILTY CLAY

LIMESTONE

CALCAREOUS SAND

NO RECOVERY

VERTICAL O SCALE
$B G X-4 A$

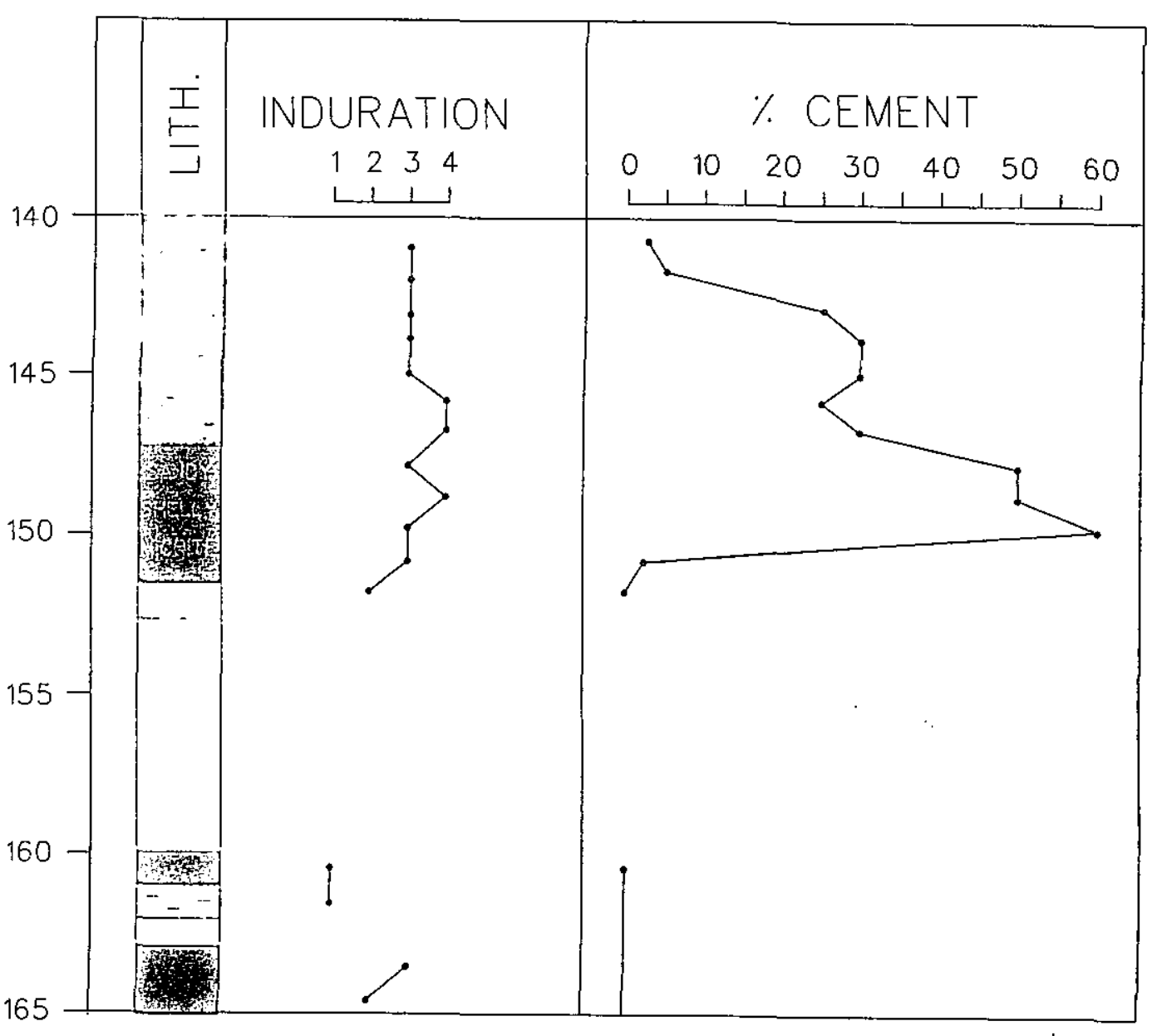

Figure 4-23

Drilling Data for

Well BGX-4A 

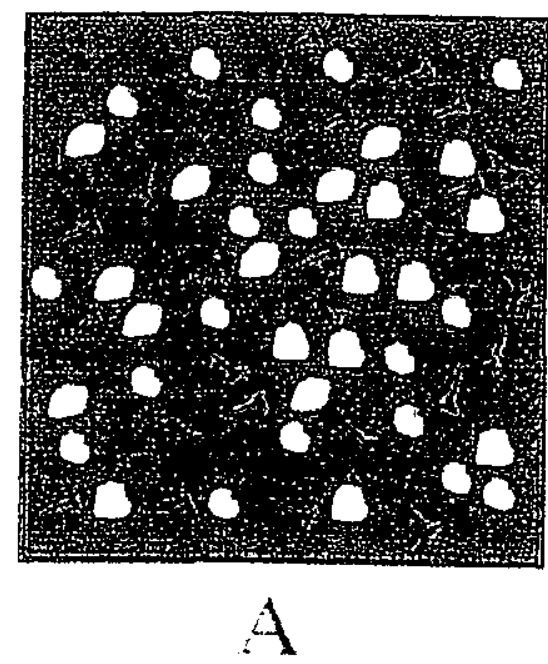

Mrginal sediment, sandy mudstente

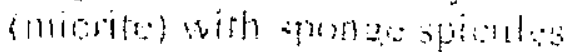

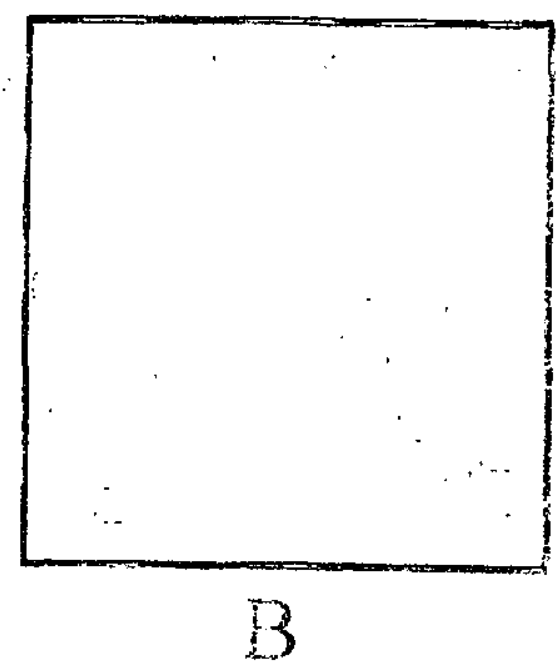

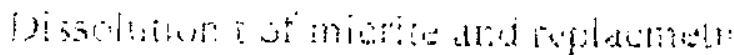

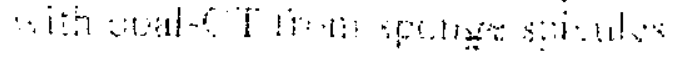

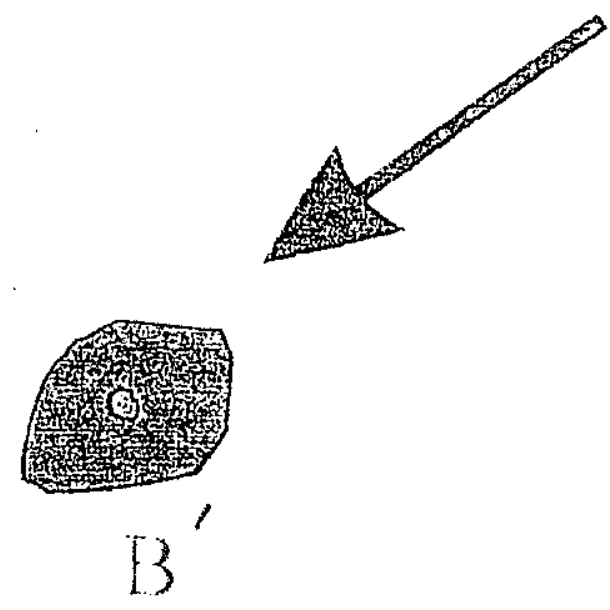

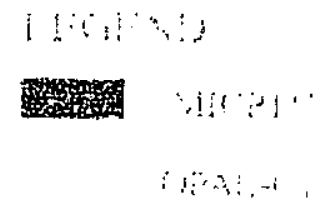

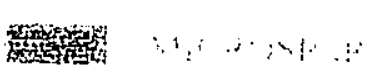

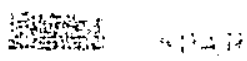

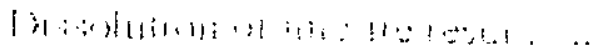

(1)

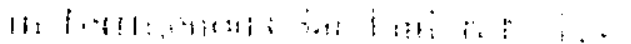

Figure 4-24 Diagrammatic Representation of the Interpreted Diagenetic History of the Siliceous Sandy Mudstone Microfacies. 


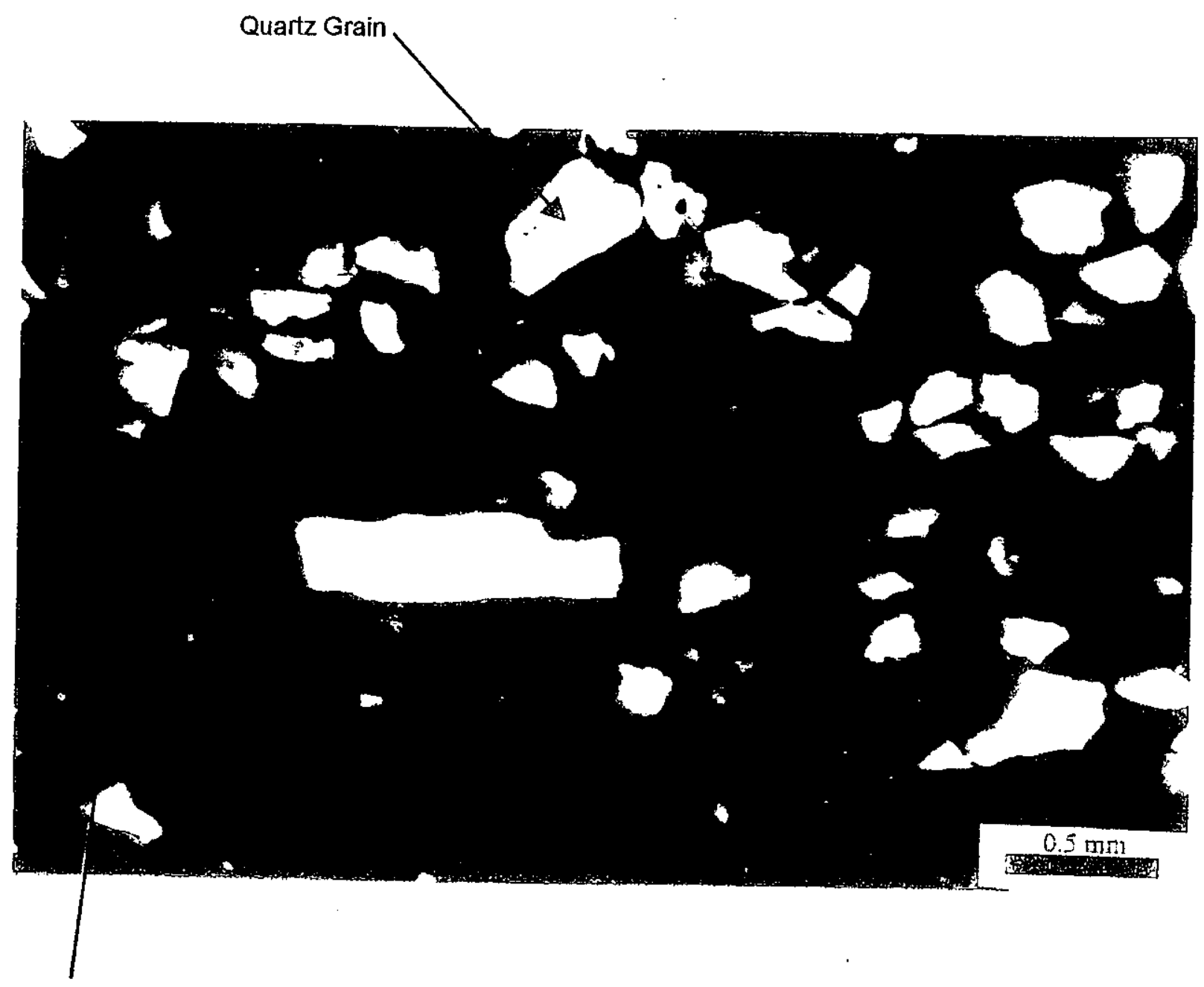

Amorphous Silica

Figure 4-25 Photomicrograph of Siliceous Sandy Mud Microfacies Tinker/Santee (Utiey) Section from Core CPT-157S3 at 108.35 Below Land Surface, Plane-Polarized Light. Amorphous (OpalCT) Silica Replaced Calcite Micrite (Mud) Matrix. 


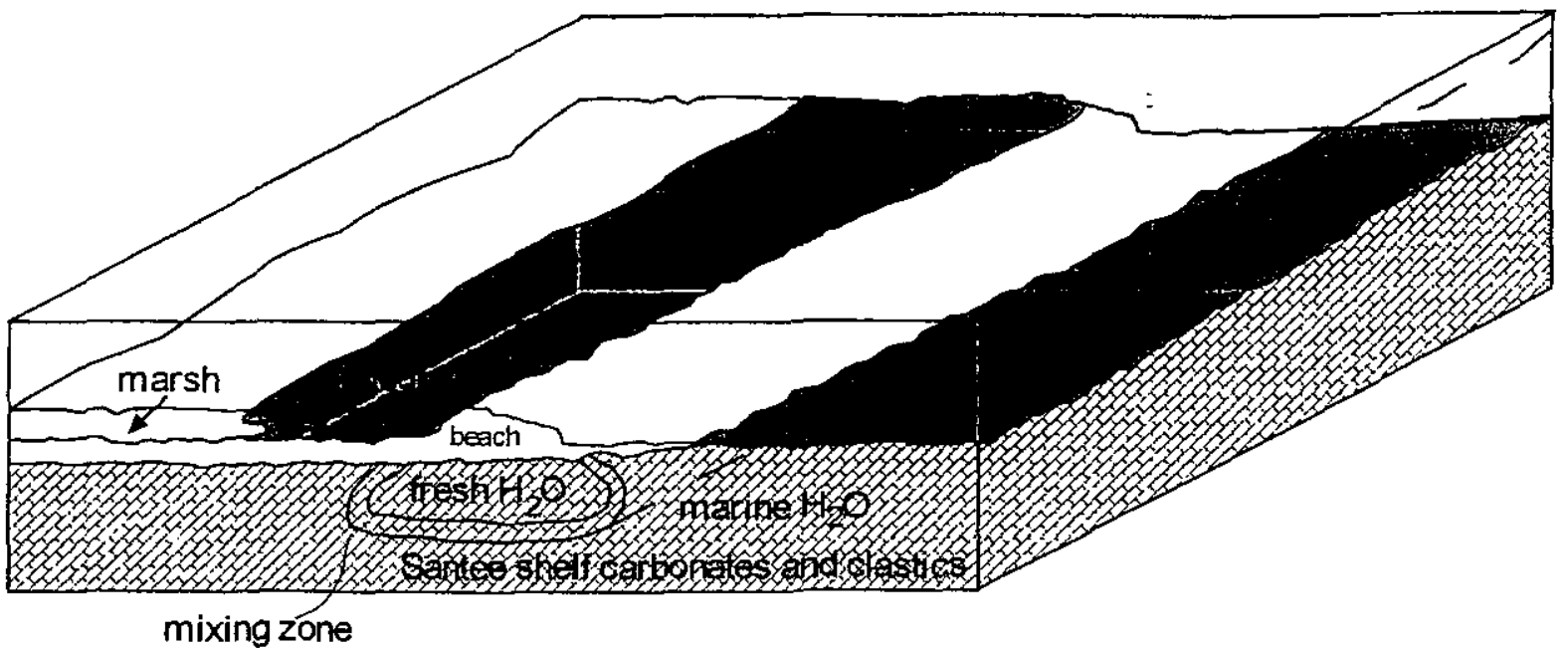

As rainwater infiltrates the subsurface beneath the beach ridge(s) into the underlying Tinker/ Santee (Utley) sediments the mixing zone interface between the indigenous marine waters and the fresh water will "wash" the sediments. The result is dissolution and silica replacement of the carbonate in the Tinker/Santee (Utley) section. As the beach shifts position through time the entire Tinker/Santee (Utley) sequence within the geographic range of the shifting shoreline environment will be affected by the changing mixing zone.

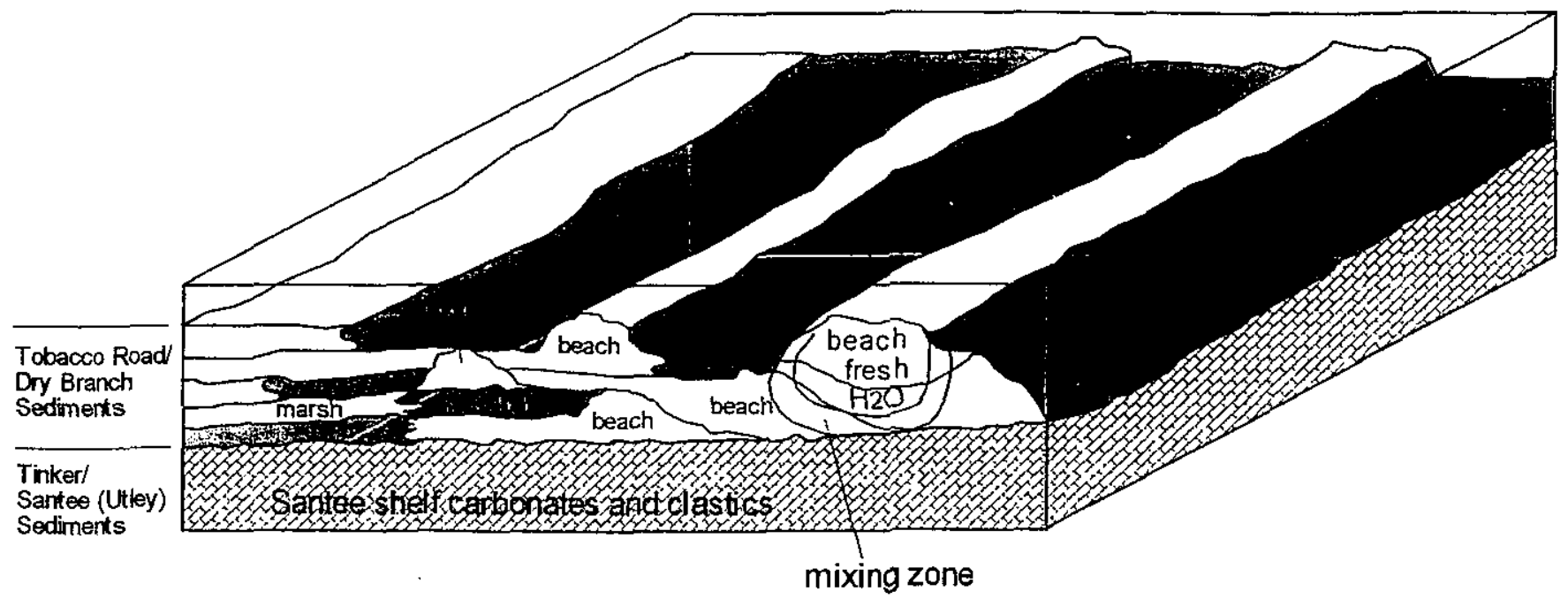

As time passes and the thickness of Dry Branch and Tobacco Road sediments increases the Tinker/Santee (Utley) sediments will be buried deeper eventually residing below the reach of the mixing zone. Here diagenetic alteration of the sequence will essentially cease.

Figure 4-26. Model for development of facies and softzones at the Savannah River Site. 


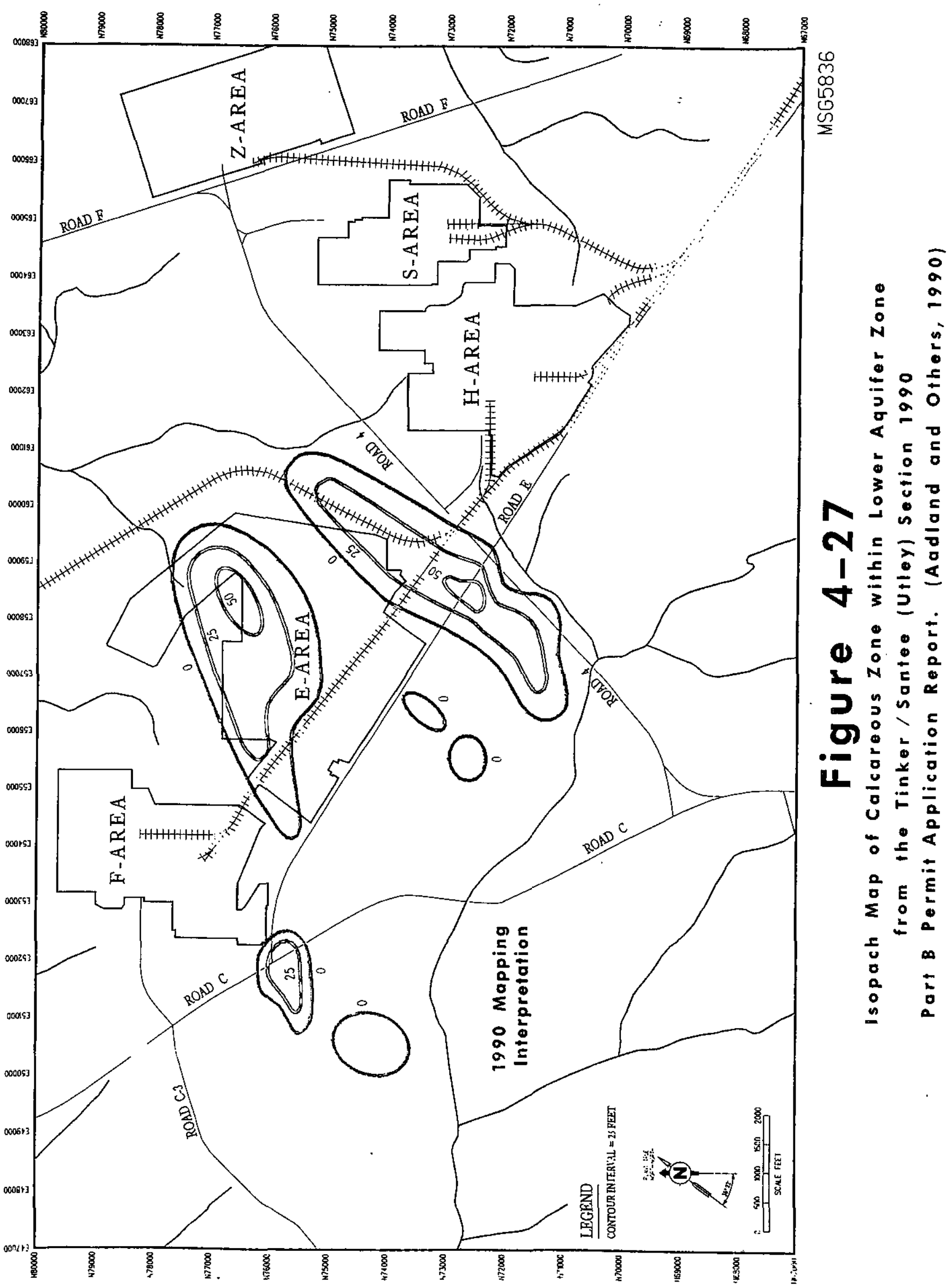




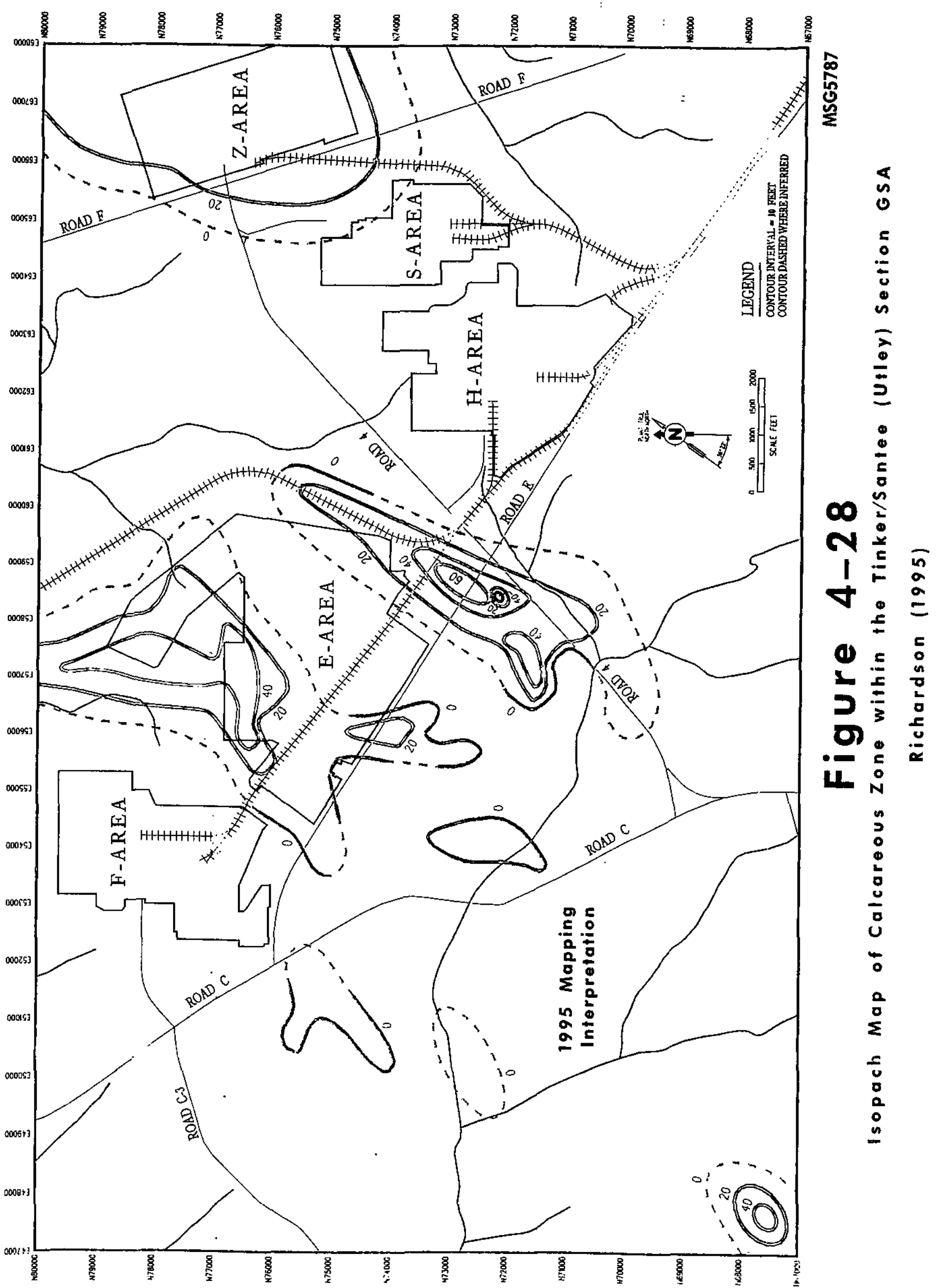




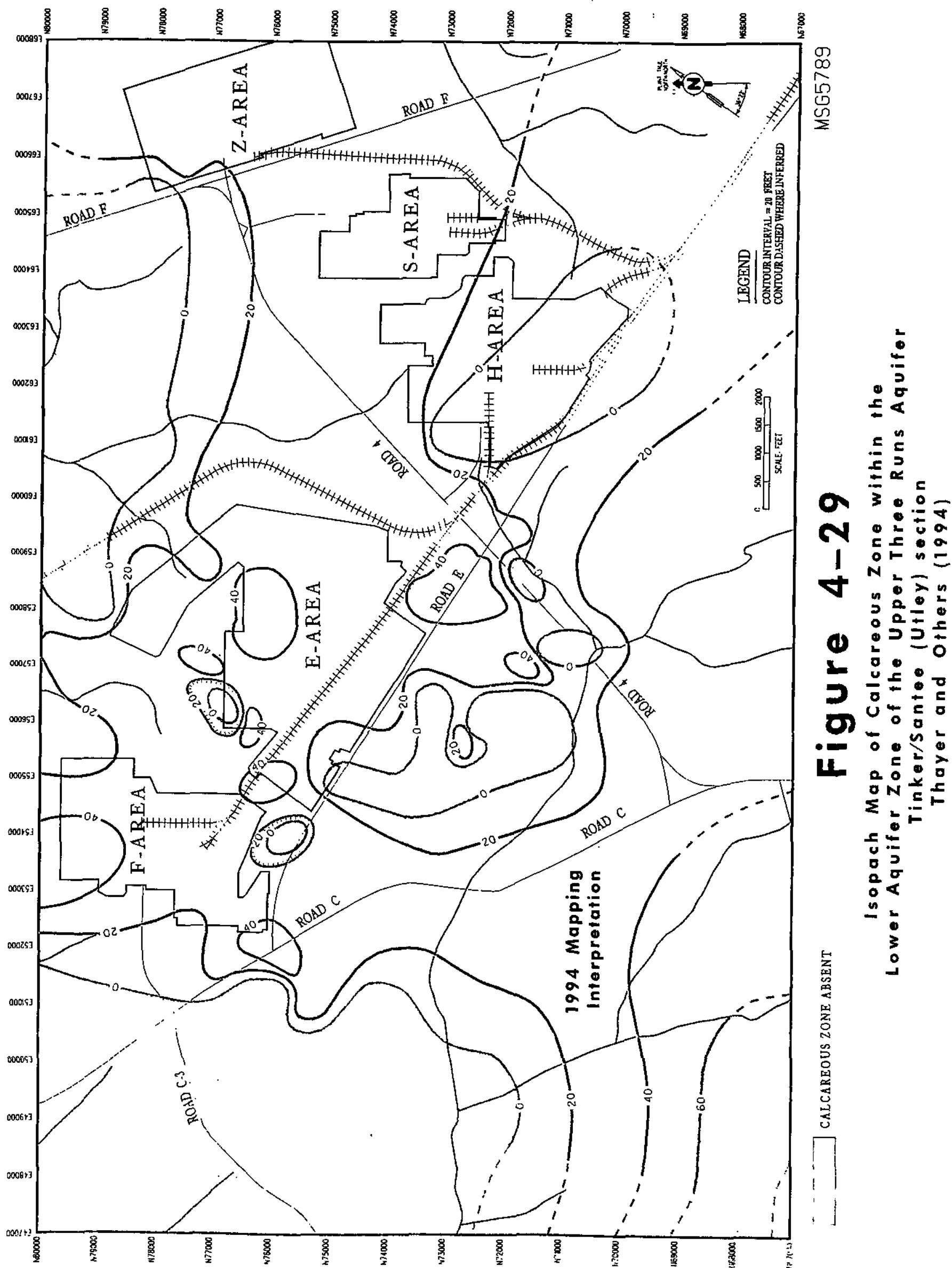




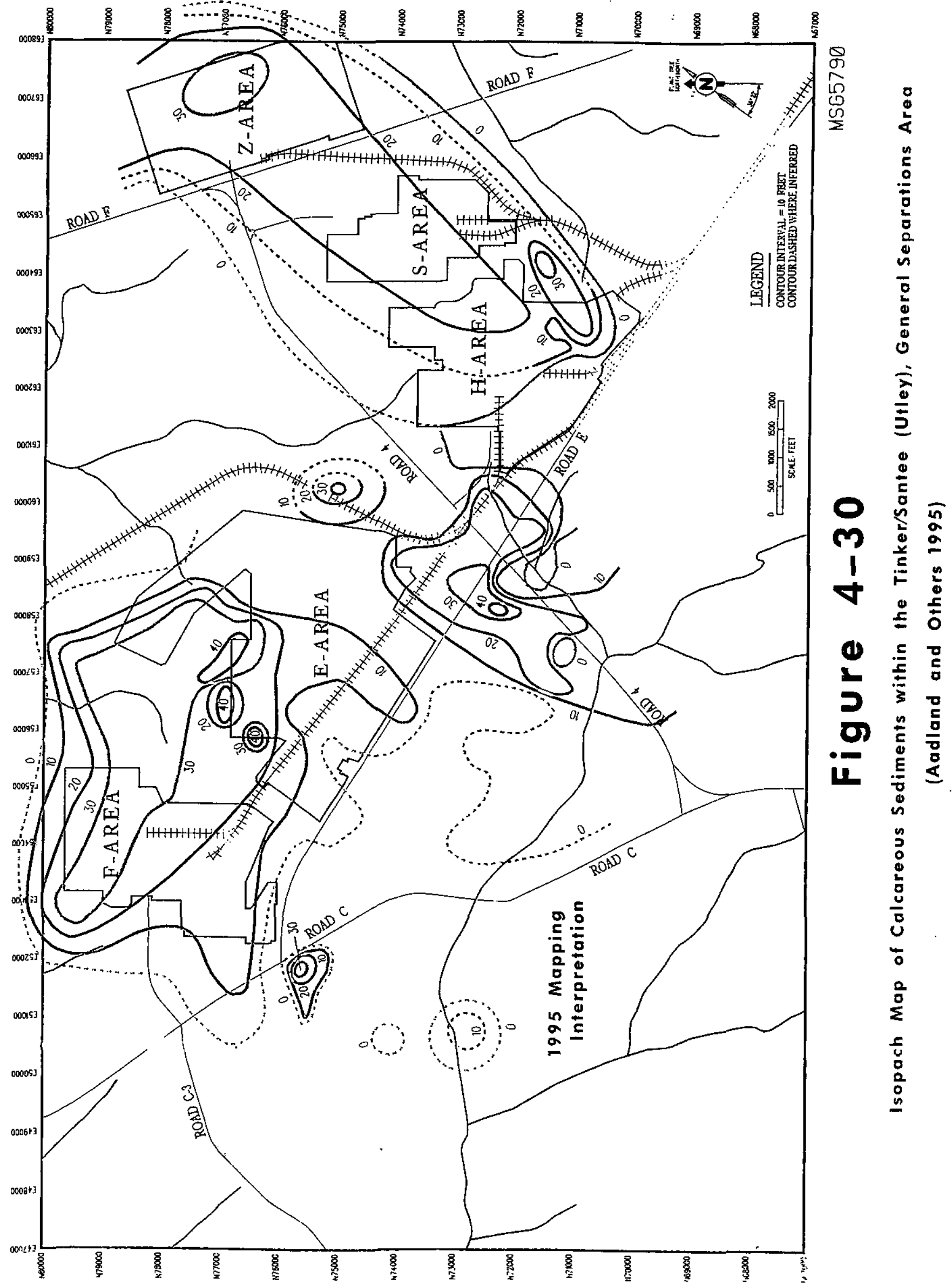




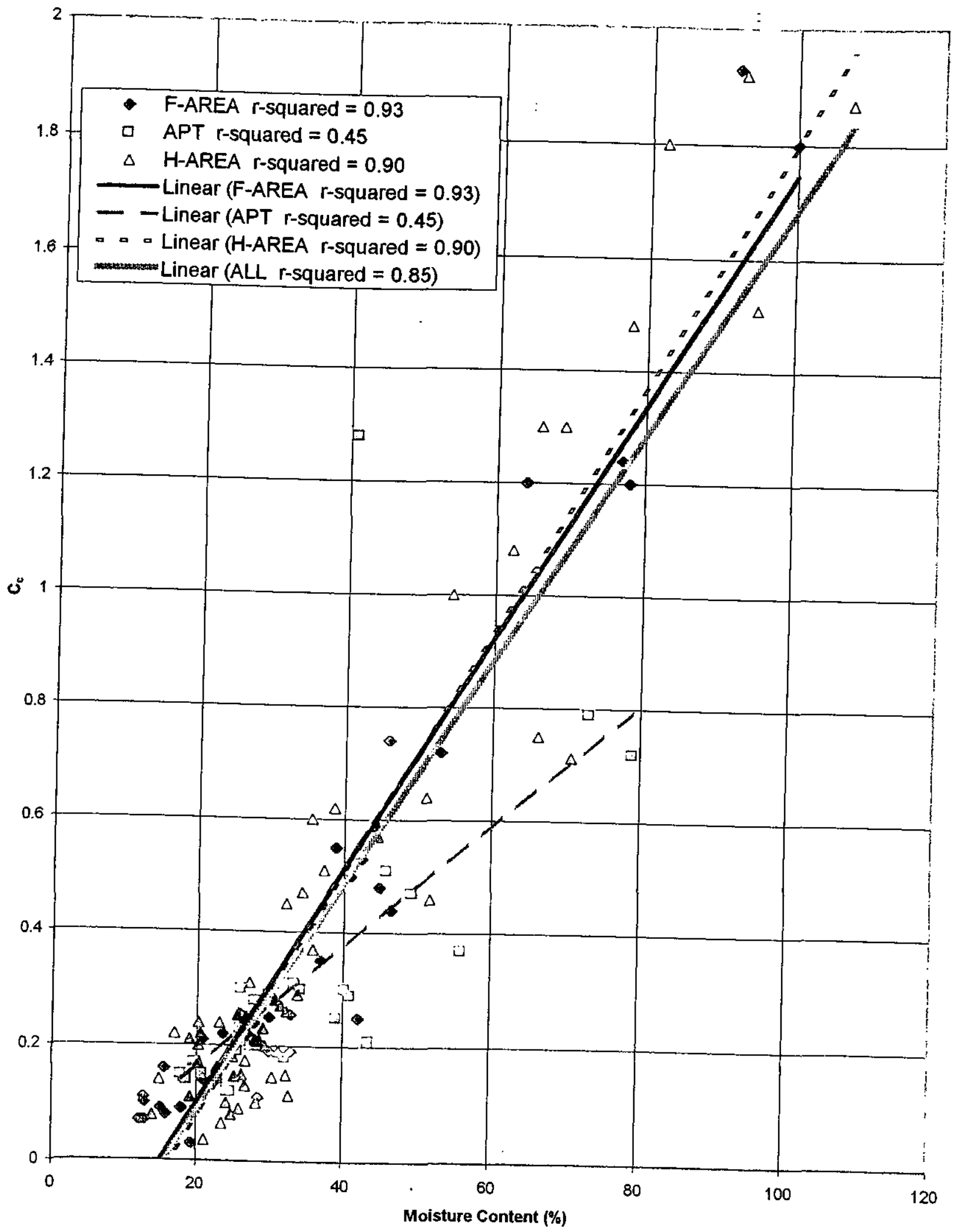

Do not use data for analysis or design without prior approval from Site Geotechnical Services Laboratory information database verification currently in progress, some data may not be verified 


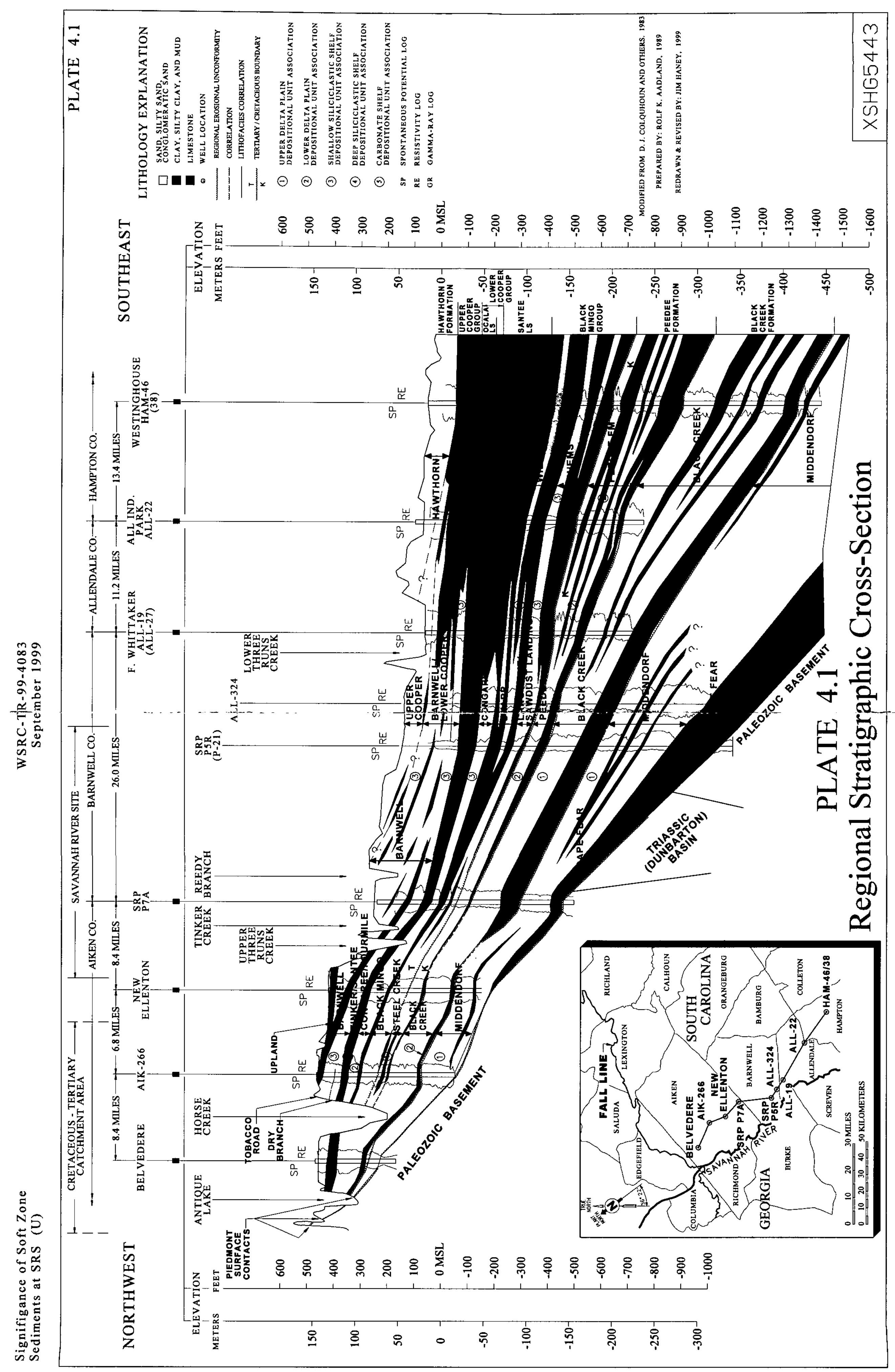




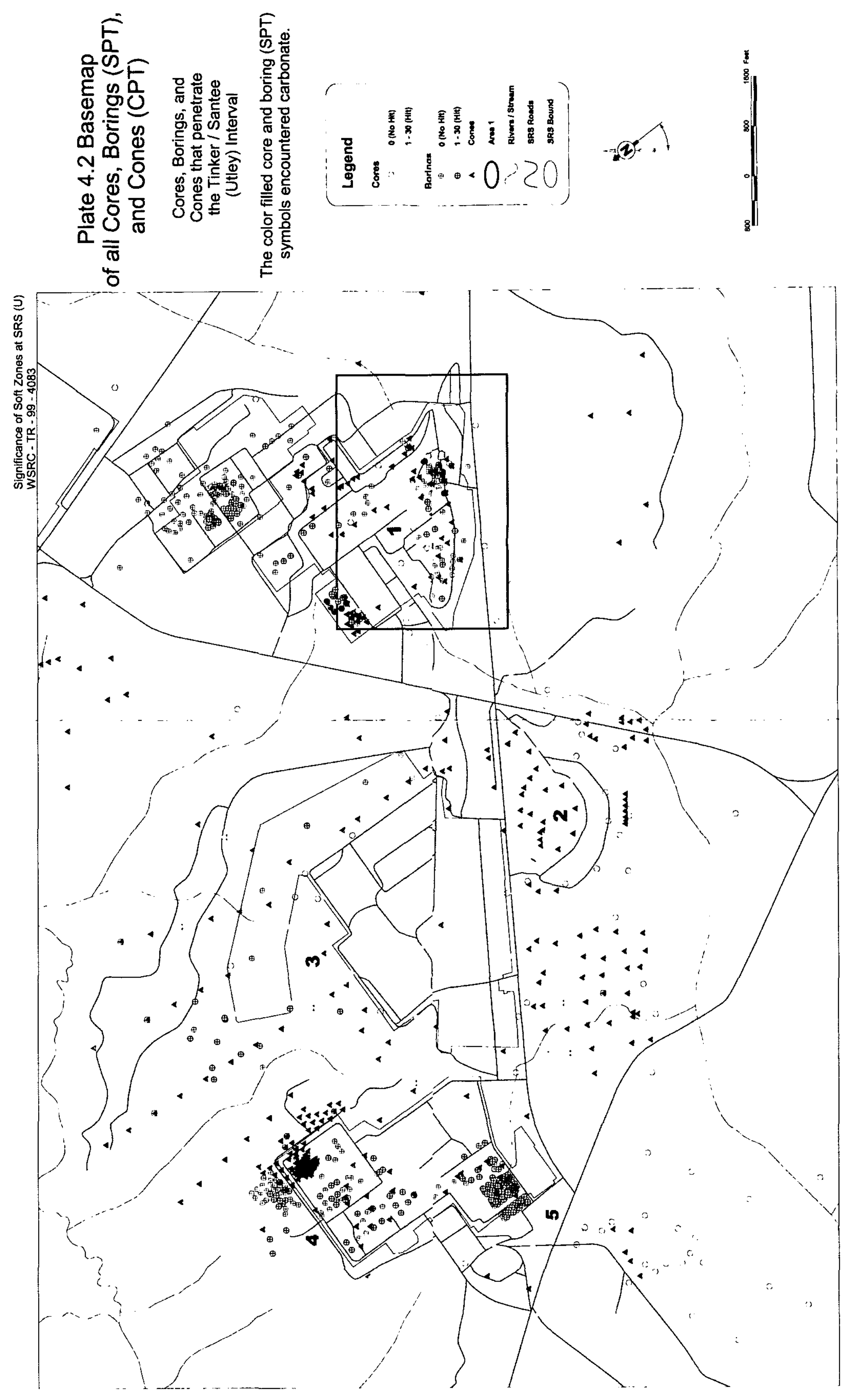



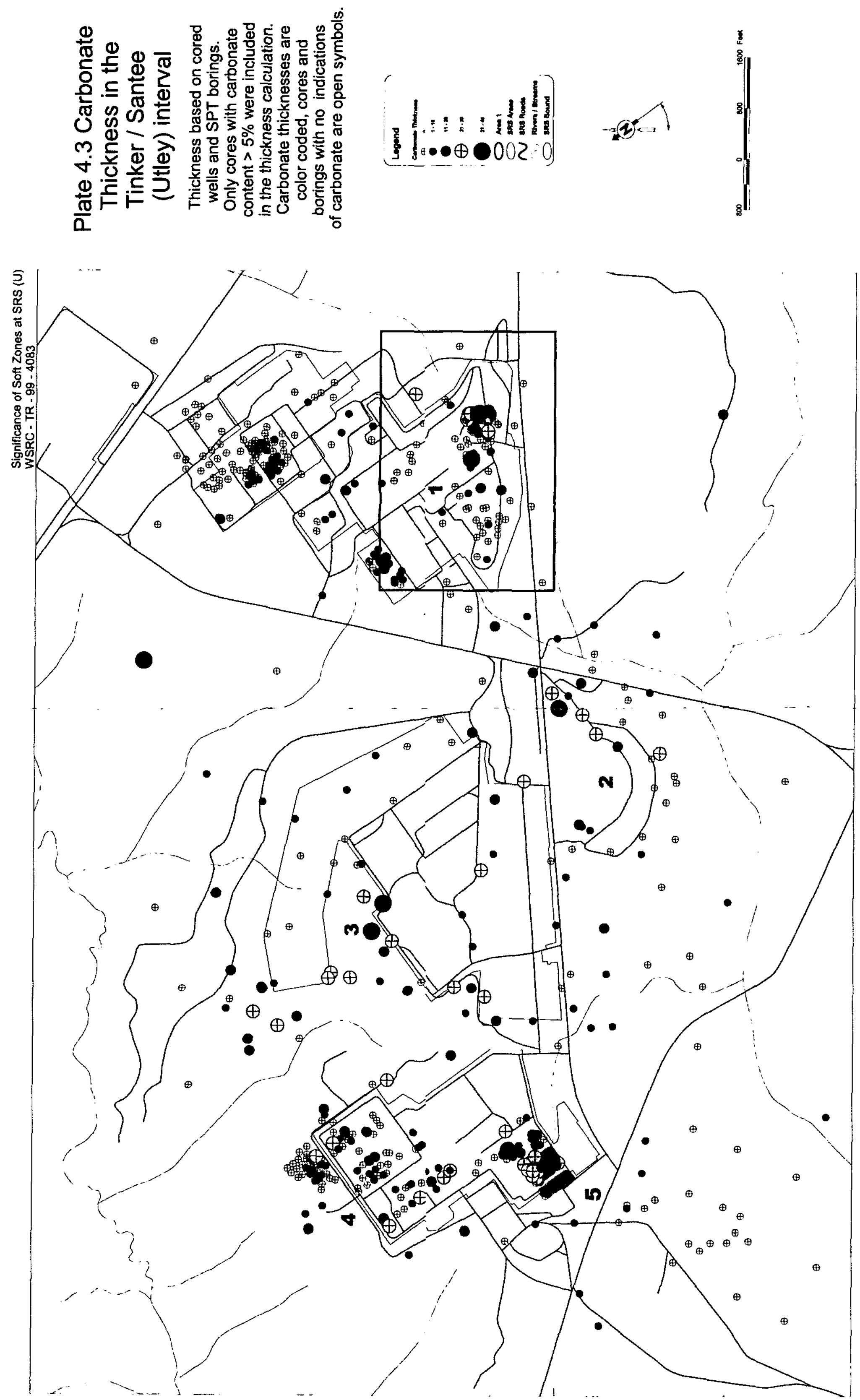
苛
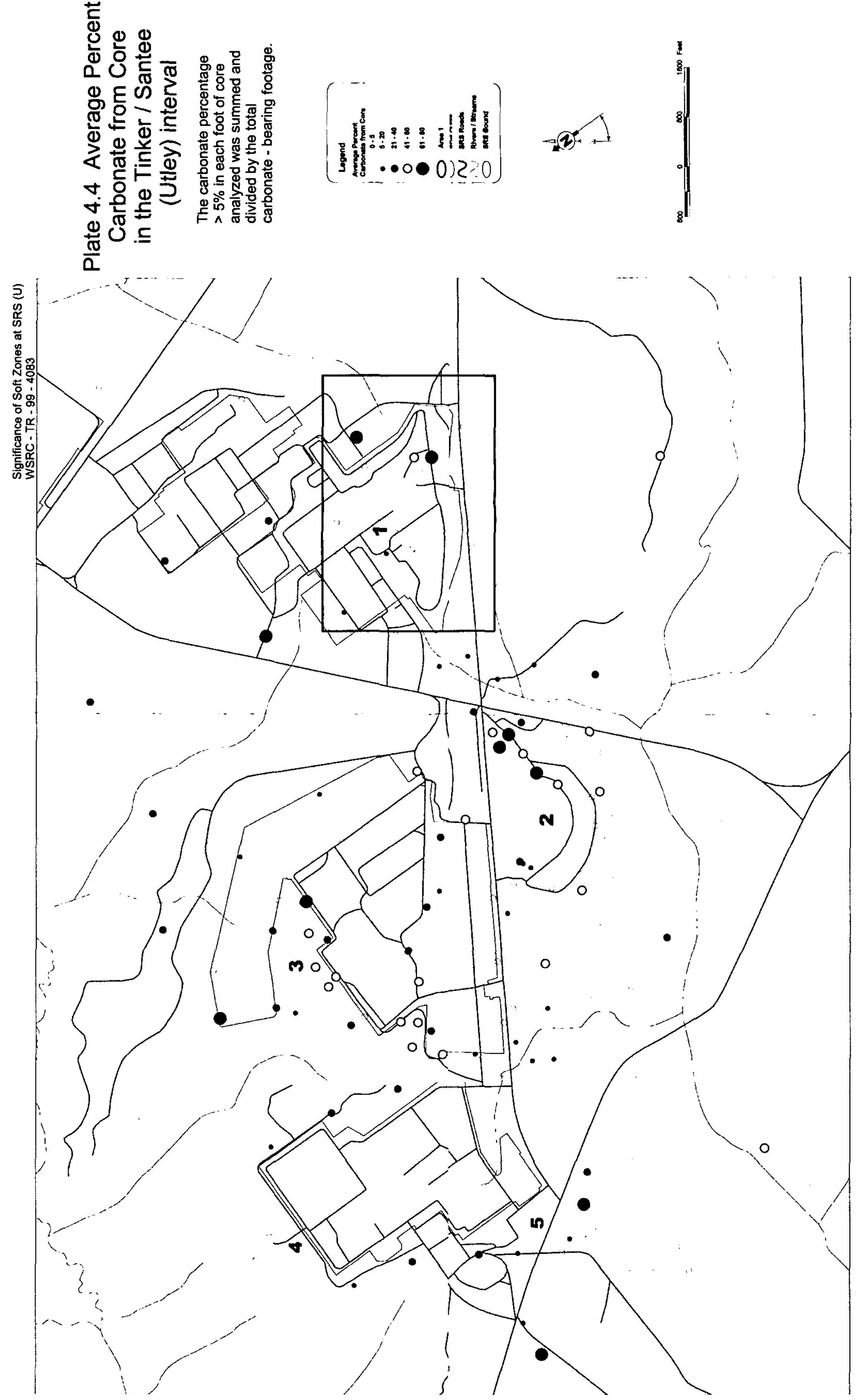


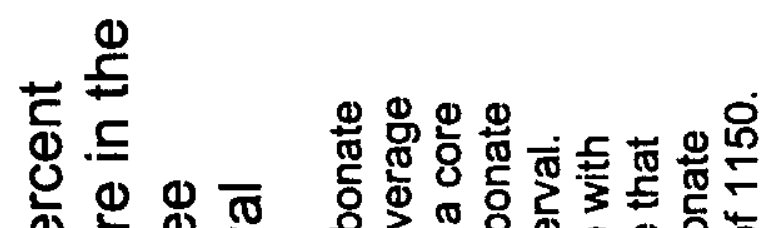

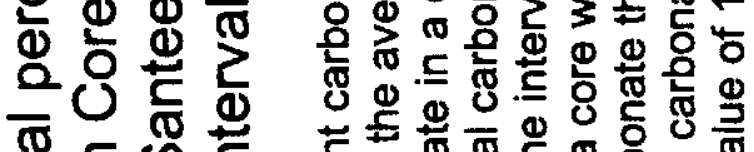
西

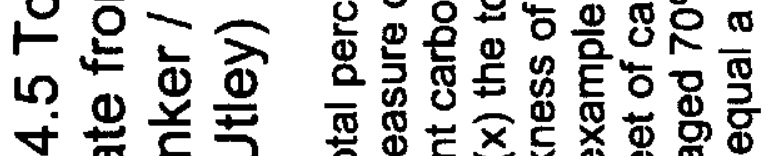

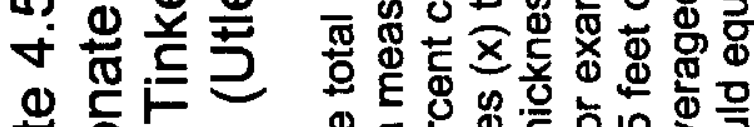

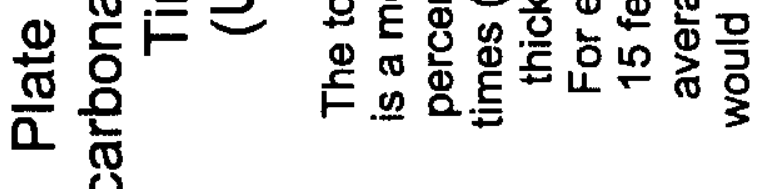
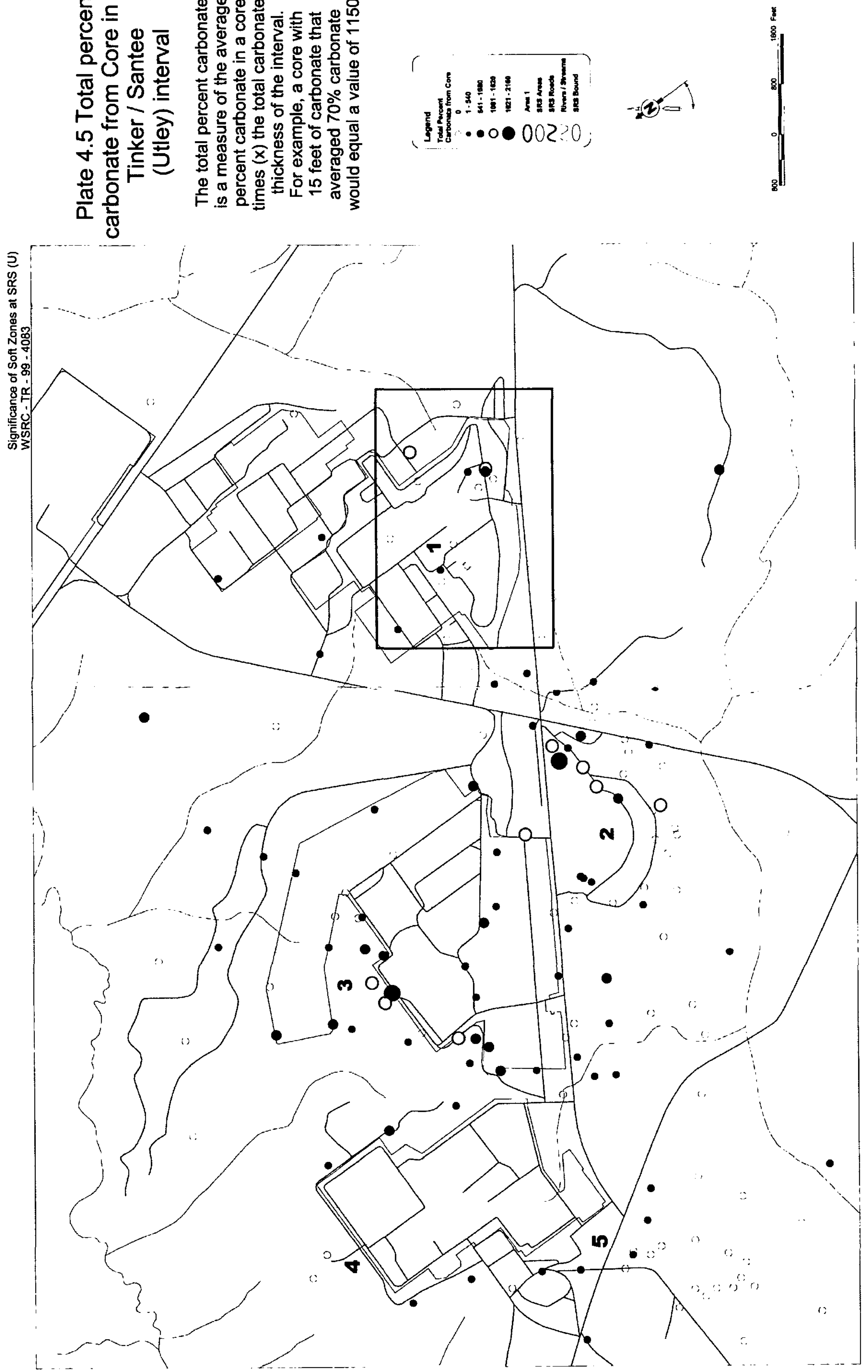


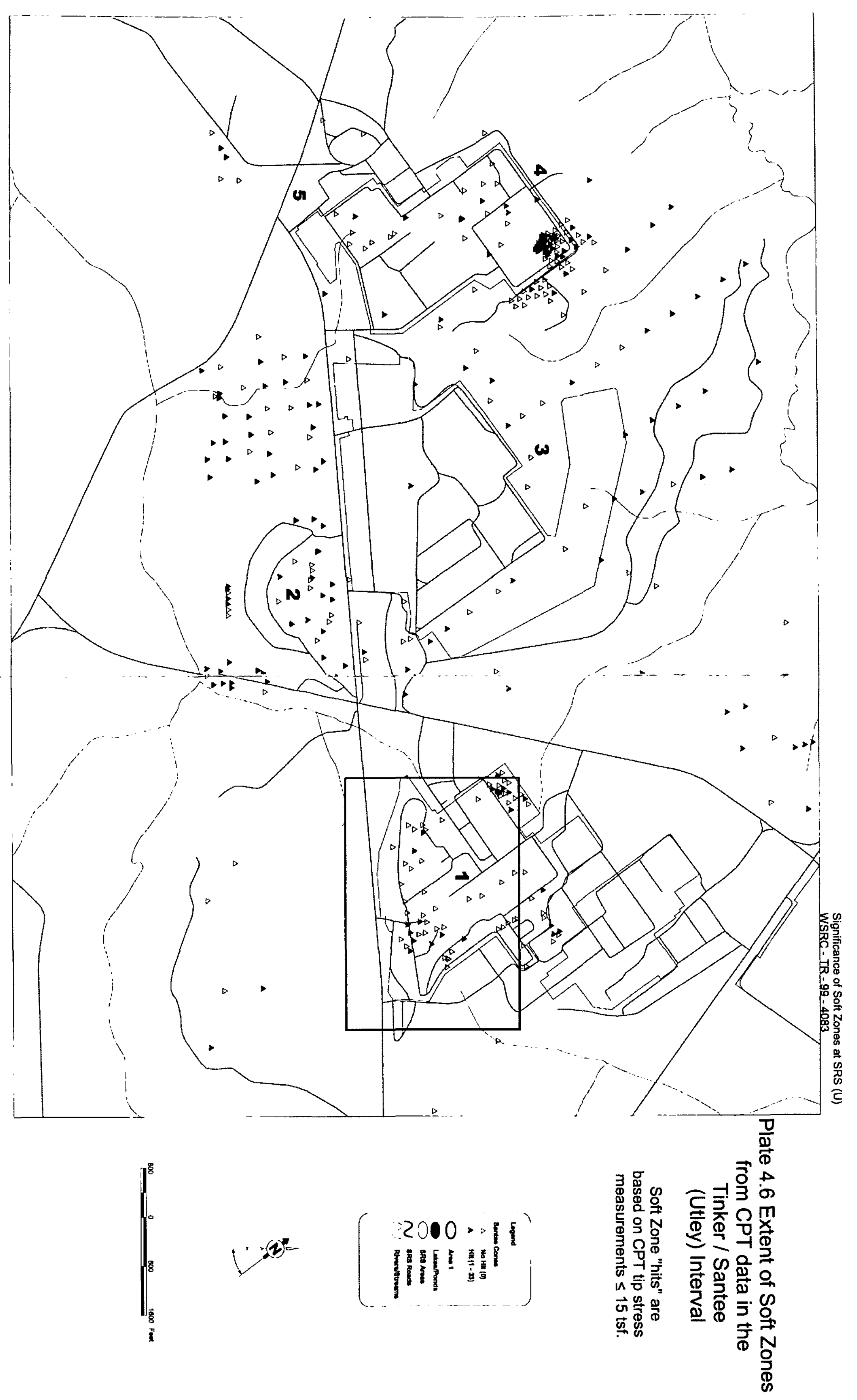




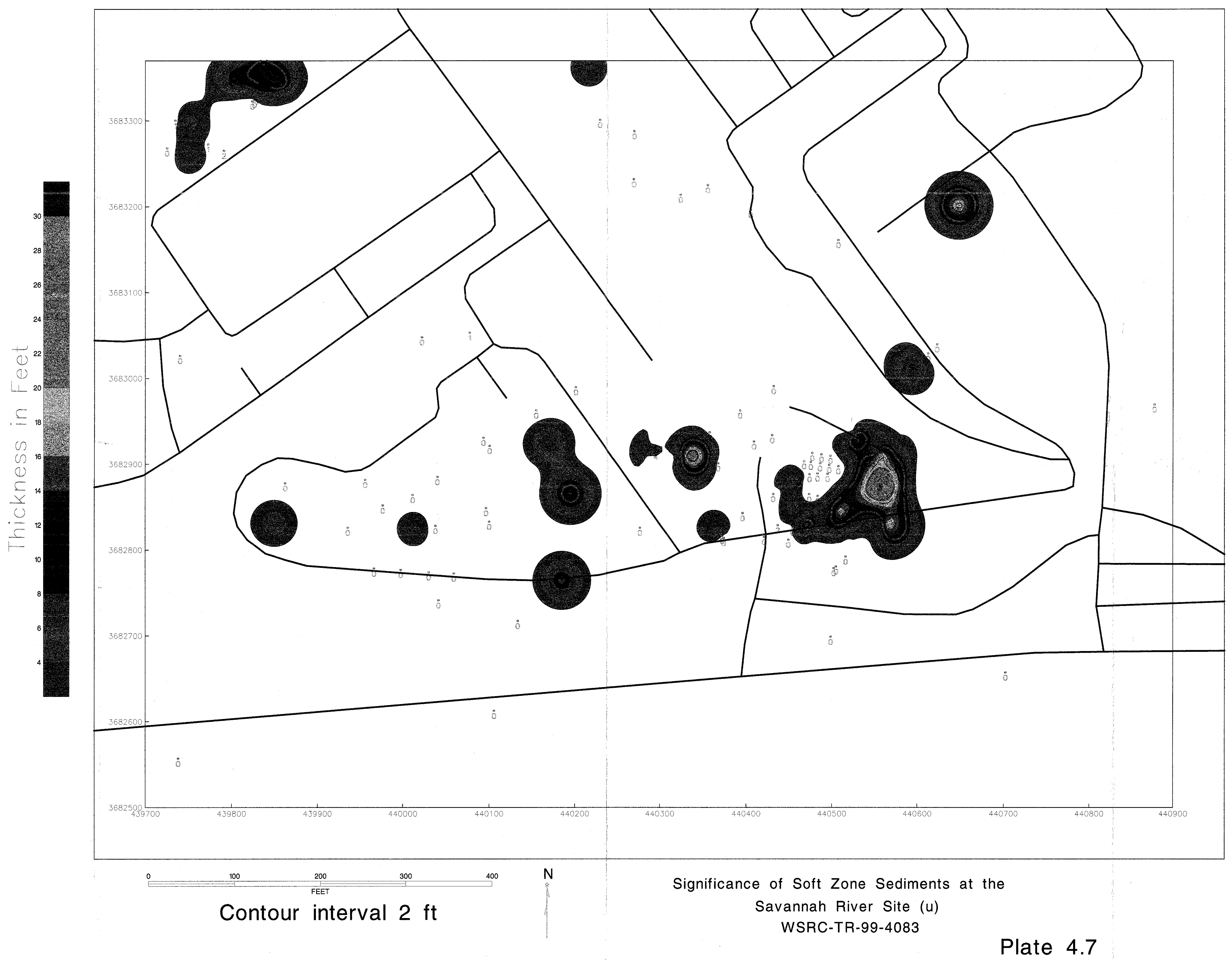


Soft Zone Thickness in the Santee/Tinker (Utley) Interval at the ITP, $\mathrm{H}$ Area

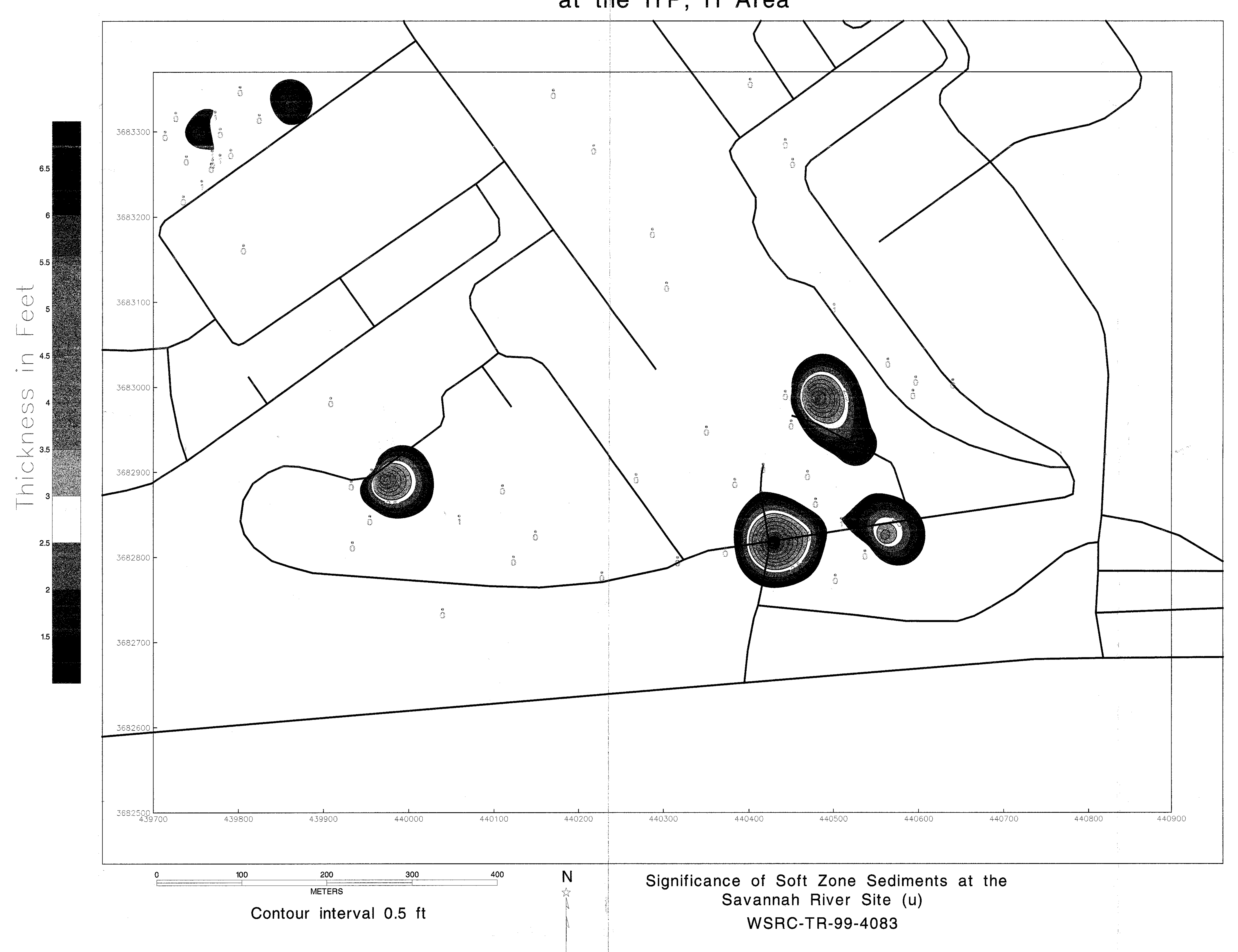

Plate 4.8 